\title{
The adequacy of institutional frameworks and practice for climate change adaptation decision making
}

\author{
By \\ Judith Helen Lawrence
}

\begin{abstract}
A thesis
submitted to the Victoria University of Wellington in fulfilment of the requirements for the degree of

Doctor of Philosophy in Public Policy
\end{abstract}

Victoria University of Wellington 2015 



\begin{abstract}
The ability of decision makers to respond to climate change impacts such as sea-level rise and increased flood frequency is challenged by uncertainty about scale, timing, dynamic changes that could lead to regime shifts, and by societal changes. Climate change adaptation decision making needs to be robust and flexible across a range of possible futures, to provide sufficient certainty for investment decisions in the present, without creating undue risks and liabilities for the near and long-term futures. A country's governance and regulatory institutions set parameters for such decisions. The decisionmaking challenge is, therefore, a function of the uncertainty and dynamic characteristics of climate change, a country's institutional framework, and the ways in which actual decisionmaking practice delivers on the intention of the framework.
\end{abstract}

My research asks if the current decision-making framework, at national and sub-national scales, and practices under it are adequate to enable decision makers to make climate change adaptation decisions that sufficiently address the constraints posed by climate change uncertainty and dynamic change. The focus is on New Zealand's multi-scale governance and institutional framework with its high level of devolution to the local level, the level assumed as the most appropriate for climate change adaptation decisions. Empirical information was collected from a sample of agencies and actors, at multiple governance scales reflecting the range of geographical characteristics, governance types, organisational functions and actor disciplines. Data were collected using a mix of workshops, interviews and document analyses. The adequacy of the institutional framework and practice was examined using 12 criteria derived from the risk-based concepts of precaution, risk management, adaptive management and transformational change, with respect to; a) understanding and representing uncertainty and dynamic climate change; b) governance and regulations; and c) organisations and actors.

The research found that the current decision-making framework has many elements that could, in principle, address uncertainty and dynamic climate change. It enables long-term considerations and emphasises precaution and risk-based decision making. However, adaptive and transformational objectives are largely absent, coordination across multiple levels of government is constrained and timeframes are inconsistent across statutes. Practice shows that climate risk has been entrenched by misrepresentation of climate change characteristics. The resulting ambiguity is compounded at different governance 
scales, by gaps in the use of national and regional instruments and consequent differences in judicial decisions. Practitioners rely heavily upon static, time-bound treatments of risk, which reinforce unrealistic community expectations of ongoing protections, even as the climate continues to change, and makes it difficult to introduce transformational measures. Some efforts to reflect changing risk were observed but are, at best, transitional measures. Some experimentation was found in local government practice and boundary organisations were used as change-agents. Any potential improvements to both the institutional framework and to practices that could enable flexible and robust adaptation to climate change, would require supporting policies and adaptive governance to leverage them and to sustain decision making through time.

This thesis contributes to understanding how uncertainty and dynamic climate change characteristics matter for adaptation decision making by examining both a country-level institutional framework and practice under it. The adequacy analysis offers a new way of identifying institutional barriers, enablers and entry points for change in the context of decision making under conditions of uncertainty and dynamic climate change. 


\section{Acknowledgements}

Undertaking doctoral research is usually something that starts a career. In my case I started after a career in the public sector and five years of consulting. The seeds of my topic were sown early, but the opportunity to explore my ideas didn't present itself until 2009, when I joined the New Zealand Climate Change Research Institute as a research associate. I have Dr Andy Reisinger and Professor Martin Manning to thank for encouraging me as I embarked on this journey, for their intellectual support along the way, for providing opportunities to test my ideas in real-life situations with decision makers, to attend overseas conferences and publish my research.

My topic is about the adequacy of institutions and the practices that govern decision making in situations of uncertainty and dynamic climate change. Such a topic suggested a blend of supervision which I received from Dr Amanda Wolf at the School of Government and Dr Andy Reisinger, a coordinating lead author for the Intergovernmental Panel on Climate Change Fifth Assessment Report. They came from very different disciplinary traditionsa social scientist and a physical scientist respectively; as a geographer I sat in the middle. For the rich experience with tough feedback, nuanced insights, great generosity of time and for always believing in the value of this research and in me, I am indebted to you both.

Thanks also to Professor Tim Smith at the University of the Sunshine Coast, Australia for helpful perspectives at the early stages while I was focusing my thesis topic, and for his ongoing encouragement. I am also indebted to two Victoria University library staff-Janet Keilar and Tony Quinn for help with literature searches and EndNote. For reading through the final version of my thesis, my sincere thanks go to my Australian friend and colleague Rosemary Calder.

This thesis could not have been completed without the many respondents from local and central government and from the non-climate policy settings - thank-you for your time and interest. Special thanks must go to Chris Cameron, Graeme Campbell, Gavin Ide, Alison Lash, Steve Markham, Frances Sullivan, Lisa McGlinchey, Sylvia Allan, Hugh Cowan, Shonagh Kenderdine and Royden Somerville for the time you all took to discuss my ideas with me as they developed. Having access to such experience across the many strands of this thesis has grounded my research in the real world. To two former public servants who have also undertaken PhD's-Elizabeth Eppel and Hugh Logan-thanks for being inspiring completers of the journey. 
Thank-you to my colleagues in the School of Government, School of Geography, Environment and Earth Sciences, New Zealand Climate Change Research Institute and Antarctic Research Institute who have been a constant source of encouragement to me. The National Climate Change Research Facility in Australia, undertook timely work which provided a backdrop into which I could dip and engage, comparing our similarities and different contexts. This opened up enduring connections with a new generation of researchers around the world who have made a difference to my thinking while undertaking this research and will continue to do so. Their body of research gives me great hope that these complex issues will be addressed before it is too late. To Jan McDonald, Karyn Bosomworth and Johanna Nalau in Australia, Karianne de Bruin in Norway, Tiago Capela Lourenco in Portugal and Marjolijn Haasnoot in the Netherland, special thanks for your collegiality and inclusiveness of me in your research spaces and places. The opportunity to meet and share ideas with the nascent society for decision making under conditions of deep uncertainty, has broadened my thinking. Thank-you Nidhi Kalra, Robert Lempert and Warren Walker for your inclusiveness and intellectual stimulation.

Thanks also go to my friends, who have kept me exercised and culturally and socially stimulated, throughout the thesis gestation. But above all, thank-you Roger for your patience and support over this and all the other journeys we have had together. In the end it will be our children, Roland and Piers, who will judge whether my contribution makes a difference to the world they are inheriting. 


\section{Contents}

Abstract

Acknowledgements ............................................................................................................... iii

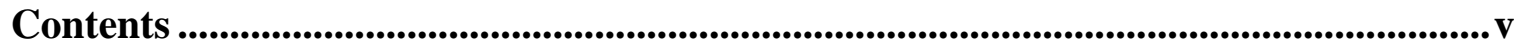

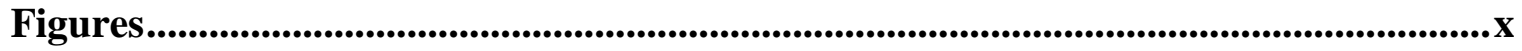

Tables

Chapter 1 Introduction.....................................................................................................................1

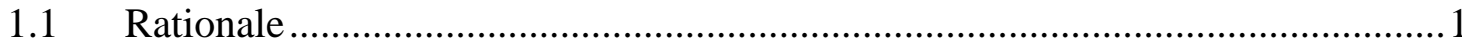

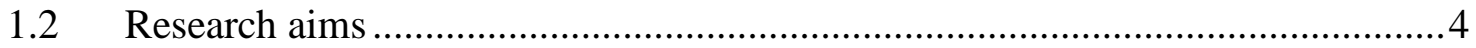

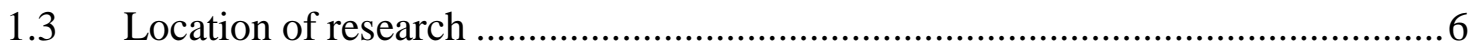

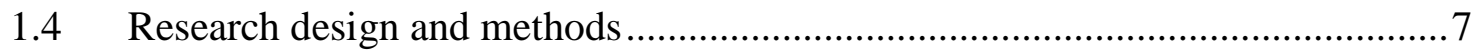

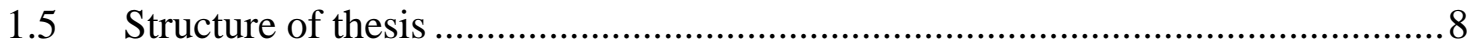

Chapter 2 The challenge for decision making …...................................................................11

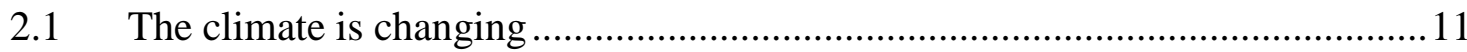

2.1.1 The climate changes-sea-level rise and increased rainfall frequency

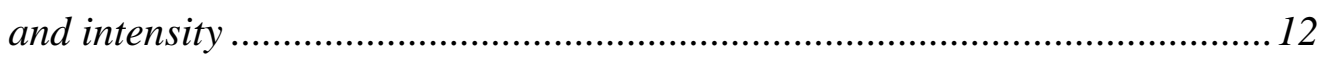

2.1.2 The damages arising from climate change impacts ...................................... 15

2.1.3 Decision-relevant climate change characteristics-uncertainty and

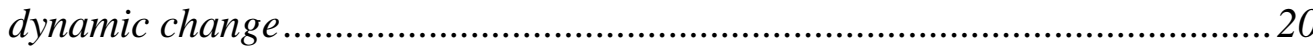

2.2 How climate change creates a decision-making problem................................21

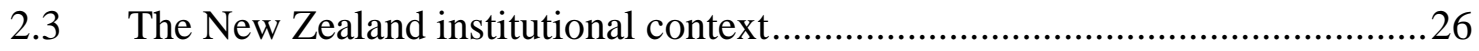

2.4 What is known about the role of institutions for addressing the decision-

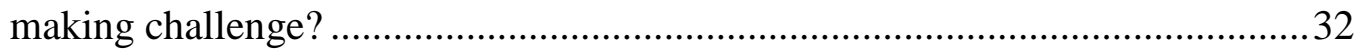

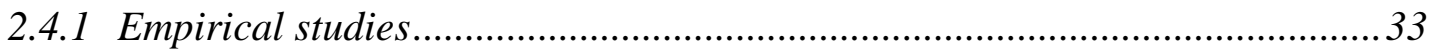

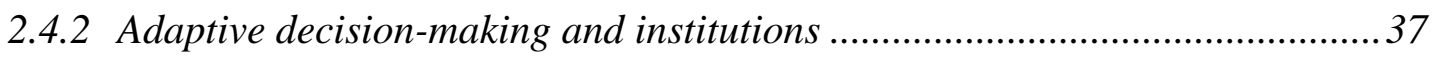

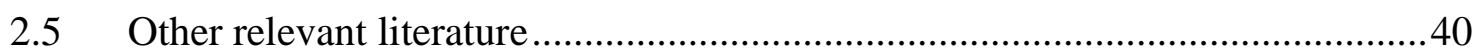

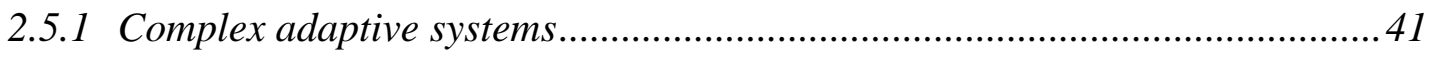




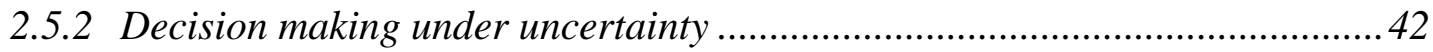

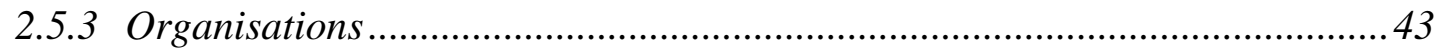

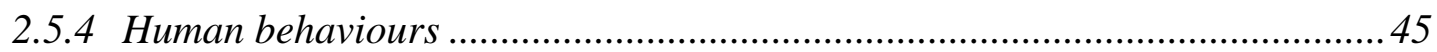

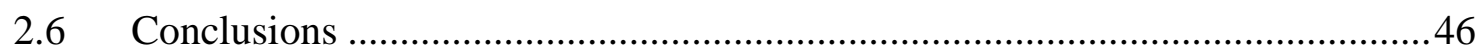

Chapter 3 Research design and process ............................................................49

3.1 Research questions and design rationale ....................................................49

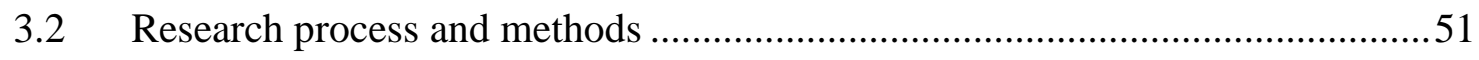

3.2.1 Examining risk-based concepts to develop adequacy criteria .........................51

3.2.2 Assessing the adequacy of the framework .................................................52

3.2.3 Understanding the current practice, its adequacy, enablers and entry

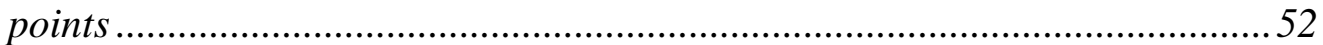

3.2.4 Scope for institutional framework and practice improvements ......................57

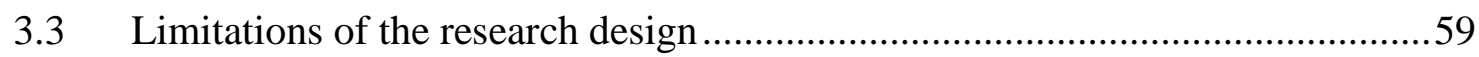

Chapter 4 How can adequacy be gauged? ...........................................................61

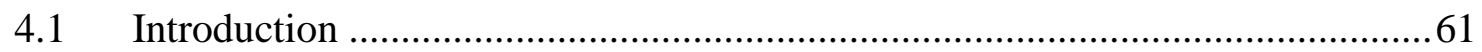

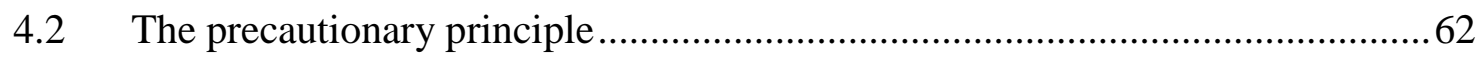

4.2.1 What is the precautionary principle? .......................................................62

4.2.2 Does the precautionary principle address uncertainty and dynamic

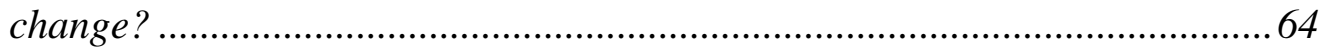

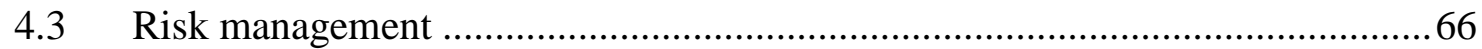

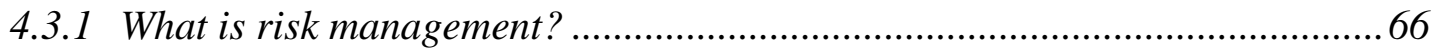

4.3.2 Does risk management address uncertainty and dynamic change? ...............68

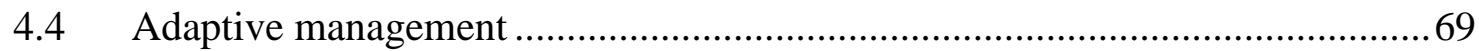

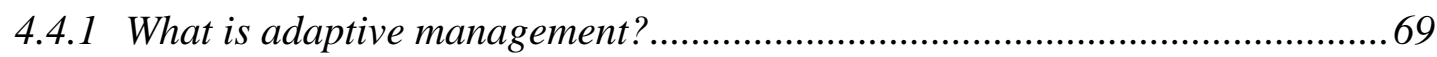

4.4.2 Does adaptive management address uncertainty and dynamic change?........ 70

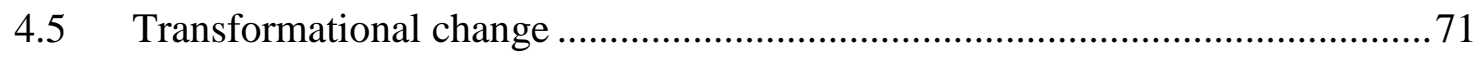

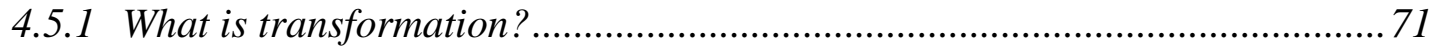

4.5.2 Does transformational change address uncertainty and dynamic

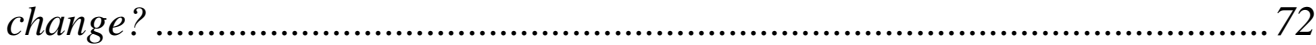




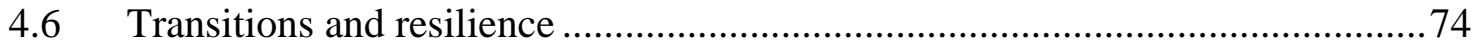

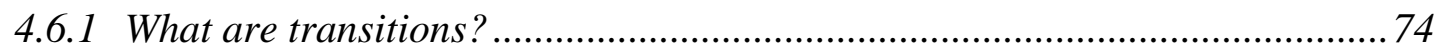

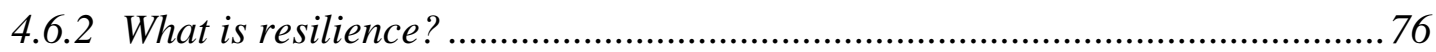

4.7 How far do the four risk-based concepts take decision making that addresses uncertainty and dynamic climate change?..................................... 77

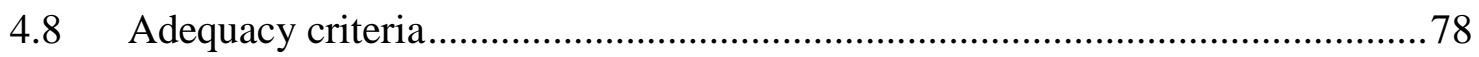

4.8.1 Understanding and representing uncertainty and dynamic climate

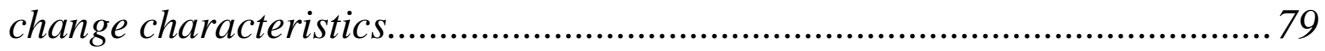

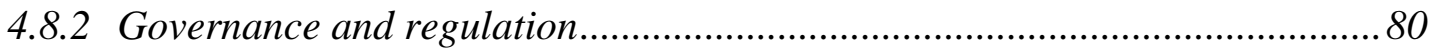

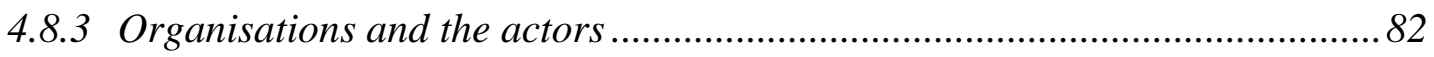

Chapter 5 The institutional framework and its adequacy ..........................................85

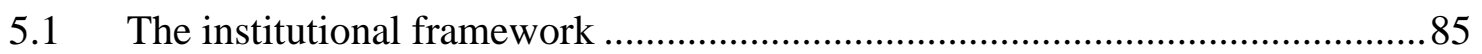

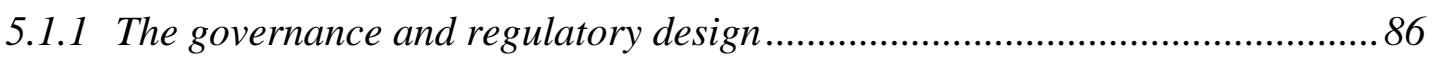

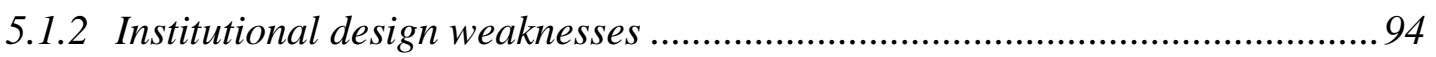

5.2 Does the institutional framework embody the four risk-based concepts?..........95

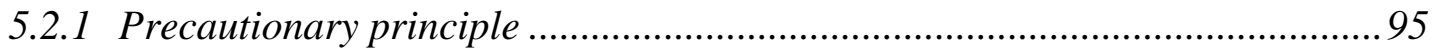

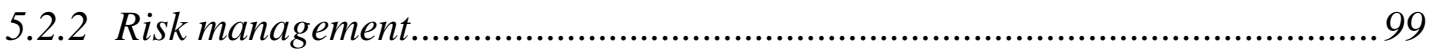

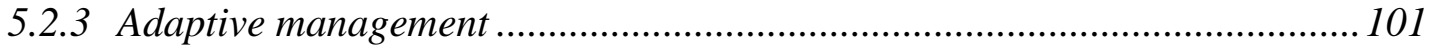

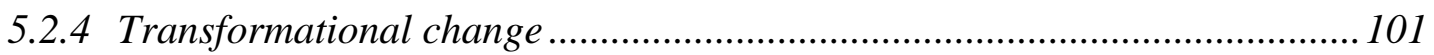

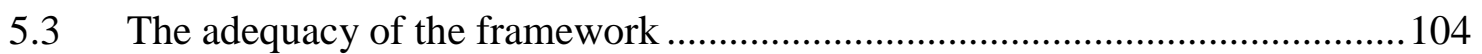

5.3.1 Understanding and representing uncertainty and dynamic climate

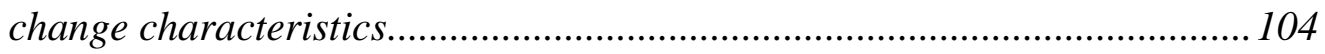

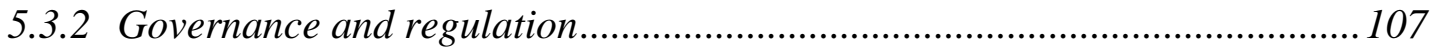

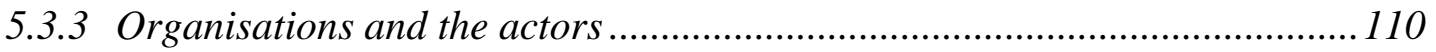

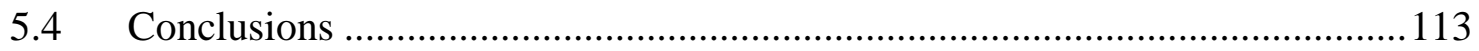

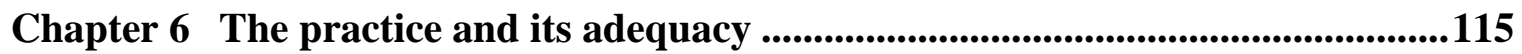

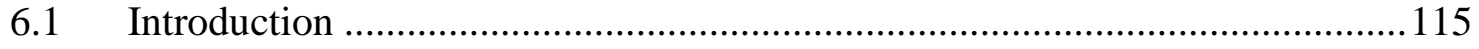

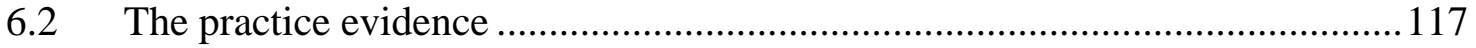

6.2.1 Understanding and representing uncertainty and dynamic climate change-the practice..... 
6.2.2 Governance and regulation - the practice

6.2.3 Organisations and actors - the practice .

6.3 The practice adequacy

6.3.1 Understanding and representing uncertainty and dynamic climate change characteristics.

6.3.2 Governance and regulation - the adequacy

6.3.3 Organisations and actors - the adequacy

6.4 Summary of the adequacy of practice

6.4.1 Understanding and representing uncertainty and dynamic characteristics of climate change ............................................................... 172

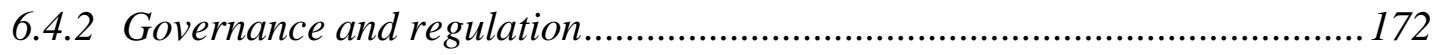

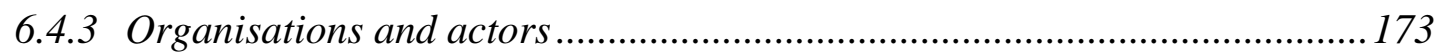

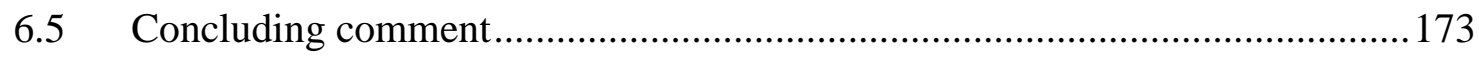

Chapter 7 Space for change ...................................................................................................175

7.1 Policy constraints on improved framework and practice .............................175

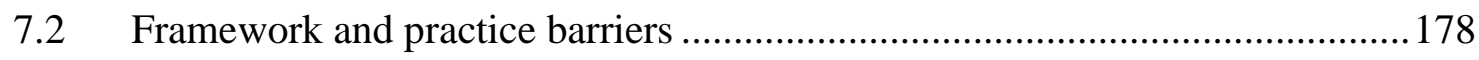

7.2.1 Understanding and representing uncertainty and dynamic climate

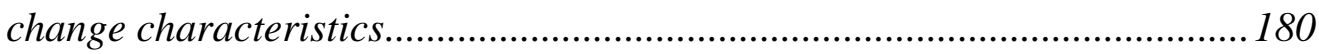

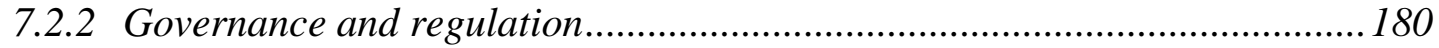

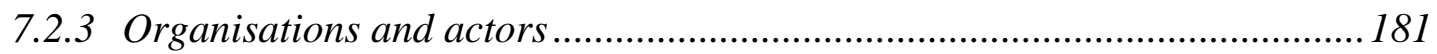

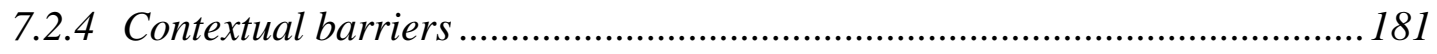

7.3 Suggested incremental legislative improvements and success factors .............185

7.4 What can be learnt from analogous non-climate decision settings?.................187

7.4.1 Institutional analogues that respond to sudden threats ............................... 188

7.4.2 Institutional analogues that respond to known progressive and changing

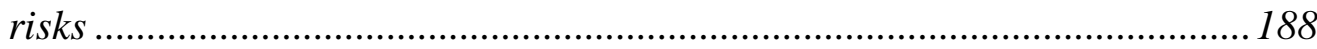

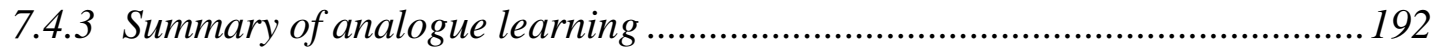

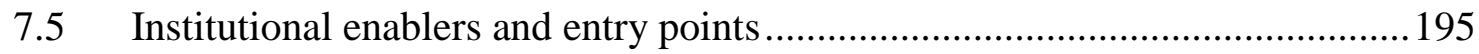

7.5.1 The institutional space and interconnections............................................. 195 
7.5.2 Enablers and entry points for improved institutional framework and practice.

Chapter 8 Conclusions and looking forward...............................................................207

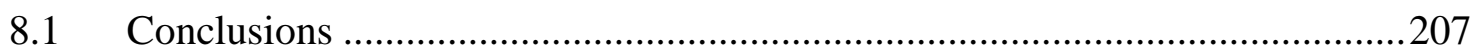

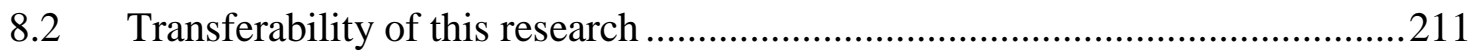

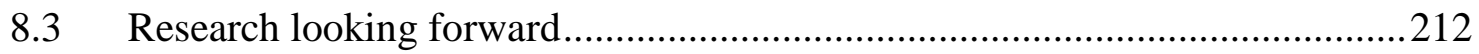

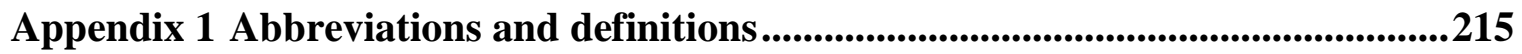

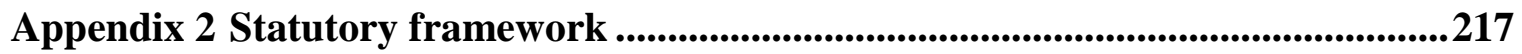

Appendix 3 Research Participants ....................................................................................221

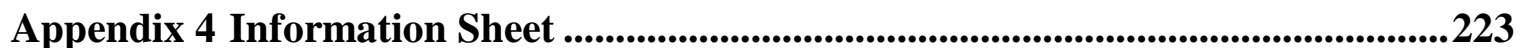

Appendix 5 Potential analogues and design features .......................................................227

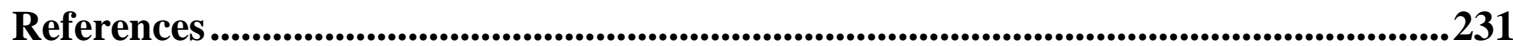




\section{Figures}

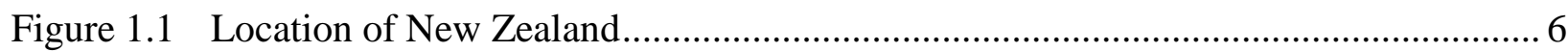

Figure 2.1 Global mean sea level rise. Upper and lower likely ranges ................................. 13

Figure 2.2 Changes in exceedance probabilities under different emission scenarios. .............. 15

Figure 2.3 Changes in extremes with changes in mean climate ........................................ 16

Figure 2.4 Risk is a combination of climate hazard, exposure and vulnerability in a socioeconomic system

Figure 2.5 The governance framework and functions

Figure 2.6 The statutory framework .29

Figure 3.1 New Zealand local government regions and districts 53

Figure 3.2 Data analysis process .56

Figure 3.3 The research process .59

Figure 7.1 Potential framework and practice design features from analogues. 194

Figure 7.2 The space for change 206 


\section{Tables}

Table 5.1 Institutional framework characteristics ........................................................... 103

Table 6.1 Current practices by four councils ................................................................... 135

Table 7.1 Barriers to uncertainty and dynamic change considerations ............................... 179

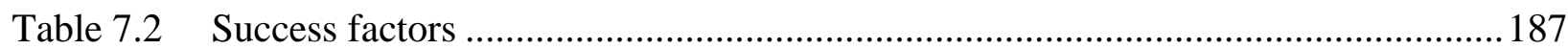

Table 7.3 Institutional enablers and entry points ...................................................... 197 



\section{Chapter 1 Introduction}

This thesis advances understanding of the adequacy of institutional frameworks and practice for making climate change adaptation decisions in the face of uncertainty and dynamic change. An examination of this decision-making challenge leads to a method for assessing adequacy of institutional frameworks and practice and suggestions about the scope for institutional framework and practice improvements. Chapter 1 establishes the rationale for focusing on institutions and climate change adaptation. It introduces the New Zealand context, the research design and methods; and concludes with an outline of the thesis.

\subsection{Rationale}

It is now well established that climate change could result in severe and widespread impacts (IPCC, 2014a). Many of those impacts will be manifested through changes in the frequency and severity of damaging weather events and the rise in sea levels (IPCC, 2014a). National, regional and local government decision makers are responsible for many types of decisions that will be affected by such impacts. For example, a changing climate will be an important consideration for urban planning, land use planning, infrastructure investment, asset management and emergency management decisions. Adaptation decisions will be required within each of these spheres as the climate changes. The definition of adaptation most widely adopted in the climate change literature derives from the Intergovernmental Panel on Climate Change (IPCC ${ }^{1}$ ) (IPCC., 2007):

Adaptation to climate change is an adjustment in natural or human systems in response to actual or expected climatic stimuli or their effects, which moderates harm or exploits beneficial opportunities. (p. 869)

While the types of climate change impacts and the most exposed locations are generally known (IPCC, 2013, 2014a), the magnitude, frequency and timing of the impacts arising from extreme events cannot be, although we know the direction of the change. For example, we know that sea level will continue to rise for centuries and that heavy rainfall will become more frequent (IPCC, 2012, 2013), but that the amount of change is still uncertain. In a nutshell, the challenge for decision makers is that they confront, simultaneously, uncertainties about the extent of climate change and the certainty that change is inevitable.

Reisinger et al. (2014) report that today's adaptation decision making is piecemeal and inconsistent between levels of government and between different locations. Combined with reported use of single numbers for climate projections, this suggests that decision makers may not be taking

\footnotetext{
${ }^{1}$ See Appendix 1 for all abbreviations and definitions.
} 
account of the uncertainty in projected impacts of climate change by the end of the century, when estimating the value of their choices. In order for communities to be able, more-or-less, to cope cost-effectively with climate changes, current decision makers need to consider both the robustness and flexibility over time of their decisions. 'Robust' in this thesis means decisions that will perform over a range of possible future conditions. 'Flexibility' means being able to change course readily as future conditions change.

Local government decision makers act within institutional constraints when deciding on land uses and infrastructure that create value persisting over long timeframes. Governments create institutions through laws and policies to limit risk of harm to society from human activities. They must be able to address risks that cannot be well-estimated today, and to do so before evidence of significant damage is obvious. The impacts of climate change are one such harm that fits this category of policy problem. Unless stated otherwise, 'risk' in this thesis refers to so-called 'downside risk', consistent with climate change literature, rather than future states assigned estimated probabilities and positive or negative values.

I use the term institutions in the sense used by the 'new institutionalism' movement which seeks to understand the role played by institutions as determinants of the outcomes of interactions of human behaviour (Ostrom, 1990). Institutions are defined as: "Sets of rules, decision-making procedures, and programs that define social practices, assign roles to the participants of these practices and guide interactions among the occupants of individual roles" (Young, 2002, p. 5). Institutions comprise formal governmental policies and rules, and informal social interactions and networks that may be visible or not (Arts, 2006).

Organisations and institutions are not synonymous; organisations are the formal arrangements that embody the social norms of the actors who use the institutional frameworks through the disciplinary practices relevant to their functions set out in statutes. Institutions are influenced by the power relations and biases of prior social interactions (Klijn \& Koppenjan, 2006) and become institutionalised by creating certainty through policies and rules. They thus set up inertia that makes change difficult. However, the same governance actors who build the certainty, are also those who can change it. Gupta et al. (2010) asked whether institutions can allow society to change fast enough to moderate the environmental changes, and which institutions create barriers and should be redesigned to better balance flexibility and rigidity.

An institutional framework comprises the documented structure and governance hierarchy that support the rules, procedures and programmes and may be codified in statutes. The processes and measures adopted by practitioners and decision makers that support the implementation of the 
framework are treated in this thesis as practice. Organisations are where the actors are grouped to enable the decisions to be made. They include the specific organisations, their characteristics and the people within them who influence how the framework is interpreted, and the design of the rules to implement the framework. Organisations operating under such frameworks make frequent decisions in uncertain and changing contexts about climate and other matters. Nevertheless, there has been limited implementation of adaptation responses to climate change (IPCC, 2014a) that take account of uncertainty and dynamic climate change characteristics. This is in part because most institutional frameworks were designed prior to climate change being acknowledged as a serious policy problem, and because of the many environmental, economic, information, social, attitudinal and political constraints (Reisinger et al., 2014).

Decision-making institutions have tended to entrench societies' need for certainty over time. This in itself is not surprising since institutions are expressly designed to confer certainty for societal functioning (Ruhl, 2012). As a result, institutions exhibit time and space constraints in their design and practice. If institutional frameworks generate certainty through measures that are fixed in time and space, decision makers will not have reason to consider the future consequences of decisions today and how they might address future change that appears uncertain at the present time. In addition, the practice of using static measures like levees and fixed hazard zones to manage flood and coastal inundation sets up societal expectations of 'safety' within the bounds of those measures. Such practice can also reduce consideration of residual risk ${ }^{2}$ under current conditions, and residual risk as it increases relative to the static protection level, as the climate changes. Static measures can also lead to path dependency if the measures cannot be adapted to the change over time or spatially. These practices constrain decision choices in future.

The IPCC concluded with "very high confidence" (IPCC, 2014a, p. 6) that impacts from recent climate extremes reveal significant vulnerability and exposure of human systems to "current climate variability". This is also referred to as an "adaptation deficit" (IPCC, 2014a, p. 23) which highlights the sensitivity of society and under preparedness to change. The continued concentration of development in low-lying coastal areas and flood plains that will be increasingly exposed to climate changes adds to the decision-makers' problem, despite some institutional frameworks having sustainable development objectives and provision for hazard risk management (Freeman \& Cheyne, 2008 ; Parry et al., 2009). Even when institutional frameworks recognise the need for a long-term perspective, there is an added challenge for achieving workable decisions in

\footnotetext{
${ }^{2}$ Residual risk is risk that remains after protection and avoidance measures—or the unavoidable risk
} 
practice, since people differ in their perception of risk, based on their different values and knowledge (Adger, Lorenzoni, \& O’Brien, 2009). People select the framing of the problem based on their background profession or life experiences (Isendahl, Dewulf, \& Pahl-Wostl, 2010), creating a contested space, which adds to the complexity of decision making. The impacts of climate change, like sea-level rise and increased frequency and intensity of rainfall, create further challenges for decision makers when under pressure from private interests, to restore normality as quickly as possible following extreme events. Pressures from private interests also occur when responsible agencies attempt to anticipate future damages by changing protection and land use planning measures, ahead of the impacts being experienced.

These compounding pressures become extremely challenging when decision makers have institutional responsibilities for climate change adaptation decisions that will need to be robust over a range of possible future climate changes. On the one hand, if decision makers anticipate change before it happens, they receive opprobrium. On the other hand, if they wait until the damage has occurred, there is lock-in to the escalating risk. Such a 'no-win' situation calls into question whether current institutional frameworks and practices will be adequate for the sort of climate changes that will occur, and if not, whether they can be amended, augmented, or will require new institutions to enable communities to cope with the changes or adapt to them.

\subsection{Research aims}

Accordingly, the aim of this thesis is to examine the adequacy of institutional frameworks and practices for making decisions about climate change risks at a local scale within a multi-layered institutional framework. The focus concerns uncertainty and dynamic change with respect to sealevel rise and increased frequency and intensity of rainfall and the consequent impacts that affect people and economic activity located along coasts and in floodplains. The research assesses the extent to which institutional frameworks and decision practices allow for, or enable, decision makers to address the uncertainty and dynamic climate change. It seeks to identify the elements that address uncertainty and dynamic change currently, or that could be augmented or redesigned to better reflect such climate change characteristics in a robust and flexible way over long timeframes and thus enable improved decision making.

The focus of this thesis on institutional frameworks and practices was motivated by a review by Dovers and Hezri (2010) of the climate change adaptation literature, which revealed a gap that this research addresses. Dovers and Hezri examined the literature for coverage of policy processes and institutions, and noted that: 
Institutions and institutional change are mentioned often but rarely specified in discussions of climate adaptation. Policy change is proposed, but the detail of policy processes less often discussed. Adaptation to increased climate change and variability will require policy interventions to change behaviours across multiple sectors, requiring policy processes constrained or enabled by institutional settings. Detailed discussion of how to redesign policy processes and institutions are especially rare at the crucial jurisdictional scales of national and sub-national policy and planning. (p. 212)

Empirical studies that analyse institutional frameworks and decision practice relevant to addressing uncertainty and dynamic climate change will inform this call for a focus on the role of institutions and institutional change in climate change adaptation discourse; and such studies could potentially lead to the design of measures that are robust and are flexible in time and space. The extent to which the identified gap in institutional analysis has begun to be filled with conceptual and empirical studies will be discussed in Chapter 2. However, to date, the few detailed studies that have been undertaken at national and sub-national levels have focused on overcoming the institutional barriers to climate change adaptation or on institutional enablers for adaptation. Few studies have analysed the adequacy of an institutional framework and practice at a national or subnational level for addressing uncertainty and dynamic climate change with a view to informing improvements to institutions for adapting to climate change. It is thus timely to address the overlapping problems of uncertainty and dynamic climate change and the challenges for decision makers that result when operating within a multi-layered institutional context with a high level of devolution to local government. These considerations lead me to my research question which is: How adequate is the current decision-making framework and practice for enabling decision makers to make climate change adaptation decisions that sufficiently address the constraints posed by climate change uncertainty and dynamic change?

Sub-questions are:

- What is the existing framework and how adequate is it?

- What are the current decision-making practices, how adequate are they and what do non-climate decision settings tell us about addressing uncertainty and dynamic change?

- What is the scope for an improved framework and practice? 
They address the extent to which and how the current decision-making framework and practice consider uncertainty and dynamic climate change; the observed barriers to robust and flexible decisions; and available enablers and entry points for better decision making, including those suggested by non-climate institutional settings.

To answer these questions it was necessary to situate the research in a specific locality and to understand the conceptual bases of that locality's institutional framework.

\subsection{Location of research}

The research was conducted in New Zealand. New Zealand presents a range of natural hazard events occurring regularly - earthquakes, coastal erosion, flooding, landslides, geothermal subsidence and volcanic activity — and therefore there is experience in managing hazard risks, including those that will be exacerbated by changing climate. Tailored institutional frameworks already exist in New Zealand for addressing the hazards experienced to date. Sea-level rise and flooding from increased rainfall frequency and intensity are the climate change impacts focused on in this thesis. The IPCC (Reisinger et al., 2014) identified them both as key climate change risks for New Zealand. Sea-level rise is expected to result in widespread damages at the upper end of projected changes with large adaptation challenges; flooding is expected to result across wide areas. While amenable to risk reduction by adaptation, more transformative adaptation to flooding will be required if there is less mitigation of greenhouse gas emissions.

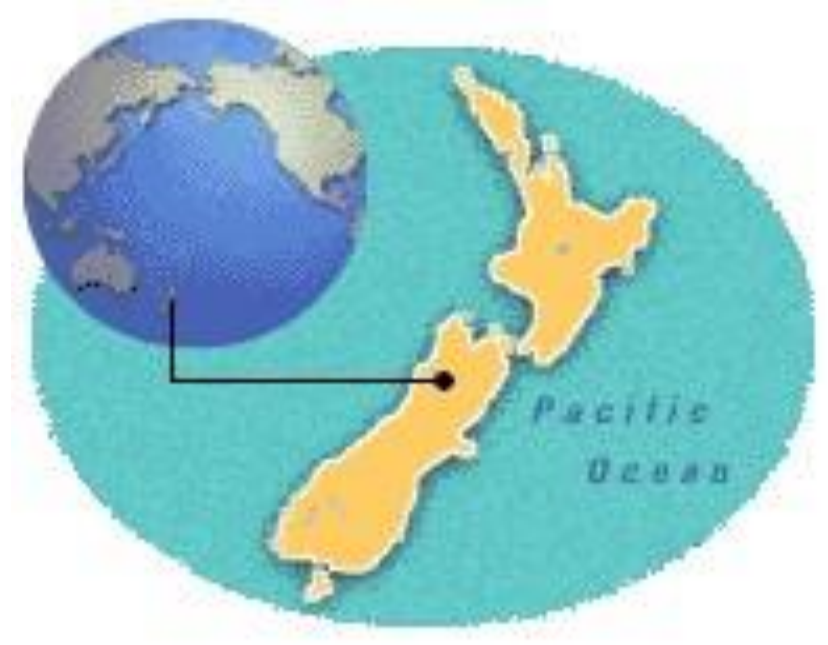

\section{Figure 1.1 Location of New Zealand}

Source: www.adventuredivas.com

Weather-related natural hazard events are ever-present in a country like New Zealand which is positioned in the 'roaring forties' surrounded by ocean (Figure 1.1). New Zealand's location, in 
combination with its elongated shape and north-south-oriented topography, drives climate conditions. These are dominated by coastal storms and flood events. Such events are the most frequently experienced natural hazards and until recently, ${ }^{3}$ the most costly hazards in New Zealand (Insurance Council of New Zealand, 2012). The impacts of hazard risk are felt locally, due to the majority of human settlements being located in areas exposed to sea-level rise and flooding risk. However, such current climate-related risks will be exacerbated by climate change, and if experienced contemporaneously across New Zealand in the future, potentially could result in social and economic consequences with national implications.

New Zealand is governed by a constitutional monarchy with one legislative House of Representatives. Some roles and responsibilities are devolved to two levels of local governmentregional and territorial. The institutional frameworks and practices that are the focus of this thesis are primarily implemented by local government. Hence, the study focused on the local government level, except where the national level has roles and responsibilities for consideration of climate change impacts.

\subsection{Research design and methods}

Undertaking a detailed multi-level study of the adequacy of institutional frameworks and practice necessitated a design and methods that could examine different drivers of practice in some depth. A qualitative methodology was employed using deductive and inductive elements, which enabled interpretations to be made of: a) the conceptual bases of the institutional framework; b) the adequacy of the framework and the actual decision-making practices used by the actors; and c) whether there is space for improved frameworks and practice for addressing uncertainty and dynamic change.

At the heart of the thesis is the development of adequacy criteria derived from the conceptual bases of the institutional framework and grouped according to their ability to guide decisions in a context of uncertainty and dynamic climate change, viz., understanding and representing uncertainty and dynamic climate change characteristics, governance and regulation, and organisations and actors.

A thematic approach to analysis was used for analysis of the empirical information collected from a sample of local and central government agencies, and from those that contribute to the decisionmaking processes. The research participants reflected the range of geographical, governance, functions and professional disciplines across New Zealand. A mix of methods was used including workshops, interviews and document analysis. This mix helped test, and, where appropriate,

\footnotetext{
${ }^{3}$ In 2010 and 2011 several catastrophic earthquakes occurred in Canterbury, New Zealand which resulted in the largest one-off cost for a New Zealand natural disaster.
} 
corroborate and validate the experiences of the participants. The suggested scope for an improved framework and practice drew from all empirical components.

\subsection{Structure of thesis}

Chapter 2 elaborates the research problem, which is the adequacy of institutions and practice for addressing uncertain and dynamic climate change in adaptation decision making. The chapter describes how the climate is changing and the impacts of that change, followed by discussion on how uncertainty and dynamic climate change characteristics combine with governance and institutional frameworks to make adaptation decisions especially difficult. The New Zealand institutional framework is summarised to provide the decision context for the institutional analysis that follows in subsequent chapters. The chapter also reviews the literature that addresses the ability of institutions to address uncertainty and dynamic climate change and establishes the gap that this thesis addresses. Other literature is introduced that is drawn on later in this thesis to reinforce the suggested scope for institutional framework and practice improvements.

Chapter 3 describes the research design and process, which follows a deductive logic when drawing from the conceptual bases of the institutional framework; and an inductive logic when drawing empirical evidence qualitatively from existing institutional frameworks and current practices within them. The analytic strategy employs a thematic analysis of the empirical data, a set of criteria for adequacy (Chapter 4) derived from decision-relevant categories of issues supported by the literature (as introduced in Chapter 2) to enable the space for improved practice to be identified. This chapter sets out the research questions, the rationale for the research design, the process and methods and the limitations of the research.

Chapter 4 develops the criteria for gauging the adequacy of the institutions and current practice. It does this by examining the implications of four conceptual bases for addressing uncertainty and dynamic change - the precautionary principle, risk management, adaptive management and transformational change. This analysis leads to the identification of criteria within three categories of decision-relevant issues for assessing the adequacy of the New Zealand institutional framework (Chapter 5) and practice (Chapter 6).

Chapter 5 describes and assesses the adequacy of the New Zealand institutional framework for addressing uncertainty and dynamic climate change. It does this first by describing the framework that comprises the documented structure and governance hierarchy and the rules, procedures and programmes that are codified in statutes. The framework is then assessed for its adequacy in meeting the criteria developed in Chapter 4 as a measure of its ability to address uncertainty and dynamic climate change. It concludes with a summary of the overall adequacy of the framework. 
Chapter 6 presents the current practice based on a thematic analysis of the empirical data collected at interviews, workshops and from document analysis. The practice is then assessed for its adequacy in meeting the criteria developed in Chapter 4 as a measure of its ability to address uncertainty and dynamic change. The chapter concludes with a summary of the overall adequacy of the practice.

Chapter 7 discusses the space for improvements in the institutional framework and practice based on incremental legislative changes suggested by research participants, demonstrated success factors evidenced by the practice, the barriers and enablers that emerged from the analysis of framework and practice adequacy and enablers from non-climate decision settings that also make decisions under conditions of uncertainty and dynamic changes. The space for change is defined in terms of enablers and entry points for implementation across the three decision- relevant categories of issues that emerged from the literature in Chapter 2.

Chapter 8 concludes this thesis by summarising the findings on whether the current decision making framework and practice is adequate to address uncertainty and dynamic climate change in adaptation decision making. The thesis concludes by discussing the contribution that its findings make to adaptation scholarship, their ability to be generalised to other locations and further research that addresses the 'implementation gap' between frameworks and practice. 



\section{Chapter 2 The challenge for decision making}

This chapter elaborates the research problem, which is the adequacy of institutions and practice for addressing uncertain and dynamic climate change in adaptation decision making. The chapter describes how the climate is changing and the impacts of that change, followed by discussion on how uncertainty and dynamic climate change characteristics combine with institutional frameworks to make adaptation decisions especially difficult. The New Zealand institutional framework is summarised to provide the decision context for the institutional analysis that follows in subsequent chapters. This chapter also reviews the literature that addresses the ability of institutions to address uncertainty and dynamic climate change and establishes the gap that this thesis addresses. Other literature is introduced that will be drawn on later in this thesis to reinforce the suggestions made about how the institutional framework and practice might be improved.

\subsection{The climate is changing}

It is well-established that human activities are changing the climate. The Intergovernmental Panel on Climate Change (IPCC, 2013) concluded that continued emissions of greenhouse gases will cause further warming and changes in all components of the climate system, noting that limiting climate change will require substantial and sustained reductions of greenhouse- gas emissions. The IPCC also reported that: the rate of sea level rise will very likely ${ }^{4}$ exceed that observed during the period 1971 to 2010 due to increased ocean warming and increased loss of mass from glaciers and ice sheets; the frequency of heavy precipitation events and the proportion of total rainfall from heavy falls will be likely to increase in the $21^{\text {st }}$ century; and increased incidence of extreme high sea levels are projected to be very likely (IPCC, 2012).

Whatever governments do globally to reduce greenhouse gases, there will be impacts from climate change because of the cumulative emissions in the atmosphere to date that will affect all countries and require adaptation (IPCC, 2014a). Sea level will continue to rise for centuries even with stringent mitigation (IPCC, 2013) and the frequency of storm events is expected to increase over this century (IPCC, 2013, 2014a; Trenberth, 2011).

Nations have pledged reductions in emissions under the Copenhagen Accord (United Nations, $1992 \mathrm{~b}$ ) to limit warming to no more than $2^{\circ} \mathrm{C}$ and to review this by 2015 to $1.5^{\circ} \mathrm{C}$. These pledges

\footnotetext{
${ }^{4}$ The IPCC (2013, p. 121) defines the italicised likelihood statements as follows. The following terms have been used to indicate the assessed likelihood of an outcome or a result: Virtually certain $99-100 \%$ probability, Very likely 90 $100 \%$, Likely 66-100\%, About as likely as not 33-66\%, Unlikely 0-33\%, Very unlikely 0-10\%, Exceptionally unlikely 0-1\%. Additional terms (Extremely likely: 95-100\%, More likely than not $>50-100 \%$, and Extremely unlikely 0-5\%) may also be used when appropriate. Assessed likelihood is typeset in italics, e.g., very likely.
} 
are in recognition of the likely damages from climate change. However, the pace and scale of actions to date fall short of the emissions targets that can be derived from global integrated assessment models. Hence higher amounts of warming are an increasingly likely future scenario (IPCC, 2013), with implications for more severe and frequent impacts from climate change.

\subsubsection{The climate changes-sea-level rise and increased rainfall frequency and intensity}

The impacts of sea-level rise, storms and increased frequency and intensity of rainfall that result from the climate changes are the focus in this thesis. The impacts will be felt separately, but will also combine in ways not experienced before at the coast, in low-lying areas and adjacent to river mouths, on flood plains and potentially some distance inland from the coast as sea-level rise interacts with groundwater (Bjerklie, Mullaney, Stone, Skinner, \& Ramlow, 2012; McGranahan, Balk, \& Anderson, 2007).

Sea-level rise Sea levels are rising because a warmer atmosphere warms the ocean, which expands in response. The IPCC has projected that warming is virtually certain to continue through the $21^{\text {st }}$ century (IPCC, 2013). The IPCC reported that under a high emissions scenario ${ }^{5}$, global mean sea level would likely rise by 0.53 to $0.97 \mathrm{~m}$ by 2100 , relative to $1986-2005$, whereas with stringent mitigation (RCP2.6), the likely rise by 2100 would be 0.28 to $0.6 \mathrm{~m}$ (medium confidence). Based on current understanding, only instability of the marine-based sectors of the Antarctic ice sheet, if initiated, could lead to a rise substantially above the likely range; evidence remains insufficient to evaluate its probability, but there is medium confidence that this additional contribution would not exceed several tenths of a metre during the 21 st century (Church et al., 2013b, p. 1173 \& 1182), although some modellers have demonstrated that rapid dynamical acceleration of ice sheets is physically possible (Katsman et al., 2011; Pfeffer, Harper, \& O'Neel, 2008). This is because the probability of the under-lying assumptions cannot be quantified from observations of the response of the Greenland and Antarctic ice sheets to climate change or variability on century timescales. It has also been noted (Domingues et al., 2008) that more than $50 \%$ of the recent sea-level rise is due to loss of glaciers and ice sheets, with that percentage continually increasing and evidence showing that the rate is accelerating (Joughin, Smith, \& Medley, 2014; Rignot, Mouginot, Seroussi, \& Scheuch, 2014; Rignot, Velicogna, van den Broeke, Monaghan, \& Lenaerts, 2011).

This means that the direction of the change in sea-level, its acceleration and levels and that dynamic ice sheet loss is likely, are known with medium confidence. However, the changes

${ }^{5}$ The high emissions scenario is Representative Concentration Pathway (RCP) 8.5. 
outside the likely range resulting from rapid disintegration of ice-sheets remain poorly understood. In other words, there is change and it is accelerating. This change could be step wise or 'lumpy'. The change therefore has two components-dynamic change that could include regime shifts, overlain by natural variability which may mask that change; and uncertainty about the timing and magnitude of the change. Figure 2.1 shows the upper and lower likely levels and their ranges for sea level globally.

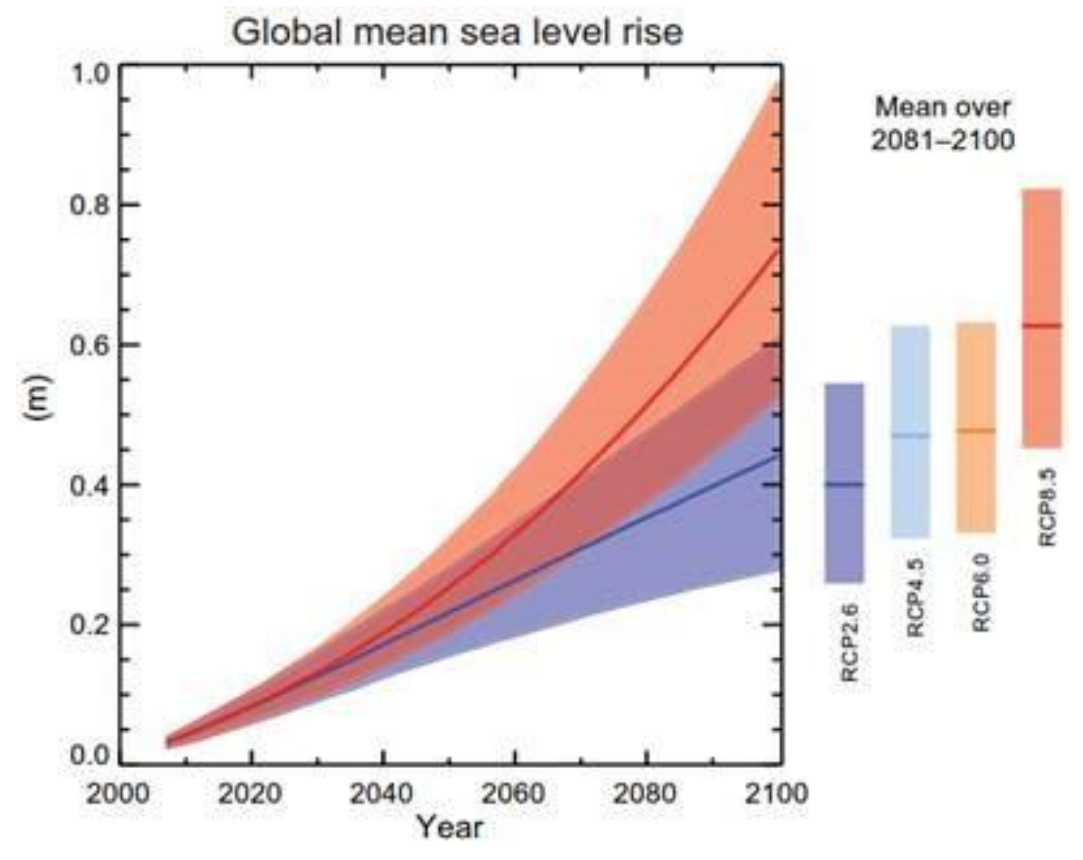

\section{Figure 2.1 Global mean sea level rise. Upper and lower likely ranges}

Source: IPCC, (2013, p. 24). Figure SPM.9 Projections of global mean sea level rise over the 21 st century relative to 1986-2005 from the combination of the CMIP5 ensemble with process-based models, for RCP2.6 and RCP8.5. The assessed likely range is shown as a shaded band. The assessed likely ranges for the mean over the period 20812100 for all RCP scenarios are given as coloured vertical bars, with the corresponding median value given as a horizontal line. For further technical details see the Technical Summary Supplementary Material.

From a decision-making perspective, the critical changes are the upward direction of the change, its continuous nature and that it is accelerating relative to the $17 \mathrm{~cm}$ per century historic rate. Importantly, even a rise of 0.5 metres will have damaging consequences and thus has significance for decision making (Hanson et al., 2011) well before some of the higher estimates are realised. Sea-level rise impacts will occur from high water events resulting in erosion and inundation at the coast, combined with storms surge, and from more gradual inundation resulting in ground salination, liquefaction and interactions with groundwater.

Increased rainfall frequency and intensity Rainfall probability distributions are also shifting. This is experienced as more storms with heavy rainfall occurring more frequently over many areas 
(IPCC, 2013). A warmer atmosphere holds more moisture and affects storm trajectories. It is the uncertainty about the timing of such events and their frequency and location that is of relevance to decision makers. There are two types of uncertainty here-where and when heavy rainfall events will occur cannot be predicted now or in the future; and how much the statistical frequency and intensity of heavy rainfall events will change as a result of climate change. These uncertainties are unlikely to be resolved before decisions are made about the location of development and infrastructure that will be affected by the changes within the lifetime of those developments.

An example, shown in Figure 2.2, illustrates how increased flood frequency in the Hutt river catchment in New Zealand is affected by two different emissions scenarios for a range of different climate models (Lawrence, Reisinger, Mullan, \& Jackson, 2013). For a design flood flow of 2,300 cubic metres per second (the black horizontal dashed lines on both graphs), the current annual exceedance probability of $0.23 \%$ (1-in-440-year event) would increase to about $1 \%$ (1-in-100year event) by the end of the century under a low-emissions trajectory (left-hand graph); and to just over 2\% (1-in-50-year event) under a high-emissions trajectory (right-hand graph). While this example is illustrative of how climate change could affect flood frequency using two plausible estimates, there is a wide range of possible future outcomes due to the uncertainty about how much the statistical frequency and intensity of storms will change. For example, some areas may experience change, while others may not, due to shifts to drier conditions with fewer storms. 

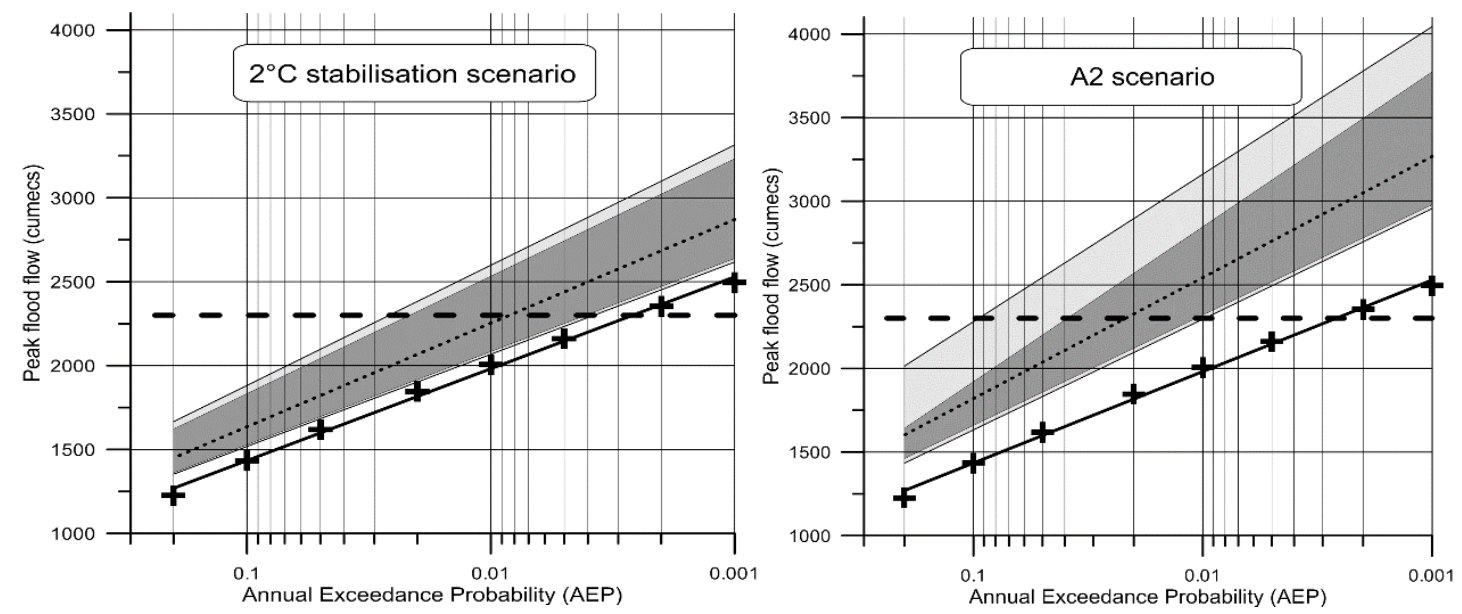

\section{Figure 2.2 Changes in exceedance probabilities under different emission scenarios.}

Source: Lawrence, Reisinger, et al. (2013)

Note: The black crosses and solid line show estimated exceedance probabilities for a range of design flood volumes. The dotted line shows the flood volumes for alternative emissions scenarios in 2090 (left: $2^{\circ} \mathrm{C}$ stabilisation; right: A2 SRES emissions) for a range of climate models. The light grey band shows the full model range, whereas the dark grey band shows the 10 to 90 percentile model range. The black dashed line shows the volume of the current design flood of $2300 \mathrm{~m}^{3} / \mathrm{s}$, with an estimated current AEP of $0.23 \%$.

Sea-level rise and increased frequency and intensity of rainfall share many similar characteristics: we know they will occur with certainty and manifest their damaging impacts during extreme events, but the magnitude and timing of their impacts is uncertain. Sea-level rise, however, differs from flood risk because it will continue for centuries, even if climate change were stopped as a result of rapid reductions in greenhouse gas emissions. Flood risk on the other hand, could stop if warming were limited and therefore would not get worse.

\subsubsection{The damages arising from climate change impacts}

In many cases, it is the extremes that lead to the most noticeable and significant impacts on human activities. Changes in mean conditions can increase damage costs at the extremes, and lead to damage thresholds being exceeded. For example, Figure 2.3 shows how a shift in mean conditions from the current situation (diagram a) affects the frequency of the extreme conditions (diagram b), by increasing expected annual average damages; and how a shift in variance (diagram c) means more variable weather that increases the damages from the extremes even further. 
a)

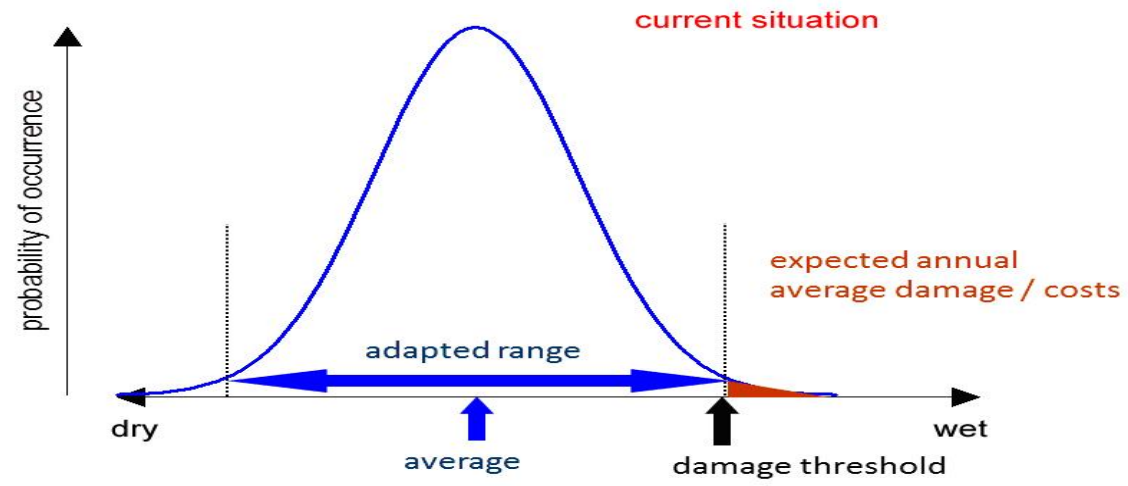

b)

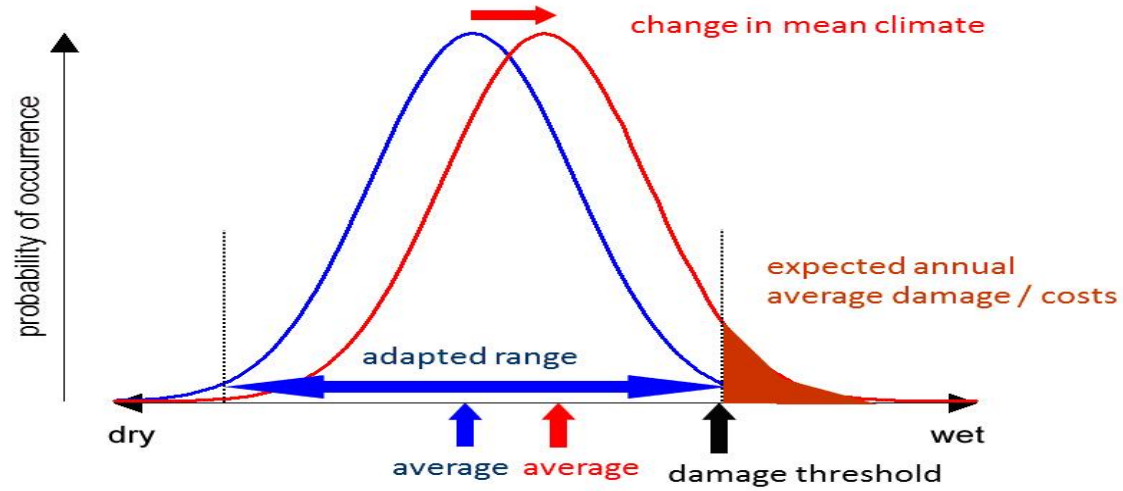

c)

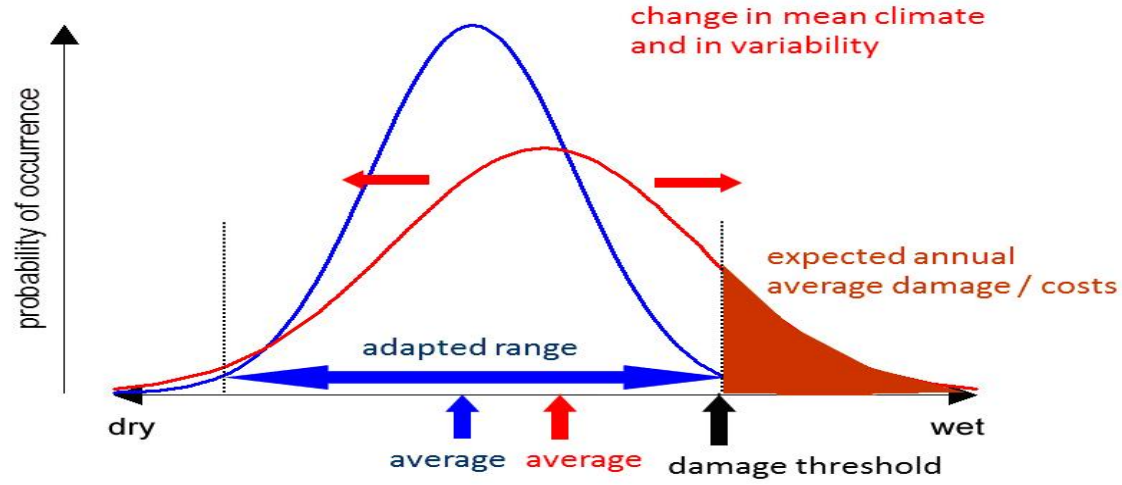

\section{Figure 2.3 Changes in extremes with changes in mean climate}

Source: Andy Reisinger adapted from IPCC (2012) Figure SPM3

The effects shown in Figure 2.3 also illustrate how changes will challenge the adaptive range of human activities by reaching a damage threshold (black arrow on diagram c) where the coping range for a particular type of extreme event is exceeded. Where the coping range is already exceeded from the current conditions shown in diagram a), and the changes shown in diagrams b) and c) occur, the coping capacity will be challenged (Burton, 2009; Parry et al., 2009). The gap between the current state of a system and a state that minimises adverse impacts from existing climate conditions and variability is called an 'adaptation deficit' (IPCC, 2014b). 
Development cycles have exposed humans and their activities to climate change impacts such as sea-level rise and increased heavy rainfall events. For New Zealand, the IPCC (Reisinger et al., 2014) highlighted increasing extreme rainfall related to increased frequency and intensity of flood damage to settlements and infrastructure in many locations as key risks from climate change. Continuing sea-level rise will increase risk to coastal settlements and infrastructure in low-lying areas with widespread damages toward the upper-end of projected changes. Regional sea-level rise is very likely to exceed the historical rate (during the period 1971-2010). In some locations, sealevel rise and increased frequency and intensity of rainfall will compound damage from other natural hazards like tsunamis, earthquake-induced liquefaction of ground, soil erosion, landslides and coastal erosion. New Zealand is exposed to all of these hazards (Department of the Prime Minister and Cabinet New Zealand, 2007) and in the future, some of them will occur contemporaneously. Flooding and sea-level rise are currently the two most significant direct impacts of climate change for New Zealand. Currently, New Zealand experiences, on average, a major flood every eight months (Ministry for the Environment, 2008c). Box 2.1 shows New Zealand examples of recent weather events and their impacts. However, decision making will have to cope with new conditions that are changing at rates and magnitudes beyond what has hitherto been experienced. 


\section{Box 2.1 Recent New Zealand weather events and their impacts}

1) A storm during April 2014 caused widespread disruption on the West Coast of the south island of New Zealand with many roofs blown off and significant damage to the electricity network disrupting supply to customers for more than a week. The following comment was reported from the Buller Electricity Chief Executive. "This is a storm none of my team have ever experienced."

(Source: The Dominion Post, 21 April, 2014)

2) A storm was experienced in Wellington in June 2013 causing widespread damage to houses, electricity networks, roads and coastal sea walls. Fifteen-metre ocean swells were recorded two kilometres off the Wellington coast. These waves were the largest recorded since 1995.

(Source: Murray Poulter. National Institute of Water and Atmosphere

http://www.niwa.co.nz/news/storm-and-snow-information-update)

3) In September 2013 a vicious windstorm with winds up to 200 kilometres per hour in the foothills, created widespread damage across the Canterbury region, uprooting forests, houses and farm assets worth more than \$68 million in damages. These winds pushed the cost of extreme weather events in New Zealand in 2013 up to \$157million.

(Source: Tim Grafton, Insurance Council of New Zealand

http://www.stuff.co.nz/the-press/news/canterbury/9317212/September-storm-costs$68 \mathrm{~m})$

4) In December 2011 a large blocking high pressure system sat to the east of New Zealand and "a pipeline of rain developed as subtropical moisture barrelled in from the north Tasman Sea." This resulted in the Nelson/Tasman region receiving very intense rainfall (e.g., $510 \mathrm{~mm}$ in 48 hours at the township of Takaka including $423 \mathrm{~mm}$ in 24 hours, well in excess of a 1-in-100year rainfall event. In the 35 years of records at that site, the previous 24 -hour record was $256 \mathrm{~mm}$. Other areas in the region received similar highly intense rainfall over the 24 -hour period (e.g., $200 \mathrm{~mm}$ in 24 hours on the Waimea plains.

(Source: Daniel Corbett, MetService

http://www.stuff.co.nz/national/6143578/Blocking-high-causes-Nelson-deluge)

Interventions to ameliorate the damage from climate change impacts are required long before damages are experienced, due to the timeframes of the decisions taken today and the lifetimes of the activities being decided (Stafford Smith, Horrocks, Harvey, \& Hamilton, 2011). Interventions, however, are perceived as costly in the short term for uncertain future benefits (Hallegatte, Shah, Lempert, Brown, \& Gill, 2012). But managing uncertainty through strong risk-avoidance approaches often implies greater initial costs (through enhanced, pre-emptive protection works, or opportunities foregone from earlier development options). Since different sections in the community differ in the value they give to near-term versus long-term risks, such decisions are inevitably difficult and require reconciling conflicting views. Also socio-economic and cultural development is likely to change those values over time. Changes in people's values and in their 
ability to respond to change in their economic and physical environment will affect their adaptive capacity (Adger, Agrawala, \& Mirza, et al., 2007; Smit \& Wandel, 2006) and will change community preferences. The value of assets at risk also will change over time, as will the technological and financial ability to undertake risk-management strategies. This becomes significant for decisions about activities that have long lifetimes (for example, housing and infrastructure which persist for many decades at fixed locations). Therefore the time horizon of the decision and its interaction with climate changes is an important consideration for decision makers. However, the timeframe of current planning and political cycles can run counter to the long-term focus required for considering climate change impacts.

Given the exposure of human settlements, what is really at stake? Sea-level rise, flooding and associated storm surge and groundwater effects have the potential to damage a wide range of social and economic sectors. Impacts include direct impacts on infrastructure, such as transport networks above and below ground, ports, airports, water supply, waste water and sewerage systems, energy and other network utilities, transportation and telecommunications, the built environment; as well as the indirect effects on health and social services, lost business, disruption to food supply and food price shocks and many other cascading effects across interconnected systems. The cascading effects on a city like New York, for example, as a result of hurricane Sandy in 2013 (Rosenzweig $\&$ Solecki, 2010) demonstrate the type of impacts that sea-level rise, storm surge and flooding can bring to the functioning of human settlements.

These impacts fall on top of existing adaptation deficits found in both developed and developing countries (Burton, 2009) which exacerbate existing differentials in income within and between countries. The larger the deficit, the larger the exposure differentials to most climate change impacts between income groups (IPCC, 2014a, pp. 547-548). Economic costs of flooding are highest in high-income countries (Hallegatte, Green, Nicholls, \& Corfee-Morlot, 2013; Munich Re Group, 2007). However, this leaves adaptive capacity out of the equation. The IPCC (2012) noted that high exposure, limited risk reduction measures and low-quality housing created an inability to cope. An assessment of the present and future flood losses in the world's largest 136 cities (Hallegatte et al., 2013) showed that the estimated costs of adaptation are well below the estimated losses without adaptation. Urbanisation of flood-prone land sets in motion long-term commitment to place, and expectations of continued 'protection' and development, creating increased exposure and vulnerability to extreme events (Burby, Nelson, Parker, \& Handmer, 2001; Hallegatte et al., 2012). Such studies suggest that there is a low level of understanding of the uncertainties and likely changes associated with climate change. This situation has relevance for how decisions are made under conditions of uncertainty and dynamic change. 


\subsubsection{Decision-relevant climate change characteristics-uncertainty and dynamic change}

Walker, Lempert, and Kwakkel (2013) identified three uncertainty considerations relevant for climate change adaptation decision making:

- not all uncertainties about the future can be eliminated (epistemic uncertainty);

- ignoring uncertainties could limit the ability to take corrective action in the future, resulting in situations that could have been avoided (lock-in);

- ignoring uncertainty can result in missed opportunities and lead to unsustainable plans and decisions based on them (path dependency).

Van der Sluijs (2007) described three ways of thinking about uncertainty and its management:

1) Uncertainty as a provisional problem, because uncertainty can be reduced. Here the predominant decision tools used are quantification;

2) An evidence-evaluation view that evaluates uncertainty using comparisons of research results. Here the predominant decision tools used are scientific consensus-building and multi-disciplinary expert panels that focus on robust findings;

3) A complex systems/post-normal science view where uncertainty is intrinsic to complex systems, cannot be quantified and where uncertainty is framed as indeterminate, and where ignorance, values, assumptions and institutional dimensions shape the questions we ask. The predominant tools used include knowledge quality assessments and deliberative and negotiated management of risk.

All three categories described by Van der Sluijs exist for decision making about sea-level rise and increased frequency and intensity of rainfall. Uncertainty can be reduced and avoided in many situations and the evidence of climate changes can inform likelihood statements such as those developed by the IPCC (Church et al., 2013b; Mastrandrea et al., 2010). Where the uncertainty is indeterminate (the timing and magnitude of extreme rainfall events and the very upper ranges of sea-level rise that are contingent on how ice sheets behave) and values are in dispute, stakes are high and decisions urgent, a post-normal method of inquiry in science has guidance for decision makers. This method of inquiry was developed by Funtowicz and Ravetz (1992). However, such complexity may be found in many decision-making settings to a greater or lesser degree. Climate change complexity presents particular relevance for decision makers because, if uncertainties are not identified, understood and communicated in the assessment of risk and design of responses, the resulting decisions will mislead and impact negatively on those relying on the decisions 
(Jones, 2001; Pielke, 1999). There are uncertainties about the value of parameters at all stages of the assessment of climate risk - the structure of the models used, the options available to decision makers, the methods used to assess risk. And both the climate parameters and societal values are shifting with time and are uncertain, as are societal expectations.

The understanding of uncertainty relating to knowledge has a long history. Knight (1921) suggested uncertainty was what was left after what could be quantified - the unknowable and uncontrollable. Others have made a distinction between real uncertainty that includes the future state of the world and uncertainty that relates to the behaviour of human actors (Quade, 1989). Funtowicz and Ravetz (1990) described uncertainty as comprising three possibilities: inadequate information that is inexact, or unreliable, or where ignorance exists. Walker et al. (2003) described uncertainty as a continuum from determinism-statistical uncertainty, scenario uncertainty, recognised ignorance; to indeterminacy - total ignorance, when discussing 'deep uncertainty', noted that uncertainty has many meanings that come from its use within different disciplines, such as engineering, physical science, statistics, economics, finance, insurance, philosophy and psychology, and is generally defined as limited knowledge. However, uncertainty is not just the absence of knowledge and new information does not always reduce uncertainty; new information can increase or decrease uncertainty. Uncertainty can make the problem appear more complex and can exist where there is much information available.

For the purposes of this thesis, uncertainty refers to claims about a future outcome, the relevant features of which can only be described as a range of potential outcomes of different magnitude and timing that are unknown; some uncertainties can be quantitatively estimated, whilst others can only be described qualitatively.

Uncertainty about sea-level rise and increased frequency and intensity of rainfall is compounded by the potential for rapid changes and surprises due to limited understanding of underlying climate and ice-sheet processes (also referred to as 'deep uncertainty' (Walker et al., 2013)) and which has significance for decisions about long-lived assets. In this thesis such dynamic change is defined as change that may occur in steps and that could result in regime shifts overlain by natural variability which may mask that change, and change that will shift the risk over time.

\subsection{How climate change creates a decision-making problem}

The characteristics of the climate change and its impacts discussed in Section 2.1 create a number of changing conditions that intersect with the activities that decision makers need to address in the present and for the future. 
The IPCC report on managing extreme events and disasters to advance adaptation to climate change (IPCC, 2012) conveyed the inter-relationships between the climate and human systems that give rise to the decision-making challenge. Figure 2.4, as elaborated by the IPCC (2014a), shows how risk of climate-related impacts results from the interaction of climate-related hazards (hazardous events and trends) with the vulnerability and exposure of human and natural systems. Changes in the climate system shown on the left of the diagram and socio-economic processes like adaptation and mitigation on the right drive hazards, exposure and vulnerability.

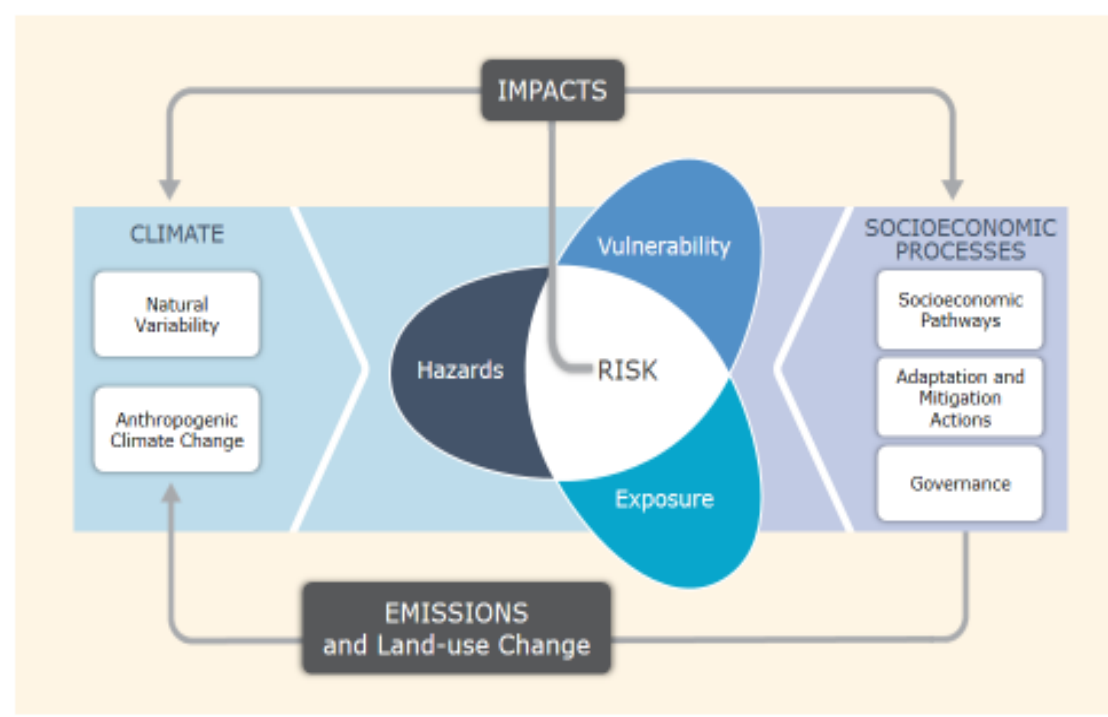

ipcc

\section{Figure 2.4 Risk is a combination of climate hazard, exposure and vulnerability in a socio-economic system}

Source: SPM1 (IPCC, 2014).

Illustration of the core concepts of the WGII AR5. Risk of climate-related impacts results from the interaction of climate-related hazards (including hazardous events and trends) with the vulnerability and exposure of human and natural systems. Changes in both the climate system (left) and socioeconomic processes including adaptation and mitigation (right) are drivers of hazards, exposure and vulnerability. [19.2, Figure 19.1]

The role played by values and aspirations in people's perception of risk and their ability to imagine the future with climate change is considered pivotal for responding to change (IPCC, 2012). This highlights the complex interactions between people, their socio-economic context, their environment and their ability to respond.

The significance of these inter-relationships for decision making about climate change adaptation is demonstrated by a number of societal characteristics and trends. For example, half the world's population resides in urban centres where most assets are located and economic activities take place (World Bank, 2010a). A high proportion of those most affected by extreme weather events 
are located in urban centres (IFRC, 2010). Ten percent of the world's population and $13 \%$ of the world's urban population are located in the Low Elevation Coastal Zone, defined as the contiguous area along the coast that is less than 10 metres above sea level (McGranahan et al., 2007). A large number of the world's population are located in low-lying areas adjacent to major river systems which will be exposed to increased frequency and intensity of rainfall events and resulting flood impacts (IPCC, 2012).

Such exposure of people has increased the damages from climate events over time (Lloyds, 2008). There has also been an upward trend in climate-related events, like flooding (Munich Re Group, 2007). For example, globally in 2013 , floods caused $47 \%$ of the overall losses and $45 \%$ of the insured losses in the first six months alone (Munich Re Group, 2013); 2011 was the year with the highest-ever economic losses recorded for the reinsurance industry at US $\$ 265$ billion up to the end of June 2011 - half of these were from weather events. The World Bank (2010b) has recognised the potential for increasing damage over time by signalling concern that climate change could increase damage from extreme events, tripling in dollar terms over the next 30 years as a result of current economic development pathways and population trends. Hanson et al. (2011) estimate that, with only a 0.5 metre rise in sea level, the population at risk would more than triple, and asset exposure increase by more than 10 times, by the 2070s when taking economic growth, sea-level rise, storm surge and subsidence into account. The level of damage and societal disruption from changing climate will also be influenced by the geographical, social and economic characteristics of specific localities (Adger, Agrawala, Mirza et al., 2007).

This picture suggests that the decision-making problem can be framed in terms of the capacity of institutions to address uncertainty and dynamic climate change that manifests in widespread damages. Dovers and Hezri (2010), in a review of the adaptation literature for coverage of policy and institutions, characterised three possible future climate conditions that make climate change especially challenging for decision makers. They highlighted the critical need to understand decision challenges that flow from the possible climate conditions in relation to institutional capacity.

In the first set of conditions, climate changes are similar to existing climate variability and so, current institutional and organisational capacity and societal memory is sufficient to make adaptive decisions. A middle range of conditions have climate variability and consequent impacts significantly greater than the ranges in climate currently experienced and, while not outside historical or institutional experience, will be challenging because difficult adjustments will be necessary. In the third set of conditions, the climate changes and variability will be beyond lived 
experience and institutional memory and thus well outside current experience and, as such, will involve regime shifts and political instability that challenge institutions' and society's ability to cope at a fundamental level. Describing possible future climate conditions in terms of institutional and societal capacity enables a link to be made between institutional analysis and the type of responses required; for example, the response typology of routine, non-routine and complex unbounded disasters described by Handmer and Dovers (2013).

The decision problem caused by the intersection of climate change characteristics with the institutions for addressing climate changes has been examined in the literature, and can be summarised as five main themes. First, climate change is a long-term problem. Sprinz (2009) defines such a policy challenge as characterised by public policy issues that last at least one generation, exhibit deep uncertainty that is exacerbated by time and that engender public good considerations both at the stage of problem generation, as well as at the response stage. Hovi, Sprinz \& Underdal (2009) suggest that developing effective long-term responses under great uncertainty and implementing a strategy consistently over time, is difficult because of commitment problems due to time-inconsistency; where the causes and effects of climate change and decisions about their effect are separated in time, and domestic politics have a short-term focus. Decisions that result in long-term spatial commitments that persist over many decades or centuries are particularly at risk (Auld \& Maciver, 2006; Stafford Smith et al., 2011). Examples include decisions on infrastructure, the location of urban development and underground network utilities.

Second, risk is changing over time due to changes in the climate and by greater exposure of people to the risk, which is exacerbated where there have been low levels of adaptation to past changes in risk (Burton, 2009). Coping strategies typically do not address future accelerated climate changes or the reduction of exposure to risk over long timeframes by changing system conditions or institutions (Pelling, 2011). The legal instruments of practice are also limited in their ability to manage change over time as discussed by Ruhl (2012):

First, dynamic, changing conditions in which uncertainty is high give law the jitters. The central theme of panarchy theory is that successfully working with the dynamic forces of complex adaptive natural and social systems demands an active adaptive management regime that eschews optimization approaches seeking stability (Holling, Gunderson, \& Ludwig, 2002). Yet one of the principal goals of law is to establish and maintain the relatively stable contexts within which other social systems...can operate over time. (p. 2) 
Third, decision makers have no or very little experience with the climate change futures envisioned by the research community, especially at the extremes (Kousky, Pratt, \& Zeckhauser, 2010) and perceive the change as a 'distant threat' (Weber, 2006). The prospect of surprises and thresholds over which new system dynamics could develop (Gunderson \& Holling, 2002; Scheffer, 2009) and make conditions worse than expected, and the fact that sea-level rise will continue for centuries even with greenhouse-gas emissions reductions, makes the decision makers' challenge even more complex. For example, the 'certainty' created from the protection afforded by sea walls and flood levees can give a false sense of security because they cannot hold the line forever (Burby, 2006).

Fourth, there are added policy and implementation risks if decisions are taken too early or too late; there will be increased costs to either present or future generations. Tobin (1995) coined the phrase 'levee effect' to describe the increased path-dependency and increased exposure of communities to risk, as development in the 'protected' area becomes entrenched, thus reducing flexibility over time to adjust to changing conditions. This has been described as maladaptation (Barnett \& O'Neill, 2010); the maladaptation transfers the risk within current and to future generations in a more costly form than may otherwise have been the case; and externalises costs to the public not affected by the impacts, either within or between generations, thus creating a public good problem (Sprinz, 2009). Where the risks are not made transparent there is also the potential for 'non-adaptation', where responses don't keep up with climate change impacts, and additional maladaptation where responses lead to the capacity to adapt being undermined (Niemeyer, Petts, \& Hobson, 2005).

Fifth, contestation of climate change has seen the national level of governments sceptical of climate change, evidenced by decision-making 'flip-flop' according to political philosophy and sector-group pressure. At the local level this is reflected in slow and difficult decision making (McDonald, 2007) leading to delay in adaptation decisions that constrains the ability to adapt flexibly. Political unwillingness of decision makers to address climate change effects over timeframes beyond their term of office at all scales of government, has led to compromise within short electoral cycles, particularly when decision makers are under 'fire' from groups with shortterm private interests (Handmer, 2008; McDonald, 2011). These types of condition, in association with uncertainty and ambiguity, have led to calls for decision-making procedures that go beyond conventional risk management practice. As a result, risk and adaptive governance frameworks have been developed to address the associated ethical issues, such as who pays and who is affected within society and how to address them through stakeholder and public deliberation that can reflect different societal values (Renn, \& Schweizer, 2009; Klinke, \& Renn, 2012). 
The themes discussed here come together to make climate change especially challenging for decision makers: uncertainty and dynamic change escalating climate impacts; changing societal characteristics and values; the continuous nature of change; and the lifetime of decisions increasing exposure of people and assets thus creating path-dependency; the perception that climate change is a distant threat; public good issues that arise within and between generations; and political economy issues related to short electoral cycles.

Decision makers already work within a constantly changing environment and have experience in decision making under uncertain conditions. But it is not apparent whether this experience prepares decision makers for making climate change adaptation decisions that are robust and flexible over long timeframes. Are decision makers able to address the type of changes described above over the long-term in order to reduce exposure to the costs of damages before extreme events occur? Importantly, since decision makers operate within institutional frameworks, can the current institutional framework and practice to manage the risks from climate change, operate effectively within the complex changing environment? How can the institutional frameworks and decision processes be designed to adjust activities over time to enable the impacts of changing climate to be managed as society also changes? A detailed examination of these questions is the subject of this thesis. Every institutional context differs. New Zealand's is described in the next section as the empirical basis for answering these questions.

\subsection{The New Zealand institutional context}

New Zealand is a constitutional monarchy and power is distributed across three branches of government-Parliament which makes the law, the executive which administers the law and the judiciary which interprets the law through the courts. ${ }^{6}$ New Zealand has two levels of government. ${ }^{7}$ Parliament is elected on a three-yearly cycle and has devolved powers to local government which is elected in a similar manner every three years to represent communities and make decisions on their behalf. Everything local government does is within a legislative framework generated and maintained by Parliament at the national level. Local government comprises 12 regional councils based on catchments and 57 smaller-scale territorial local governments, which include 16 district councils and cities. There are also five combined regional and district councils, called unitary

\footnotetext{
${ }^{6}$ Refer to http://www.parliament.nz/en-nz/about-parliament/how-parliament-works/oursystem/00CLOOCHowPWorks111/our-system-of-government

${ }^{7}$ The material in this section draws from the author's knowledge of the institutional framework (having worked within in it for three decades) and from the documented history which is cited where available.
} 
authorities, which include the recently formed Auckland Council which is responsible for about a quarter of the New Zealand population.

New Zealand has an Environment Court, which is a special purpose court operating outside the hierarchy of courts of general jurisdiction, comprising a Judge and several Environment Commissioners operating under the Resource Management Act 1991 (RMA). The Environment Court addresses the intersection of the law and policy in two ways: by declaring whether local authority policies and planning measures give legal effect to central government policies under the RMA; and by adjudicating on appeals to determine whether policies and planning measures should stand or not (Somerville, 2013). Of relevance to climate change risk in this thesis are those policies and measures relating to land use, subdivision, coastal permits or a combination of these and the location of infrastructure and utilities. The Court decisions can be appealed only on points of law to the High Court, and beyond that to the Supreme Court.

National-level arrangements for managing climate-related risks, including disasters arising from extreme events, are set out in most countries' national legislation and confer powers, duties, functions and financial accountability across agencies and at different scales (IPCC, 2012). New Zealand, however, has some unique institutional arrangements and experience in managing natural hazards that, in theory at least, should enable changing climate risk and the consequent costs to communities to be reduced.

Management of natural hazards, land-use planning, provision of water services and planning for civil defence emergency management are devolved to local government as part of an institutional regime that comprises powers held at national, regional and local governance levels with respect to those functions. Consideration of the impacts of climate change is part of this regime. The institutional framework embodies precaution, risk and the interests of future generations, to greater or lesser extents, depending on the statute and the practice under it (Ministry for the Environment, 2009, 2010). The governance framework and functions, and the statutory framework and its supporting institutional arrangements are shown in Figures 2.5 and 2.6. These statutory responsibilities and regulatory provisions, the organisations, functions and professional disciplines, and the supporting institutions outside the statutes (guidance, information, informal processes) comprise the institutional framework referred to in this thesis-defined as the documented structure and governance hierarchy that support the rules, procedures and programmes that are codified in statutes, and the organisations and measures that support the implementation of the framework through practice. The framework sets out the roles and responsibilities at national, regional and local levels for land use planning, natural hazard risk 
management, planning for the effects of climate change, provision of water infrastructure and emergency management. The responsibilities were designed to be implemented in a complementary way across governance scales (Bosselmann \& Grinlinton, 2002).

\section{Central Government}

National Policy Statements and NZ Coastal Policy Statement

Non-statutory guidance

Emergency management plans

Sets framework and devolves powers

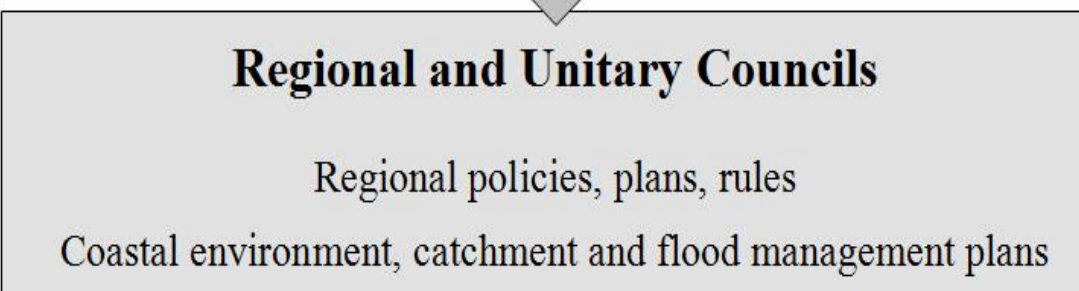

Sets framework for local rules

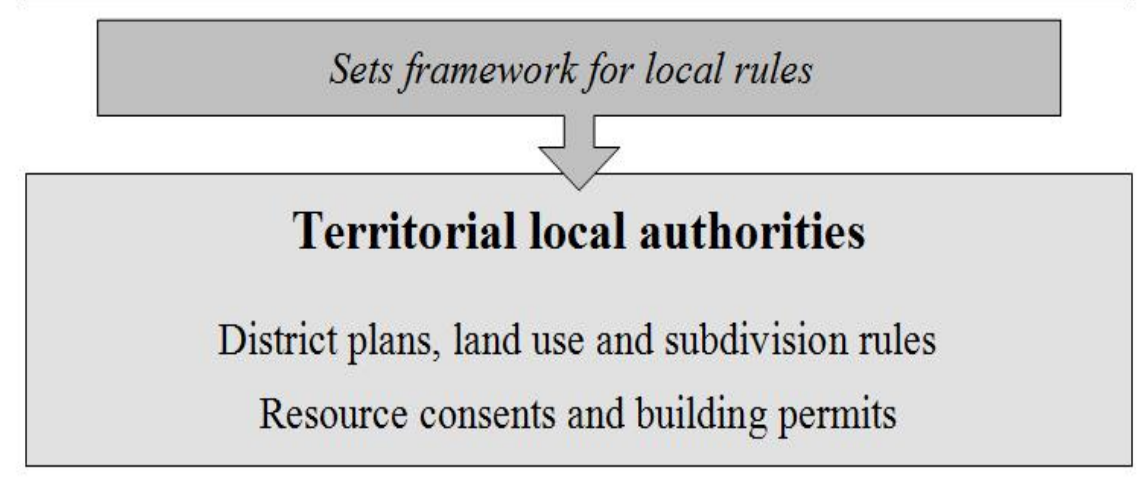

Figure $2.5^{8}$ The governance framework and functions

\footnotetext{
${ }^{8}$ Refer to the Glossary for definition of terms.
} 


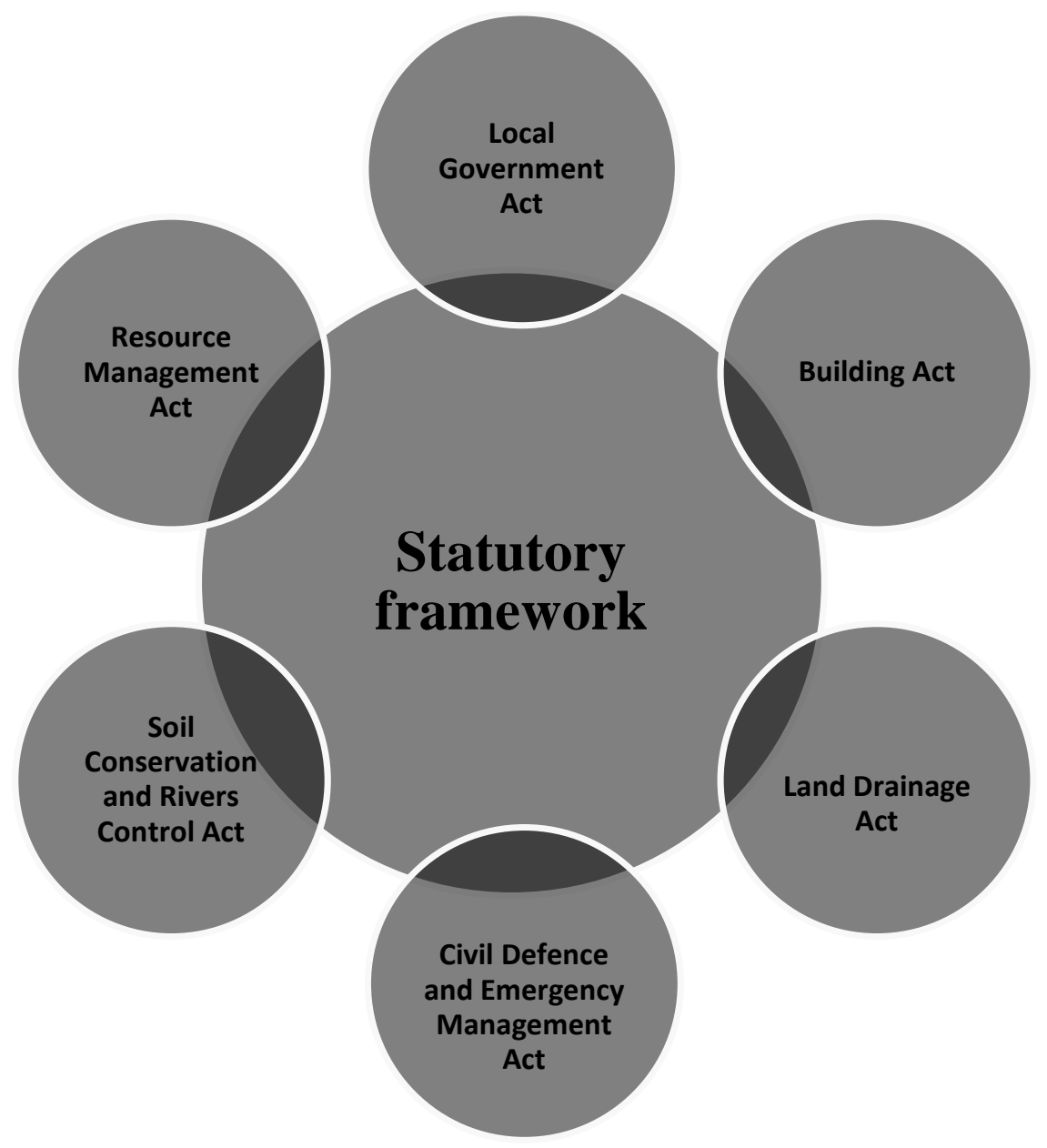

Figure 2.6 The statutory framework

The primary statute that empowers local government is the Local Government Act 2002 (LGA). It enables local councils to exercise functions independently and fund activities to reflect their community social, economic, environmental and cultural well-being. Local government has both sole and shared responsibilities for example; sole responsibility for storm water, waste water, water supply and some airports, and shared responsibility with central government ${ }^{9}$ and other agencies for transport infrastructure and energy utilities. Implementation is through 10-year longterm plans and 30-year infrastructure plans. The Local Government Official Information and Meetings Act 1987 governs open information provision to the public related to its responsibilities and provides for Land Information Memoranda to note impediments on properties. Territorial local councils issue building permits under the Building Act 2004 (BA) and subdivision consents under the RMA. Principles that underpin these responsibilities are community consultation, transparency, financial responsibility and liability in event of failure to act responsibly and with competence.

\footnotetext{
${ }^{9}$ Central government in a New Zealand context refers to the national governance scale.
} 
The RMA is the primary statute for integrated resource management, including land-use planning. It is administered by central, regional and territorial local government. Its purpose is "the sustainable management of natural and physical resources" (RMA section 5) and has other relevant provisions for climate change adaptation (see Appendix 2), including "consideration of the effects of climate change" (RMA section 7 (i)) - effects which include cumulative effects, highprobability and low-probability effects with high potential impact. There is also provision for avoidance and mitigation of natural hazards. The RMA was designed to be exercised through a hierarchy of mandatory and optional instruments at all levels of government (Hansard, 1989): primary statutory requirements and principles (mandatory); promulgation of National Policy Statements (NPS) and National Environmental Standards (NES) (optional); adherence to any NPS or NES that is issued (mandatory); regional policy statements, plans and rules (optional, but rules must be given effect at the district level); regional coastal plans (mandatory at the regional level); and district plans and rules (mandatory at the district and city levels). The New Zealand Coastal Policy Statement (NZCPS) 2010, provided for under the RMA (which is mandatory and includes direction for climate change adaptation at the coast for sea-level rise, storm surge and associated wave height), is the only statutory guidance for decision makers relevant for considering climate change effects. Non-statutory guidance in technical manuals is provided on how to approach decision making for sea-level rise and for increased frequency and intensity of rainfall (Ministry for the Environment, 2008b; Woods et al., 2010). A 2004 amendment to the RMA to consider the effects of climate change reflected government policy in which central government took responsibility for policy on greenhouse gas emissions reduction through an economy-wide economic instrument (Rive, 2011) (a carbon tax in 2004 and in 2008 an emissions trading scheme). Adaptation to climate change was made the responsibility of local government where the impacts would be felt (Rive \& Weeks, 2011) on the basis of subsidiarity, meaning that an issue should be addressed at the lowest level of capable authority affected (Huntjens et al., 2012; Lebel et al., 2006).

The remainder of the framework comprises flood and erosion control through the Soil Conservation and Rivers Control Act 1941 (SC\&RCA) administered by regional and unitary councils, which has the objective of preventing damage by floods, preventing and mitigating soil erosion and utilising land in a manner that achieves these objectives. There is a Land Drainage Act 1908 (LDA) administered by regional and territorial local authorities for maintaining watercourses and drains. These two statutes govern and enable funding of flood risk management in New Zealand. An emergency management system manages disaster risk at national and local levels of government under the Civil Defence and Emergency Management Act 2002, (CDEMA) and the 
National Civil Defence and Emergency Management Strategy 2007 which sets out four types of risk-management activities-readiness, response, recovery and reduction-known as the 4Rs. An Earthquake Commission Act 1993 (EQCA) provides insurance funding for residential property damage from natural disasters, administered by the Earthquake Commission, which is funded through a levy on private property insurance, for underwriting damages up to $\$ 100,000$ per claim.

Three historic trends have shaped the institutional framework in New Zealand and affect how climate change adaptation decisions can be considered - the period up to the major economic and institutional reforms of the 1980s, the 1980s reforms and the period after them to the present.

1) The period up to the 1980s was characterised by strong central government organisations like the National Water and Soil Conservation Authority (NWASCA) which, in partnership with local government, funded delivery of large flood protection schemes and soil conservation activities. These were designed to minimise the effects of damaging high-intensity rainfall events, made worse by historic land clearance of New Zealand's highly seismically active land (McCaskill, 1973). Public safety and development of land-based primary industry was the driver, based on engineering practice under the SC\&RCA and the LDA.

2) The second period began in the mid-1980s, a period in which major economic efficiency (Evans, Grimes, Wilkinson, \& Teece, 1996) and institutional reforms saw devolution to local government of functions previously carried out at the national government level, as government implemented market-driven policies (Memon \& Gleeson, 1995). The RMA, passed in 1991, integrated some functions (water, natural hazards, air and land use) but not others (flood control and soil conservation). Organisations of state were abolished and new ones set up (NWASCA was abolished, Ministry for the Environment established and functions devolved to local government). What emerged during this period was integrated natural resource management, while emphasising environmental 'bottom-lines' above which markets could operate (Bosselmann \& Grinlinton, 2002; Perkins \& Thorns, 2001). 'Environmental effects' practice by planners dominated within this enabling legislation (Perkins \& Thorns, 2001).

3) The third period started around the mid-2000s and continues to the present. It has seen a shift in power back to the centre, with a focus on process efficiency. ${ }^{10}$ Changes during this period included limitations on public involvement in decision making, new organisations for handling consents at the national level of government rather than at local level (an Environmental Protection Agency was set up in 2011), ${ }^{11}$ suspending of local body elections in one region and replacing

\footnotetext{
${ }^{10} \mathrm{http}: / /$ www.mfe.govt.nz/rma/reform/phase-two/2013-rma-amendments.html

11 http://www.epa.govt.nz/Publications/EPA_Annual_Report_2012.pdf
} 
elected representatives with politically appointed commissioners in $2010^{12}$ and governance changes occurring through local government amalgamations. ${ }^{13}$ In 2004, provision for consideration of the effects of climate change was added to the RMA. ${ }^{14}$ The latter part of this period has been punctuated by the series of earthquakes in Canterbury from 2010 and throughout 2011 which saw cross-scale government practice gaps identified for earthquake risk (Canterbury Earthquakes Royal Commission, 2012). ${ }^{15}$ This catalysed a proposal to elevate consideration of natural hazards and the effects of climate change to matters of national importance in the RMA (New Zealand Government, 2013), and an amendment to the LGA $^{16}$ in 2014 requiring local government to prepare transparent strategic infrastructure plans for a timeframe of 30 years.

\subsection{What is known about the role of institutions for addressing the decision-making challenge?}

The issues that create the decision-making problem discussed in Section 2.3 have a common 'institutional' thread. There has been an increasing call among scholars to consider institutional dimensions (Burton, Huq, Lim, Pilifosova, \& Schipper, 2002; Naess, Bang, Eriksen \&Vevatne, 2005; Adger, et al., 2007). A gap in scholarship has been revealed about the role of institutional settings as barriers and enablers of changed practice across multiple sectors for making climate change adaptation decisions. In particular, Dovers and Hezri (2010) observed that discussion of policy processes and institutions are limited at the national and sub-national scales. They emphasised the close dependencies among institutional frameworks, organisations, policy processes, policy instruments and management. They also highlighted that insights could be gained from other areas such as legal parameters, politics, and governance. These insights were seen as enabling climate change adaptation to be embedded into institutional systems through cross-functional and cross-scale decision making under uncertainty, and by addressing issues of capacity and devolution, policy evaluation and learning. Such dependencies between the formal governmental institutions and the informal institutions that support or are affected by adaptation, inform the approach taken in this thesis.

For a problem like climate change, Young (2002) suggested that institutional design should match the specific problem characteristics with specific institutional arrangements that 'fit' the problem.

\footnotetext{
${ }^{12}$ Following the government review of Environment Canterbury in 2010 the Environment Canterbury (Temporary Commissioners and Improved Water Management) Act was passed by government on 30 March, 2010, giving the government temporary powers to suspend local council elections in Canterbury and to appoint commissioners to replace elected councillors.

${ }^{13} \mathrm{http}: / / w w w . l g c . g o v t . n z /$ lgcwebsite.nsf/wpg_URL/Reorganisation-Index

${ }^{14}$ Section 7 (i) of the RMA

${ }^{15}$ http://canterbury.royalcommission.govt.nz/

${ }^{16}$ Local Government Act 2002 Amendment Act 2014 (14/55) received the Royal Assent on 7 August 2014.
} 
He elaborated this for the dynamic and uncertain characteristics of climate change, by suggesting that institutional arrangements need to be anticipatory and able to be adjusted as conditions change, and thus 'fit' the nature of the problem. Young suggests two further matters that influence the capacity of institutions to address a problem like climate change: 'interplay' and 'scale'. Interplay acknowledges that systems operate horizontally and vertically and that institutional responses to climate change will need to have the same characteristics, while scale acknowledges the levels at which the climate system and its impacts operate in space and time dimensions. These concepts help to link the characteristics of climate changes to the characteristics of institutions.

\subsubsection{Empirical studies}

There has been an increasing number of empirical studies at national and sub-national levels that reflect institutional responses to climate change impacts. These studies comprise those that address regulatory and legislative institutions and their implementation, organisations and actors, and those that make the link with enablers for implementing adaptation. The extent to which these studies address 'fit', 'interplay' and 'scale', is now presented.

Burch (2010) in a study of three British Columbia cities in Canada concluded that using existing resources to re-work the path-dependent institutional structures, organisational culture and policymaking processes that characterise hitherto unsuccessful climate change policies, was critical for adaptation action. However, while interplay was touched upon, the significance of uncertainty and dynamic climate characteristics for institutional 'fit', or of 'scale', were not explicitly discussed.

Juhola, Peltonen, and Niemi (2012) constructed a measure of adaptive capacity across Nordic countries and, in doing so, concluded that adaptive capacity determinants are better placed at the national level because they influence regional adaptation; and that modes of governance influence institutions, for example, if power in governing is equitably allocated. This empirically-based study confirmed previous scholarship (Adger, Arnell, \& Tompkins, 2005; Keskitalo, 2010) that multi-level governance affects adaptive capacity at each level of a governance system. Thus 'interplay' and 'scale' were considered, but not 'fit' with respect to uncertainty and dynamic change characteristics.

An institutional analysis of adaptation to climate change conducted at municipal level for flood responses in Norway (Naess et al 2005) found: that the institutional framework for flood management provided weak signals for proactive flood management, due to policy and implementation occurring at different governance levels; that new perspectives, tools and guidance developed at the national level were not integrated at the local level, because of slow learning and reliance on key individuals, and differences in culture and perceptions between governance levels. 
High-level event-driven responses after floods were the norm. Political power issues, attention to special interest groups and unwillingness to address climate change, were important drivers, which reinforced earlier observations made by Olsson and Folke (2001); Wilbanks and Kates (1999). Again 'scale' and 'interplay' feature, but 'fit' relating to uncertainty and dynamic change characteristics of climate change, does not.

A municipal-level study in South Africa (Pasquini, Cowling, \& Ziervogel, 2013) found that adaptation was constrained by the diversity of responsibilities and legislative gaps related to climate change considerations, creating complexity and lack of clarity about roles and responsibilities. The role that the legislative framework played in constraining adaptation at different levels of government was highlighted. Municipalities were not mandated to undertake climate change adaptation activities; little attention came from the national or state levels, which resulted in little attention at local levels to climate change adaptation. Party political patronage and attention to short-term gains by politicians influenced the attention to individual benefits over 'social good'. 'Scale' and 'interplay' were features, but 'fit' was not.

In an Australian case study (Abel et al., 2011) on sea-level rise, coastal development and planned retreat, five guiding principles based on institutional analysis were derived for implementing planned retreat from the coast: allocation of mandates and resources between levels of government according to effectiveness at each level; strengthened development rules and incentives to relocate as unwanted thresholds are reached; change in incentives as circumstances change; reassignment of public and private benefits, costs, risks, uncertainties and responsibilities from governments to development beneficiaries; and institutionalisation of disasters as opportunities for change arise, to remove signals to rebuild at the same location. This study integrates 'scale', 'interplay' and 'fit' issues into the framework and practice principles; it does not, however, address how the framework can be implemented in practice based on the principles. An implicit assumption appears to have been made that the institutional framework and principles would be adopted by those in power.

A study conducted in three developed country jurisdictions-United Kingdom, Australia and the United States (Preston, Westaway, \& Yuen, 2011) — specifically examined how institutions are framing adaptation and the processes used to adapt. They developed criteria to judge the success or otherwise of the adaptation planning undertaken to-date. Key weaknesses in the framework and practices were identified. These included limited consideration of the non-climate context of climate change adaptation decision making and of enablers that could increase adaptive capacity, such as access to capital for adaptation responses that can reduce vulnerability. They made the link with climate risk ('fit'), noting that adaptation decisions largely do not take them or future risks 
into account; by keeping adaptation guidance under review, acknowledging the role of uncertainties and change when making decisions on future risk. The importance of procedural aspects of adaptation planning and of the governance architecture means that this study places institutions at the centre of its examination. It is, however, left to others to examine the respective roles of the framework and the practice for implementing 'successful' adaptation.

A study based on literature, document analysis and expert elicitation developed six characteristics of institutions that promote adaptive capacity (Gupta et al., 2010) for responding to continuous and unpredictable climate changes. Institutions that promote adaptive capacity are those that: (1) encourage the involvement of a variety of perspectives, actors and solutions; (2) enable social actors to learn continuously and improve their institutions; (3) allow and motivate social actors to adjust their behaviour; (4) can mobilise leadership qualities; (5) can mobilise resources for implementing adaptation measures; and (6) support principles of fair governance. These characteristics address 'fit' by enabling adaptive capacity; 'interplay' by acknowledging the potential value of regulating responsibilities between actors and adopting multi-level management approaches; and 'scale' by highlighting the importance of social actors.

Framework contributions have provided useful bases for empirical studies with a focus on institutions. Examples include Moser and Ekstrom (2010) who developed a simple framework for assessing institutional barriers to adaptation which enables entry points for adaptation decisions to be located. In an empirical application in California (Ekstrom, \& Moser, 2014), institutional barriers were found to be the most significant at the early stages of adaptation as the actors attempted to stabilise societal problems akin to maintaining 'certainty'. Other studies have considered whether the local level can address climate change impacts without national-level regulatory direction (Keskitalo \& Kulyasova, 2009; Rive \& Weeks, 2011) thus addressing the scale-dependencies of decision making. There have also been calls for actor-centred and comparative research to explain institutional barriers (Eisenack \& Stecker, 2012). Interactions among decision makers, in terms of who initiates adaptation planning and leads the process, the role of spatial boundaries and the mandates necessary for adaptation to continue as the conditions change, and how 'rules of engagement' influence outcomes, are some of the institutional issues raised by Moser (2009).

Such scholarship has moved the discussion on to governance and organisational issues as they relate to adaptation decision making in empirical settings. In a United Kingdom coastal setting (Nicholson-Cole \& O'Riordan, 2009), unclear adaptation goals, undervalued coastal cultures and icons and a range of individual and social factors conspired across scales to act as barriers to 
adaptation. When considering decentralisation and its role in adaptation, Brockhaus and Kambire (2009) highlighted institutional flexibility by those with planning mandates and the opportunities for common learning and information sharing across organisations and individuals, as critical enablers for adaptation. In a discussion of adaptive capacity, Inderberg and Eikeland (2009) highlighted additional factors that affect the role of institutions in adaptation: learning within organisations and constraints from 'blindness' to innovations, and 'locking-in' to old approaches that entrench the status quo; organisational ability to act which is influenced by prevailing norms, values and cognitive influences; and whether the actors can align the instruments of practice to these institutions or change the institutions. The relationship between organisational learning and governance when addressing a complex co-ordination problem such as adapting to climate change raises the limits to regulatory approaches implemented through hierarchical power of public governance. The role of networks and partnerships in making effective adaptation decisions that are legitimate in the eyes of those affected raises the importance of legitimacy for implementation of climate change adaptation (Winsvold, Stokke, Klausen, \& Saglie, 2009). Collectively such studies have moved the scholarship to a wider consideration of institutional 'fit', 'interplay' and 'scale' as enablers of climate change adaptation.

Dutch planning institutions that promote climate-proof planning for flood-prone areas are strongly path-dependent and need to build more flexibility into the existing rules and procedures (Van den Berg \& Coenen, 2012). This study sought to understand how contextual factors of municipal size, extreme-weather experience and increased risk influence the implementation of local adaptation. They concluded that experience of extreme events was the strongest trigger for adaptation; smaller rural municipalities can act more quickly than larger urban ones and are responders to extreme climate events, but they have a 'wait-and-see' attitude towards new policymaking and need acute problems before acting. Larger urban authorities on the other hand, were reported as having integrated actions horizontally across policy domains to achieve enhanced action. By considering the need for flexibility, this study has highlighted issues of 'fit', interplay and 'scale' within and between institutions.

A recent comparative study between Switzerland and Georgia, USA (Hill Clarvis \& Engle, 2015) coined the term 'bridges' to reduce barriers, thus adding to the notion of transforming barriers to enablers discussed by Burch (2010). The claim regarding 'bridges' was that it allowed a more nuanced identification of leverage points that can lead to implementation of targeted interventions that are adaptive. The levers identified were all supporting contextual enablers like networks, flexibility, knowledge and integration. These address 'interplay' and 'scale' issues, and by so doing, support the weaknesses in institutional 'fit'. Such enablers have a role in integration of 
governance across scales and create stronger interplay of decision making for incentivising adaptation.

While these empirical studies all come from different contexts, there are common features that can be scaled up and applied in different jurisdictions as suggested by Smit and Wandel (2006). There is also a role for purposeful experimentation to leverage changed practice, through the use of learning tools that enable uncertainty and dynamic climate change to be explicitly addressed; which is a gap in the scholarship to date.

\subsubsection{Adaptive decision-making and institutions}

Institutional frameworks and their practice for adaptation have been the subject of literature arising from consideration of barriers to adaptation. Smit, Burton, Klein, and Street (1999) discussed a framework for systematically defining adaptation decision making in terms of three questions: Adaptation to what? Who or what adapts? How does adaptation occur? They highlighted that climate extremes and variability are integral parts of climate change along with changes to mean conditions and that these climate characteristics can inform a differentiation of adaptations according to purpose, timing, temporal and spatial scope, effects, form and performance. Since spatial and temporal factors can be linked to activities with different scope, purpose and performance, such differentiation can enable uncertainty and dynamic climate change to be addressed explicitly. Adger et al. (2009) suggested that values and ethics, risk, knowledge and culture, construct societal limits to adaptation, that they change over space and time and shape the development and operation of the rules and institutions that govern risk.

The scholarship emerging from the Netherlands has had a particular focus on adaptive decision making as a way of managing uncertainty and long-term planning horizons and on the differentiation of adaptation over time and space. Kwadijk et al. (2010) suggested approaches based on the concept of 'adaptation tipping points' for understanding how long current risk management strategies will continue to be effective under different climate change scenarios, and thus when alternative adaptive strategies will be needed. Such approaches help answer questions such as: What are the first issues that decision makers face as a result of climate change? What are the vulnerabilities of current activities? What could make current approaches fail? What are the adaptation options and their path-dependencies? This thinking has shifted the focus of decision makers from protection, to managing risk and uncertainty through adaptive management (Haasnoot, Kwakkel, Walker, \& ter Maat, 2013; Haasnoot, Middelkoop, Van Beek, \& Van Deursen, 2011). It has also shifted the debate around the balance of responsibility for preparing for future damages (Terpstra \& Gutteling, 2008) to bearing and sharing between agents and 
communities (Handmer, 2008), thus highlighting the dependencies between institutions and those affected by institutional responses. These latter studies are at the country or regional scale within countries, noting as Schroter, Polsky, and Patt (2004) did, that assessments done at the scale of decision making will be more useful. Others have suggested that having multiple layers of decision making supports more robust decision making (Pahl-Wostl, 2009). Whether these claims hold in practice is examined further in Chapter 6 and 7.

Termeer, Biesbroek, and van den Brink (2012) in their review of regional governance of climate adaptation in the Netherlands identified the challenges to implementation of adaptation practice, from legal principles. They identified fragmentation and uncertainties, as critical barriers that could be addressed by organising connectivity, by connecting policy domains, scales, and leadership, and by experimenting to overcome lock-in of practice (for example, re-allocating responsibilities and costs and benefits). Finally, they suggested rethinking legal and policy principles to enable flexibility through adaptive capacity, thus linking to property rights and the extent to which the law can change them.

The characteristics of adaptation measures that can perform over a range of plausible futures was the subject of seminal work by Lempert, Popper, and Bankes (2003) on the use of robust decisionmaking analysis for addressing long-term policy problems. Robust decision making uses an iterative and interactive approach that encourages decision makers to think systematically and creatively about potential surprises and possible responses to them. The four principles that underpin the approach are:

1) Consider large ensembles of scenarios

2) Seek robust rather than optimal strategies

3) Achieve robustness with adaptivity

4) Design analysis for interactive exploration of a range of many plausible futures.

In parallel to this work has been the development of a number of flexible implementation approaches that have been applied at sub-national levels — adaptive pathways (Barnett et al., 2014; Wise et al., 2014), dynamic adaptive policy pathways (Haasnoot et al., 2013; Walker et al., 2013) and real options analysis (Ranger, Reeder, \& Lowe, 2013 ). These are all variations on the robust decision-making approach and build in change over time more explicitly using a range of scenarios of the future. There are only a few cases where these analysis tools have been codified into institutional practice under national-level institutions, for example, water management by the Dutch Delta Commission and flood risk management by the United Kingdom Department of Environment, Food, and Rural Affairs. These relate primarily to structural defences. 
Only a few scholars have addressed whether adaptive management can be given effect in a spatial context (Roggema, 2009; Van Buuren et al., 2013; Wilson, 2006; Wilson \& Piper, 2010) and whether it can address long timeframes using incremental, transitional or transformational approaches (Roggema, 2009; Wise et al., 2014). Spatial planning is commonly implemented through regulatory frameworks. In the United Kingdom, flood risk, for example, is implemented through centralised national planning policy and guidance, but planning horizons used in plans are not aligned to the long-term horizons of climate change, and the policy process is tightly constrained by precedent, hierarchy and centralised control (Wilson, 2006).

There are relatively few studies that address the role of law as an institution for adapting to climate change. In addition to Termeer et al (2012) discussed above, McDonald (2011) in an Australian context identifies the enabling ability of law for adaptation. Regulation that reduces exposure and sensitivity to climate hazards by providing funding architecture for adaptation costs and liability for climate impacts and addresses accountability for decision making about adaptation, are identified as key enablers. The down-sides of legal institutions, processes and principles that constrain adaptation were also highlighted. These included compensable property rights that impede new regulation, high levels of uncertainty, irreversibility, place-based impacts and the inter-relationships between climate change impacts and the socio-economic context within which they occur. The conclusion was that legal processes and instruments need to be more adaptive and responsive to change while maintaining legitimacy and legality so that governance arrangements can be both robust and flexible at the same time.

A legal scholar in the United States (Ruhl, 2010, 2012) commented on the 'fit' of environmental law for a problem like climate change. He suggested with respect to adaptation that avoidance of disasters is an adaptation priority; that the ability to reconfigure cross-policy linkages and tradeoffs frequently at all scales and across the scales of governance, will be necessary; that 'back-end' decision methods that rely on active adaptive management and greater variety and flexibility of regulatory instruments and multi-scale governance networks and conciliation, will be necessary. His final observation was about implementation through the legal systems and the challenge this brings in managing dynamic aspects of the physical world through instruments that create social stability; they will have to become adaptive themselves while maintaining a level of social order. Thinking about how to initiate adaptive responses within such constraints, has emerged from adaptive management scholarship. For example, Birkmann et al. (2010), coming from a disaster management perspective, highlighted an entry point as a 'window of opportunity' for effective adaptive decisions after extreme events, thus bringing hazards and disaster research closer to the needs of local climate change decision makers. Such windows may be smaller than previously 
thought, however (Adger \& Barnett, 2009), given the focus on recovery following major disasters and institutional inertia at such times. The ability of adaptation after events to increase otherwise avoided damages, had adaptation been anticipated for known risks has been highlighted (Glavovic, Saunders, \& Becker, 2010).

While empirical studies of institutional issues for climate change adaptation have increased over the last ten years, few of them have suggested how institutions can be used to implement adaptation. Dovers and Hezri (2010), in particular, noted the need to move from the outcomes of policy and institutional change, to the practical mechanisms of institutional change. The body of risk and adaptive governance scholarship (see section 2.5.2) has sought to address informal institutional processes as practical means of implementing adaptation. However, only a few of the empirical studies have at the same time linked institutions to the uncertainty and dynamic climate change characteristics. This means that the 'fit' of the institutions to the decision-making problem, the statutory instruments and their supporting architecture, and their adequacy for addressing uncertainty and dynamic climate change, are largely unexplored. If 'scale' and 'interplay can be used as a proxy for governance level and the dependencies between them, then the relationship between them and 'fit', has also been largely unexplored.

This thesis focuses on these unexplored areas. It does this by undertaking an empirical study of the adequacy of institutions and practice within a multi-scale governance system where the framework, at least in theory, would appear to contain some of the necessary components to address uncertainty and dynamic climate change. Whether it does and indeed can, is examined in Chapters 5, 6 and 7.

\subsection{Other relevant literature}

The literature reviewed in Section 2.4 has identified a gap that this thesis examines about the adequacy of the institutional framework and practice for making climate change adaptation decisions where there is uncertainty and dynamic change. Critical to understanding the gap in the institutional literature, is examining the components of complex adaptive systems that form the basis of the climate change decision challenge and which is discussed in Section 2.5.1. A discussion of decision making under uncertainty follows in Section 2.5.2. While this thesis focuses on the formal rules embodied in law and as practised, the role of informal rules and behaviours that influence practice under the institutional framework are also relevant to an institutional adequacy analysis, in particular the role of organisations and human behaviours within them. These are discussed in Section 2.5.3. 


\subsubsection{Complex adaptive systems}

This thesis sits within a broader context that acknowledges that both natural systems and human systems change in non-linear ways and are integrated systems of concern, as summed up by Folke et al. (2002):

...evidence that has been accumulating in diverse regions all over the world suggests that natural and social systems behave in nonlinear ways, exhibit marked thresholds in their dynamics, and that social-ecological systems act as strongly coupled, complex and evolving integrated systems. (p. 437)

The governance frameworks, institutions and the actors responsible for managing changing climate risk form a complex adaptive system. Complex adaptive systems have been described by Duit \& Galaz (2008) as containing non-linear causal effects between and within systems where 'equilibrium' is temporary and moving, and thus contain variety in systems behaviour. The characteristics of such systems include agents with no direct control, thus self-organisation dominates and can give rise to unstable and temporary equilibriums that have low predictability. Three well-acknowledged characteristics of such system effects - threshold effects, surprises and cascading effects (Duit \& Galaz, 2008) — can be seen in governance and institutional frameworks that dominate resource management decision-making domains, such as natural hazards and water, and non-climate systems that are designed for managing financial markets and human epidemics, for example.

\section{Threshold effects}

Threshold effects dominate climate change impacts and the institutional responses to them. For example, coastal hazard management and flooding occur episodically, followed by institutional responses that are dominated by 'protection' and 'response' paradigms. Such responses include zoning and disaster responses, which are either static in time and space or reactive post-facto. Such responses can entrench the status quo by increasing the expectation of communities on those responsible agencies for visible protection actions (Hall, Brown, Nicholls, Pidgeon, \& Watson, 2012). This compares with anticipatory and precautionary planning, which could avoid or reduce at least some of the future damages.

\section{Surprises}

Surprises operate where there is interconnectedness between parts of systems and with external factors (Gunderson \& Holling, 2002) and where there is uncertainty about how the feedback processes operate at different scales and timeframes. Surprises occur when the outcomes are different from the human expectations of system behaviour, based on the status quo and driven by 
past experience. Financial crises, climate events, biosecurity incursions and epidemics are cases in point. However, some have argued that these types of examples are 'predictable surprises' (Bazerman, 2006) and are thus 'gray swans' ${ }^{17}$ (Stein \& Stein, 2014).

\section{Cascade effects}

Cascade effects occur when thresholds are crossed and surprises occur with 'unexpected' and compounding consequences across wide scales, or for long periods of time with impacts that reflect the interconnected nature of complex adaptive systems. Examples include; the initial and ongoing effects of the 2008 financial crisis; the long-term, disruptive and widespread social costs of Hurricane Katrina; and the flow-on effects to the national economy from the Canterbury earthquake series in New Zealand in 2010 and 2011 (for example, the increase in the price of insurance and the large GDP effects).

\subsubsection{Decision making under uncertainty}

Decision science contributes to understanding the role played by institutions. The concepts of robustness and flexibility have been used to develop institutions for addressing deep uncertainty (Hall, Lempert, et al., 2012; Lempert \& Collins, 2007; Lempert \& Schlesinger, 2000; Lempert, Groves, Popper, \& Bankes, 2006). This body of work informs a definition of robustness as the ability of institutions to perform well across a range of conditions and flexibility as the ability of institutions to adjust to changing conditions.

It has been widely observed that decision making to reduce damage has been slow to develop (Bulkeley \& Betsill, 2006; Fankhauser, Smith, \& Tol, 1999; Hallegatte, 2009; IPCC, 2014a). A key contributor to 'delay' is the widespread view that science will deliver more certainty over time and the best course of action will emerge. The expectation of certainty persists even as science has delivered greater ranges in estimates of future sea-level rise for example (Church et al., 2013b; Nicholls \& Cazenave, 2010; Pfeffer et al., 2008; Vermeer \& Rahmstorf, 2009), making it clear that planning to any level will result in a range of residual damages that will require further risk reduction. Burton et al (2002) observed that the expectation of certainty can in part be explained by climate science being presented from a 'top-down' perspective, rather than from a decisionmaking perspective. Such presentation has led to a culture of reliance on 'evidence' for decision making, and institutional frameworks and practices designed to deliver 'certainty' for those affected. This combines with the practice of 'central tendency' (averages), 'just give me a number' (single expression of risk), use of 'fixed' and 'static' measures in protection (levees) and spatial

\footnotetext{
${ }^{17}$ A development on the theme of Black Swans coined by Taleb (2010) because prior to Europeans landing in Australia all swans were thought to be white.
} 
planning (spatially fixed hazard lines) that can mischaracterise the extremes of risk and engender a false sense of security about the future ('the levee effect') (Tobin, 1995).

Several areas of scholarship have suggested how uncertainty and dynamic climate change can be approached. For example, Hallegatte (2009) suggested five possible methods: a) selecting 'no-regret' strategies that yield benefits even in the absence of climate change; $b$ ) favouring reversible and flexible options; c) buying 'safety margins' in new investments; d) promoting soft adaptation strategies, including long-term prospective; and e) reducing decision time- horizons, noting that the negative and positive aspects of such measures need to be considered.

However, these methods do not address how values and legitimacy of decision making can be practically addressed in complex decision settings like climate change adaptation, where uncertainty and change are present; risk governance scholarship seeks to do this (Renn, 2008). Risk governance includes and goes beyond traditionally practised risk assessment, risk management, and risk communication. It addresses the legal, institutional, social and economic contexts in which a risk is evaluated. In particular, risk governance considers the complex relationships between actors, rules, conventions, processes, and mechanisms that govern how risk information is framed and collected, analysed and communicated, and how management decisions are taken (Renn, 2008). Central to risk governance is inclusiveness of the actors, based on the normative assumption that understanding different values and perspectives will result in decisions that reflect societal values better than purely technocratic risk considerations (Renn \& Schweizer, 2009).

\subsubsection{Organisations}

Risk decisions are taken within organisations that comprise the formal functions and by the actors within them. Berkhout (2012) placed organisations and their actors as central in societal adaptation to changing climate and argued that adaptive responses by organisations are tempered by the processes of perception, evaluation, enactment and learning by the organisations. He argued that, for organisations to adapt, changes in all these processes are necessary and the extent to which adaptation is undertaken by organisations will be determined by both endogenous factors (capacity to change and the risk appetite), and the external economic and institutional context. Berkhout, Hertin, and Gann (2006) suggested that organisations face obstacles in adapting to climate, because they receive weak or ambiguous signals of climate change impacts and face uncertainty about the benefits from adaptation measures, which makes autonomous adaptation within organisations unlikely. This is because routines are deeply entrenched, dynamic capabilities are 
expensive to maintain, signals of something different or new aren't always recognised because evidence is absent and there is blindness to the evidence or its significance isn't acknowledged. Because new knowledge needs to be codified into the institutional frameworks before it can be acted upon, Berkhout et al. (2006) highlighted the important role that learning plays as an iterative cycle within organisations as conditions change. They also show that humans can reflect on the implications of their behaviour, learn and adjust in light of their experiences. Organisational management literature has elaborated this process. For example, learning from experienced disasters and place-based practice can inform how transition practice can be designed when addressing uncertainty and change. Learning processes were characterised by Argyris and Schön (1978) as single-loop and double-loop, defined respectively as learning that occurs from a direct stimuli which is adopted in operating practices without being questioned, and learning that arises from critical assessment and leads to changes in the norms, policies and objectives. Triple-loop learning has introduced a new dimension about 'learning how to learn' (Hargrove, 2003). Learning has been identified in climate change adaptation scholarship (Folke et al., 2010; Folke, Hahn, Olsson, \& Norberg, 2005; Pahl-Wostl, 2006) as critical for better understanding of how organisations can adapt and build capacity that enables them to move from incremental learning, through reframing, to transformative learning. This has led some to suggest that continuous learning and dialogue with stakeholders to understand values and preferences is necessary for implementation of effective adaptation strategies (Dessai \& Hulme, 2007) and that these form an integral part of the adequacy of institutional frameworks to address uncertainty and dynamic climate change. The role of organisational learning in driving institutional change has been highlighted (Berkhout, 2012; Berkhout et al., 2006; Burch, 2010; Pelling, 2011) and in particular, its role in addressing institutional rigidity (Preston, 2013) which leads to path dependency, where current practice is driven by past decisions and disciplinary practice built on traditions (Measham et al., 2011; Naess et al., 2005).

Pahl-Wostl (2009), developed a framework for addressing the dynamics and adaptive capacity of resource governance regimes as multi-level learning processes. The framework makes a distinction between formal and informal institutions, the role of state and non-state actors, the relative roles of bureaucratic hierarchies, markets and networks as the major parts of the governance regimes, suggesting that current institutional arrangements continue to exhibit single-loop learning styles of decision making for climate change adaptation. The distinction between formal and informal processes and state and non-state actors usefully unbundles the different locations of actors and institutions that operate in different ways. 
To elaborate institutional thinking further, Pahl-Wostl, Holtz, Kastens, and Knieper (2010) developed a framework for analysing complex water management regimes that links organisational management thinking with transitioning to new management regimes. In it, social learning builds decision capacity through shared understanding of rules and practices, to overcome barriers that derive from interdependency between elements of the system and that can enable a move to more flexible decision making. They suggest that such processes of learning can help move regimes from prediction and control, to adaptive and integrated regimes that are better suited to addressing uncertainty and dynamic change. Fundamental to this process, is experimentation (Pahl-Wostl et al., 2010). For example, by experimenting with new approaches to flood management, flood managers learn that the regulatory environment within which they operate creates barriers to adaptive management.

\subsubsection{Human behaviours}

Dovers and Hezri (2010) highlighted how cognition drives the perception of the risk and thus the behaviours that influence the nature of the decision-making institutions, the organisations within which decisions are taken and the disciplines of practice. Decision making and community preferences are influenced by perceptions that in turn influence behaviours-people overestimate the likelihood of another risk similar to one not previously experienced and for risks experienced frequently they under-update their assessment of another event occurring (Kousky et al., 2010). This was also borne out by a re-analysis of the events leading up to Hurricane Katrina in New Orleans (Glavovic \& Smith, 2014). These observations are based on the seminal work of Kahneman, Slovic, and Tversky (1982) who elaborated human cognitive biases that result from the use of heuristics to make judgements under uncertainty (for example, representativeness, availability and adjustments from an anchor). These biases can misrepresent uncertainties in the short- and long-term and create estimation errors about unpredictable climate changes when considering near-term decisions that endure over long timeframes.

Decision tools for representing uncertainty can exacerbate these effects. For example, flood forecasting has historically been based on predictions of the future from historical experience and has been expressed as annual return intervals (ARI) or annual exceedence probability (AEP). Such expressions of risk are poorly understood by the public. Dessai and Hulme (2004) attributed this to cognitive illusions, affecting people's perceptions and actions. They based these observations on the experiments conducted by Slovic (1987) where the same information about risk was presented in different formats (a $2 \%$ chance compared with a 2 in 100 chance) and the perception of risk was different. Communicating uncertainties for sea-level rise can be complicated by the 
influence of variability; variability observed now can appear greater in effect than changes in sea level rise which appear distant (Weber, 2010).

Young (2002) points out that institutions are not actors and therefore those who design them must consider how they influence the behaviour of those they affect. Drawing from March and Olsen (1998) Young makes the distinction between the logic of consequences and the logic of appropriateness. The former focuses on the benefits and costs of available options, and providing incentives to change behaviour, whilst the latter focuses on people being motivated by what they consider to be 'right and proper' and who will accept 'legitimate' restrictions. These behavioural characteristics thus influence how institutions can deliver adaptation across multiple scales under conditions of uncertainty and dynamic change.

\subsection{Conclusions}

Three institutional themes have emerged from this chapter that combine with uncertainty and dynamic change to make climate change a difficult problem for decision makers to address. These can be summarised as follows:

1) Understanding and representing the climate change risk characteristics that change over time in some uncertain ways and are dynamic, potentially creating surprises that are outside humans' coping range and thus require new approaches for decision making. The framing of the risk within institutional practice can affect the expectations of communities and thus the ability of institutions to address uncertainty and change. For example, the practice of 'central tendency' using average conditions, single numbers or one scenario to reflect the risk in the future, mischaracterises the influence of extreme events and surprises of a dynamic kind.

2) Governance and regulatory frameworks are typically designed to set the 'ground-rules' for society. As such, they embed an assumption that management decisions can be based on estimates of future conditions that are certain. This does not fit well with the uncertainty and dynamic climate change characteristics and can create path-dependencies that make decision making more complex and potentially more costly over time. Institutional arrangements operate at multiple scales relying upon connections between the levels for decisions of a complex nature. Governance arrangements that lack such connections have difficulty accommodating the complexity wrought by uncertainty and dynamic change.

3) Organisations that operate within the institutional frameworks comprise structures, disciplines and capabilities that are driven by different purposes, standards and professional practices. Different conceptual bases for framing risk and different competencies for addressing risk add to the complexity of making decisions under conditions of uncertainty and dynamic 
change. Cognitive behaviours will influence actors in different ways compounding the decisionmaking processes.

These three decision-relevant groups of issues are compounded by the critical factor of time; decisions taken today for activities that have long lifetimes will be the most exposed to uncertain and dynamic climate change. Institutions of practice that operate to fixed timeframes or have no built-in monitoring or review, different decision cycles for connected activities and short election cycles that focus decision makers on short timeframes, will compound this effect.

This chapter has set out the nature of climate change risk; the problem that this poses for decision makers; the institutional context within which climate change adaptation decisions are made in New Zealand; and the relevant literature that foreshadows the analysis and conclusions made later in this thesis. This chapter has shaped three decision-relevant groups of issues that will be used to structure the analysis of the framework and practice adequacy in New Zealand-understanding and representing uncertainty and dynamic climate change characteristics, the governance and regulations, and organisations and the actors. Chapter 3 follows with a discussion of the research design and methods used. 



\section{Chapter 3 Research design and process}

This chapter describes the research design and process. It sets out the research questions, the rationale for the research design, the process and methods and the limitations of the research.

\subsection{Research questions and design rationale}

Climate is changing over time and the precise location, timing and magnitude of changes enhanced by global warming have elements of uncertainty and dynamic change. Chapter 2 established the need to evaluate governing frameworks and institutional practice for their ability to perform under constantly changing climate that is punctuated by 'surprises' and has some predictable and unpredictable elements - uncertainty and dynamic change. Decisions will be made today by local and central governments and other public and private agents about the location of land uses and infrastructure that persist over long timeframes. Understanding whether current decision-making frameworks and practices are adequate for such decisions at a national and sub-national level is the aim of this thesis.

Flowing from this, with a focus on New Zealand, my research question asks:

How adequate is the current decision-making framework and practice for enabling decision makers to make climate change adaptation decisions that sufficiently address the constraints posed by climate change uncertainty and dynamic change?

To answer this question, as well as to ascertain the implications of the empirical analysis of the adequacy of the framework and practices, the following questions are addressed:

- What is the existing framework and how adequate is it?

- What are the current decision-making practices, how adequate are they and what do non-climate decision settings tell us about addressing uncertainty and dynamic change?

- What is the scope for an improved framework and practice?

The framework and the actors within the New Zealand decision-making setting are many and varied in their professional disciplines, their locations within different levels of government and within their organisations. Nevertheless, the relatively small size of the country provides an accessible 'space' for the research. New Zealand's multi-scale institutional framework, where decisions at each level are dependent on and can affect other levels, creates dependencies. A tailored research design to fit this context was necessary to enable understanding of how the 'location' of the decision maker, and the dependencies across the levels of decision making and 
how organisations and the different actors influence decision-making uncertainty and dynamic change.

Blaikie (2000) suggests that, where the empirical reality being examined has many layers, a mixture of methods can be used as a way of corroborating and validating information. A qualitative and iterative approach has been chosen based on a conceptual examination of the institutional framework, on empirical information from semi-structured in-depth interviews and workshops with practitioners and decision makers, and from examination of relevant documents. This choice of research methods is broadly similar to the logic set out by Flick (2002, pp. 212-216) who suggested the following factors when choosing a research approach and methods: depth and breadth of information; germane sources of information; appropriate to the participants; compatible with data collection methods and data interpretation. Its use of triangulation follows Glaser and Strauss (1967) who describe the design adopted as 'source' triangulation between several broad types of primary data which validates results across individual sources and enables correction of investigator bias in interpretation of participant reflections.

Where the exploration of participant perspectives and realities are being sought, qualitative methods enable the researcher to examine practice in depth across a range of participants. Qualitative and in-depth information was important because decision making takes place within a messy and highly complex political setting, full of informal networks and reflecting a range of values, interests and pressures on decision makers. Such characteristics can make it difficult to elicit understanding of the layers of complexity when using quantitative methods that rely solely upon the researcher's interpretation of the results and leave little room for elaboration of responses.

A mixture of qualitative methods therefore was used to provide additional depth and breadth to the enquiry. In addition to documents, workshops and interviews with participants from central and local government across a range of decision functions were employed. These varied sources provided relevant contextual information that enabled reflections to be made across all sources of information about how the actors use the institutions and operate within their organisations.

The appropriateness of the methods for the context was tested in a workshop of local government practitioners early in the research process. The feedback received from the workshop identified some constraints on openness from the participants, suggesting that individual interviews would provide a more 'secure' environment within which to elicit greater depth and nuance that could inform the research question. The personal approach through interviews and follow-up discussions also enabled trust to be built with the participants by focusing on their concerns. The methods used enabled a picture to be built of the context, an understanding of the conceptual bases of the 
legislative framework and its adequacy, the current practice and its adequacy, the enablers and entry points to identify the scope for improved decision making.

Using several sources of information for this research enhanced the value of individual participant sources, and deepened the understanding of the issues that emerged during the research process. This resulted in a much richer set of information than what might have emerged from any one approach (Silverman, 2011). A conceptual examination of the institutional framework forms the starting point of the iterative research process. The inductive elements of the method, (used with the deductive examination of the framework) in an interpretive qualitative manner, is the main way to explore a research question that seeks to elicit patterns of relationships or issues in practice, rather than confirmation of a theory (Silverman, 2011). The research process and methods are now set out.

\subsection{Research process and methods}

\subsubsection{Examining risk-based concepts to develop adequacy criteria}

To gauge the adequacy of the institutional framework and practice, it was necessary to establish a set of criteria. Chapter 4 sets out how I did this. The starting point was to examine four risk-based concepts that are designed to assist decision making in the context of pervasive uncertainty and dynamic change. They were chosen because they provide a range of different approaches to minimising risk of harm to society and, in particular, for managing risk where it is uncertain and changing over time, sometimes in surprising ways. The concepts chosen also have currency in the literature about climate change risk decision making. They are described according to their characteristic stance on addressing a given situation: the precautionary principle; risk management; adaptive management; and transformational change. The four concepts were assessed according to how well each enabled uncertainty and dynamic change to be addressed. This assessment was complemented by transitions and resilience thinking where this informed the analysis. From this analysis, several characteristics of frameworks and practices emerged that were judged as enabling uncertainty and dynamic change to be addressed by decision makers. These were used as criteria for assessing the adequacy of the current framework and the practice. Adequacy was defined in terms of capacity to allow or enable decision makers to respond to the climate change decision challenge, discussed in Chapter 2, through the institutional ground rules and conditions encountered in practice. 


\subsubsection{Assessing the adequacy of the framework}

The New Zealand institutional framework (introduced in Chapter 2) was then described in more detail, and is presented in Chapter 5. This description was developed from my own knowledge, commentaries from the literature and government documents about the history of the framework, and information derived from interviews and workshops conducted for this research. The adequacy analysis of the framework, which is also presented in Chapter 5, drew on the criteria established in Chapter 4. This enabled the extent to which the criteria were 'wired into' the institutional ground rules to be gauged, and thus whether, or how, uncertainty and dynamic climate change can be addressed in decision making that is undertaken within those institutions.

\subsubsection{Understanding the current practice, its adequacy, enablers and entry points}

\section{$\underline{\text { Data collection }}$}

The data-collection objective was to assemble as complete a baseline understanding of the current practice as feasible, prior to assessing its adequacy. Practice is undertaken at a number of loci within each government entity and influenced in turn by the structure of the organisation and the disciplines of the practitioners. A distinction is made in this thesis between those who advise decision makers or have administrative authority for decisions and are driven by their organisational function and professional disciplinary practice, and decision makers who are elected democratically by the community they represent and are empowered by statute to make decisions. It was thus necessary to capture the range of these characteristics because many different decisionmaking functions are affected by changing climate, including strategic and long-term planning, council and community asset management, infrastructure, land-use planning, natural hazard and flood management and emergency management.

Accordingly, practice information was collected from a sample of practitioners and decision makers who were selected using purposive sampling to reflect their functions within a council or organisation or for their particular experience or role. This enabled the complexity and potential influence of the different governance arrangements, organisations and disciplinary practices to be assessed. Interviews were complemented with document analysis and workshops. Ethics approval was received from the Victoria University of Wellington Ethics Committee in January 2011.

Respondents were initially recruited in four geographic locations (see Figure 3.1) -from the Auckland, Wellington, Dunedin, and Tasman/Nelson regions. These selected locations exhibited a range of features and processes that related to the research questions (Silverman, 2011, p. 388) 
and provided a spread of council types (a unique new unitary ${ }^{18}$ structure-Auckland Council; unitary_-Tasman and Nelson; regional-Otago and Greater Wellington; city_Dunedin and Wellington; and district - Kapiti Coast, councils); different mixes of urban and rural situations; and councils at different stages of addressing climate risks. A snowball approach (Creswell, 2009) was used to recruit further respondents from additional councils and agencies in New Zealand during the research process. These were suggested by participants or identified from the researcher's knowledge of people with relevant experience and insights. This allowed for deeper examination of specific issues that arose during the course of the interviews, or to reflect new approaches being developed by some councils. Interviewing stopped at the point where no further new information relevant to the emerging themes was being added (Silverman, 2011).

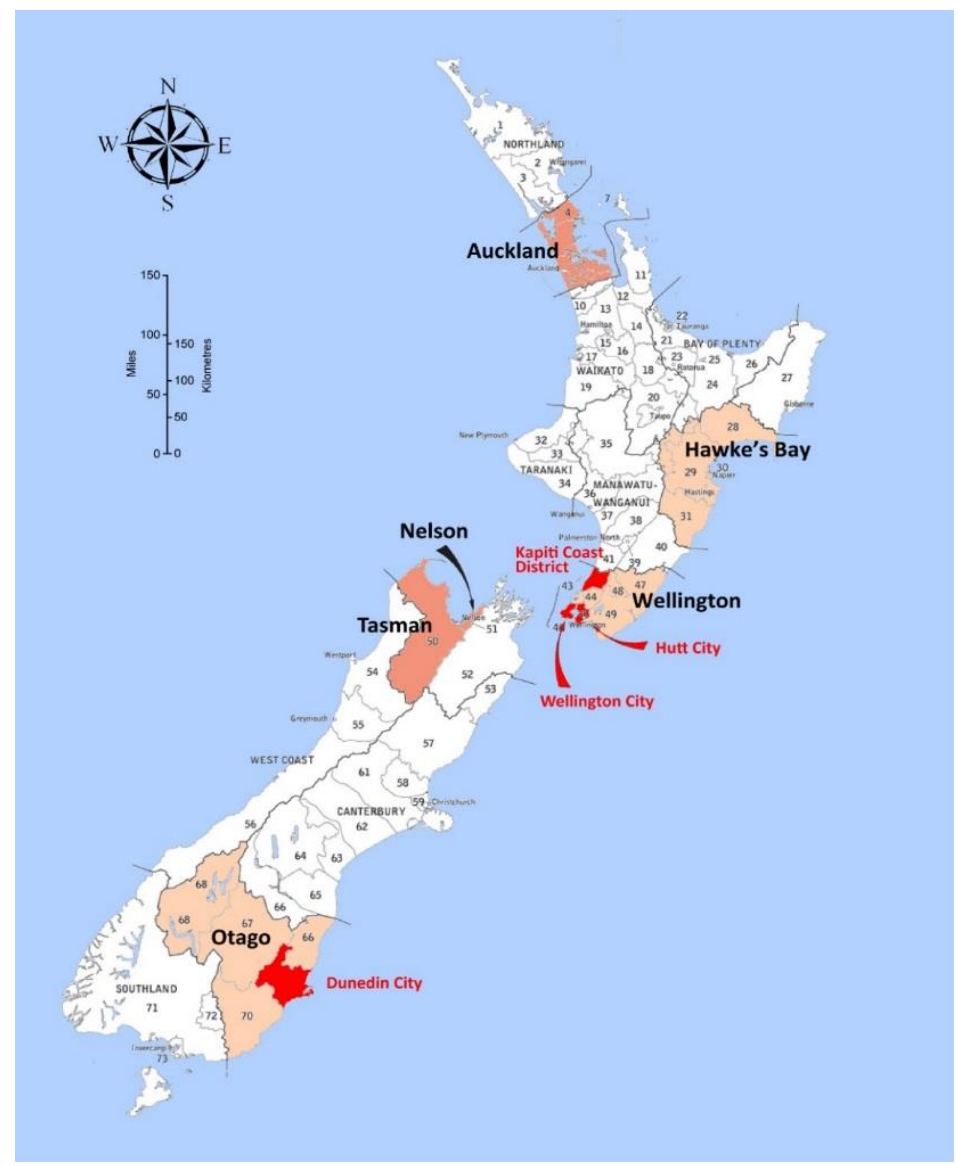

\section{Figure 3.1 New Zealand local government regions and districts}

Source: http://www.creativenz.govt.nz/en/getting-funded/funding-forms/map-territorial-local-authorityboundaries

Note: The light pink shaded areas are regional councils; the dark pink shaded areas are unitary councils; the red shaded areas are district councils including city councils

\footnotetext{
${ }^{18}$ A unitary council is one that has regional and territorial local government functions.
} 
Fifty-six in-depth semi-structured interviews (lasting one to two hours) were conducted during 2011 and 2012. Participants included strategic planners, spatial/statutory planners, engineers, emergency managers, catchment and flood managers, hazard managers, climate change officers, chief executives, politicians, legal professionals, central government policy and infrastructure advisors and local government association advisors (see Appendix 3). The interviews were designed to elicit the actual current practices employed and the institutional barriers to and enablers of decision making for addressing uncertainty and dynamic climate change. The characteristics of the climate risk were described in an information sheet (information sheets and consent forms are in Appendix 4) which was emailed to the respondents ahead of the interview and then summarised verbally at the beginning of each interview. A semi-structured interview process served as a framework within which participants talked about their experience. The interviews were digitally recorded and notes taken, with the interviewer interacting to clarify, seek elaboration in more depth or to keep the respondents focused on the research questions. The digital recordings were transcribed for their analysis later.

A similar process was used to recruit and interview respondents from non-climate decision settings that addressed uncertainty and dynamic change, to elicit learning that could inform suggested institutional framework and practice in such conditions. Seven potential analogous decision settings were chosen (see Table 1, Appendix 5). Thirteen respondents were interviewed (one to two hours each) across five institutional contexts - earthquakes, insurance, financial supervision, superannuation and surgical risk management. A desktop study was undertaken of pandemic and biosecurity management in the New Zealand context. ${ }^{19}$ Respondents were recruited from technical, policy, management and governance roles using a similar process to that used for the current practice interviews. Interviews focused on the institutional framework and instruments used for managing uncertainty and dynamic change; their flexibility, time-sensitivity at the planning, implementation and/or response stages. The themes that guided the semi-structured interviews are shown in Appendix 4. The data were analysed for their similarities and differences as policy problems (see Table 1 Appendix 4) and for their consideration of uncertainty and dynamic change using a similar thematic approach to that used for current practice interviews (see Table 2 Appendix 4).

Reports, statutory planning documents, court decisions and commentaries on them were examined separately to understand the degree to which a consistent set of concepts was used to consider

\footnotetext{
${ }^{19}$ I was unable to access informants for pandemic and biosecurity risk due to their priorities at the time.
} 
uncertainty and dynamic climate change, and as a demonstration of the actual practices employed by the respondents and their organisations.

Subsequent to the 2011-2012 main interviews, further discussions were conducted with practitioners and decision makers about new practice developments that occurred between 2012 and 2014. The objective was to ascertain in what ways new developments might be shifting the adequacy of practice to reflect uncertainty and dynamic climate change. Observations were made and feedback sought by the researcher using presentations of preliminary research findings during seven workshops held between 2012 and 2014 as a member of a government-funded research programme. ${ }^{20}$ These interactions with the research participants formed input to the subsequent adequacy analysis and for identifying the scope for institutional framework and practice improvements.

\section{$\underline{\text { Data analysis }}$}

The interview and workshop material was analysed thematically, informed by a process described by Braun and Clarke (2006, p. 12).

To begin, the data were summarised according to five general topics used to structure the interviews (Appendix 4). Initial thematic categories were generated-approach, scale, standards and timescale - to describe the framework and practice elements. This involved identifying commonalities across participant responses and looking for any unique issues that might provide new insights into current practice. The coded data were reviewed for quotations that spoke to emerging themes. The themes were then defined and named. The final choice of quotations used in this thesis reflect consistently raised issues that illustrate the three decision-relevant categories of issues that form the structure of the thesis, following further iteration with the conceptual analysis. Figure 3.2 depicts the overall process.

\footnotetext{
${ }^{20}$ Community Vulnerability, Resilience and Adaptation to Climate Change programme led by the New Zealand Climate Change Research Institute at Victoria University of Wellington.
} 


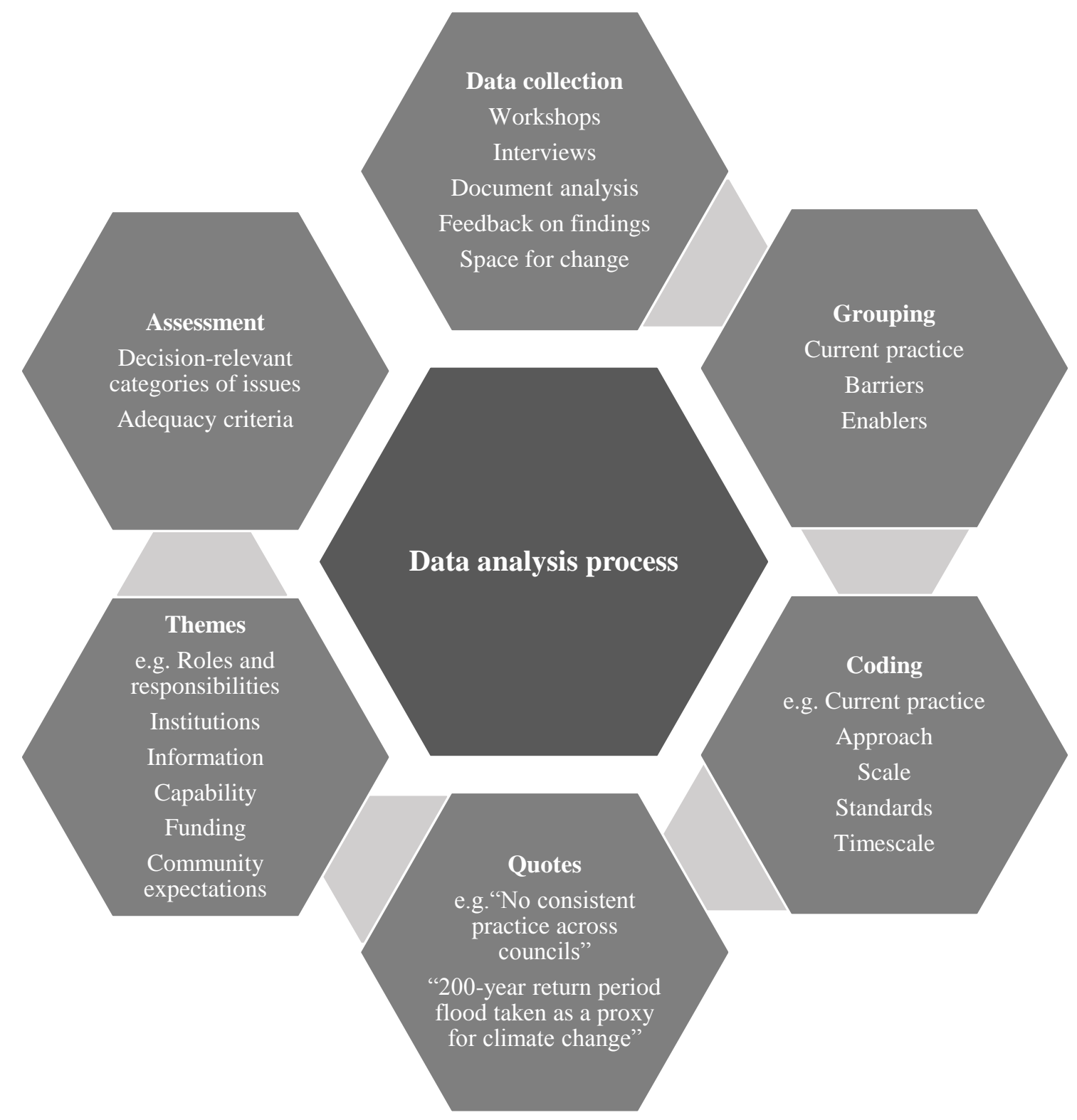

Figure 3.2 Data analysis process

The thematic approach adopted was highly iterative. It drew from the interviews and workshops as well as the document analysis and from my own knowledge gained from having worked within similar organisations and having advised on related practices within national and regional government. The data were first grouped according to the general questions that formed the basis of the interviews and workshops-current practice, barriers and enablers, and impact of uncertainty on decision making. Then each grouping was coded for approach, scale, standards, timeframes; quotes were identified for each group: for example (for practice) "no consistent practice across councils" (this was a consistent comment across the two types of local government, planners, engineers, flood managers and emergency managers); "200-year return period flood taken as a proxy for climate change" (a regional council flood manager). Themes were defined in 
terms of frequency of occurrence or their particular illustrative qualities and named; for example, roles and responsibilities, institutions, information barriers, capability, funding and community expectations. These were derived from the literature that informs institutional analysis under uncertainty and dynamic change in a climate change adaptation context. After iteration with the literature presented in Chapter 2, these themes were grouped into three categories of decisionrelevant issues: understanding and representation of climate risk; governance and regulations; and organisations and the actors that emerged from them.

In a second analytical pass, the empirically derived information on institutional frameworks and practice was assessed for its adequacy in Chapters 5 and 6 respectively, using 12 criteria developed in Chapter 4 for addressing uncertainty and dynamic change and presented using the three categories of decision-relevant issues. The institutional framework and practice adequacy assessments embody discussion of the barriers to consideration of uncertainty and dynamic climate change.

\subsubsection{Scope for institutional framework and practice improvements}

The measure of the adequacy of current institutional frameworks and practice inevitably leads to asking whether there is scope for framework and practice improvements; improved, in the sense that they could enable robust and flexible responses over time for responding to uncertainty and dynamic climate changes.

The space for change was assessed using incremental legislative changes suggested by research participants, demonstrated success factors evidenced by the practice, learning that emerged from the analysis of framework and practice adequacy and from non-climate decision settings that also make decisions under conditions of uncertainty and dynamic changes. Enablers and entry points for improvements in the framework and practices were identified and the analysis is presented in Chapter 7.

The suggested possible scope for improvements was reality checked in discussions and workshops with practitioners and decision makers. The feedback received helped gauge the suitability of possible improvements for their ability to overcome institutional barriers and their salience in decision-making settings. These interactions with participants were conducted in three different ways:

(1) During the course of the research analysis phase group dialogue and meetings with councils were used to test preliminary ideas for framework and practice improvements with a sample of practitioners and decision makers from local councils at regional and city councils in Dunedin and 
Wellington (flooding and sea-level rise), Wellington and Lower Hutt (flooding) and Tasman/Nelson (sea-level rise and flooding).

(2) Towards the end of the research, the enablers that emerged from the analysis of current practice, the analysis of frameworks and practice in non-climate decision settings and initial ideas for framework and practice improvements were discussed with a sample of participants in a number of settings-individual discussions, workshops and through presentations to council decision makers-by asking questions such as: How do the suggested improvements address uncertainties, dynamic change and long timeframes? What enablers are necessary for uptake of the preliminary design? Do these enablers exist currently? If not, how might they be achieved and over what timeframe? What are the main barriers to use of such a design? How might the design be enhanced for usability? This enabled drawing from the experience of councils that were experimenting with a range of approaches during the course of this research.

(3) Possible framework and practice improvements were also presented to the decision makers at five councils (Auckland, Hutt City, Dunedin City, Otago Regional Council and Greater Wellington Regional Council) enabling reflection on any different drivers operating within the decision making and practitioner roles within the decision-making process. The approach used for these interactions was to describe the climate problem; identify the implications for local and central government; present the suggested framework and practice improvements; and ask the participants to assess the ability of them for addressing uncertainty and dynamic climate changes. The feedback was used to refine the initial thinking about space for framework and practice improvements.

In summary, the design used for the research iterates back and forth between the criteria for adequacy developed from the four concepts shown in the middle of Figure 3.3 and the framework and current practice and their adequacy and the reflections from the non-climate decision settings. The iterations provided an element of internal validation (Silverman, 2011, pp. 367-369) of the efficacy of the adequacy findings and the suggested space for improved decision-making practice. Such iterative approaches have been found to be most helpful in research where there are multiple views and beliefs and hence different realities, as described by Charmaz (2006). This is the case for decisions about how to manage climate change risk. The approach enabled examination of common threads between the framework, the current practice and non-climate decision settings and was able to give a number of bounded situations from which to draw out new learning. The methods used reflect what Crotty (1998, p. 2) describes as a 'scaffolding' approach, a metaphor for building a research process fashioned to suit the particular research purpose. 


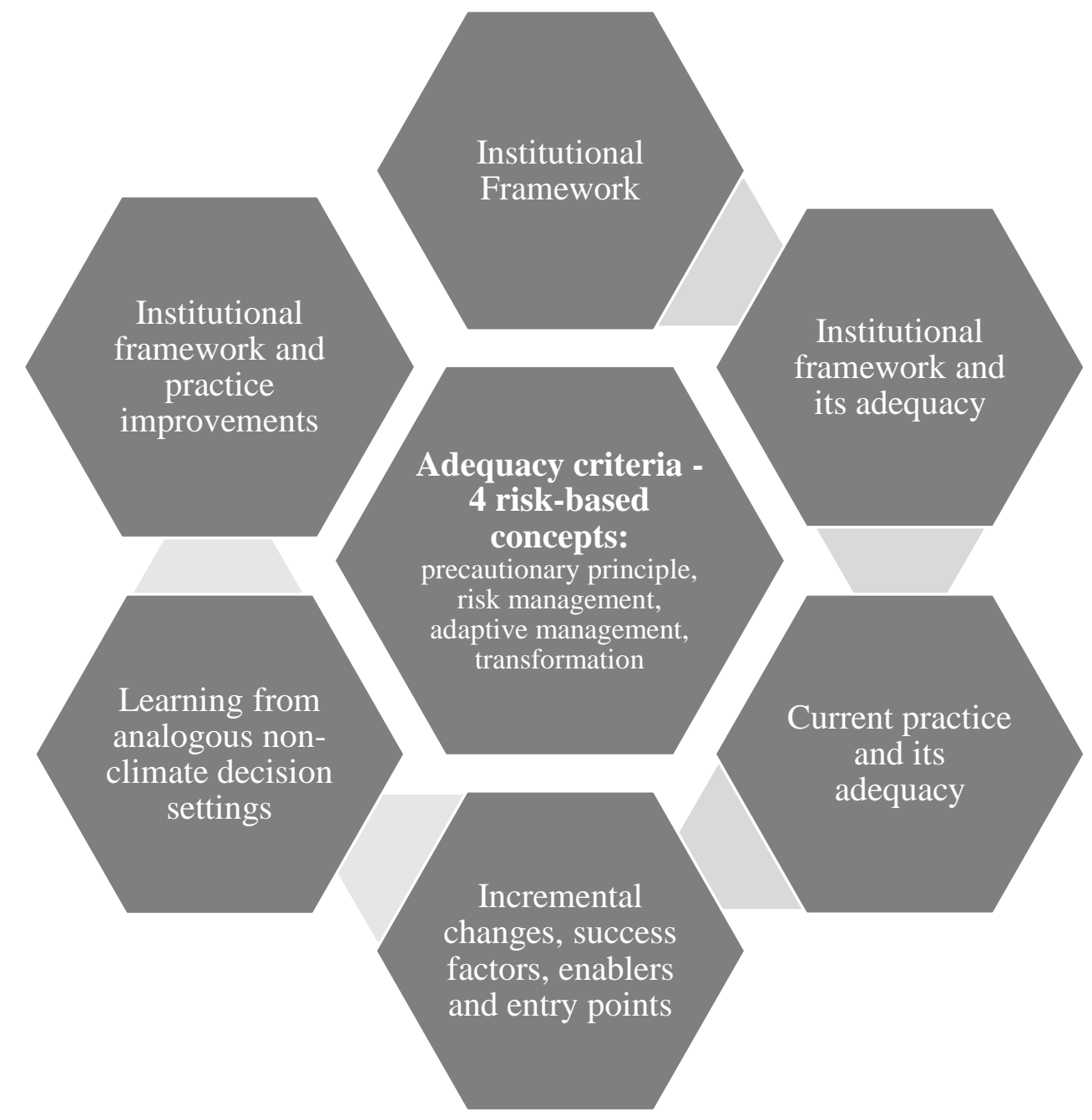

Figure 3.3 The research process

\subsection{Limitations of the research design}

There are three aspects of the research design and its implementation that could be viewed as having limitations.

First, the subject matter of my research is complex in two respects-the characteristics of the climate changes and the decision-making framework and practices that consider them. The risk this posed was one of scope, and the possibility that crucial aspects of the problem could be missed. These risks were mitigated by focusing the research question only on the adequacy of the institutional framework and practice to address uncertainty and dynamic climate change, on the institutional barriers, enablers and entry points for suggesting improvements to the framework and practice, and on sea-level rise and increased flood risk as the climate change impacts considered. This helped contain the research endeavour. The influence of social factors like values, culture and politics are well rehearsed in the literature as barriers to climate change adaptation. The focus 
was particular to institutional barriers contingent on the institutional and governance framework and the practice under them in New Zealand. Focusing the thesis in this way, enabled an in-depth analysis of a national and sub-national institutional framework and practice, revealing new insights and contributing a novel approach to assessing institutional and practice adequacy.

Second, there was a possibility of researcher bias. Creswell (2009) highlights the reality that researchers' philosophical and theoretical perspectives can influence the research procedures. My disciplinary training in physical geography and my prior observations and experiences arising from natural hazards assessment, policy processes, climate change science and advice on governance and risk management, drove the choice of research topic and the starting proposition. The research questions and research design flowed from this. The design of the research using mixed methods has built-in checks and balances that have, to the extent possible, managed any researcher bias. Potential bias was monitored by checking respondent meanings during the interviews, or at later follow-up workshops and discussions, and by checking against the literature. In addition, the interview material was not taken at face value. Rather, the layers of information were analysed and cross-checked with respondents and documents as part of the research design set out in this chapter. Researcher knowledge of and experience with the subject matter of the inquiry, enabled deeper analysis of the issues and access to a wide range of respondents and networks, that may not otherwise have been possible.

Thirdly, the use of snowball sampling runs the risk that the researcher loses control over the sampling of respondents, thus increasing bias. In this thesis, snowball sampling was used as part of a purposive sampling method set up and directed by the researcher. Where snowball sampling was used, trusted advisors identified additional respondents with particular expertise or operating in a particular function in an organisation, to give a wider set of perspectives on the research questions. The effect was to reduce potential researcher bias, by having access to a more diverse set of respondents, and to deepen the analysis. 


\section{Chapter 4 How can adequacy be gauged?}

This chapter develops criteria for judging the adequacy of an institutional framework and decisionmaking practice. A framework will be adequate to the degree it allows or enables decision makers to take into account uncertainty and dynamic climate change; a practice will be adequate to the degree that the decision rules reflect uncertainty and dynamic change and are translated into decisions based on them. The starting point for considering adequacy is conceptual. Concepts underlie decision rules that guide implementation of institutional frameworks. In this chapter, four risk-based concepts are examined that provide a range of bases for addressing uncertainty and dynamic climate change: the precautionary principle; risk management; adaptive management; and transformational change. Each has currency in the climate change literature. Their implications for addressing uncertainty and dynamic climate change are assessed. This analysis leads to the identification of criteria for assessing the adequacy of the New Zealand institutional framework (Chapter 5) and practice (Chapter 6).

\subsection{Introduction}

Adequacy criteria are required to judge the ability of the institutional framework and practice to address uncertainty and dynamic climate change. An adequacy criterion is, in general terms, a principle or standard by which something can be measured. Institutional frameworks are commonly underpinned by guiding principles. These can assist actors to think about complex interlinked environmental and social issues like climate change in particular ways, and thus guide management decisions. Making decisions when the future is uncertain and changing in dynamic ways with potentially large and complex consequences suggests that risk-based concepts are most relevant, where risk is taken in the sense defined by AS/NZS ISO 31000 (2009) as "the effect of uncertainty on objectives". Managing such risk could involve a range of responses, from transferring the risk to future generations by doing nothing, anticipating the risk by undertaking 'protective' or avoidance measures, adapting to the risk at defined points in time, or undertaking more transformative change. Such choices are affected by who society thinks should pay and when, what role public policy and implementing agencies play in reflecting societal preferences and what suite of levers they use to make the decisions. To guide such choices, institutional frameworks are set up by governments based on prevailing concepts. For example, institutional frameworks often contain statutory principles or purposes that must be reflected in decision processes, and ultimately in the decisions themselves, such as the precautionary principle, sustainability and resilience.

For the purposes of this thesis, four risk-based concepts were chosen for examination because they provide a range of different approaches to minimising risk of harm to society and, in particular, 
for managing risk where it is uncertain and changing over time, sometimes in surprising ways. The concepts are widely embodied in formal institutions for considering the uncertain and changing nature of risk when managing complex linked environmental and societal problems. The concepts are: the precautionary principle; risk management; adaptive management; and transformational change. All four concepts have been used in climate change adaptation discourse, as reflected in the five IPCC Working Group II assessments since 1991, with greater focus on transformational change in the fifth assessment report IPCC (2014a) and on risk management in the special report on risk of extreme events and disaster risk for managing adaptation (IPCC, 2012).

An analysis of the four risk-based concepts are complemented with consideration of two other concepts - transitions and resilience-which have been applied in climate change adaptation discourse. Transitions describe processes to a changed state and resilience is an objective of riskbased decision approaches. Consequently, these will be drawn on only to the extent that they inform the assessment of the four main concepts and their adequacy.

The four concepts are not mutually exclusive and each has an associated critical tradition, implying that there is no one 'best practice'. Each concept enables a slightly different lens to be taken to the underlying question of the adequacy of the institutional framework and practice to deal with uncertainty and dynamic climate change. For example, precaution is inherent in the concept of risk management (managing risk is a precautionary activity due to the unknowns that risk management implies and the high stakes when effects are irreversible), risk management is inherent in adaptive management (due to adaptive management being a tool that can be used to manage change over time). These lenses in turn, can be used to inform transformational change (new activities or states that manage risk over time) in climate change adaptation decisions - they become interrelated in adaptation practice by managing uncertainty and dynamic change. All four concepts were used (informed by transitions and resilience thinking) to ensure that the dominant and emerging conceptual bases of climate change adaptation frameworks and practice are assessed and can inform the criteria used for assessing the adequacy of the institutional framework (Chapter 5) and practice (Chapter 6).

\subsection{The precautionary principle}

\subsubsection{What is the precautionary principle?}

The main idea underpinning the precautionary principle arises from anticipating uncertainty and the possibility of large consequences or irreversibility. The precautionary principle has developed to mean that uncertainty should not be used as a defence for inaction in such situations. Or, to put 
it another way, avoidance or protective action should be taken ahead of full scientific proof of harm. It is therefore a principle designed to be used in situations of uncertainty.

Its modern origins go back to the German idea of Vorsorgeprinzip or 'foresight' (BoehmerChristainsen, 1994) which came from an ethical tradition of 'responsibility' associated with technology change (Jonas, 1984). The principle has become enshrined in environmental policy since the late 1970s (Fisher, Jones, \& von Schomberg, 2006) and in international environmental law since the 1980s; for example, through the Ministerial Declaration of the Second International Conference on the Protection of the North Sea in November 1987 and the Montreal Protocol on Substances that Deplete the Ozone Layer (Cameron \& Abouchar, 1991). Underlying the legal codification of the precautionary principle is the notion of 'do no harm', where the consequences of modern day rapid economic and technological change have an increasing potential to do so (McDonald, 2007).

The precautionary principle achieved prominence in the Rio Declaration on Environment and Development in 1992. Principle 15 of the Rio Declaration states:

In order to protect the environment, the precautionary approach shall be widely applied by States according to their capabilities. Where there are threats of serious or irreversible damage, lack of full scientific certainty shall not be used as a reason for postponing cost-effective measures to prevent environmental degradation. ${ }^{21}$

The Rio Declaration embodies 'serious irreversibility of damage' and 'uncertainty' as guiding principles. Thus, consideration of thresholds for irreversibility and uncertainty of science in decision making became inextricably joined together with the notion of not delaying decisions where the proof had not yet been fully established, but where there was a likelihood of consequences that could be large or irreversible. This set the framework for subsequent international instruments specifically targeted at climate change.

For example, Article 3.3 of the UN Framework Convention on Climate Change 1992 (UNFCCC) applies the precautionary principle directly to climate change decision making, taking the notion further by giving more specific guidance for its application:

\footnotetext{
${ }^{21}$ Refer to http://www.unep.org/Documents.Multilingual/Default.asp?documentid=78\&articleid=1163
} 
The parties should take precautionary measures to anticipate, prevent or minimise the causes of climate change and mitigate its adverse effects. Where there are threats of serious or irreversible damage, lack of full scientific certainty should not be used as a reason for postponing such measures, taking into account that policies and measures to deal with climate change should be cost effective so as to ensure global benefits at the lowest possible cost. ${ }^{22}$

The principle here challenges the notion that science increases certainty and thus one can wait to take action. The UNFCCC construction of the precautionary principle uses terms such as 'anticipate, prevent or minimise' giving some guidance about the types of responses that could be employed and making the distinction between responses that occur after a climate 'event' that causes damage and a precautionary one that suggests responses before a climate event. The precautionary principle is thus characterised as an anticipatory principle because it recognises that climate change has the potential for widespread and large consequences for societal functioning which can be avoided, or at least minimised. The UNFCCC formulation, however, leaves parties to respond within their national circumstances 'as appropriate' or 'subject to the capability of States'. It also introduces notions of 'cost-effective measures' and 'lowest possible cost' guiding implementation to avoid unnecessary costs that could be regretted.

\subsubsection{Does the precautionary principle address uncertainty and dynamic change?}

As a conceptual guide, the precautionary principle primarily alerts decision makers to situations of uncertainty where the consequences could be high or irreversible, suggesting cautious anticipation ahead of climate events. Otherwise there is limited guidance, leaving the nature of the response to the decision maker and giving no guidance for consideration of dynamic changes, or to the particular operational practice context. The utility of the precautionary principle relies upon how actual response measures within a quasi-legal context can accommodate uncertainty and dynamic change effects. However, its translation into legal guidance and consequent practice is far from simple and uncontroversial.

For example, Fisher et al. (2006) set out several criticisms of the precautionary principle: it can serve a 'no-risk' and 'non-science'-based approach; it is imprecise and lacks coherence; it can serve to justify arbitrariness. The 'no risk' criticism (Sunstein, 2003) when used in a normative sense is broad and unspecific, thus leaving interpretation wide open. The 'unscientific' criticism (Wirthlin Worldwide., 2000) rejects the notion that a precautionary approach has value for decision making because it is imprecise and assumes that certainty will emerge from science.

\footnotetext{
${ }^{22}$ Refer to http://unfccc.int/resource/docs/convkp/conveng.pdf
} 
However, others (Fisher, 2001; Stirling, 1999; Tickner \& Kriebel, 2006) suggest that the principle has value because it invites close attention to what the science is saying, thus enabling consideration of the uncertainties and a range of policy responses to address them within their particular physical, cultural, economic and political context. However, while this could happen, it is not assured by virtue of the principle by itself.

Another criticism is that the principle invites different constructions and therefore lacks coherence (Stone, 2001). The adequacy or otherwise of the principle for considering uncertainty and dynamic change depends to a large degree on how the legal codification is specified for application across scales and timeframes (Tickner \& Kriebel, 2006).

Others claim that the precautionary principle is used to justify arbitrary decisions because using the principle does not need 'facts' or certainty as a basis (Marjone, 2002). The corollary is that, when uncertainty and high consequence exist together, using information as if it were certain is problematic (Fisher \& Harding, 2006) potentially resulting in unintended consequences when the future turns out to be different.

Focusing on uncertainty where there is a risk of 'serious' and 'irreversible damage' can be a strength of the precautionary principle because the consequences could overwhelm the coping ability of the institutions in the future, thus compounding negative impacts on society. But the principle does not address dynamic change over long timeframes and gives little guidance for policy assessment and the handling of qualitative uncertainty in institutional frameworks for precautionary governance, or for giving effect to the principle through regulation (Dovers \& Handmer, 1995, 1999; Fisher \& Harding, 2006; Stirling, Renn, \& van Zwanenberg, 2006).

Importantly, the precautionary principle gives no guidance on the degree of precaution appropriate in different settings and for different types of uncertainty, particularly where precautionary prevention or avoidance of harm lead to costs and cause harm themselves. Nor does the precautionary principle resolve the question of what an acceptable level of risk in the future is, what costs are acceptable in achieving it and what measures can be used to make those judgements. The precautionary principle only provides decision makers with a conceptual basis for considering these questions where uncertainty exists. Nevertheless, in circumstances of 'deep uncertainty', the precautionary principle can provide the driver for the design of methods that are adaptable over time, and thus make decision makers aware that decisions can be made in circumstances that are uncertain. 
The precautionary principle highlights that uncertainty is not a reason for inaction, where the potential consequences are high or irreversible and the timing and magnitude are unknown. It enables identification of the future consequences of today's decisions. Being attuned to precaution enables decision makers and their communities to have a better appreciation of what could be at stake and to anticipate risks that could be avoided or minimised.

\subsection{Risk management}

\subsubsection{What is risk management?}

Risk management as a concept has traditionally paid attention to the likelihood of various outcomes and the associated magnitude of harms. This has pervaded risk assessment and its management. Such an approach has its origins in the work of the economist Knight (1921) who made a distinction between 'risk' and 'uncertainty', defining the former as being present where an action can result in different mutually exclusive outcomes where the probability is known, and the latter where the probabilities are unknown. This formed the basis of risk analysis as a technical assessment tool which was initially applied to potentially dangerous technologies and industrial processes, with strong roots in fact gathering for the modelling of risk events (Krimsky \& Golding, 2006) in the fields of toxicology and engineering. Although not the first to do so, Vick (2002) made the distinction between 'objective frequency', based on computation, and 'subjective beliefs' based on expert judgement. Historically, risk analysis has concentrated on the former, while underestimating the existence and power of the latter. This has significant implications in risk assessments where the probability is low but the consequences of damage are large, leading to Vick's observation that the adequacy of risk assessment often rests on which of the two distinctions is appropriate. This has implications for managing climate change as a problem, because 'objective frequency' which is relied upon in institutional settings that seek certainty, can only partially address uncertainty and dynamic changes over long timeframes.

Climate change risk management has been influenced by scholarship on the social dimensions of risk, starting with White (1945), and followed by Kates (1971). They sought to explain human adjustment to natural hazards and challenged notions of natural causes by placing hazards within human choices theories. Such studies led to the emergence of risk classifications based on the nature of the hazard, the medium of exposure and the nature of the consequences (Burton, Kates, $\&$ White, 1994). Cultural theory of risk (Rayner, 1992) placed the perception of risk within the attributes of the cultural group, ideology and organisational norms that determine lifestyle choices and behaviours. What emerged was a discourse about the inter-relationships between the social and physical systems and the role of organisations and actors within them, as discussed in Chapter

2. Risk analysis has demonstrated this distinction between the social and physical world, where 
the technical analysis purports to quantify the risk, while societal perceptions do not lend themselves to such treatment. These foundations formed the basis of how risk became framed in IPCC assessments.

The IPCC identified three important epistemological constructs (Jones et al., 2014) —idealised risk, meaning the conceptualising of the particular problem (for example, dangerous anthropogenic interference with the climate system); calculated risk, meaning the product of modelled historical and observed, and theoretical information; and perceived risk, meaning the subjective judgement that people make about idealised risk. These three types of risk combine at a societal level as an objective threat of harm and a product of social and cultural experience, thus reflecting socially constructed risk. Social and cultural values and beliefs have a strong influence where there are controversial risks (Leiserowitz, 2006). Climate change risk therefore sits within a wider spectrum of risk conceptualisation. This means that the management of risk will require both predictive types of risk analysis and more qualitative types that enable those affected by policy to be involved.

In the climate change context, there has been a move from the technical, calculated, framing of risk often based on averages and historic records which are projected forward, to a more iterative form of risk management in which reassessment follows assessment and action over long timeframes (Jones et al., 2014). These latter approaches to risk management acknowledge the social determinants of risk that affect its perception and acceptability (Adger, 2006) and that technical assessments are insufficient by themselves for making 'good decisions' (Jones et al., 2014; Pidgeon \& Fischhoff, 2011). However, iterative risk management has been slow to be embedded into practice, in part because the institutions within which risk management is embedded (for example, in Cabinet guidance and standards in the United Kingdom and elsewhere) still reflect the former conceptualisation of risk, which is difficult to change (Pidgeon \& Butler, 2009).

Another related issue with risk management as a decision approach is how risk is communicated and therefore understood (discussed in Chapter 2), highlighting how statistical probability statements are often not well understood. Cognitive biases contribute to perceptions of what is 'risk-based', which differs amongst professional disciplines; engineers can call an approach 'riskbased' when it is reflecting only the physical risk, rather than the differential vulnerabilities within communities arising from societal, cultural or economic factors in combination with the physical risk. Like the precautionary principle, risk management as a decision approach can become limited if the way it is used differently, in different contexts, is not made transparent. 


\subsubsection{Does risk management address uncertainty and dynamic change?}

The technical framing of risk or 'objective frequency' has become a dominant risk paradigm. This is despite the well-developed methodologies available for iterative risk assessment that have been applied using robust decision-making approaches (Lempert et al., 2003). Where both physical and societal perceptions are changing over time, an iterative risk management process can overcome the limitations of technical quantitative framings of risk; for example, for the extremes of flood risk, and for sea-level rise where uncertainty is high in some respects. Systems for assessing such risks have been developed in a climate change context, where expert judgement of likelihood statements (probability) are assigned in terms of confidence and described qualitatively (Mastrandrea et al., 2010) (for example, as used in the 2007 and 2013 IPCC assessment reviews) thus addressing both 'objective frequency' and 'subjective beliefs'.

Where there is deep uncertainty, however, risk management often does not take account of the implications of extreme events (for example, financial crises or unfamiliar risks not experienced before (Kousky, 2009; Taleb, 2010)). The different types of uncertainty that typify climate change as a policy problem (Chapter 2) contribute to the limitations of quantitative risk assessments as often applied in situations of deep uncertainty. Ambiguity and ignorance, as discussed by Wynne (1992), are often neglected areas of uncertainty, thus the limitations of a typically applied risk assessment will not be considered, leading to 'one track to the future' approaches that 'close down' potential alternatives (Wise et al., 2014) and create constraints on the development of innovations that respond to risk.

In his discussion of the heuristics and biases associated with risk assessment, Freudenburg (1992) suggested that many of the probabilistic techniques used can be prone to systematic errors which are overlooked when final estimates are presented. He attributes this to five problems: overconfidence in the ability to foresee all possible failure modes; insufficient sensitivity to small sample size problems; failure to see system interactions and interdependencies; calibration errors; and cognitive dissonance. These factors become especially problematic when addressing issues with low probability estimates (for example, extreme climate events). We cannot test such phenomena. They are non-falsifiable and are prone to unforeseen changes. Risk management applied with such biases are incomplete, especially when they are constrained by reliance on quantified and quantifiable inputs alone, outside the social determinants of risk. The most significant limitation of risk management for addressing uncertainty and dynamic climate change arises from assuming that risk management requires simply hazard identification, risk estimation 
and risk evaluation; the management of changing risk profiles is the challenge for managing climate risk.

On the positive side, risk management can address known uncertainties where parameters can be quantified and where uncertainty and change pervade an issue. More fundamentally, risk by definition is about uncertainty, meaning that there is no single estimate of the future. This also means that risk management approaches need to be designed differently for low-probability/highimpact outcomes, compared with high-probability/low-impact outcomes when deciding on response options; the appropriate level of expert and community deliberation will need to be different (Glavovic, 2014). Risk management can support new approaches (for example, sensitivity testing of policy choices, using models and climate change scenarios to characterise changing risk conditions (Lempert \& Collins, 2007; Lempert et al., 2003)).

Risk management enables the consequences of the potential impact to be considered explicitly where those consequences are high and can be quantified. However, this depends on how it is applied. It can have limitations in situations of deep uncertainty where the future is unlikely to be like the past, the consequences are high and where dynamic climate changes are likely and the uncertainties cannot be quantified. Risk management can also be prone to an overly rationalist, top-down development of risk management decisions. This implies that concepts that can address change over time and can engender bottom-up, actor-centric development of responses may offer alternative entry points for considering uncertainty and dynamic climate change over long timeframes. Robust decision making (see Chapter 2) can be used in this way. In addition, risk governance scholarship (Renn, 2008) has developed to address the role deliberative processes can play in engendering greater consideration of values and preferences of actors and communities in decision making, when risk is characterised by high levels of ambiguity or deep uncertainty. Thus risk management decision making and adaptive management can be linked.

\subsection{Adaptive management}

\subsubsection{What is adaptive management?}

Adaptive management focuses on taking incremental actions then learning from them to inform future actions. The concept of adaptive management, or learning by doing, comes from evolutionary biology (Smit \& Wandel, 2006) and has been discussed in ecosystem management in the context of ecosystem functioning and its structural change (Holling, 1978). The underlying assumption is that there is limited ability to predict the future behaviour of natural systems, and hence adaptive responses that improve practices through experimentation and learning (PahlWostl et al., 2007) are necessary for addressing changing socioeconomic boundary conditions. 
Adaptive management as a concept features in several disciplines including ecology, natural hazards, and planning and policy. It has developed as a concept applicable for managing uncertainty and dynamic change in a climate change context (IPCC, 2014a) where 'adapt' means to make fit for some purpose, and 'adaptation' includes the process of adapting and the condition of being adapted (Smit et al., 1999). 'Adaptive capacity' developed as a concept within adaptive management thinking as a necessary condition for the adaptability of systems. Adaptive capacity was defined by Folke et al. (2002) to mean the ability of a socio-ecological system to cope with novelty without losing options for the future; and by Walker et al. (2002) to reflect learning, flexibility to experiment and adopt novel solutions. Consideration of adaptive management has also emerged from risk governance scholarship. For example, Klinke \& Renn (2012) suggest adaptive and integrative capacity for adaptability and flexibility in risk governance institutions, in response to actual outcomes or expected consequences, to moderate quantitative estimates of risk. They suggest that finding out how actors perceive and frame the risk problem and whether they find it acceptable or tolerable, has implications for how adaptive management is implemented.

Adaptive management implies a deliberate action to change operating conditions either in anticipation or at the point when conditions change. Two critical traditions in adaptive management thinking have emerged. One is deductive in which hypotheses are compared (Gunderson, 1999) which for complex systems may be unclear due to high connectivity and feedback loops. The other is an inductive one where insights can be drawn from new information and applied to analysis. Induction implies that dynamic learning can increase sensitivity to the unexpected (Stankey, Clark, \& Bormann, 2005) by increasing adaptive capacity. Adaptive management can be seen as prescriptive (Van der Brugge \& Van Raak, 2007) when anticipating an impact.

\subsubsection{Does adaptive management address uncertainty and dynamic change?}

Adaptive management has the ability to change system structure spatially and over time and is focused on managing uncertainties through learning and recalibrating responses to the changed conditions. It increases the ability of the system to operate within a wider range of environmental conditions, thus increasing resilience. Therefore, adaptive management has conceptual and practical relevance for managing uncertainty and dynamic climate change because it can enable temporal and spatial change.

By focusing on the maintenance of system functioning using incremental adjustments, adaptive management enables dominant operating practice and 'culture' to maintain status quo thinking (Foxon, Reed, \& Stringer, 2009). This can set up path dependency which will constrain adaptive 
responses to changing risk profiles over time. This is in contrast to the use of the precautionary principle to manage uncertainty, which is by definition anticipatory in its guidance to responses.

Adaptive management that involves only incremental adjustments may not be sufficient to address those extremes and surprises that are outside human experience and which may require more fundamental change in the institutional frameworks and practice in anticipation of such changes (Reisinger et al., 2014). The speed of adaptation will need to reflect the rate and amount of climate change. By relying upon existing governance and institutional arrangements and management objectives to manage such change could make any necessary transformational change more difficult and costly in the future (Park et al., 2012; Stafford Smith, 2013).

Van Buuren et al. (2013) identified the dependency between adaptive management and the institutional frameworks supporting the consideration of uncertainty and dynamic climate change. They concluded that institutions are necessary that can enable present-day decisions to be made that do not constrain future decisions and that these can be assured by planning processes that are interactive, supported by multiple governance scales and by cost sharing between public and private interests. This can be achieved by using adaptive management to inform adjustments to anticipated future risk, signalled with adequate time for the adjustments to be made ahead of the climate impacts occurring, and thus introduce anticipatory components to manage dynamic change (Haasnoot et al., 2013). Conceptually this means that precaution (taking action before proof of impact), risk management (signalling future threats) and adaptive management (adjusting) come together.

\subsection{Transformational change}

\subsubsection{What is transformation?}

The concept of transformational change derives from resilience theory (Gunderson \& Holling, 2002) and, in particular, from the notion that there are shifts over thresholds between stability domains (Scheffer, 2009). This change is described by (Walker, Holling, Carpenter, \& Kinzig, 2004) as the capacity to create a fundamentally new system when ecological, economic or social structures make the existing system untenable. In a climate change context Pelling (2011) questioned whether adaptation is merely accommodating change rather than contesting it. This makes a case for the concept of transformation by suggesting that current systems and paradigms, including institutional frameworks, are rarely critically challenged.

Park et al. (2012) suggested that transformational responses may be needed to address climate changes. Kates, Travis, and Wilbanks (2012) differentiated transformational adaptation from incremental adaptation as adaptations adopted at a large scale or intensity; adaptations that are new 
to a location or system; and adaptations that change the location of activities (Kates et al., 2012). Howden, Crimp, and Nelson (2010) described transformational change in the agriculture sector as involving both incremental and transformational changes that sit on a continuum of responses to climate change. Nelson, Adger, and Brown (2007) made the distinctions between transformations as a result of a deliberate process and transformations that occur as a result of unexpected or unintended outcomes of an event. O'Brien (2012) has questioned whether transformational climate change adaptation decisions can be carried out in a deliberative manner that is sustainable, and whether transformational change can be distinguished from adaptations to other stressors such as economic and demographic change.

Specific transformations at various scales and locations (as defined by Kates et al. (2012)) require institutional design that is flexible, anticipatory and fit for a changing future (Dovers \& Hezri, 2010). This is because the institutions that are responsible for managing climate risk may themselves need to transform. Inertia may mean that this can only happen after 'shocks' like extreme climate events or political and economic crises that lead to regime shifts (for example, the reforms of the 1980s in New Zealand (Lawrence, Wolf, \& Reisinger, 2013)). At such times, decision makers are challenged to think about what they wish to achieve. Are they protecting the status quo or are they enabling what is valued to be resilient over time under different conditions, and for future populations that will have different values?

Answers to such questions are reflected in shifts in values, perceptions, the way individuals, groups and organisations interact in the governance and political context (Folke et al., 2010; Smith \& Stirling, 2010) involving actors that bridge multiple governance scales (Olsson, Folke, \& Hahn, 2004). The IPCC (Reisinger et al., 2014) highlighted the debate over whether transformational responses can be supported by existing institutional frameworks as the need for transformational adaptation increases with the rate and magnitude of climate change. This need becomes critical where long lifetimes and lead-times are involved (Stafford Smith et al., 2011) and highlights the importance of co-ordination across governance domains and levels of decision making (Palutikof et al., 2013; Productivity Commission, 2012).

\subsubsection{Does transformational change address uncertainty and dynamic change?}

Transformational change as a concept inherently addresses uncertainty and dynamic climate change, enabling decision makers to address changing flood frequency, climate surprises and sealevel rise. This is because it is based on the ability to move from one state to another, over defined timeframes. Transformations that typically occur after shocks to a system will inevitably be followed by a transitional period before adjustment to a 'new normal'. The concept of 
transformational change embodies notions of long timeframes and shorter ones that are step changes to new systems, thus can be applied to activities that endure for short and long timeframes.

However, transformations can be arbitrary in much the same way as critiques of the precautionary principle claim. When transformational change results from exogenous conditions unrelated to climate change impacts (for example, from a catastrophic natural event (earthquake) or from human-made crises (a global financial crisis) or when transformational change occurs as a result of climate events, there is the possibility that the transformation misses adaptations that are based on using current levers (for example, by applying spatial planning measures in a way that reduces current risk). The IPCC (2014a, p. 25) observed that "A first step toward adaptation to future climate change is reducing vulnerability and exposure to present climate variability (high confidence)."

Also, transformational change can be disruptive with many flow-on effects to other parts of society. Transformational changes can mean that decisions are made by those with a private interest in land-use activities, for example, that affect others who have no decision-making power. The idea of transformational change is most useful where the activities involved have long life timeframes and where lead-time needs to be considered because of potential adjustment costs (Stafford Smith et al., 2011). An example would be retreat of coastal and floodplain settlements and the services that support them from sea-level rise and coastal inundation. Such transformations would require targeted interventions to support governance and decision-making co-ordination and, as suggested by (O'Brien, 2012), this support may not be forthcoming.

The value of thinking about transformational change is that it 'fits' with the notion of dynamic change, in the sense that it contemplates system regime shifts. It enables the alignment of physical climate conditions to the potential impacts on society at the deep uncertainty end of the uncertainty spectrum. However, it is far from clear whether governance and institutions can be transformed deliberatively ahead of damage occurring, and thus whether they can anticipate dynamic changes that have not been experienced before and which are not seen as urgent policy priorities. More major changes that might require transformational responses are the very ones that society, through its governance and institutions, appears reluctant to intervene on. This is because they are perceived as uncertain and a distant threat (Weber, 2010) and thus do not get policy attention in advance of damage. Shocks to human systems often engender transformational change in governance and institutions only after the fact (Klein, 2005).

Transformational change as a theory has value for thinking about particular types of adaptations. There is a paucity of experience applying this thinking although it is growing. There are questions 
about whether the definition of transformational adaptation may constrain its operationalisation in decision-making settings (Klein et al., 2014). Useful distinctions can be made about transformational change that are autonomous and undertaken by individuals and firms, and those that are deliberate and taken by public agencies that have responsibilities for the institutions of practice. There is therefore more research required in the context of institutions and their ability to facilitate transformational change (Klein et al., 2014).

\subsection{Transitions and resilience}

Two other concepts have been gaining currency in climate change adaptation scholarship and practice - transitions and resilience. Transitions describes a process to a changed state and, as such, it is a means of getting to an adaptive response or a transformed state. Resilience describes an outcome or an objective of risk-based decision approaches and is used in this way here.

\subsubsection{What are transitions?}

The idea of transitions derives from technology innovation science and was defined by Rotmans, Kemp, and Van Asselt (2001) to mean continuous processes of societal change whereby the structure of society (or subsystems of a society) fundamentally changes. A transition concerns the following (adapted from Loorbach and Rotmans (2010)):

- large-scale technological, economical, ecological, socio-cultural and institutional development that influence and reinforce each other;

- long-term process that covers at least one generation (25 years) for framing short-term decisions;

- looking backwards and forwards to set short-term and long-term goals;

- learning by doing;

- experimentation;

- understanding a number of options;

- interactions between different scale levels (niche, regime, landscape);

- engagement with and interaction between stakeholders.

The idea of transitions evolved from research on how socio-technical systems change over time, to the introduction of a dynamic component (Geels, 2004; Geels \& Schot, 2007; Rip \& Kemp, 1998). Transitions occur by way of interactions between niches (where innovation occurs), sociotechnical regimes (where incremental change occurs) and landscapes (which reflect the institutions that embed political, social and cultural values). 
Transitions thinking also appears in ecological literature and has developed several relevant scholarly frameworks based on natural systems that deal with transitions to new states and, ultimately, transformation of systems. Factors that influence change in biological systems (for example, thresholds of change and reorganisation of communities and their processes of support (Gunderson \& Holling, 2002; Scheffer, 2009)), are relevant for consideration of uncertainty and dynamic climate change because of the interactions between human systems and institutions for the regulation of harms to society.

Transitions thinking has been used in water management contexts in the Netherlands to inform the management of uncertainty, and as a bridge to communities through processes that engage in social learning. Van der Brugge, Rotmans, and Loorbach (2005), in their review of Dutch water management transitions, described transition processes as leveraging a change from short to long time horizons, from fragmented to an integrated approach at multi-scales, with multiple actors and domains, and from linear knowledge-building to 'learning-by-doing and doing-by-learning'. It thus differs from incremental adaptation because the end point is a new system state.

The idea that transitions are processes for innovative, self-reinforcing system design, has relevance for new institutional arrangements to govern uncertainty and dynamic climate change. Rotmans (2005) suggests that transition theory captures the complexity of multi-level systems and thus has relevance to governance and institutions. However, others (Shove \& Walker, 2007) suggest that the prescriptive nature of transitions in public policy means that the actors can capture the scope of the transition process. While this characteristic is common to all concepts in risk-based decision making, it raises the question of who decides on the direction or change, and how is it decided. This becomes particularly significant for problems that have contestation, complexity, uncertainty and management dilemmas and because transitions conceptually conjure up the notion of developing understanding through experimentation, monitoring, evaluation and course-correction.

The concept of transitions enables decision makers to think in terms of continuous adjustment of policies and plans outside current paradigms of control to a paradigm of shaping a strategy in space and over time-in effect, purposefully driving toward a new state. The potential scale and possibility of climate surprises and questions about whether incremental adaptive management will be sufficient (Adger \& Barnett, 2009) drives thinking about transitions to new system states. Transition thinking enables management to focus on moving towards long-term change in the system functions and thus sets the stage for transformational change. Foxon et al. (2009) suggest that adaptive management can provide important feedbacks into transition management which can manage long-term change. As such it can address uncertainty and implicitly enables the impacts 
of dynamic change to be addressed in decision making. Transition management has some similarities to adaptive management; it can enable goal setting, the ability to address spatial and time scales for change and to enable governance and institutional change to occur.

Consequently, transitions as a concept can form part of any of the four risk-based concepts discussed above because it can focus attention on the process for getting from the status quo to a precautionary policy stance, to an incremental, or to more transformative adaptation that addresses uncertainty and dynamic change. Thus transitions is used here as a contributing concept.

\subsubsection{What is resilience?}

Resilience as a concept has been used since Classical times, most commonly to describe "leaping, jumping or rebounding” (Alexander, 2013, p. 2708). Since then, this meaning has persisted through the centuries in mechanics, medicine and psychology until it was applied to natural systems theory by Holling (1973) as a concept to help understand the ability of ecosystems to be sustained in their original state when affected by perturbations. Geographers then transferred the concept to human ecology and made the link to climate change discourse (Adger, 2000). The engineering meaning to 'bounce back' to an equilibrium following perturbation has persisted in a parallel discourse by Holling (1996) who discussed how systems can respond by passing thresholds that send a system into a new state as a result of multiple stressors. Walker et al. (2004) elaborated this further to describe transformational change where state variables are lost and new ones gained, thus not returning to the original state. These shifts between different stability domains are described by Scheffer (2009) as critical transitions.

Resilience therefore encompasses elements of the other four concepts. It has, however, become so well-used that it is being interpreted in several different ways, giving rise to criticism that it is imprecise and lacks coherence. Alexander (2013) cautions that the term could over-promise what it can offer. Significantly, for consideration of climate change impacts, the use of resilience for infrastructure planning has retained its 'bouncing back to the status quo' meaning. This means that its use may not be accounting for uncertainty and changing risk over the lifetime of long-lived assets. This could result in path dependency of current assets and make more significant change in the future more difficult and costly. To the extent that more recent developments in resilience thinking address regime shifts, it is similar to transformational change and transitions to such change. But resilience as a theory and as a basis for governance and institutional design is still evolving. Accordingly, I consider resilience in this thesis as an end objective of the four risk-based concepts. 


\subsection{How far do the four risk-based concepts take decision making that addresses uncertainty and dynamic climate change?}

In reality, each concept is a partial basis for decision making under conditions of uncertainty and dynamic climate change and thus can be used individually or in combination. Different types of decision and timeframes will suggest that one or other of the concepts may be more or less relevant as guiding principles in a particular decision context.

The precautionary principle focuses attention on possible future consequences and irreversibility which enables actions to be taken ahead of evidence of harm. It is thus an anticipatory concept. It does, however, lead to wide interpretations due to its imprecise definition and gives no guidance on the degree of precaution that might be appropriate or acceptable in particular settings. Consequently, it only gives conceptual guidance where uncertainty exists and no guidance where dynamic change occurs.

Risk management and its implementation highlight potential consequences and, where they are known, quantifies them. It thus has the ability to clarify the future possibilities of change. However, risk management can have limitations where deep uncertainty exists and change is dynamic, when it is applied using historic conditions for future risk where the future will not be like the past. It thus can bolster status quo responses which create potential path dependencies and reduce flexibility and consequent resilience. Risk management can, however, inform robust decision making and qualitative assessments of risk by expert elicitation that combine objective frequency and subjective beliefs and thus address uncertainty and dynamic change.

Adaptive management addresses uncertainty and dynamic change explicitly in an incremental way and often reactively post hoc. This has limitations for anticipating 'surprises' and dynamic change. It focuses on maintaining the current systems, while adjusting to the future. However, it has value as a transition to a future regime shift using social thresholds identified as triggers for adaptation that are anticipated ahead of the physical changes. This can enable short- and long-term goals to be realised and address long timeframes and lead-time.

Transformational change as a concept can address uncertainty and dynamic change because it is conceptually based on the ability to move from one state to another over defined timeframes by anticipating change. It thus can enable consideration of different timeframes and lead-times for different decisions. However, transformational change is a nascent theory in need of further empirical examination. 
Transitions thinking has the potential to address the regime shifts envisioned as necessary for sealevel rise and extreme rainfall events by addressing timeframes and lifetimes of decisions and thus address uncertainty and dynamic change. Resilience, as an end objective for adaptation, is complementary to the other four concepts if it is framed in a way that encompasses robustness over a range of possible futures and flexibility to change course, thus addressing uncertainty and dynamic climate change.

\subsection{Adequacy criteria}

Drawing from the four risk-based concepts, and the insights their analysis offers, specific criteria are now identified for assessing the adequacy of the New Zealand institutional framework and practice for addressing uncertainty and dynamic climate change. The criteria are based on those elements of the four risk-based concepts that have institutional relevance for their ability to guide adaptation decisions in a context of uncertainty and dynamic climate change. They are grouped according to: 1) understanding and representing uncertainty and dynamic climate change characteristics; 2) governance and regulation; and 3) organisations and the actors. These categories and the criteria within them are derived from the literature and first discussed in Chapter 2, from the analysis of the four concepts discussed in Sections 4.3-4.5 and, where relevant, resilience and transition thinking.

Understanding and representing uncertainty and dynamic climate change characteristics relates to how such characteristics are reflected in the institutional framework (Chapter 5) and understood and represented in practice (Chapter 6). Relevant criteria include uncertainty treatment, lifetime of decisions, framing of climate change risk, and consistency and accessibility of climate change risk information.

Governance relates to whether the governance form can enable consideration of uncertainty and dynamic climate change (Chapter 5) and how governance form influences practice (Chapter 6). Regulations relate to how the roles and responsibilities are defined (Chapter 5) and influence practice across multiple scales (Chapter 6). Relevant criteria include precautionary decision making, risk consideration over long timeframes, experimentation and learning, codification of changing risk and complementary measures, and transitioning to new institutions.

Organisations and actors relate to how organisational form and function, and actor characteristics are reflected in the institutional framework (Chapter 5) and how they influence practice (Chapter 6). Relevant criteria include learning across disciplines and scales, leadership, and engagement to reflect community values and expectations now and in the future. 
Satisfying each of the criteria within each of the three categories will not be sufficient for institutional adequacy, since they only address the institutional framework and practice elements of climate change adaptation, which is the focus of this thesis. Their relative importance will vary depending on the specific decision-making context, but they are all expected to have some important role to play in decision-making contexts, either individually or in some combination. The criteria are used in Chapters 5 and 6 to judge whether the New Zealand institutional framework and practice are likely to support an effective adaptation response to climate change.

\subsubsection{Understanding and representing uncertainty and dynamic climate change characteristics}

As discussed in Chapter 2, climate changes have particular characteristics that make decision making on sea-level rise and flood risk a challenge for decision makers. In summary, the defining characteristics are: uncertainty at the extremes; sea-level rise will not stop for centuries, even if greenhouse gas emissions are stopped today; dynamic change including physical regime shifts will be overlain by natural variability, which may mask change and uncertainty about the timing and magnitude of the change. Where these characteristics intersect with public and private interests there are challenges for decision makers. How the implications of uncertainty and dynamic climate change are understood will affect how institutional frameworks are designed and thus how effective their implementation can be when adapting to climate changes.

a) Treat climate changes as uncertain in some respects and consider unlikely but severe damaging changes as well as 'best estimates' of change. [Uncertainty and dynamic change treatment]

This criterion recognises that the way climate changes are framed within institutions will affect how implementation is undertaken, and thus the adaptation choices made. If this is explicit in the institutional framework and understood by the actors, then timeframes and lead-times can be accounted for in the different types of decisions made.

b) Work with a changing risk profile to ensure that responses that are fit for a specific timeframe do not make it more difficult to respond to risks that emerge only after this timeframe. [Lifetime of decisions]

This criterion acknowledges the risk of maladaptation that arises if adaptation choices lock in current development pathways based on expectations of communities that current protection responses will continue. It also speaks to the need for flexibility that enables course correction in the future. 
c) Frame climate change risk in ways that can be understood by and are relevant to different interests. [Framing of climate change risk]

The communication of risk is affected by cognitive behaviours. This criterion addresses cognitive biases that affect how different groups in society interpret risk information. For example, attention to time-inconsistency as a driver for decisions will require communication formats to be developed that resonate with different timeframes and perspectives.

d) Develop and manage information bases that inform climate risk consistently over time and are accessible to public and private interests. [Consistency and accessibility of climate risk information]

This criterion addresses continuity of information and its accessibility over time as technology changes, and thus addresses the management of time-inconsistency between decisions made today and their monitoring and management over long timeframes as climate changes occur.

\subsubsection{Governance and regulation}

The risk-based concepts discussed in this chapter are reflected variously in formal rules that define decision making and decision implementation. Governance roles and responsibilities occur and are exercised at multiple levels of government. Regulations give more prescribed guidance as to how this should be done through practice. Governments, by definition, have the interests of society as a whole as their remit. This includes the 'do no harm' principle which, in the context of climate change, means avoiding or minimising damages. However, managing risk under conditions of uncertainty poses many challenges, not least the tension between desired certainty within regulatory frameworks and their practice, and the uncertainty of climate change outcomes and the concurrent changes in societal structures and values. This suggests the need for flexibility.

e) Prevent harm by anticipating potential damages and have supporting measures that would reduce or avoid such damages, without relying exclusively on information 'precision' and 'certainty' of evidence. [Precautionary decision making]

While 'evidence' of change drives governance and regulatory responses to climate change, this criterion acknowledges that some aspects of sea-level rise and increased flood risk are not certain, and are unlikely to be, before decisions in the near-term will be made. Institutions that can accommodate this situation are critical for effective adaptation. 
f) Address risk over long timeframes and recognise that decisions taken today will affect the ability to change course in the future. [Risk consideration over long timeframes]

The use of static instruments of practice can create lock-in of decisions that increase exposure and vulnerability of those 'protected'. This criterion suggests that near-term decisions can set up path dependency that can reduce response options in the future, or at least make them more costly to implement.

g) Enable experimentation and learning that addresses changing community values over time and enables institutional settings and their application to be adjusted over time. [Experimentation and learning]

This criterion acknowledges the reality of climate change and that it is, in some respects, a new issue for decision makers that has not been experienced before (for example, the continuous and contemporaneous change associated with sea-level rise across many sites). The potential to stretch the capability of responsible agencies and their ability to co-ordinate adaptation across governance scales is high.

h) Have the ability to codify changing risk into formal instruments that can guide practice across multiple scales in reinforcing ways and recognise that other measures will be necessary to complement formal rules for them to be effectively sustained over time. [Codification of changing risk and complementary measures]

This criterion recognises the interdependencies between different governance scales and that formal rules operate with a context of climate information and the capacity to understand and use it. It also recognises that some measures operate more efficiently at the different levels of government and that some supporting activities will be necessary to enable the adaptation to be implemented.

i) Have the ability to transition to new institutional states that can address uncertainty and dynamic change by making continuous adjustments ahead of societal and physical thresholds that take timeframes and lead-time into account. [Transition to new institutions]

Some climate change impacts like sea-level rise will require transformational responses since land currently occupied by human activities and their services will be under water in the future. Also, change in the frequency of high intensity rainfall events will challenge existing coping capacity of institutions. This criterion acknowledges such capacity issues and the requirement for continuous 
adjustment ahead of thresholds in coping capacity to enable chaotic responses, and thus the magnitude of the harm to society, to be minimised.

\subsubsection{Organisations and the actors}

Organisations comprise the structures that reflect the institutional framework. They are where the roles and responsibilities in the regulatory space are assigned and implemented through people within diverse professional disciplines and by the decision makers at different governance scales. Decisions are influenced internally within organisations by the organisational culture, behaviours and leadership; and externally by community and private interests which place expectations on organisations and the actors within them. Organisations addressing climate change occur at multiple governance levels. Climate change adaptation competes with the many different functions of those organisations for the attention of decision makers. These characteristics of organisations have an important part to play in the implementation of climate change adaptation. The ability of organisations and the actors within them, to learn, innovate and manage risk over long timeframes is challenged by their governing arrangements, which are short term on 3-year election cycles, and by constantly changing actors over time. Tensions from such time-inconsistency, capacity changes and between public and private interests challenge the decision-making processes, especially where decisions are made close to the affected populations. Such tensions are compounded by the different professional disciplinary practices within organisations which operate from different conceptual bases and use different tools for the management of risk. Organisations, the actors within them and the cultural and cognitive drivers that influence how they operate determine whether adaptation to climate change occurs and how it is undertaken.

j) Have the capacity for organisational learning to align instruments of risk management practice across the different disciplines at multiple scales. [Organisational learning across disciplines and scales]

This criterion addresses the 'unlocking' of entrenched practice that can raise expectations of status quo protection beyond its 'use-by date', and thus enable more flexible responses to be developed over time that reflect uncertainty and dynamic climate change.

k) Have leadership capability within organisations that can manage complex and changing circumstances, and manage across governance scales and the different functions. [Capability to lead complex and changing risk across scales and functions]

Complexity of governance and changing circumstances will require leaders to manage across functions and between governance scales before damage is apparent to those who will be affected. 
This will demand new styles of leadership and capability in organisations that can work in conditions of ambiguity and change.

l) Have the ability to interact and learn from engagement with communities to enable changing and different values to be reflected in decision making. [Community engagement to reflect values]

Community values will be changing at the same time as climate changes. This means that such values will need to be well-understood for successful adaptations to occur. Institutional frameworks and practice will be required that can work with a wide range of affected communities and individuals to ensure equitable outcomes. 



\section{Chapter 5 The institutional framework and its adequacy}

This chapter describes and then assesses the adequacy of the New Zealand institutional framework for addressing climate change uncertainty and dynamic climate change. It does this first by elaborating the framework described in Chapter 2, which comprises the documented structure and governance hierarchy, and the regulations that set out the functions and powers of organisations and the processes for implementing them. This is based on documents that set out the governance structure and the empowering statutes. The framework is then assessed for its adequacy using the criteria developed in Chapter 4 that stem from the four risk-based concepts. This gives a measure of the ability of the framework to address uncertainty and dynamic climate change. The chapter then draws conclusions about the overall adequacy of the New Zealand institutional framework for addressing uncertainty and dynamic climate change.

\subsection{The institutional framework}

Chapter 2 outlined the elements of the New Zealand institutional framework that govern decision making relevant to climate change adaptation: where the governance lies at multiple levels (national, regional and territorial local government, and the role of the Courts); the legislation administered by local government across the statutory functions of planning (Resource Management Act-RMA), flood management (Soil Conservation and Rivers Control ActSC\&RCA, Land Drainage Act—LDA), building (Building Act and Building Code-BA), infrastructure asset management (Local Government Act-LGA) and emergency management (Civil Defence and Emergency Management Act-CDEMA); and highlighted the genesis and evolution of the legislation derived from its historical context. The design thinking behind the framework is now discussed. Appendix 2 shows the statutory provisions. 


\subsubsection{The governance and regulatory design}

\section{The Resource Management Act 1991}

The architect of the RMA, the Rt. Hon. Sir Geoffrey Palmer, on the Bill's introduction in $1989,{ }^{23}$ identified the thinking behind the design of the RMA:

- greater efficiency of process;

- clarification of the roles and responsibilities of central government, making it part of the resource management process, through national policy statements to which local government must have regard;

- national coastal policy statement to guide regional coastal management, national environmental standards to provide firm guidance under which regional and district plans can develop;

- clarity of people's rights and obligations to ensure greater certainty for landowners and greater specificity by councils about controls and the reasons for them;

- integration of consents across natural resources;

- examination of the full range of means to achieving environmental outcomes desired by the community.

The RMA was designed to be exercised through a hierarchy of mandatory and optional instruments at all levels of government (Hansard, 1989): primary statutory requirements and principles (mandatory); promulgation of National Policy Statements (NPS) and National Environmental Standards (NES) (optional); adherence to any NPS or NES that is issued (mandatory); regional policy statements, plans and rules (optional, but rules must be given effect at the district level); regional coastal plans (mandatory at the regional level); district plans and rules (mandatory at the district and city levels); and supported by the mandatory New Zealand Coastal Policy Statement (NZCPS) 2010, which includes direction for climate change adaptation at the coast for sea-level rise, storm surge and associated wave height. Central government also provides non-statutory optional guidance on planning for coastal management and floods (Ministry for the Environment, 2009, 2010; Woods et al., 2010). Change over time is addressed through periodic 10-yearly reviews of the statutory instruments, but with provision for plan changes at other times. The RMA

\footnotetext{
${ }^{23}$ Hansard, 5 December 1989.
} 
thus sets up an expectation of a central government supporting the devolved functions at the lower levels of government. The relevant provisions are set out in Appendix 2.

The hallmark of the legislation was to be integrated environmental management (land, water and air) driven by a normative set of ecological principles embodied in section 5 of the RMA, based on 'sustainable development' and the 'precautionary principle'. The principles based on sustainable management of natural and physical resources were to be operationalised through provisions at national, regional and district levels of government, addressing the allocation of resources and their use (Bosselmann \& Grinlinton, 2002). The interests of future generations and uncertainty are intrinsic parts of the framework (see RMA section 5 (2) in Appendix 2). The statutory tools in the RMA are part of a 'command and control' regime (Carlman, 2005) for the sustainable management of natural and physical resources, that reflects a hierarchical planning structure at national, regional and local levels, which depends on consistency between the levels (Carlman, 2005). Carlman also suggests that, while this design can enable climate change adaptation, it is limited by what can be measured now with 'certainty'; the mix of mandatory and voluntary provisions across the hierarchy exposes those operating within the mandatory part of the framework to missing supporting policies and measures that are optional, that could reinforce decision making at a local level.

Two key questions arise for climate change adaptation from the framework design. First, can periodic reviews and consequent adjustments consider adaptive practice or enable adaptive practice? While reviews provide space for change in the control mechanisms, in practice the initial measure can generate path dependency; for example, a hazard line or a levee at a snapshot in time, and existing use rights set up by the measures at the local level. This is because the measures adopted limit the degree to which adaptation can take place at a later time for land uses that have longer capital turnover periods. The constraints set up by private property owners' expectations and the dominant structural measures used instil a sense of safety into those 'protected', and expectation of ongoing protection, or enshrine property rights as existing uses at the local level.

The second question is whether the implementation of effective adaptation relies upon all instruments at all levels of government being mandatory and in place together in time. The hierarchical regime in the RMA was envisaged as providing the supporting architecture that could integrate resource management across levels of government. ${ }^{24}$ In particular, government saw its role as one of dealing with 'spillover' effects, where private uses of land had implications for other parties, where people had inadequate information, such as for hazards, and providing certainty to

${ }^{24}$ Resource Management Bill, Third Reading speech by Hon. Simon Upton, Minister for the Environment, 1991. 
people as to what is and isn't acceptable to the wider community. Balancing flexibility and certainty was explicitly considered as the RMA was being developed (Ministry for the Environment, 1988). Government agreed that it had "a role in hazard mitigation through information provision, policy direction, disaster relief and management, where appropriate", (p. 20).

Local government was viewed as having both strengths and weaknesses in resource management. For example, its technical capabilities for considering regional and national issues were questioned, but decision making located close to affected communities was valued-the subsidiarity principle. However, it was considered that, where devolution occurred, there could still need to be an ability for higher levels of government to express regional and national priorities in a decision-making role, and as a participant. There was much debate about the particular roles Ministers should assume and the integration of those roles with responsibilities of other agencies within government and at the different levels of government.

This needs to be seen in the context of the time. There was a legacy of previous governments' interventions in the 'national interest', such as the National Development Act 1979 which led to the so-called 'Think Big' projects and the growing desire for public participation in the decisionmaking processes (Palmer, 2013). The passing of the Official Information Act in 1982 followed. A new government opened up the economy to international markets, removed subsidies to the private sector and public agencies, and reformed local government through amalgamation of the more than 800 units of local government to 86 units. The ideas of decentralisation and devolution that drove these reforms were adopted by successive governments after the 1980s on the basis that they were more 'efficient' and made public and private interests more explicit. The resource management regime was framed as addressing market information failures and for interests like the natural environment not being represented (Kerr, Claridge, \& Milicich, 1998).

Integration of consents and procedural requirements across the resource domains of land, air and water were the subject of debate by those engaged in the RMA review process. It was thought that regional government should provide the integrative mechanism and territorial local authorities (TLAs) undertake functions within the wider regional framework. Land use planning could be totally devolved to TLAs, or at the discretion of regional councils. Four models were proposed for public discussion: RMA with a regional focus, RMA with a regional TLA split, an RMA with central/local split between minerals and coastal on one hand, and water and soil, land use, air and noise on the other; and separate resource management acts (Hansard, 1989). 
The Review Group, set up by the new government in 1990 (Randerson, Crosson, Salmon, Tremaine, \& Wheeler, 1990), explicitly considered national policy statements (NPS) as providing "a useful mechanism for co-ordination of policies on a nationwide basis in order to achieve the purposes of the Act" (p. 26), replacing the then current law that required central government to approve regional schemes throughout New Zealand (although the Crown could make submissions on schemes as they were being prepared, and on resource consents). The public process associated with NPS, the expression of NPS in general terms rather than in directive terms and the ability to seek judicial review of Ministers' decisions included in the RMA were designed to address concerns that there could be a potential for central government to abuse the NPS through ad hoc intervention (a protection against abuse of central power). There was also discussion of whether NPS should be brought into effect by way of amendment to the Act, or be non-statutory. Making NPS consistent with the purposes of the RMA was one way of addressing the concerns about ad hoc intervention, and about NPS being too vague to have effect. The relationship between the levels of government with respect of NPS led to the final RMA having lower levels of government being required to give effect to NPS if the NPS so directs, otherwise they would have been 'superfluous'.

This was an elegant balance between devolution to the local level, but with the ability of the national level to influence outcomes if it chose to (with the exception of the NZCPS which was made mandatory), depending on the capacity of local government to undertake its responsibilities. This is a theme to which the Rt. Hon. Sir Geoffrey Palmer returned to in his memoir, commenting that:

Local governments were barely up to the task and frankly did not do as well as they should have done. Central government did not help; instead, it resolutely refused to make national policy statements and did not use regulations to provide uniform standards in areas where they were needed. (Palmer, 2013, p. 431)

The co-ordination between levels of government was specified in law (section 36B RMA Power to make joint agreements, see Appendix 2), but the mechanisms were left to local councils to decide. Examples include Memoranda of Understanding, informal agreements between Chief Executive Officers and co-ordination via a Resource Managers Group, regional council Special Interest Groups based on professional disciplines, and Lifelines groups under section 60 of the Civil Defence and Emergency Management Act. There is also provision for transfer of power (section 33 RMA, see Appendix 2), and delegation of functions to other public authorities (section 
34 RMA, see Appendix 2) which enable councils to co-ordinate the management of resources between levels of government.

However, Klein (2005), in a review of the RMA practice, observed that: “...initial studies of planning practice arrived at the conclusion that integrated management is not practised in a systematic and consistent fashion, but rather in an irregular and fragmentary manner" (p. 299). It took a long time for the national instruments of practice to be promulgated. For example, the first NES was promulgated under the RMA in 2004, 13 years after the RMA was enacted. The RMA was amended almost each year. The Ministry for the Environment provided information and guidance and no climate- or hazards-relevant NPS has been promulgated by government, except for the NZCPS promulgated by the Department of Conservation that was required under the RMA. Simplified processes in the 2003 and 2005 amendments to the RMA may have made the NPS processes easier to conduct, albeit limiting opportunities for Environment Court appeals and public participation. Lack of legal certainty, substantial plan divergence and loopholes in legal protection were described by Klein as the disadvantages of the lack of comprehensive binding national standards and statements. Klein also identified a capability deficit at councils and an inadequate co-ordination architecture.

\section{Soil Conservation and Rivers Control Act 1941 and Land Drainage Act 1908}

The SC\&RCA and the LDA had their origins in the historical clearing of land for farming in the 19th and first part of the 20th centuries and the effects arising from the large rainfall events that occurred during that period (McCaskill, 1973). The harms included damage to hill country and access to it, large quantities of sediment and debris strewn downstream over farmland and flooding in low-lying areas. The need to 'conserve' the land and 'control' the effects of flooding were the drivers for the legislation. It also gave rise to professional soil conservators and river engineers over the following period who undertook the protection activities and the land drainage for farming. Protection was achieved through farm-based plans, large river control schemes and land drainage schemes, undertaken at catchment level. Elected catchment boards at local government level were formed and funding mechanisms set up under the statute in cost-sharing arrangements with central government. These activities persist today in regional councils, but without central government funding arrangements, except for where adverse climate events and natural disasters occur (Ministry for Primary Industries., 2014). The role of central government has become an underwriter of last resort, post hoc. 


\section{Local Government Act 2002}

The focus of the LGA is on the current and future provision of core services to towns, cities, rural districts and regions, including local infrastructure, local public services, regulatory functions such as planning and hazard management, civil defence and emergency management, pest and biodiversity management. The vast bulk of the services comprise the 'three waters' (water supply, waste water and storm water) and road infrastructure, which together comprise "more than $\$ 100$ billion of community assets" (New Zealand Office of the Auditor-General, 2014, p. 3). ${ }^{25}$ The Local Government Act is the umbrella legislation that sets out the functions and powers of local government entities - the services, governance and funding arrangements to deliver them. The management of the services is based on long-term plans (10-year time horizon) and strategic infrastructure plans (30-year time horizon) based on sustainability as an outcome for the provision of these services. More recently, resilience has become the primary outcome for local government infrastructure services in accordance with the National Infrastructure Plan 2011 (New Zealand Government National Infrastructure Unit, 2013). Risk management has become focused on resilient outcomes as an end objective.

\section{Building Act 2004 and Code}

Local government administers the Building Act and Code within their territories by regulating building work, establishing a licensing regime for building practitioners and setting performance standards for buildings to achieve sustainable development and the emphasis is on the safety of people within buildings. The Code includes standards for flooding that affects buildings.

\section{Civil Defence and Emergency Management Act 2002}

The CDEMA provides for a national strategy that is based on sustainable management of hazards through the $4 \mathrm{Rs}$ of disaster risk reduction that are used globally for such activities: readiness, response, recovery and reduction (New Zealand Government, 2008). These activities have a local government component and co-ordination across agencies at national and local levels through Lifelines groups, which plan the interconnectedness of infrastructure and utilities and other response organisations such as health, police, justice and social services that respond to disasters. The reduction activities are envisaged as being carried out through planning under the RMA.

\section{Central government guidance}

The institutional framework is supported by a number of guidance documents. These were envisaged by the RMA architects (Hansard, 1989) as a part of the institutional regime and reflected

\footnotetext{
${ }^{25}$ New Zealand's GDP is NZ\$246 billion. Refer to http://www.stats.govt.nz/browse_for_stats/economic_indicators/gdp/info-releases.aspx
} 
in the roles and responsibilities of central government in the governance hierarchy. These provide clear guidance on use of the precautionary principle, risk management and an adaptive approach to consideration of uncertainty and change. For example, the guidelines for local government for climate changes is entitled: "Preparing for coastal change" (Ministry for the Environment, 2009 ). It is anticipatory and acknowledges change. Key principles embodied in the guideline for planning and decision making about coastal margins include:

Precautionary approach: Decision-making takes account of the level of risk, uses existing knowledge and accounts for uncertainties. A precautionary approach should be used when making planning decisions that relate to new development as well as to changes to existing development within coastal margins.

Progressive risk reduction: New developments should not be exposed to, nor increase, the levels of coastal hazard risks over their intended serviceable lifetime. For existing developments the level of risk should be progressively reduced. (p. 21)

The guideline goes on to provide examples of applying these principles, such as incorporating flexibility to deal with changing risks and uncertainties; using a risk-based approach to decision making regarding coastal development; and avoiding actions that make it more difficult to cope with coastal hazard and climate risks in the future.

Ongoing change is provided for in the guidance by highlighting the need for consideration of higher sea levels than a base sea-level rise and for continuous change over longer timeframes beyond the end of this century using an additional allowance of $10 \mathrm{~mm}$ per year sea-level rise beyond 2100:

We recommend that for planning and decision timeframes out to the 2090s (20902099): (1) a base value sea-level rise of $0.5 \mathrm{~m}$ relative to the 1980-1999 average be used, along with, (2) an assessment of potential consequences from a range of possible higher sea-level rise values. At the very least, all assessments should consider the consequences of a mean sea-level rise of at least $0.8 \mathrm{~m}$ relative to the 1980-1999 average. For longer planning and decision timeframes beyond the end of this century, we recommend an additional allowance for sea-level rise of $10 \mathrm{~mm}$ per year beyond $2100 .{ }^{26}$ Ministry for the Environment (2009 p. 8)

${ }^{26}$ Note that this guidance is based on the IPCC AR4, and thus is currently being reviewed following IPCC AR5. 
Another guideline, "Preparing for future flooding"(Ministry for the Environment, 2010) and an accompanying technical guide for estimating the effects of climate change on flood flow (Woods et al., 2010), take a risk-based approach based on likelihood and consequence with a link to the design life of what is being protected. Changing risk is built into the guidance. A distinction is made between the change in frequency and likelihood that is consequent upon climate change, and 'freeboard' which is the factor of safety above a design flood level for flood mitigation structures. Both are to be applied. The guideline also points out that historic flood events will be less indicative of future events and that statistical flood data analysis will have to change to reflect this. When highlighting the significant uncertainties in estimates of rainfall, flow and inundation associated with inputs, parameter choice errors in modelling and assumptions about antecedent condition, which can be as large as climate change impacts, the following guidance is given:

However, because climate change is likely to have a significant impact on flow, and much of that impact can be calculated, these broader uncertainties should not prevent efforts to include climate change in flow estimation. Where possible you should try to estimate the error bounds of the calculations. (Ministry for the Environment 2010, p. 14)

To manage the uncertainties, the guidance recommends that a number of climate change scenarios are used to span the range of future possibilities.

Planning guidance relevant to addressing uncertainty can also be found in a guide to section 32 of the RMA (Ministry for the Environment, 2014). This section of the RMA sets out the requirements for evaluation reports on policies, plans and other methods. The guide addresses uncertainty, but dynamic change over long timeframes is only indirectly addressed in discussion of appropriate discount rates for cost benefit assessments (p. 60), the use of scenarios for testing the robustness of policies over time (p. 61), the different approaches for managing risk (p. 45), and by acknowledging that policies and rules will need to be flexible, that adaptive management is appropriate for new uses, that the NPS can be worded to defer to a lower-level plan that has better access to information over time (although this could now be ultra vires the RMA, following the Supreme Court Decision on King Salmon ${ }^{27}$ (see discussion of the NZCPS below) and to the use of the precautionary principle. The technical basis of the risk assessment is sourced to a GNS Science tool box for risk-based land use planning for natural hazards ${ }^{28}$ which does not address dynamic change in hazard risk that is envisaged in climate change characteristics as discussed in

\footnotetext{
${ }^{27}$ Environmental Defence Society v New Zealand King Salmon SC 82/2013, [2014] NZSC 38, April 2014.

${ }^{28} \mathrm{http}: / /$ www.gns.cri.nz/Home/RBP/Risk-based-planning/A-toolbox
} 
Chapter 2. The result is a two-dimensional probability $X$ consequence typology which acknowledges that expert knowledge will change over time, reflecting uncertainty. This does not convey the type of uncertainties that are contingent on climate change, and which will likely exacerbate the hazard risk.

\subsubsection{Institutional design weaknesses}

There are weaknesses across the suite of statutes that form the institutional framework for considering uncertainty and dynamic climate change. Having fragmented statutes means that the links between statutes are weak; each statute largely operates separately. Therefore, there is the potential for inconsistencies to arise between the RMA and the Building Act (and Code), and these two statutes and the SC\&RCA, where land uses in flood-prone areas are controlled based on probability statements that are different. For example, section E1.3.1 of the Building Code makes the link with the RMA by envisaging the RMA primarily addressing flooding of other properties, while section E1.3.2 envisages buildings being able to withstand a flood of $2 \%$ probability of annual occurrence. While a link is made with the RMA, there is no link with the SC\&RCA. This highlights the potential for inconsistency if different levels of precaution are adopted under each statute for flood probabilities, which is possible since the two statutes are administered at two different governance scales.

There is also the potential that provisions in statutes other than the RMA that could complement the consideration of the effects of climate change are not used or used in ways that counteract planning under the RMA. Protection decisions under the SC\&RCA that rely upon hard structures can entrench current land use patterns, thus potentially increasing damages when design levels are exceeded from extreme climate events. There is also potential, where voluntary measures like NPS are not used, for councils to have insufficient supporting regulations to be able to justify planning controls in areas expected in the future to be subject to sea-level rise or inundation from storms and riverine flooding. The hierarchical nature of the framework means that if one level of government does not exercise its roles and responsibilities, then the ability to change course from current practice can be compromised. For example, if regional councils do not promulgate regional rules (e.g., for hazard management that includes potential climate change impacts) then territorial local government has no powers to change existing uses that are in harm's way. 


\subsection{Does the institutional framework embody the four risk-based concepts?}

\subsubsection{Precautionary principle}

The precautionary principle is only explicit in one statutory instrument-NZCPS (see Appendix 2). Section 5 of the RMA sets out the purpose as "sustainable management" which is steeped in the precautionary principle emanating from the Brundtland Commission (United Nations World Commission on Environment and Development, 1987) and the Rio Conference (United Nations, 1992a). Sustainable management as a principle within the law is to be 'promoted', implying a normative and deliberate implementation through the instruments in the RMA. This is reinforced by sections 6 and 7 of the RMA which provide specific elaboration of the sustainable management principle. They specify matters of national importance and other matters which are intended to be 'environmental bottom-lines' (Palmer, 2013). The intent was to reduce the possibility of irreversible effects on the environment because the matters specified were considered by Parliament as non-substitutable (see Chapter 2). An amendment to the RMA in 2003, which is now encompassed in section 32 (2) (c), states that the evaluation of plans and statements "must take into account the risk of acting, or not acting if there is uncertain or insufficient information about the matter of the policies, rules, or other methods". This appears to be the first time language directly reflecting the precautionary principle has been written into the RMA. The Environment Court has concluded that there is no 'standard of proof' for future events even if the probability was lower than $50 \% .{ }^{29}$ However, the Court did not see that the risk assessment under section 32 necessarily required the precautionary principle, since the statutory guidance for the assessment was in the definition of "effect" (see Appendix 2). The Final Decision of the King Salmon Board of Inquiry held that the definition of "effect" in section $3,{ }^{30}$ the definition of "environment" in section 5(2), and section 104 (1) (a) of the RMA, ${ }^{31}$ imply that decision makers should be cautious where there is uncertainty and where there is likely serious harm and irreversibility. Accordingly, the courts have held: ${ }^{32}$

The precautionary approach may be applied in making the judgment where, on the totality of the evidence, [the Court] finds that due to scientific uncertainty, exercise of the consent would be likely to cause serious or irreversible harm to the environment.

\footnotetext{
${ }^{29}$ See Clifford Bay Marine Farms Ltd v Marlborough District Council C 131/03.

${ }^{30}$ Using Shirley Primary School v Christchurch City Council, [1999] NZRMA 66 at [220]-[222]), and Fore World Developments Limited v Napier City Council, EnvC Wellington W29/2006 at [30].

${ }^{31}$ Using McIntyre v Christchurch City Council, [1996] NZRMA 289.

${ }^{32}$ Ngati Kahu Ki Whangaroa Co-operative Society Limited v Northland Regional Council, [2001] NZRMA 99 at [161].
} 
A government review of sections 6 and 7 of the RMA in 2012 suggested that the courts have weighed economic and environmental factors in achieving sustainable management of natural resources (Minister for the Environment, 2012), rather than using sections 6 and 7 as 'environmental bottom-lines' in the sense that they are protecting natural resources from irreversible and non-substitutable changes as discussed by Neumayer (2007). There has been much debate about whether decision makers should weigh up the importance of competing values based on expert judgement, or apply the precautionary principle based on a threshold of damage or irreversibility as specified in sections 6 and 7 of the RMA. This has now been settled in the Supreme Court (see footnote 5 above). The Court confirmed that sections 6 and 7 are intended as 'environmental bottom-lines' and to be applied by those undertaking functions under the RMA, rather than a matter to help interpretation, or weighed up across interests at the local level. They also determined that the NZCPS, which embodies the precautionary principle, is tantamount to a 'rule' and therefore must be implemented by regional councils and TLAs in their plans that guide consents for activities.

The purpose statement of the RMA at section 5 (2) defines sustainable management (see Appendix 2). At clause (a) it notes the need for meeting "the reasonably foreseeable needs of future generations". This clause introduces longer timeframes for consideration of "effects" which are defined in section 3 of the RMA.

These effects include:

(d) any cumulative effect which arises over time or in combination with other effects - regardless of the scale, intensity, duration, or frequency of the effect, and also includes-

(f) any potential effect of low probability which has a high potential impact.

These clauses clearly anticipate an exacerbator like climate change with respect to other natural hazards, effects that we know will happen and those that we know about, but which may be less frequent (unknown timing) and of a large scale (unknown magnitude and timing). These are the type of effects envisaged in the precautionary principle and discussed in Chapter 4. Sections 3 (d) and (f) therefore anticipate uncertainty. The scope of these sections of the RMA could include sealevel rise, extreme climatic events, climate variability at many scales and changes in flood frequency. However, it is debatable whether these clauses anticipate dynamic climate change over time, although they do not rule it out. No discussion of this could be found in the Resource Management Law Reform documents, nor any subsequent analyses of the RMA. 
The explicit statutory mandate for consideration of climate change is in section 7 (i) of the RMA, under which all those exercising functions and powers are to "have particular regard to the effects of climate change". This was added to the principal Act "to require local authorities to plan for the effects of climate change" by section 3 (b) of the RMA (Energy and Climate Change) Amendment Act 2004. Because the effects of climate change sit within section 7 of the RMA, the clarification afforded by the Supreme Court referred to above enables climate change effects to be considered as an 'environmental bottom-line' for those exercising functions and powers under the RMA. The explicit consideration of climate change effects in the RMA has added to the existing provisions in sections 30 and 31 that require "the avoidance or mitigation of natural hazards".

These latter two provisions (effects of climate change and hazard avoidance and mitigation) need to be viewed in the context of the purpose of the RMA at section 5. It could therefore be argued that the RMA embodies the precautionary principle by virtue of sustainable management and the definition of "effects". This conclusion is further reinforced by the mandatory NZCPS which has an explicit policy on the precautionary principle (see Appendix 2). This statutory instrument must be given effect by local authorities and thus operates as statutory direction on how councils and agencies of government must develop their plans and grant consents. It is to be adopted for considering "effects" on the use and management of coastal resources that are "uncertain, unknown, or little understood, but potentially significantly adverse", to "meet the needs of future generations", where potential losses and harm are "avoidable" so that natural adjustments can occur. These are elements that underpin the precautionary principle.

The RMA section 32 Report undertaken on the draft NZCPS, states (Board of Inquiry New Zealand Coastal Policy Statement, 2008, pp. 33-34):

It is considered that Policy 5 [Precautionary approach] in conjunction with the other policies of this NZCPS is the most appropriate means of achieving the objectives of the NZCPS because the policy is:

- effective in recognising that there are knowledge gaps in relation to coastal information;

- effective in enabling activities to proceed in a carefully managed manner;

- efficient in providing guidance on when a precautionary approach should be adopted;

- efficient as it generates medium to high benefits and low to medium costs. 
The NZCPS also embodies other elements of precaution that can consider uncertainty. For example, it has a timeframe for decisions about sea-level rise and coastal hazards. It nominates "over no less than 100 years" and "at least 100 years" as the planning horizon (Policy 10 Reclamation and de-reclamation (2) (a); Policy 24 Identification of coastal hazards (1); Policy 25 Subdivision, use and development in areas of coastal hazard risk). By planning in the knowledge of long-term irreversible changes decision makers can apply the precautionary principle. Sea-level rise is explicitly addressed by Policy 24 (e) "Cumulative effects of sea-level rise, storm surge and wave height under storm conditions", changes that will be irreversible and thus can invoke the precautionary principle.

The NZCPS provides the statutory direction that enables councils to give effect to the precautionary principle through policies and plans at regional and local government levels. The Supreme Court decision (see footnote 5 above) also makes it clear that the NZCPS is not something that gets weighed up again at regional and local level through plans; rather they are the policies that must be given effect. The King Salmon Supreme Court decision is helpful in clarifying the cascade of decision-making instruments that was envisaged in the RMA when enacted and serves to reinforce the power of instruments at the different levels of government - central government (NZCPS, NPS and NES); regional government (regional plans and water and air consents); territorial local government (district plans and land-use consents).

Other parts of the statutory framework for considering changes in climate are, however, less explicit with respect to the precautionary principle. The objects of the SC\&RCA (section 10) relevant to climate change and its effects are set out in Appendix 2. Underlying this activity was, and still is, the implicit concept of public agencies undertaking precautionary activity ahead of harm to manage the effects of extreme climate-related events, even though the statute was enacted after a period of major climate events.

The Local Government Act (LGA), under which local government in New Zealand operates, has sustainable development provisions that reflect the reasonably foreseeable needs of future generations, the social, economic and cultural interests of people and communities and the avoidance or mitigation of natural hazards (see Appendix 2 section 14 (1) (h) (i) and (iii), and section $11 \mathrm{~A}(\mathrm{~d}))$.

It could be argued that the wording in the LGA, by being underpinned with sustainability principles, means that it embodies the precautionary principle by anticipating future hazards that are exacerbated by climate change and are uncertain. Its focus on the long term is designed to draw 
attention of decision makers to the effects of their decisions today for future generations which, by definition, are uncertain.

The Building Act (BA) has some similar provisions that guide the exercise of building controls for the purpose of protection of public safety, safe egress and durability. In section 3 (a) (iv), "buildings are [to be] designed, constructed, and able to be used in ways that promote sustainable development". These provisions anticipate future harm which is uncertain in its timing and character, thus embodying an element of the precaution principle. The Building Code gives regulatory effect to the BA with respect to surface water under a heading of "Moisture" E1 using probability standards to reflect safety levels for those using the building and any other property. The implications of this are discussed in section 5.1.2 above.

Section 7 of the CDEMA embeds the precautionary principle explicitly in two ways: a section entitled "the precautionary approach" suggesting caution in exercising functions even if there is uncertainty about the risks; and in section 3 by way of a similar clause to the LGA based on "sustainable management of hazards" (see Appendix 2). Matters relevant to development of civil defence emergency management plans are included in section 38 which refers to current and future generations (see Appendix 2). This mirrors the intergenerational provisions in the RMA and LGA which focus decision-makers' attention on the long term, which may result in precautionary actions.

The precautionary principle is largely implicit in the framework by embodying in other textual references "sustainable management" and "sustainable development". Where it is explicit in the NZCPS, it provides considerable guidance to decision makers about where and why it should be used. How it should be used has been recently clarified by the Supreme Court in the King Salmon case referred to in Section 5.1; it is to be applied at the top of hierarchy of instruments and not be weighed up again at the lower levels of government when plans and plan changes are promulgated. This also removes any discretion about whether it should be applied. However, it is the sole regulatory expression of how to operationalise the precautionary principle available to decision making about climate change adaptation; relating to sea-level rise only.

\subsubsection{Risk management}

The New Zealand institutional framework has several references to risk as part of its requirements on those exercising functions under the law; for example, RMA section 32 (2) (c) requires assessment of the risk of acting or not acting if there is uncertain or insufficient information about the subject matter of the provisions. Section 45 (2) (g) encompasses risk in relation to its potential magnitude in addition to uniqueness or irreversibility (see Appendix 2). 
The NZCPS Policy 27 acknowledges the difficulties of changing existing activities, like ports and airports for example, and that hard structures may be the only practical means of protecting infrastructure. But it also promotes a long-term sustainable risk reduction approach and transparent assessment of consequences of options relative to the 'do-nothing' option, and to the social costs of hard protection structures. By introducing a 'do-nothing' option this serves to focus attention on several possible outcomes, thus entertaining the idea of uncertainty and dynamic change.

The LGA has embedded risk in several provisions: financial risk and risk of investment. This could be interpreted to encompass anything affecting those risks during the investment cycle, or to the financial risk to councils, and could conceivably include climatic risks. The LGA Section 101B requiring local government to prepare infrastructure strategies, embeds risk as part of its resilience objective for infrastructure over 30 years. Section 101B (3) (e) sets out what such a strategy should take into account and includes identification and management of risks relating to natural hazards and making financial provision for those risks. This provides a framework for anticipating changing risk, even if today it is uncertain in some respects.

The BA does not explicitly encompass the concept of risk other than setting up a process for defining low-risk buildings and determining the risk profile of buildings in terms of the integrity of the building from a public safety perspective. The Building Code, however, envisages risk by setting flood probability standards for the public safety of buildings (see Appendix 2).

The CDEMA is steeped in risk language within its purpose of sustainable management of hazards. Risk is defined as "the likelihood and consequences of the hazard" in section 4 Interpretation. The purpose of the legislation is explicit about risk management by encouraging and enabling communities to achieve acceptable levels of risk by identifying, assessing and managing risks, consulting and communicating about risks, identifying and implementing cost-effective risk reduction and by monitoring and reviewing the process. Matters relevant to development of civil defence emergency management plans include in section 38: "the benefits to be derived for people and communities from the management of hazards and risks". This implies reduction of harms through risk management.

Risk management is scattered across all parts of the framework. Each statute has slightly different ways of expressing risk. For example, in the CDEMA, the notion of acceptable levels of risk is introduced. This begs the question as to who decides what is acceptable and whether it is for current or future generations. It also raises the question as to whether the concept of 'acceptable' levels of risk is used in other decision contexts (see discussion of acceptable risk in Chapter 6). 


\subsubsection{Adaptive management}

The New Zealand institutional framework has no specific references to adaptive management. Such approaches, however, are not ruled out. NZCPS Policy 27 provides some flexibility for decision making for important infrastructure decisions. This could conceivably guide the use of staged adaptive approaches to risk reduction over longer timeframes. Chapter 6 gives examples of where adaptive management has been practised in resource management decision making for managing environmental effects.

The only statute that does embody explicit provision for adaptive management in New Zealand is the Exclusive Economic Zone and Continental Shelf (Environmental Effects) Act 2012 (EEZA). This statute is not part of the climate change adaptation institutional framework but it shows that it is possible to formulate an adaptive management approach in the law, albeit for addressing issues of the commons, rather than situations on land where existing property rights have been assigned already. This statute has express provisions for adaptive management which is defined to mean starting an activity on a small scale for a short timeframe so the effects on the environment and existing interests can be monitored. This allows activities to be consented in stages relating to the duration, area, scale or intensity or the nature of the activity. A recent example of its application was where a resource extraction consent was declined on the grounds of the scope and significance of the environmental effects and those on existing uses. ${ }^{33}$ Section 6 (2) of the EEZA requires "caution and environmental protection" and it was found that the adaptive management approach and conditions proposed by the applicant were insufficiently certain and robust. Because of uncertainty about current and future impacts and uncertainty about the receiving environment, the adaptive management approach was not thought to be robust enough for its application. However, this is an example of how the precautionary principle and risk management have informed adaptive management, and been used to design thresholds to trigger action before effects are damaging and irreversible. By being part of New Zealand jurisprudence, experience with such an adaptive approach could inform the application of adaptive management for addressing climate change uncertainty.

\subsubsection{Transformational change}

Some of the most significant transformational changes in New Zealand were the institutional reforms of the 1980s and early 1990s which gave rise to the RMA, the devolution of powers to local government for resource management and local government amalgamations. This was a

\footnotetext{
${ }^{33}$ Refer http://www.epa.govt.nz/EEZ/trans_tasman/decision/Pages/default.aspx
} 
response to an economic and political crisis driven by the particular market ideology of the day (Lawrence, Wolf, et al., 2013). It was a reactive transformation, rather than an anticipatory change.

The institutional framework has only one indirect reference to transformational change. The NZCPS requires, in the assessment of strategies for significant existing development likely to be affected by coastal hazards, the identification and planning for "transition mechanisms and timeframes for moving to more sustainable approaches" (Policy 27). Transitions and timeframes were included to acknowledge the lock-in effect of existing infrastructure on future generations so that more sustainable forms of coastal risk reduction are considered (Board of Inquiry New Zealand Coastal Policy Statement, 2008, p. 346). This policy anticipates transformational change that will eventually be required for adapting to sea-level rise, by retreat of communities from the coast, to enable an orderly change in land uses ahead of the physical effects of the climate changes.

There have, however, been historic examples of transformative actions to address flood risk and coastal hazards using retreat, but outside the regulatory framework. Coastal examples are documented in Turbott (2006), most of which occurred after climate events. One was a deliberate retreat strategy at Muriwai beach near Auckland, New Zealand, albeit with limited private assets affected. One community-based project in the Auckland region included voluntary purchase of flood-prone properties as part of a community stream restoration programme (Vandenbeld \& MacDonald, 2013). In the case of the Canterbury earthquakes that occurred in 2010 and 2011, the New Zealand government used a transformational response called 'red zoning' to prohibit occupation of properties in the zone after the earthquakes for public safety reasons, and then set up a payment system, based on rateable value at a prior point in time. ${ }^{34}$ The common factor in these transformational responses was the availability of funding for the purchase of properties or the ability to transfer development rights elsewhere. Table 5.1 summarises of the extent to which the framework embodies the four risk-based concepts.

\footnotetext{
${ }^{34}$ Refer to http://cera.govt.nz/residential-red-zone
} 
Table 5.1 Institutional framework characteristics

\begin{tabular}{|c|c|c|c|c|}
\hline Theories & $\begin{array}{l}\text { Precautionary } \\
\text { principle }\end{array}$ & Risk management & $\begin{array}{l}\text { Adaptive } \\
\text { management }\end{array}$ & $\begin{array}{l}\text { Transformational } \\
\text { change }\end{array}$ \\
\hline Definition & $\begin{array}{l}\text { Where there are } \\
\text { threats of serious or } \\
\text { irreversible damage, } \\
\text { lack of full scientific } \\
\text { certainty shall not be } \\
\text { used as a reason for } \\
\text { postponing cost- } \\
\text { effective measures } \\
\text { to prevent } \\
\text { environmental } \\
\text { degradation }\end{array}$ & $\begin{array}{l}\text { The management } \\
\text { of the product of } \\
\text { the likelihood and } \\
\text { probability of harm }\end{array}$ & $\begin{array}{l}\text { Iterative response } \\
\text { to uncertainty and } \\
\text { change as system } \\
\text { feedback is } \\
\text { received }\end{array}$ & $\begin{array}{l}\text { Regime change in } \\
\text { the fundamental } \\
\text { attributes of a } \\
\text { system }\end{array}$ \\
\hline $\begin{array}{l}\text { Addresses } \\
\text { uncertainty and } \\
\text { dynamic } \\
\text { change? }\end{array}$ & $\begin{array}{l}\text { Large consequences } \\
\text { or irreversibility } \\
\text { because of } \\
\text { uncertainty } \\
\text { Dynamic change is } \\
\text { not explicit }\end{array}$ & $\begin{array}{l}\text { Addresses } \\
\text { uncertainty where } \\
\text { probabilities can be } \\
\text { defined } \\
\text { Dynamic change } \\
\text { not explicitly } \\
\text { addressed }\end{array}$ & $\begin{array}{l}\text { Addresses } \\
\text { uncertainty and } \\
\text { dynamic change }\end{array}$ & $\begin{array}{l}\text { Addresses } \\
\text { uncertainty and } \\
\text { dynamic change }\end{array}$ \\
\hline $\begin{array}{l}\text { Resource } \\
\text { Management Act }\end{array}$ & $\begin{array}{l}\text { Implicit in the } \\
\text { definition of } \\
\text { "sustainable } \\
\text { management", } \\
\text { "future generations" } \\
\text { "effects", sections } 6 \\
\text { and } 7 \\
\text { 'environmental } \\
\text { bottom-lines' for } \\
\text { reasons of } \\
\text { irreversibility and } \\
\text { non-substitutability }\end{array}$ & $\begin{array}{l}\text { Implicit in hazard } \\
\text { provisions of RMA } \\
\text { and explicit in } \\
\text { central government } \\
\text { guidance } \\
\text { Dynamic change } \\
\text { explicit in coastal } \\
\text { hazard and rainfall } \\
\text { guidance }\end{array}$ & $\begin{array}{l}\text { Adaptive } \\
\text { management not } \\
\text { explicit but not } \\
\text { ruled out }\end{array}$ & No \\
\hline $\begin{array}{l}\text { New Zealand } \\
\text { Coastal Policy } \\
\text { Statement }\end{array}$ & Explicit & Implicit & Implicit & $\begin{array}{l}\text { Implicit in } \\
\text { reference to } \\
\text { "transitions" }\end{array}$ \\
\hline $\begin{array}{l}\text { Central } \\
\text { government } \\
\text { guidance }\end{array}$ & Explicit & Explicit & Explicit & No \\
\hline $\begin{array}{l}\text { Soil } \\
\text { Conservation } \\
\text { and Rivers } \\
\text { Control } \\
\text { Act/Land } \\
\text { Drainage Act }\end{array}$ & Implicit & Implicit & No & No \\
\hline $\begin{array}{l}\text { Local } \\
\text { Government Act }\end{array}$ & $\begin{array}{l}\text { Implicit in } \\
\text { "sustainable } \\
\text { development" }\end{array}$ & $\begin{array}{l}\text { Explicit in } \\
\text { infrastructure } \\
\text { planning }\end{array}$ & No & No \\
\hline
\end{tabular}




\begin{tabular}{|l|l|l|l|l|}
\hline Theories & $\begin{array}{l}\text { Precautionary } \\
\text { principle }\end{array}$ & Risk management & $\begin{array}{l}\text { Adaptive } \\
\text { management }\end{array}$ & $\begin{array}{l}\text { Transformational } \\
\text { change }\end{array}$ \\
\hline Building Act & $\begin{array}{l}\text { Implicit in } \\
\text { "sustainable } \\
\text { development" }\end{array}$ & $\begin{array}{l}\text { Implicit in } \\
\text { providing flood } \\
\text { probability } \\
\text { standards }\end{array}$ & No & No \\
\hline $\begin{array}{l}\text { Civil Defence } \\
\text { and Emergency } \\
\text { Management Act }\end{array}$ & Explicit & Explicit & No & No \\
\hline
\end{tabular}

\subsection{The adequacy of the framework}

Chapter 4 identified three groups of decision-relevant issues: understanding and representing uncertainty and dynamic climate change characteristics; governance and regulation; and organisations and actors. These, with the specific criteria developed for each of the three categories, are now used to analyse the adequacy of the institutional framework, noting that satisfying each of the criteria will not be sufficient for institutional framework adequacy and that their relative importance will vary depending on the decision context. They are all expected, however, to play some important role in decision making, either individually or in combination.

\subsubsection{Understanding and representing uncertainty and dynamic climate change characteristics}

Chapter 2 discussed the characteristics of climate change that are unlike some other risks that confront decision makers - sea levels will rise continuously for centuries and engulf existing settlements and their services, and change community functioning; dynamic changes could include regime shifts that have hitherto not been experienced by society, including sea-level rise and increased frequency and intensity of rainfall events. Uncertainties have been reflected in the framework through the precautionary principle and risk management to varying degrees. But the framework does not reflect dynamic climate change characteristics explicitly. The criteria developed in Chapter 4 are now used to assess the adequacy of the framework

\section{a) Uncertainty treatment}

Treat climate changes as uncertain in some respects and consider unlikely but severe damaging changes as well as 'best estimates' of change.

Underlying statutory frameworks is the creation of certainty (Ruhl, 2012). New Zealand law is no exception. However, the framework in New Zealand goes further than some other jurisdictions like the United Kingdom, Australia, the Netherlands and Canada (see Chapter2) by embodying 'sustainable development' and 'sustainable management' as objectives. These have the capacity to guide consideration of uncertainty and change in the future. The framework in the RMA 
embodies the idea that "effects" (including climate change effects) encompass potential effects that accumulate at different scales, intensities, duration and frequency and in particular effects of low probability which have high potential consequences. It also anticipates that effects can combine to cause harm and thus can encompass climate as an exacerbator of other hazard risks like erosion or coastal inundation, for example. The NZCPS is even more explicit than the RMA principles, by identifying how uncertainty and change might be incorporated into planning controls. These provisions in the framework, in theory at least, encompass the ability to consider uncertainty and dynamic climate changes. It could be argued that provisions for avoiding and mitigating natural hazards, consideration of the effects of climate change and the consideration of the foreseeable needs of future generations, alongside the CDEMA regime for reducing risk, enable this to be done, making it an adequate treatment of uncertainty.

\section{b) Lifetime of decisions}

Work with a changing risk profile to ensure that responses that are fit for a specific timeframe do not make it more difficult to respond to risks that emerge only after this timeframe.

Some guidance provided from the national level of government includes uncertainties and the changing nature of the climate risks (Ministry for the Environment, 2008b; Woods et al., 2010), while other guidance (Minsitry for the Environment, 2014) does not. There is a misalignment of guidance between hazard management and climate change adaptation. This derives from parallel academic and policy discourses, and from the different critical traditions embedded in the different professional practices of the different statutory functions within organisations.

One way the RMA planning processes can address changing climate risk profiles is through the required periodic reviews (over a 10-year review cycle) for regional and district plans which affect land-use decisions. In theory, this provides opportunity for updating changing information about climate risk. However, the ability to influence change in land uses and to upgrade adaptation options is limited by the measures used to identify and plan for those risks. Measures like hazard lines on maps and flood levees, which are static in time and place and thus can lock in expectations of protection and existing use rights at a local level, are examples that limit such opportunities. There is, however, provision for regional councils to effect land-use controls through rules that override existing uses. This provision in the RMA (see Appendix 2) anticipates change happening. While it is possible in theory to address uncertainty and dynamic change through such provisions, in practice, adequacy of the framework is dependent on other influences related to governance scale, the role of private land owner pressure on the decision makers not to exercise such rules, for example, and are discussed in Chapter 6. 


\section{c) Framing of climate change risk}

Frame climate change risk in ways that can be understood by and are relevant to different interests.

The framework itself cannot influence the understanding of climate risk, except through expert evidence proffered at council hearings and at appeals to the special purpose Environment Court, and at higher courts, as a matter of practice. Councils and the Ministry for the Environment at the national level of government provide information about climate change effects. Framing of climate change risk in understandable and relevant ways for the range of interests is dependent on the dissemination of information about hazard risk (which local government is required to provide to the public), and on the capability of the professional disciplines within councils and their consultants, based on expert knowledge and information framed by the Intergovernmental Panel on Climate Change (IPCC), for example. The challenge here is with consistency of the framing of climate change effects that represents the uncertainty and dynamic climate changes. Consistency will be influenced by the particular level of expertise and the different conceptual bases of the professional disciplines within the responsible organisations. Because there are different councils at regional and district level conveying such information at each unit of local government, the possibility that the characteristics of the climate risk will be framed differently is high and inconsistency could arise when identifying the risks and responding to them across the country. This could create inequitable outcomes for different communities across jurisdictional boundaries and result in differential vulnerabilities. While framing is dependent on the practice, the framework has the ability to enable this criteria to be met but the fragmented set of statutes that govern hazard risk and climate change effects is likely to result in risk being framed in different ways.

\section{d) Consistency and accessibility of climate risk information}

Develop and manage information bases that inform climate risk consistently over time and be accessible to public and private interests.

Information is obtained at multiple scales and requires regular updating. Making information available in accessible forms for ongoing understanding and assessing uncertainties and dynamic climate changes requires strong co-ordination between levels of government and with private agencies (consultants and research institutes) to ensure that the most up-to-date information is available. It also requires information to be readily available to the general public, for which the framework makes provision. Risk information is often contested by communities (McDonald, 2007) since they fear the information will affect property values. However, such information is required to be made available in New Zealand law by section 44A of the Local Government 
Official Information and Meetings Act (see Appendix 2). This is required to enable choices to be made by councils and communities about the level of risk that they wish to bear. It also helps avoid the transfer of risk from private interests to the public purse.

While the framework can enable information bases to inform climate risk consistently over time and be accessible to decision makers and communities, whether it does, is a matter of practice and dependent on organisational and individual staff capability in councils. The level of devolution to lower governance scales could arguably create a barrier to meeting this criteria as information becomes dispersed and potentially inconsistent and inaccessible.

\subsubsection{Governance and regulation}

The institutional framework assigns clear roles and responsibilities across multiple levels of government. While the framework has a high level of devolution of functions and powers to local government, it retains powers at a national level. These powers enable national priorities to be identified, and for a level of efficiency to be achieved where it makes sense for the national level to do so. This is a specific design feature of the RMA and the LGA as discussed in Section 5.1.1 above. This feature stands out as different from a number of other jurisdictions globally; for example, the United Kingdom where more centrist governance exists for flood risk management (Pitt Review, 2008) and Australia where the states hold centrist power over local government planning functions under a federal system of government (McDonald, 2010).

\section{e) Precautionary decision making}

Prevent harm by anticipating potential damages and have supporting measures that would reduce or avoid such damages, without relying exclusively on information 'precision' and 'certainty' of evidence.

The framework under the RMA anticipates potential future harm from natural hazards and climate change. The extent to which information needs to be 'precise' and 'certain' is something that the courts have deliberated upon. There are several factors that influence a 'finding of fact' - the existence of facts for a finding: the court must be satisfied on the balance of probabilities, rather than beyond reasonable doubt; and that the court is persuaded by the evidence. ${ }^{35}$ The RMA at section 30 (d) (v) refers to "actual or potential effects of the use, development or protection of land, including the avoidance or mitigation of natural hazards..." Potential effects are, by definition, uncertain as to their timing and magnitude and can also encompass dynamic climate change. So while the planning processes will be seeking certainty of outcome for affected parties,

\footnotetext{
${ }^{35}$ Brookers' commentary on the RMA at paragraph RM104.03.
} 
this will be weighed by the courts in terms of "sustainable management" and the prospect of "low probability and high consequence" climate events. The location of "climate change effects" in the principles section of the RMA also will influence this weighing process. Again, in theory, uncertainty and dynamic climate change can be considered based on the evidence put before the council and the courts.

\section{f) Risk consideration over long timeframes}

Address risk over long timeframes and recognise that decisions taken today will affect the ability to change course in the future.

Timeframes for planning for the future vary across the suite of statutes in the framework; for example, 10, 30, 50 and more than 100 years are provided for in RMA plans, for infrastructure, buildings and sea-level rise respectively. This adds to the fragmentation of statutes and their practice. The ability to change course in the future is governed to a large extent by the manner in which the framework is practised. But the setting of timeframes for planning will inherently lead to decisions that reflect snap-shots-in-time and thus limit flexibility. As discussed in b) above, the use of static instruments of practice can create lock-in of decisions that increase exposure and vulnerability of those 'protected', thus creating path dependency that can reduce response options in the future, or at least make them more costly to implement. Definitive hazard lines for controlling land uses at the coast, or flood levees in low-lying areas, are fixed in time and space and reduce flexibility to change course in future. Addressing risk over long timeframes requires flexible instruments of practice, systems for monitoring and continuity of information provision and some consistency in the application of practice across levels of government. The framework as currently structured as a fragmented set of statutes with slightly different ways of addressing uncertainty and change and information provision, arguably, is inadequate for meeting this criteria. Whether the framework can enable decisions taken today to be mindful of the ability to change course in the future can only be demonstrated through the practice.

\section{g) Experimentation and learning}

Enable experimentation and learning that addresses changing community values over time and enables institutional settings and their application to be adjusted over time.

By its very nature, the effect of a statutory framework is to build a body of case law which is then applied by 'learning by doing'. The case law developed by the Environment Court and in turn by the High Court or Supreme Court, guides subsequent application of the RMA by the responsible agencies at the different levels of government. Over time, this also reflects changing values and new knowledge, which in turn could reflect the changing climate risks. Changes to the statutory 
framework, the organisations administering it and at what level decisions are taken have occurred over the lifetime of the institutional framework. The institutional settings have changed in response to changing values, in response to changing priorities and the relative power of different interest groups. An example of experimentation outside the institutional framework which is proposed for inclusion as a tool for water management in the RMA was the Land and Water Forum (Land and Water Forum, 2012), a collaborative governance model. It was essentially an 'experiment' in the water management domain that could change the institutional framework settings. This means that experimentation and learning by the actors operating within the framework can certainly occur and influence the shape of the institutional framework that governs climate change effects. There is therefore potential for local government to work with central government across governance scales on climate change adaptation. This occurs outside the framework processes, in informal and some more formal ways as demonstrated by the Land and Water Forum example. Experimentation and learning are not specifically enabled by the framework except through the case law that is built over time through practice.

\section{h) Codification of changing risk and complementary measures}

Have the ability to codify changing risk into formal instruments that can guide practice across multiple scales in reinforcing ways, and recognise that other measures will be necessary to complement formal rules, for them to be effectively sustained over time.

As discussed in Section 5.1.1, the interdependencies between different levels of government was a particular design feature of the RMA and its relationship with other legislation (CDEMA and the BA for example) was also provided for, in part. This feature of the RMA is reflected in the roles and responsibilities assigned to the different levels of government and in the available tools for giving effect to the purposes of the RMA. For example: NPS and NES; call-in procedures where matters traverse several local jurisdictions or where the matters are of national importance at the national level; regional policies and plans with rules at the regional level; and district plans and rules at the territorial level of government. It is a matter of policy that guidance and information are provided to those making decisions at lower governance scales and several guidance documents have been issued, as discussed in Sections 5.1 and 5.2. However, these are not mandatory, neither is their regular updating. Whether other measures are instigated is also a matter of policy and resources. The need for them to support co-ordination across the elements of the framework has been raised in the context of links between natural hazards and climate change (Glavovic \& Smith, 2014), but there is little evidence that this has been integrated into statutory frameworks, even when the opportunity has arisen; for example, when the LGA amendments were made in 2014 for infrastructure planning (see section 101B of the LGA in Appendix 2). Lifelines 
Groups under the CDEMA have the ability to facilitate co-ordination but the focus in the framework is on "pre-event planning" and "to reduce infrastructure outage risk and minimise restoration time when outages occur". ${ }^{36}$ It is a short-term, event-based framework. The overall framework is not well integrated across functions, with each statute constituting a separate code. This makes it inadequate to address uncertainty and dynamic climate change. Whether practice can be implemented with greater integration is discussed in Chapter 6.

\section{i) Transition to new institutions}

Have the ability to transition to new institutional states that can address uncertainty and dynamic change by making continuous adjustments ahead of societal and physical thresholds that take timeframes and lead-time into account.

Institutional change is a matter of policy and as such can be changed by the government of the day. The statutory framework has evolved over time and thus does have the ability to change. However, the degree to which such change enables continuous change ahead of harm thresholds and takes timeframes and lead-times into account is weakly developed in the framework. The different timeframes for planning set out in $\mathrm{f}$ ) above are one expression of that. The NZCPS and the climate change guidance material signal timeframes and lifetimes of different activities that need to be taken into account, based on the 'sustainable management' principle in the RMA. The ability for other parts of the framework to reflect timeframes and lifetimes is affected by the fragmented nature of the statutes and the lack of clear statutory responsibilities to do so.

The fact that adaptive decision making has been included within institutional design is positive. The EEZA legislation discussed in Section 5.3.4 is one such example. To the extent that long-term planning for council infrastructure will take the probability of climate change into account in staging asset construction is another example. The ability of the institutional framework to take thresholds, timeframes and lead-time into account will, to a large degree, depend on available tools that develop to give effect to framework principles that anticipate uncertainty and change. The tools currently available like the guide for section 32 assessments under the RMA give limited guidance on uncertainty and none on dynamic change. Tools that can address both uncertainty and dynamic change are discussed in Chapter 8 when considering the space for change.

\subsubsection{Organisations and the actors}

Institutional frameworks are implemented within organisations that are assigned roles and responsibilities under the statutes. Organisations have cultures and operating practices that are

\footnotetext{
${ }^{36}$ Refer http://www.civildefence.govt.nz/cdem-sector/lifeline-utilities/lifelines-groups/
} 
different, depending on the statute and level of government at which they operate. Central government agencies are answerable to Ministers who reflect a wide range of national interests. Local governments are answerable to elected councillors who reflect the immediate community interests. Climate change considerations conflict at all levels with the plethora of short- and longterm interests. For frameworks to be adequate, a number of capabilities and supporting mechanisms need to be in place and working well. Whether the New Zealand institutional framework enables these mechanisms and capabilities to come to the fore is now addressed.

\section{j) Organisational learning across disciplines and scales}

Have the capacity for organisational learning to align instruments of risk management practice across the different disciplines at multiple scales.

Organisational learning is closely tied to the abilities of leaders and the personnel within organisations. Learning is also affected by continuity of personnel that defines institutional memory' within organisations. These are not characteristics that are driven from the primary institutional framework discussed in this chapter, but have an influence on how the framework is put into practice. Local government is held to parliamentary account through the Office of the Auditor-General which undertakes audits of council long-term plans and periodic reviews of aspects of local government performance. The recent report on funding and management of water supply, waste water and storm water services is one example relevant to the adequacy of the framework for considering uncertainty and dynamic climate change (New Zealand Office of the Auditor-General, 2014). As well as analysing the state of the assets and where and when new investment is needed, the review also analysed whether asset management practice is giving local authorities the information they need to continue providing services into the future. While identifying that management was adequate for the short to medium term, it concluded that local authorities need to do more to manage infrastructure and financial strategies for the long-term, given the wider economic and population changes we face.

The report highlighted several important matters that needed to be in place for addressing the longterm challenges: sustainable services based on a long-term fiscal strategy; decision making informed by planning and risk management; co-ordination amongst those involved in asset services across disciplines; better use of the best data; and greater consistency in the collection of data on which long-term planning can be undertaken. The greatest tension throughout the report was the ability of councils to sustain services in an affordable way. The issues identified will have a flow-on effect for the consideration of climate change, which will exacerbate risk for the delivery 
of water services, whether that is availability of water, reduction of waste water or the performance of storm water systems as rainfall increases in frequency and intensity.

This example illustrates that cross-disciplinary co-ordination as an enabler of service delivery has been recognised as a necessary condition for reducing risks to organisations. However, the report is silent on the ability to learn from current risk levels for managing future uncertain and dynamic climate change. The closest the report comes to hazard risk is mention of "risks...posed by major geo-hazards" (p. 9) in reference to the recent Canterbury earthquakes that had economy-wide effects on the New Zealand. This illustrates that organisational learning appears to be related to experienced near-term events and that organising connectivity across policy domains is a necessity for addressing the complexity of climate change adaptation.

\section{k) Capability to lead and anticipate complex and changing risk across scales and functions}

Have leadership capability within organisations that can manage complex and changing circumstances, and manage across governance scales and the different functions.

Leadership is also something that does not appear in the institutional framework relevant to climate change adaptation. At the central level of government, leadership is inherent in the State Sector Act 1988 which governs the performance of Chief Executives in the state sector. Part 4 of the State Sector Act specifically provides for: "Senior leadership and management capability in Public Service". Chief Executives of local government agencies are accountable to their elected members for their performance, which is based in part on the performance of their organisations and reviewed by the Office of the Auditor-General through their Long-Term Plans.

Complexity of governance and changing circumstances will require leaders to manage crossfunctionally and between levels of governance, before damage is apparent to those who will be affected. The ability to work with ambiguity and change will be essential. Administrative arrangements at central government level enable 'whole-of-government' activities to help coordinate complex policy and operational issues. For climate change this has evolved since the 1980s when the first whole-of-government climate change policy group was set up in the Ministry for the Environment, following the establishment of the IPCC. Other co-ordination organisations included placing the climate change policy development in the Department of the Prime Minister and Cabinet in 2001, followed by a special purpose climate change 'office' set up within the Ministry for the Environment in 2003 to manage climate change policy implementation across the public sector, including adaptation to climate change. This latter arrangement was disestablished in 2005 and continues in part within the Ministry for the Environment and in part within the Ministry of Primary Industries. Cross-government climate change adaptation committees have 
existed for short periods during and since these organisational attempts at co-ordination of policy development and its implementation. Change in organisational form has led to ambiguity about the significance of climate change adaptation for New Zealand. This is evidenced by the paucity of climate change adaptation activity documented in the IPCC Assessment Report 5 (Reisinger et al., 2014) and by the calls for greater central government use of NPS to support local initiatives to address future climate changes (Local Government New Zealand, 2011).

\section{l) Community engagement to reflect values}

Have the ability to interact and learn from engagement with communities to enable changing and different values to be reflected in decision making.

The framework does address how organisations might approach engagement. There are formal statutory processes that enable engagement to take place; for example, the ability to resolve disputes (Kenderdine, 2010). There was a proposal in 2013 (Ministry for the Environment, 2013) to add an optional collaborative planning process to the tools for engagement for water management decisions under the RMA, but it has not yet been enacted. The processes described rely upon a quasi-legal context for resolution which is not conducive to problem solving in the sense that community-based solutions can be proffered, discussed and resolved (Ruhl, 2010). The experience of the Land and Water Forum (Land and Water Forum, 2012) shows that even where the latter takes place and broad consensus is arrived at, its implementation must still go through the legal processes in the institutional framework. Also, governments have the ability to pick and choose recommendations and can thus trump consensus reached within the processes. These processes in themselves, therefore, do not make the framework adequate for enabling understanding of the values of communities and of changing circumstances like climate change; other mechanisms will be needed which will be discussed in Chapter 8 .

\subsection{Conclusions}

Precaution and risk are the primary drivers of the current framework. While uncertainty is implicit in the framework, dynamic change over long timeframes is not anticipated in any explicit way, except for post-hoc consideration under the CDEMA. However, consideration of dynamic change is not ruled out, but is dependent on the measures used to implement the framework. Adaptive management is not ruled out within the framework either, but it is not explicit as an underlying theory.

The NZCPS stands out as one part of the framework that anticipates change to more sustainable solutions and potentially to transformational change, by foreshadowing 'transitions' to address 
changing risk. Transformational change is not contemplated in the framework except for this implicit suggestion in the NZCPS.

Guidance provided from the national level of government encourages a precautionary and riskbased approach to planning for coastal and flood management and contemplates changing risk over time in its technical recommendations. The guidance on RMA section 32 assessments is riskbased but, while acknowledging the need for flexibility, it is silent on dynamic change over time. It does, however, signal the importance of considering timeframes and thus the lifetimes of activities are envisaged for consideration. However, the guidance directs decision makers towards a two-dimensional framing of risk, thus emphasising static risk assessment that has potential maladaptive implications for the future. Where change over time is signalled, how this can be done within the decision-making context, is less clear. The national guidance has no statutory authority, except where used by the courts as general guidance in particular circumstances.

The CDEMA is quite explicit about both precautionary actions and risk management, but its focus is primarily on readiness, response and recovery; risk reduction is envisaged as happening under the RMA, and the linkages between the two management regimes are weak.

The LGA has adopted precaution and risk management for long-lived assets, and the BA is explicit about risk management, but within a focus on building integrity for public safety. It is weakly linked to land-use planning. The SC\&RCA, while implicitly addressing precaution and risk, is also weakly linked to the RMA, and has a predominant focus on hard structural measures for 'protecting' those at risk of flooding. This limits its utility for consideration of adaptive or transformative change, because it can lock in status quo development patterns.

Overall, the framework has many parts that address uncertainty and, potentially, dynamic change. The framework is highly fragmented and devolution adds to its fragmentation and complexity. There is potential for the actors at different governance scales to 'cherry-pick' parts of the framework, due to the non-mandatory status of some instruments; for example, NPS, NES, guidance, information and regional rules. The institutional framework sets up the potential for inconsistency of practice across governance scales and across the country. This means that the framework, has the potential to be an inadequate guide for climate change adaptation decision making for sea-level rise and increased rainfall frequency and intensity. The adequacy of the framework, however, cannot be fully tested without an assessment of how it is implemented in practice. 


\section{Chapter 6 The practice and its adequacy}

\subsection{Introduction}

Practice in this thesis refers to how the institutional framework is implemented through the hierarchy of instruments available in the statutes, how governance roles and responsibilities are exercised across scales and how organisations, practitioners and decision makers operate.

New Zealand practice occurs within the constraints of a physical environment that is very exposed to climate-related damages. Sixty-five percent of the population and much critical infrastructure is located within five kilometres of the coast (Statistics New Zealand, 2010). More than 100 cities and towns are located on flood plains, exposed to sea-level rise and increased flood frequency and intensity from climate change. Development in coastal areas and on flood plains has intensified as communities have become more affluent (Reisinger, Lawrence, Hart, \& Chapman, 2015). The value of development has risen and private property right expectations have entrenched risk. This is despite the statutory responsibilities that have existed in law for many decades to avoid and mitigate natural hazards and to inform communities about them.

Chapter 5 set out those elements of the institutional framework that could, in principle, address uncertainty and dynamic climate change. However, it would appear from the evidence on the ground, that either the institutional framework or the practice under it (or both), have not been effective in curbing expansion and intensification of development in areas at risk from sea-level rise and flooding. Practitioners had mixed views about whether it was the framework or the practice that limited consideration of uncertainty and dynamic change. This was summed up by the following respondent comment:

The statutory framework just doesn't let you address the dynamics of changing risk over time. The whole framework needs to be better integrated, with greater flexibility and with greater use of national instruments and support like better funding mechanisms for retreat and for risk mapping. [Unitary council strategic manager]

As New Zealanders' reliance on interdependent technology and infrastructure grows, vulnerability to failure from external and internal causes also grows, including from climate change (Department of the Prime Minister and Cabinet New Zealand, 2007). Flooding is currently the most frequent natural hazard experienced in New Zealand (Ministry for the Environment, 2008c). The incidence of a major flood on average every eight months (Ministry for the Environment, 2008c, p. 1) comes at a significant cost. For example, the estimated costs of the damaging 2004 floods were $\$ 380$ million (2006 dollars) (Department of the Prime Minister and Cabinet New Zealand, 2007, p. 62). 
Coastal squeeze between development and an advancing sea, increasing frequency of storm events and flooding as a result of climate change raise the prospect of the costs and societal disruption of such events becoming worse. Climate change adaptation is a relatively new issue for decision makers at all levels of government. But local government is not without experience addressing the consequences of climate-related extreme events like coastal erosion and inundation, riverine and surface flooding and related landslips, all natural hazards likely to be exacerbated by climate change.

As concluded in Chapter 5 assessing the adequacy of the institutional framework also requires examination of how the current practice addresses current and future changing climate risks. Thus, how the adaptation decision-making practice delivers on the intention of the framework, and whether and how practice is adequate for addressing uncertainty and dynamic climate change, is now assessed.

The practice is presented first, based on data collected from practitioners and decision makers at interviews and workshops at a selection of central, regional and local units of government in New Zealand, and from relevant documents. As discussed in Chapter 3, the data collected was coded by consistency of theme, across the wide range of participant respondents. The resulting analysis drew from those responses that were shared by the majority of respondents. These are reflected in the quotations, tables and boxes used for illustration of the themes that emerged. This evidence is presented in three sections representing the categories of decision-relevant issues derived in Chapter 4: a) understanding and representing uncertainty and dynamic climate change characteristics; b) governance and regulations; and c) organisations and actors. These categories are applied here to the practice expression of the institutional framework; in Chapter 5 they were applied to the institutional framework itself.

Understanding and representing uncertainty and dynamic climate change characteristics relates to how such characteristics are understood by the practitioners and decision makers and how the measures used in decision making reflect uncertainty and dynamic climate change.

Governance relates to how the governance form, for example its multi-scale nature, affects practice. Regulations relate to how the roles and responsibilities are exercised through processes and implemented through measures.

Organisations and actors relate to how organisational form and function and actor characteristics influence decision making. These categories are not mutually exclusive, since each interacts to a 
greater or lesser extent. They are used to provide a structure for presenting the practice and identifying the primary location of barriers to adequate practice.

Having discussed the practice evidence, the adequacy of the practice to address uncertainty and dynamic climate change in adaptation decision making is assessed, using the 12 criteria derived from the concepts of precaution, risk management, adaptive management and transformational change developed in Chapter 4. The barriers that emerged from the adequacy analysis provide the basis for identifying enablers, entry points and improved framework elements and practices and are discussed in Chapter 7.

\subsection{The practice evidence}

\subsubsection{Understanding and representing uncertainty and dynamic climate change-the practice}

Understanding and representing climate change risk are interrelated. The understanding and representations can be detected in the way climate change data are presented, how information is managed and accessed and how climate risk is monitored. The implications can be seen in the design of institutional practices and in adaptation decision making. These findings were derived from the literature cited in Chapter 2 on climate change characteristics and a document analysis. How the research participants understood the climate risk and its representation was gauged at workshops and through interviews by asking how uncertainty affected their consideration of climate change effects and through discussions about the availability of data and the type of data and information they could access. The full range of views were assessed through a thematic analysis (described in Chapter 3) and a pattern emerged which is now discussed.

\section{Uncertainty and dynamic change}

Uncertainty was perceived as an undifferentiated concept. Respondents consistently did not express awareness of the different types of uncertainty in climate projections and, in particular, of irreducible uncertainty and dynamic change or its decision significance. Also, respondents consistently made no distinction between knowing the trajectory of change and not knowing how it will manifest. For many respondents, uncertainty and changing climate risk signalled 'caution'. Their reactions to climate change risk and caution revealed two main patterns: either climate risk was left out of consideration because it could not be included in quantitative risk assessments, or they believed that further research would resolve the uncertainties.

Respondents described as challenging, the prospect of translating a trend that has large variability, into measures that reflected such change over time. This was regarded as too difficult, or impossible, as shown by the following practitioners: 
How do you change - adapt_-your time frame when it turns out that the one you had is inadequate? For example, when the changes in the natural environment require you to adapt quicker, revise the input information into planning in shorter intervals or trigger a plan revision earlier than after a major destructive event. [Research scientist]

We use the MfE guidelines, but these talk about a far too low temperature increase. So the challenge is to get that uncertainty up there to the developers and central government to acknowledge that there is this 'tail' and the change in temperature or sea level could be much higher. The challenge is to get measures in place where everyone is required to use a sort of 'minimum climate change scenario'. The other challenge is that the climate science information that is being used to develop such guidelines or regulations is getting out of date too. We need to keep up with the new information that arises and we need to integrate it into our legislation, both prescriptive and intent-based legislation. [Consultant engineer]

Such comments, were made consistently by practitioners and in the documents reviewed and showed why risk assessments did not reflect change over time, and thus why they continued to use static measures for protection at the coast or along rivers.

Councils that had undertaken assessments of climate change risk included Hawkes Bay Regional Council, Kapiti Coast District Council, Auckland Council, Wellington City, Dunedin City, Christchurch City and Canterbury Regional Council. However, some councils had only recently included assessment of sea-level rise and storm surge; for example, for coastal hazard risk in the Wellington Region by Bell and Hannah (2012). Such assessments were typically undertaken by a small number of New Zealand-based consultants, or by the National Institute of Water and Atmospheric Research (NIWA) using NIWA scenarios downscaled from IPCC scenarios. The larger city councils undertook sea-level rise assessments using external consultants; for example, Christchurch (Tonkin and Taylor, 2013a) and Wellington City (Tonkin and Taylor, 2013b) Councils, while Dunedin City Council undertook a higher-level scan of climate change risks (Fitzharris, 2010) which suggested priority issues for council attention.

Examination of such reports showed that they commonly leave the uncertainties hidden in the analysis and thus have potential for mischaracterisation of the risk. For example, one of these assessments used a single sea-level rise scenario for 'pragmatic' reasons based on a single 100year sea-level rise scenario to the year 2115 (Tonkin and Taylor, 2013a, p. 2) and two simplistic heuristics were used that both obscure the uncertainties. For example, the report states that "sea- 
level rise can be simply added to the present day storm tide levels for predicting future extreme inundation levels" (p. 30) and freeboard added to account for "localised wave effects and other uncertainties" (p. 30). Reasons given for this approach were that storm surge is a major component of coastal inundation but future storm surge will depend on the frequency and intensity of low pressure systems driving storm events about which there are significant uncertainties due to climate change over the next 100 years; and that tidal characteristics are expected to be unaffected by future sea-level rise (although others note that this will depend how much sedimentation keeps pace with sea-level rise). ${ }^{37}$ The report gives the impression that all uncertainties are accounted for; but they are obscured by using one scenario of the future and by using simplistic heuristics.

The approach for characterising sea-level rise risk was, during the course of this thesis research, evolving rapidly. For example, evidence given at recent district plan changes and consent appeals for subdivisions combines storm tide and wave height in a 'joint probability' (Goring, Stephens, Bell, \& Pearson, 2011) and then adds wave run-up or overtopping acknowledging the secondary uncertainties. This approach was recently adopted in a subdivision appeal to the Environment Court. ${ }^{38}$ The appeal was dismissed on the grounds that allowing the subdivision

is not an efficient use and development of the natural and physical resources of the area as it proposes the addition of significant further assets to the property thereby increasing the risk of exposure to coastal hazards contrary to the provisions of Objective 5 and Policy 25 of the NZCPS. (para. 181)

The use of 'freeboard' to address uncertainties such as sea-level rise and storm surge is inappropriate, since it combines two allowances: freeboard proper is the allowance above design levels that accounts for modelling error and physical uncertainty, such as that associated with the integrity of a seawall or a levee. It should not be used for any additional allowance for sea-level rise and storm surge [Engineering consultant]. Rather, it should be used to set floor levels to cover secondary or residual flow effects. ${ }^{39}$ The Environment Court case cited above also demonstrated that, where standardised approaches are absent and a number of expert witnesses give contrary evidence, the court is placed in the difficult position of having to unravel which evidence to use; a situation that could be assisted by an NES.

\footnotetext{
${ }^{37}$ R.G. Bell, NIWA, personal communication, 2015.

${ }^{38}$ Gallagher v Tasman District Council, Decision No: [2014] NZEnvC 245,.3 December 2014

${ }^{39}$ R.G. Bell, NIWA, personal communication, 2015.
} 
Decision makers also have difficulty when the information base is changing, especially at the extremes, and they want to apply a precautionary approach to coastal decision making that is consistent with the New Zealand Coastal Policy Statement (NZCPS). One climate scientist noted:

We have known for quite some time that there is this 'tail risk' - the information exists-but it seems that it's only now that this is starting to be taken into account in decision-making.

...but councillors are assessing the MfE guidance in terms of what is at stake politically over the near term. [City council planner]

The juxtaposition of extreme events with low probability, and short-term focus of some decision makers emerged as a theme across the interviews and workshops. There was a desire by practitioners to better understand the uncertainty and be able to represent it in ways that could be understood by decision makers to enable planning over longer timeframes. How this was being done is discussed in the next subsection.

Even where relevant climate information was available, practitioners reported that there was a reluctance on the part of decision makers to apply the information to decision making and to address the full range of implications, due to perceived uncertainty about climate change and its effects. Given the diverse understanding of climate change risk in communities and amongst decision makers, one practitioner at a workshop expressed the common view that, "it appears an unrealistic expectation that some sort of consensus might be possible across interests". There was some scepticism expressed at workshops by a minority of decision makers about anthropogenic climate change, and a lack of understanding was exhibited about councils' responsibilities for considering the effects of climate change. Fear of legal challenge from aggrieved property owners, given the 'uncertainties', was reported by participants as creating inertia within some councils to consider climate change impacts and address their consequences.

Decision makers at the Nelson City and Tasman District Council workshops expressed a shared view that the different degrees of knowledge about climate change, different attitudes and values amongst them and the pressure of electoral success made it difficult to address climate change adaptation head-on (Lawrence \& Manning, 2012). Wellington City and Hutt City council participants described practice that focused on a small range of options, with the full consequences of those options not presented or discussed before the options were chosen. Wise et al. (2014) also note this tendency to narrow down the options early. It was reported that such results were used as 
the 'acceptable' option. These examples show that uncertainty and dynamic climate change characteristics are not well understood.

Practitioners also reported that public pressure, or public contestation from private interests, were dominant drivers of decisions and their timing. When the political stakes and uncertainties were high, practitioners would "pick a number for simplicity" [District council engineer] and thus "discount the long-term risk implications and embed a sense of unfounded security in decisions for activities that endure over long time frames" [District council strategic planner].

The simplification of climate change information for decision makers was a common theme across the practice. This was typically done by using averages or single estimates of climate parameters, or by using one scenario as a proxy for the future. Simplification was compounded in the flood management context, by projecting past experience forward to the future. This had the effect of playing down uncertainties and not reflecting the extremes or frequency changes in the future associated with climate change.

\section{How data, information and monitoring affect understanding of climate change risk}

Understanding climate change risk is dependent on up-to-date and accessible climate data and its presentation that reflects the characteristics of the risk. Data and information sources were fragmented across several science providers, government agencies and consultants. Data fragmentation constrained practitioners' and decision-makers' ability to assess climate risk and monitor change. Each council was commissioning modelling, impacts studies and options analyses when there were common elements of interest across all councils. The lack of a national approach to such assessments and analysis and the absence of a repository of information relevant to climate change adaptation led to the 'wheel' being reinvented each time a council undertook its own study. Practitioners considered this an inefficient way of local government discharging its responsibilities, opening them up to litigation over the adequacy of their databases for decision making. Evidence of such litigation includes a High Court challenge to the use of hazard risk information in a coastal context. ${ }^{40}$

Practitioners reported inconsistency of practice emerging across New Zealand which was exacerbating risk and creating inequalities, depending on the vulnerability of each community and its ability to resource such studies. Contributing to this was the interpretation of the risk-based approach promoted in central government guidance (Ministry for the Environment, 2009, 2010) in terms of physical impacts, rather than social and cultural vulnerability. Monitoring of changes

${ }^{40}$ Weir v Kapiti Coast District Council, [2013] NZHC 3522, 19 December 2013. 
in risk was weakly developed and highly variable across New Zealand, depending on the size and capability of councils, and the availability and type of information available nationally.

A common practice used in flood management was to update the databases after each major climate event as described by Williman (2010) (a regional council flood engineer) by assessing the damage consequences and updating return periods, thus managing change over time post facto. While necessary to protect design levels of flood schemes as constructed, this approach does not anticipate extreme events above design levels, nor changes in flood frequency over time. One flood management consultant noted that, while some regional councils do this routinely after flood events in major rivers, such updating of data usually happens only when reviewing major flood protection schemes every 10 years, and often at longer intervals, making it a static approach in time and space. The erosion of design protection over time, with changed frequency of flood events associated with climate change, was weakly understood by many of the spatial planners interviewed and at the workshops and was not integrated into planning practice. One planner demonstrated this by the comment that areas protected by flood levees were "risk free".

Despite new sea-level rise information being available that clearly identified uncertainties at the upper range of projections, councils were still taking a number as though it was the upper limit; a practice inconsistent with the uncertainties (Church et al., 2013a; Hinkel et al., 2015).

The fragmented and ad hoc approach to collection of climate change risk was affecting how the participants understood climate risk. There was little evidence found that uncertainty and dynamic climate change characteristics were being systematically included in decision-making processes by councils, although that was beginning to change during the course of this research amongst some councils through expert evidence from scientists. The practices presented here demonstrate a lack of understanding of the uncertainty and dynamic climate change characteristics.

\section{Communication of uncertainties and dynamic change}

The way climate risk was being communicated conveyed unrealistic certainty and precision about climate change risk. Perceptions of certainty arise when averages, best estimates or single numbers are used in place of a range of outcomes, including extreme outcomes. Certainty perceptions are exacerbated by probability formats that do not convey the long-term nature of a changing and nonlinear risk. For example, some practitioners commented that the Building Code's 2\% AEP or 1:50 year recurrence interval per year was inadequate for planning purposes, since most buildings last at least twice a building's 50 year design life. Increased flood frequency was routinely omitted in the design of planning measures. Instead, static instruments were used, such as hazard lines on 
maps, to denote risk with rules to avoid damages, even though these were uncertain and could be misinterpreted as conveying safety.

Some communication of probability created misunderstanding of risk exposure (Lawrence, Quade, $\&$ Becker, 2014). This occurred when only one or a few scenarios of possible future climate change were used. Consequently, only a small range of response options was available in the decision processes. Restricted options suited decision-makers' to close off options early to meet decision deadlines, as highlighted in the previous sub-section. Evidence of this practice came from practitioners, council papers, and plans and council committee meetings. Nevertheless, practitioners were observed by me at council meetings keeping all options on the table through the advice they gave to decision makers.

\section{$\underline{\text { Toward better practice }}$}

Some advances in practice were observed during the course of this research. The Auckland Council's Unitary Plan hearings process began in 2015 and there is expert evidence to be heard on coastal hazard risk ${ }^{41}$ that closely follows the approaches to uncertainty management suggested by Hinkel et al. (2015) and Church et al. (2013a) who point out how an upper bound or high-end scenario for sea-level rise can be applied in coastal risk management practice. Such an approach has already been applied to the Thames Estuary 2100 (TE100) by Ranger et al. (2013 ). It has the potential, if accepted in the Auckland Unitary Plan, to create a new basis for avoiding future climate change impacts in Greenfield sites and thus act as a circuit breaker to path dependency. However, to date, it was evident from the research that such approaches are being introduced in an ad hoc fashion through Plan and consent hearings and are not yet reflected in national guidance.

In a flooding context, Lawrence, Reisinger, et al. (2013) showed that highlighting 'tail risk' and uncertainty using diagrams similar to Figures 2.2 and 2.3 in Chapter 2 had the effect of shifting understanding of the decision significance of uncertainty and dynamic climate change amongst flood risk management engineers and decision makers in the Wellington region. This understanding subsequently translated into use of the dynamic adaptive pathways approach for anticipating change (Haasnoot et al., 2013). ${ }^{42}$ This approach is based on a visual representation of change over time in this case, using a 'metro map' indicating decision points where course correction will be necessary in the future. The approach thus addresses uncertainty in the decision

\footnotetext{
${ }^{41}$ See Auckland Unitary Plan Hearing 022 Natural hazards and flooding. Evidence by R.G Bell and S. Stephen at https://hearings.aupihp.govt.nz/hearings

${ }^{42}$ This has occurred at the Greater Wellington Regional Council. Such application of the Dynamic Adaptive Policy Pathways approach in New Zealand is part of a partnership between the New Zealand Climate Change Research Institute and Deltares, undertaken by Judy Lawrence and Marjolijn Haasnoot.
} 
context and flexibility in the responses. An important lever for changed practice in the Wellington regional case was the use of a serious simulation game. ${ }^{43}$ Using the game enabled council practitioners and decision makers to experience decision making over long timeframes under uncertain and changing conditions. This has begun to change the current practice of using historical data and extrapolating it forward as noted by one of the practitioners:

We used to take historical data and extrapolate and it worked! So they [council decision makers] have a real hard time to change that approach. It's a challenge to make that head-change! [District council strategic planner]

There were other innovative approaches for addressing uncertainty and dynamic change used by other councils. The Canterbury Regional Council framed climate change within the context of weather events already experienced, and which will get worse. The practitioners highlighted the council obligations with respect to weather and climate impacts and the economic implications of climate-related risks (R. Cooper, Environment Canterbury, personal communication, 2014). By so doing, council got a better appreciation of climate change as an exacerbator of risk. The Tasman District Council used chance and lifetime concepts to explain risk probabilities to the community: 1 in 4 chance of a 100-year event in the next 30 years; or a $63 \%$ chance that an asset with a 100year life-span will experience a 100-year ARI event (L. McGlinchey, Tasman District Council, personal communication, 2012). For the Takaka flood management plan this opened up consideration of community experiences of flooding and related them to what is likely in the future.

These examples demonstrate a nascent shift in practice that reflects an understanding of uncertainties in coastal settings and in human behavioural characteristics in decision-making settings as discussed in the literature in Chapter 2: framing risk through experience of decision making under conditions of uncertainty (Van Pelt et al., 2015 ); bringing the consequences of climate change forward by locating it in the present as an experienced risk (Evans, Milfont, \& Lawrence, 2012); and framing activities with respect to their lifetime (Stafford Smith et al., 2011). The practice shift identified has enabled participants to relate to the risk and thus understand the decision relevance of uncertainty and dynamic climate change.

\section{Summary}

Understanding and representing uncertainty and dynamic climate change characteristics is weakly developed in practice. The themes that emerged included: a low level of understanding of the

\footnotetext{
${ }^{43}$ The Sustainable Delta Game developed by Deltares and partners in the Netherlands.
} 
decision significance of uncertainty and dynamic climate change characteristics; a reluctance by practitioners and decision makers to represent such characteristics and use a range of future scenarios that might result in inaction because of the uncertainty conveyed; the use of simplistic heuristics of the future which concealed extremes in climate and their implications for future generations; fragmented information sources and inconsistent data used across councils; each council reinventing the wheel through individual assessments and decisions, thus creating inconsistencies and inefficiencies in undertaking climate change adaptation. The result was shown to be increasing path dependency by misrepresenting future consequences of climate change and creating a false sense of security (Lawrence et al., 2014). Scientists with new knowledge about sea-level rise and flood risk were using council hearings and informal processes to integrate the knowledge into decision making. Also councils were beginning to use their understanding of human behaviour to reframe the risks in ways that could be understood to enable more flexible measures to be adopted.

\subsubsection{Governance and regulation-the practice}

Governance relates to how the governance form affects practice; for example, how the governance scales influence the way climate change risk characteristics are addressed and whether instruments at each scale are exercised. The governance arrangements define roles and responsibilities in the statutes and thus define the location of regulatory practice. Regulations relate to how the roles and responsibilities are exercised through processes and implemented through measures.

\section{Governance-the exercise of roles and responsibilities at multiple scales}

The governance arrangements are set out as assigned roles and responsibilities at multiple governance scales - national, regional and territorial local government. Overlapping roles and responsibilities were observed and considered by the research participants as complicating consideration of climate-related risks and hazards management. The balance between where decision making has been exercised at the different levels of government has shifted over time, largely in response to governance crises, pressures on natural resource allocation, climate-related events or with the political ideology of the time (Lawrence, Wolf, et al., 2013). Over the last five years, as the RMA processes have been streamlined through successive amendments, ${ }^{44}$ more decision making has been undertaken at the national level. For example, the establishment of the Environmental Protection Agency in 2011 provided for consents to be heard in the first instance,

\footnotetext{
${ }^{44}$ Resource Management (Simplifying and Streamlining) Amendment Act 2009 and the Resource Management Amendment Act 2013.
} 
instead of at local government level, for matters of national significance (such as major roads, water projects, energy supply projects and salmon farms).

The degree to which each level of government exercised its climate-related functions and responsibilities depended on the perception that the decision makers had of their community's wishes, as expressed at the polls, pressures from specific interests and through formal consultative processes. This was demonstrated in the Kapiti Coast district, when the electorate voted a council out at the 2013 elections following the council applying coastal hazard information to Land Information Memoranda and as a basis for stricter planning controls in a proposed district plan (Allan \& Fowler, 2014). An independent review following a High Court decision on the use of the hazard information ${ }^{45}$ recommended that the hazard maps and the draft spatial plan be withdrawn for reassessment and community dialogue (Allan \& Fowler, 2014; Carley, Komar, Kench, \& Davies, 2014). This was subsequently done and further consideration is underway.

How central government addressed climate change adaptation emerged consistently as an important influence upon whether, and to what extent, local government addressed long-term climate risk. No National Policy Statement (NPS) or National Environmental Standard (NES) has been developed for sea-level rise or flooding affected by climate change, nor for climate change adaptation. Voluntary guidelines only have emerged from central government, as discussed in Chapter 5. Practitioners considered that an NPS similar to the NZCPS for climate-related hazards was necessary to enable them to defend land-use controls in court following property owner or community challenge. Where territorial local authorities (TLAs) attempted to constrain land uses through plan rules, practitioners and decision makers described how they felt the full brunt of community concern about controls over private property interests and land values (e.g., Kapiti Coast District Council).

However, central government has remained staunch in only providing light-handed guidance to councils at both levels of local government, not wishing to 'direct' local government, a stand historically supported by regional councils and the Ministry for the Environment (Logan, 2013). The fragmentation of functions has led to different agents within and across governance scales doing different parts of the practice or, in some cases, not using instruments at their disposal. For example, despite an NPS on flooding having been drafted in 2009 following a flood risk review undertaken by the Ministry for the Environment (Ministry for the Environment, 2008c), it was never progressed to the statutory stages. Also, regional councils have not actively promulgated

\footnotetext{
${ }^{45}$ Weir v Kapiti Coast District Council, High Court of New Zealand NZHC 3522, 19 December 2013.
} 
rules in regional plans (e.g., Otago and Wellington) to control existing and proposed land uses as new climate change information is made available. This has created a lack of integration and has reduced the ability of the Environment Court to apply regional rules when assessing subdivision and building consents that are taken to appeal ${ }^{46}$ (Kenderdine, 2010).

Better integration between regional and district levels of government was called for by local government respondents to provide more robust support for the development of climate change rules in district plans, in part, for the reasons outlined in the following comments:

There seems to be the situation that all individual councils are spending money on it. A combined approach may be a good idea to share resources. For example, just the expertise present in this room here right now could be a solid basis to draw from. [Emergency manager]

A national agency participant observed that “all the statutory tools are available but they aren't all used and they aren't well integrated across council functions". Another commented that the decision-making process tended to drive different types of proposals in a council against each other, rather than there being a framework for integrated decision making.

Local government has been largely left to work out the implementation methods using its devolved powers and voluntary guidelines from central government. The weak signals from central government on climate change adaptation stemmed back to the separation enunciated by government in the 2004 RMA amendment (see Appendix 2) between climate change mitigation (greenhouse gas reduction domestically through an emissions trading system, and international policy) responsibilities at central government level, and climate change adaptation at local government level through consideration of the effects of climate change (see 2004 amendment to the RMA in Appendix 2). Nevertheless most regions do not have binding regional rules to guide land-use decisions that could anticipate uncertainty and changing risk levels. Regional council climate hazard planning functions are applied through regional policy statements (RPSs) and plans, and the provision of hazard information on which the detailed land-use controls could be formulated by TLAs. Where climate change risk had not been regionally identified, or policies and rules had not been promulgated through an RPS or a plan (the norm), TLAs struggled to develop land-use planning rules that anticipate changing climate risk.

An example of regional rules is shown in Table 6.1 and must be given effect by district councils. This was a deliberate design feature of the RMA to foster consistency of approach between regions

${ }^{46}$ Otago Regional Council v Dunedin City Council [2010] NZEnvC 279, 12 August 2010. 
and districts (Randerson et al., 1990). Some regional council respondents reported that their councils haven't wanted to direct TLAs, especially where existing land uses are at risk (e.g., Otago and Wellington Regional Councils where no regional rules exist for hazards or climate change effects). TLA respondents on the other hand expressed a desire to have more specific direction from regional rules and NPSs on climate change risks and other natural hazards to support their local-level efforts to manage current and future climate-related hazards. Kapiti Coast District is one such council where this was expressed. Its failure to successfully promulgate local-level rules on coastal hazards and climate change effects was in part due to the absence of regional rules. TLA respondents also reported that, without regional rules, it was difficult for the NZCPS to be implemented; having regional rules reduced any ambiguity about implementation of rules by TLAs that address "climate change effects". The significance of regional rules was highlighted in an Environment Court decision where such rules were absent. ${ }^{47}$ This resulted in a development being allowed in a locality that was highly exposed to flooding and sea-level rise that will be exacerbated over time. This particular case demonstrated lack of integration between a regional and a city council's policies, plans and rules, reflected in frustration expressed by the practitioners:

For me, it is really frustrating to have lack of integration, wasted effort, massive gaps, doubling up. This is a local government structural issue, and an argument for greater effectiveness if the regional efforts were coordinated in a more systematic way. [Regional council strategic planner]

It [climate change] doesn't feature in cross-council shared services priorities. [City council asset manager]

Some attempts at integration across multiple governance scales have been made to develop crossregional hazards plans that incorporate climate change, but some have foundered. After several attempts had foundered in the Wellington region, another attempt began in 2014 (Wilde, 2014):

We need to work together to achieve this so the four city councils in the regionPorirua, Wellington, Hutt City and Upper Hutt - and Greater Wellington Regional Council, will work on the development of an integrated hazard management...

The strategy will mean that local authorities will not have to 'reinvent the wheel' when it comes to natural hazards. We will have a regional framework that we can use, when we are putting together district and regional plans and will be able to work 
seamlessly across the region when responding to natural events. [Chair, Greater Wellington Regional Council]

In 2014, two city and regional groupings of councils initiated a more collaborative and seamless process for the provision of hazard information, strategic consideration of hazard risk affected by climate change and the development of more comprehensive regional and district planning controls (Dunedin and Otago Regional Council, and the TLAs in the Wellington region and the Greater Wellington Regional Council).

There was some evidence that the governance form may help integration across roles and responsibilities. Unitary councils with combined regional and district functions that have staff of long-standing have been able to implement measures to address climate risk more readily than regional or district councils by themselves. For example, Tasman District Council (a unitary authority with both regional and district functions and powers) successfully concluded the implementation of coastal hazard land-use controls with minimum contestation and recourse to the courts, ${ }^{48}$ in part, because land-use planning and coastal hazard management could be integrated under the one governance arrangement.

Other factors identified by participants that contributed to successful implementation of regulations included having a comprehensive and strategic approach to addressing climate risk over at least 10 years; political leadership and experience of repeat climate events; and where engagement processes using interactive means of communicating the characteristics of the climate risk have been used.

The separation across the different roles between levels of government was a consistent theme to emerge. Some regional councils thought that hazard risk considerations in planning instruments were the preserve of the district councils and this was reflected in their hazard plans (e.g., Otago and Greater Wellington Regional Councils). On the other hand, Hawkes Bay Regional Council developed a detailed plan with regional rules in a Regional Coastal Environment Plan that has to be implemented at the district level. In other cases, both regional and territorial councils address climate change risk (e.g., Canterbury Regional Council and Christchurch City Council), but differently. In the former case, Canterbury Regional Council used specific rules to limit replacement and extension of existing uses based on coastal erosion hazard, while the Christchurch

\footnotetext{
${ }^{48}$ Gallagher v Tasman District Council, Decision No: [2014] NZEnvC 245, 3 December 2014
} 
City Council focused on a number of natural hazards related to riverine flooding, sea-level rise and coastal inundation in specific locations individually.

There was some practice that sought to make linkages between functions like flood control and land-use planning or between different functions within council functions; for example, linkages between natural hazards planning and sea-level rise. But there were few linkages made between increased flood frequency and intensity associated with climate change and flood risk management, or between climate change and recovery after climate emergencies, or for asset planning.

\section{$\underline{\text { Towards better integration }}$}

Attempts have begun to better integrate practice. Wellington City Council, after an extreme event, linked several council functions by examining the effects of sea-level rise on options for seawall repair following severe storm damage at Island Bay, Wellington City Council.

After the June 2013 storm we placed a temporary rock barrier in the broken section of seawall to protect the footpath and road, and this will remain in place for the time being. Before we decide to reinstate the wall, the Council is working with the Island Bay community to look at possible changes to the beach and foreshore. Our consultation with the community so far has shown there is strong interest in reconsidering the future of Shorland Park and the beach area, and in exploring the feasibility of softer engineered options that could better cope with storm surges and rises in sea levels. ${ }^{49}$

This response occurred reactively, rather than proactively, but nevertheless started a process that could lead to integration of consideration of uncertainty and dynamic climate change into decision making. This example showed leadership by practitioners and decision makers and opened up opportunities for public engagement on long-term climate change risks.

In 2011, practitioners considered a combined approach as unlikely to happen, or even unthinkable under current governance arrangements, as reflected in the following comment by a regional council engineer: "You're talking about a combined district plan!"

But by late 2012, momentum gathered for governance reform (Palmer, Driver, Gardiner, \& Jackson, 2012) and by 2013, the Local Government Commission was considering reform proposals in several regions of New Zealand (Local Government Commission, 2014) and by 2015,

${ }^{49}$ Refer http://wellington.govt.nz/your-council/projects/island-bay-seawall-replacement 
several of these have been proposed. ${ }^{50}$ Proposals to amalgamate district and regional functions into new unitary authorities would have the effect of combining planning across the two levels of local government with regional strategy guiding local land-use decisions and thus enabling regional and district functions to be better integrated.

Linked to local governance reform were proposals to further amend the RMA to require greater consistency of planning. Suggested changes included clearer national direction and tools; a single local resource management plan that addresses future environmental and development priorities and covers all local, regional and national issues, replacing the range of planning documents that exists today; and comprehensive management of natural hazards in planning and consenting (New Zealand Government, 2013). These amendments have not yet been enacted but are proposed for progression during $2015 .^{51}$

\section{$\underline{\text { Regulatory practice }}$}

A consistent theme to emerge from respondents was that each council was "doing its own thing" and that there was no accepted generic practice under the institutional framework. This is illustrated by the following participant observations:

There is no 'current approach' as everyone uses different approaches. [Regional council engineer]

There is an absence of a best practice model plan or approach that particularly small councils could use off-the-shelf, especially where scientific information involves ranges of outcomes and uncertainties. [Strategic planner]

However, on closer examination, it became apparent that the actual practices were entrenched in the operating traditions of professional disciplines that use standard methodologies or the recommended risk-based approaches to consider uncertainty and dynamic change (AS/NZS ISO 31000, 2009; Ministry for the Environment, 2008b; NZS 9401, 2008; Woods et al., 2010). These are discussed further in Section 6.2.3. The focus of assessments and the data on which they are based is discussed in Section 6.2.1. The focus in this subsection is on how that information is used through the regulatory system to address uncertainty and dynamic climate change.

Regional and district plans and coastal environmental management plans that did address climaterelated coastal hazards all adopted measures that were variations on risk-based progressive hazard zones with distance from the coast, and rules that reflect risk and consequence to control different

\footnotetext{
${ }^{50}$ Refer to http://www.lgc.govt.nz/

${ }^{51}$ Refer to http://beehive.govt.nz/release/rma-reform-agenda-outlined
} 
types of activities. Measures reflected in rules included stopping an increase in the footprint of existing dwellings (Tasman District Council), or requiring floor levels to be raised above a defined flood level or sea level (Auckland Council) or requirements for removable buildings (Kapiti Coast District Council). The Hawkes Bay Regional Coastal Plan includes all three of these methods (Hawkes Bay Regional Council, 2012). Consideration of the effect of sea-level rise on flood management in the lower reaches of catchments, is a recent practice in the preparation of statutory (land-use) and non-statutory (flood management) plans by Canterbury and Wellington Regional Councils, but not undertaken routinely by other councils. The interaction of sea-level rise with groundwater (McGranahan et al., 2007) has not hitherto been considered in coastal zone or flood risk management in New Zealand practice, even though these effects could be felt (Manning, Lawrence, King, \& Chapman, 2015).

Climate change consideration in flood risk management has lagged behind consideration for coastal settings. For consideration of flood flows affected by climate change, councils use the Ministry for the Environment guidance (Woods et al., 2010) as a 'rule of thumb', but reported difficulties using the guidance. Reflecting a range of future scenarios when analysing response options or defining measures in the regulatory setting was especially problematic, explained by practitioners as due to the 'certainty' of evidence required within the regulatory processes. There was a view held by most of the respondents that the institutional framework did not enable rules that could include a range of possible climate change outcomes.

These difficulties in translating the climate change characteristics into regulatory practice have led to the choice of static measures for flood 'protection'. For example, typically used protection structures (levees) and hazard lines in plans, by definition, are static in time and space. Their design is typically based on a limited assessment of the probability of specified events in the future to represent likely future climate conditions. The IPCC has made probability statements for sea-level rise (Church et al., 2013a) and the Ministry for the Environment guidance recommends consideration of higher sea-level rise conditions for planning existing and new long-lived assets (see Chapter 5). However, there are no such probabilities assigned to future flood events. The guidance for flood flows recommends use of scenarios, suggests heuristics to reflect change in risk and recommends that decisions be taken that reflect the level of 'acceptable risk' based on expert judgement; but the practice evidence observed and discussed with participants does not reflect this guidance. The implications of the practice, are that likely future climate conditions and potential damages are being misrepresented with climate risk is consequently entrenched. 
Cost-driven decision making was another theme to emerge that had consequences for consideration of climate risk:

The two basic pieces of local government legislation contain very explicit guidance about decision making with financial aspects included as one of the most important ones. That is, councils must consider the costs of various options and choose the most cost-effective one. [City council strategic planner]

Cost-effectiveness was being assessed using cost-benefit analysis which made it difficult for councils to weigh the long-term consequences of decisions taken today for urban settlements and infrastructure that persist for many decades and thus are affected by changing risk levels. There were difficulties reported when comparing options that could be implemented immediately and give benefit to existing property owners, with longer-term staged options (like retreat from the coast or floodplain) that could benefit future generations and the wider community (Hastings District Council, 2012). This was described by respondents as comparing 'apples and oranges'. High discount rates (between $8 \%$ and $10 \%$ ) were commonly used for such assessments which resulted in structural responses as the 'best' option. Respondents viewed this practice as biasing decisions towards the short-term costs and benefits of response options and to structural measures that would be costly to recalibrate in the future.

This issue was addressed by De Bruin and Ansink (2011) for investments in flood protection measures under climate change uncertainty. They concluded that:

...a combination of the discount rate, climate change uncertainty, and the cost structure of structural and non-structural measures determines the optimal mix of investments in these measures. A higher level of annual flood damage and later resolution of uncertainty in time increases the optimal investment decision. Furthermore, the optimal investment decision today is influenced by the possibility of the decision-maker to adjust his decision at a future moment in time. (p. 4)

The distinction was made between structural measures that have high fixed costs relative to annual costs and non-structural measures that have low fixed costs relative to annual costs and this formed the basis of an approach to address the effect of time on decisions about climate change under uncertainty.

A strong tension between costs to private land owners compared with the wider community ratepayers was identified as a key pressure when such choices are being assessed; having its origins 
in the short-term focus of private interests compared with the long-term responsibilities of councils for the ratepayers as a whole, combined with perceptions of uncertainty about climate change.

Table 6.1 is a summary of a range of current practices used by four different types of council to address coastal and flood risks. They include a regional council, one district council, one unitary council and a metropolitan city council. These are typical of the range of governance arrangements and regulatory practices across New Zealand. 
Table 6.1 Current practices by four councils

\begin{tabular}{|c|c|c|c|}
\hline $\begin{array}{l}\text { Hawkes Bay Regional } \\
\text { Council } \\
\text { Coastal hazard zoning, } \\
\text { regional rules }\end{array}$ & $\begin{array}{l}\text { Tasman District } \\
\text { Council } \\
\text { Flood hazard } \\
\text { assessment }\end{array}$ & $\begin{array}{l}\text { Wellington City } \\
\text { Council } \\
\text { Sea-level rise } \\
\text { assessment, strategic } \\
\text { planning }\end{array}$ & $\begin{array}{l}\text { Kapiti Coast } \\
\text { District Council } \\
\text { Coastal hazard } \\
\text { planning }\end{array}$ \\
\hline $\begin{array}{l}\text { Approach } \\
\text { Multiple risk zones for } \\
\text { coastal erosion and } \\
\text { inundation- } \\
\text { progressively stronger } \\
\text { regulations apply } \\
\text { where risk is higher } \\
\text { Regional rules apply to } \\
\text { each zone restricting } \\
\text { structures, dwellings } \\
\text { and footprint expansion } \\
\text { in existing } \\
\text { developments }\end{array}$ & $\begin{array}{l}\text { Approach } \\
\text { Risk reduction } \\
\text { scenarios: zoning and } \\
\text { building controls; } \\
\text { structural protection; } \\
\text { flood flow path } \\
\text { protection; river gravel } \\
\text { management } \\
\text { Based on LiDAR } 52 \\
\text { elevation data and } \\
\text { modelled flood hazard } \\
\text { using (WaterRide) to } \\
\text { create static maps for } \\
\text { peak flood depth and } \\
\text { velocity, difference } \\
\text { mapping for scenario } \\
\text { comparison, depth x } \\
\text { velocity hazard maps } \\
\text { and animations of } \\
\text { modelled floods } \\
\end{array}$ & $\begin{array}{l}\text { Approach } \\
\text { Scenario-based for } \\
\text { strategic assessment of } \\
\text { the consequences of a } \\
\text { range of sea levels } \\
\text { across a range of } \\
\text { values and the costs of } \\
\text { responses } \\
\text { A tactical (short-term) } \\
\text { and strategic (long- } \\
\text { term) approach for } \\
\text { different assets } \\
\text { Integrating future sea- } \\
\text { level rise scenarios into } \\
\text { projects and areas } \\
\text { affected by storm } \\
\text { damage }\end{array}$ & $\begin{array}{l}\text { Approach } \\
\text { Progressive } \\
\text { development } \\
\text { controls (set-back } \\
\text { lines) over almost } \\
\text { entire coast since } \\
1979 \\
\text { Coastal erosion } \\
\text { hazard risk } \\
\text { assessment } \\
\text { undertaken 2004- } \\
\text { 2012 projecting } \\
\text { shoreline within 50 } \\
\text { and 100 years incl. } \\
\text { risk of sea-level rise, } \\
\text { erosion (1,800 } \\
\text { properties affected) } \\
\text { Unmanaged and } \\
\text { managed (with } \\
\text { protection) impact } \\
\text { scenarios presented } \\
\text { Hazard information } \\
\text { on Land Information } \\
\text { Memoranda* } \\
\text { Multiple risk zones } \\
\text { for coastal hazards } \\
\text { including sea-level } \\
\text { rise; Proposed } \\
\text { District Plan } \\
\text { included, 'no build' } \\
\text { seaward of 50-year } \\
\text { line and existing } \\
\text { buildings restricted } \\
\text { to current footprint } \\
\text { and floor area; } \\
\text { 'relocatable' } \\
\text { buildings between } \\
\text { line. Structural } \\
\text { protection not }\end{array}$ \\
\hline
\end{tabular}

${ }^{52}$ LiDAR is Light Imaging Detection and Ranging for mapping terrain.

${ }^{53}$ WaterRide is a software platform for flood management that enables spatial and time varying data to be portrayed visually and interactively. Refer http://www.waterride.net/Philosophy.html 


\begin{tabular}{|c|c|c|c|}
\hline $\begin{array}{l}\text { Hawkes Bay Regional } \\
\text { Council }\end{array}$ & $\begin{array}{l}\text { Tasman District } \\
\text { Council }\end{array}$ & $\begin{array}{l}\text { Wellington City } \\
\text { Council }\end{array}$ & $\begin{array}{l}\text { Kapiti Coast } \\
\text { District Council }\end{array}$ \\
\hline $\begin{array}{l}\text { Scale } \\
\text { Coastal hazards } \\
\text { assessed for numerous } \\
\text { coastal settlements } \\
\text { across the whole } \\
\text { region's coastline }\end{array}$ & $\begin{array}{l}\text { Scale } \\
\text { Urban area and } \\
\text { adjacent rural land } \\
\text { located within } \\
\text { floodplain }\end{array}$ & $\begin{array}{l}\text { Scale } \\
\text { Across the city for } \\
\text { specific projects and } \\
\text { wider interest across } \\
\text { the region }\end{array}$ & $\begin{array}{l}\text { Scale } \\
\text { Whole district and for } \\
\text { specific local } \\
\text { settlements for } \\
\text { consistency }\end{array}$ \\
\hline $\begin{array}{l}\text { Standards } \\
\text { One sea-level rise } \\
\text { scenario: } 0.5 \mathrm{~m} \text { by } \\
2100 \\
\text { Inundation event } 2 \% \\
\text { AEP }\end{array}$ & $\begin{array}{l}\text { Standards } \\
\text { 10-, 20-, 50-, 100- and } \\
\text { 200-year ARI flood } \\
\text { events } \\
\text { 200-year ARI a proxy } \\
\text { for climate change } \\
\text { effect (which would } \\
\text { become a 100-year } \\
\text { ARI by } 2090 \text { under } \\
\text { annual rainfall } \\
\text { projections using } \\
\text { (Woods et al., 2010) }\end{array}$ & $\begin{array}{l}\text { Standards } \\
\text { Five sea-level rise } \\
\text { scenarios: } 0.6 \mathrm{~m}, 1.5 \mathrm{~m} \text {, } \\
2.2 \mathrm{~m}, 3 \mathrm{~m} \text { and } 3 \mathrm{~m} \text { plus } \\
\text { storm effects }\end{array}$ & $\begin{array}{l}\text { Standards } \\
\text { Potential shoreline } \\
\text { retreat based on a } \\
\text { sea-level rise of } 0.3 \mathrm{~m} \\
\text { within } 50 \text { years and } \\
0.9 \mathrm{~m} \text { within } 100 \\
\text { years }\end{array}$ \\
\hline $\begin{array}{l}\text { Timeframes } \\
\text { Assessment 2003/04 } \\
\text { updated in } 2008 \\
\text { Erosion risk: } \\
\text { - 'current' c. next } 10 \\
\text { years } \\
\text { - long-term based on c. } \\
\text { 50-year planning } \\
\text { interval (by 2060) } \\
\text { and c. 100-year } \\
\text { interval (by 2100) } \\
\text { Inundation-event } \\
\text { probability of 2\% AEP }\end{array}$ & $\begin{array}{l}\text { Timeframes } \\
\text { Climate change } \\
\text { projections to } 2090\end{array}$ & $\begin{array}{l}\text { Timeframes } \\
\text { Has avoided use of } \\
\text { specific timeframes } \\
\text { Concentrating on the } \\
\text { effects and response } \\
\text { options. The lower } \\
\text { scenarios could } \\
\text { correspond to a } 2100 \\
\text { date }\end{array}$ & $\begin{array}{l}\text { Timeframes } \\
\text { 50- and 100-year } \\
\text { timeframes used to } \\
\text { indicate two risk } \\
\text { scenarios } \\
\text { * Note that following } \\
\text { independent review } \\
\text { and community } \\
\text { challenges, hazard } \\
\text { maps and new district } \\
\text { plan rules have been } \\
\text { withdrawn while they } \\
\text { are being reassessed. }\end{array}$ \\
\hline
\end{tabular}

Table 6.1 illustrates the variation in practice across councils, but also some similarities. Progressive hazard lines in coastal settings are used to manage the impact of changing risk. However, being based on 'best estimates' of the future and a static spatial expression of risk, they do not reflect either continuous sea-level rise risk over time or the effect of extreme events on top of sea-level rise. Only the Wellington City Council assessment included storm surge, but no regulatory effect has yet been given to this study.

Where whole district or regional scale risk assessments have been undertaken for coastal areas there is, in principle, greater consistency of practice, but the use of different standards and timeframes at each locality to reflect risk can negate this. For example, the Wellington City and 
Kapiti Coast District councils are located within the same region and the Greater Wellington Regional Council has not yet completed regional coastal hazard policies for the territorial councils to apply in their district plans. The Wellington City Council is only now taking an initial strategic approach to sea-level rise impacts, which Hawkes Bay and Kapiti took at least a decade ago. Wellington City Council commissioned an analysis of the climate change impact 'hotspots' in its district, adopting a strategic approach for longer-term effects and a tactical approach for consideration of infrastructure upgrades that will be affected in the future by sea-level rise. The council deferred consideration of planning rules until the implications of climate change impacts had been assessed in terms of the social, economic, and cultural and amenity values across the city, and response options discussed with the community. The implications for the city are large. Much of the CBD and its development, the airport and the port facilities are on land raised in an historic earthquake in 1855, which is low-lying and also at risk from liquefaction during earthquakes and tsunamis. ${ }^{54}$

The use of scenarios across a range of futures for flooding in the Tasman district for flood management, and for strategic planning in Wellington City, enabled several possible futures to be considered. The Tasman District Council used a 200-year rainfall event as a simplified heuristic for the climate change effect which would become a 100-year event by 2090 (using the central government guidance). Two of the councils started their consideration of coastal hazard risk with a high-level strategic planning process. This identified hazards and long-term development trajectories that informed the assessment of response options across the region. The focus on wider development issues enabled coastal development pressures and alternative locations for development to be identified, thus steering new developments away from the coast. Hazards management rules were integrated into a wider comprehensive plan, thus providing a wider context for rule changes and for addressing options for existing settlements at risk. The effect was to reduce opposition to restrictions on development and enabled resolution through the RMA processes. The Tasman District Council had to prepare a 'strategic business case' for the hazard rules before proceeding under the RMA, but this was supported by an Environment Court declaration under Section $86 \mathrm{D}$ of the RMA. ${ }^{55}$ The declaration avoided further entrenchment of status quo development at the coast by averting a rush of development applications under the old rules. Despite the positive outcome, the inefficiency of having to do this was questioned by the respondent.

\footnotetext{
${ }^{54}$ Refer to http://wellington.govt.nz/about-wellington/emergency-management/prepare-for-an-emergency/tsunami

55 Tasman District Council [2011] NZEnvC 47, 28 February, 2011. Application by the Tasman District Council to make rules operative under section 86D of the Resource Management Act 1991.
} 
The implementation of regulatory plans for coastal risk management by the three councils shown in Table 6.1 took decades to become operative. In two cases this was sustained over several political cycles; only Hawkes Bay and Tasman (and Canterbury, see Box 6.1) regions have operative plans that reflect the coastal risk. However, in Hawkes Bay, the regional council supports retreat policies whilst the Hasting District Council is under pressure to provide temporary hard structures at the coast. Meanwhile, a long-term strategy is being devised by the joint councils across the region through a process set up in 2014 under a Joint Committee for the Proposed Regional Coastal Strategy. ${ }^{56}$ The purpose of the Strategy is to:

...determine the desired form of the coast in the long term taking into account the hazards that it will be exposed to, pressure associated with human habitation on land adjacent to the coast, and affordability to the community; and what policy, planning and physical work is required to achieve that. It will also set priorities for various actions and/or activities. (p. 16)

How long the process will take to resolve is moot, given that there have been ongoing issues with visible coastal erosion and development since the 1930s ${ }^{57}$ While some progress has been made in all locations, the processes are long, subject to development and community pressures and have the potential to unravel if political resolve changes. The challenge for councils is demonstrated in the following participant responses:

Most plans have some words on climate change in there. Again it's a resourcing issue. Everyone is trying to invent the wheel because there is no 'template' plan or approach that councils could easily be using off the shelf. There's not much out there and especially small councils have a lot of these glossy words included in their plans, but little actual implementation. It's a strategic decision at council level. And for some councils it's too expensive to do it. [Unitary council strategic planner]

One city strategic planner commented:

...the challenge with climate change is whether it actually gets drawn down into the strategic management process and planning decisions.

\footnotetext{
${ }^{56}$ The relevant Hastings District Council paper can be found at: http://www.hastingsdc.govt.nz/files/agendas/Planning\%20and\%20Regulatory\%20Committee/2014-06-19 /Planning\%20and\%20Regulatory\%20190614\%20Agenda.pdf

${ }^{57}$ Refer to page 10 at http://www.hastingsdc.govt.nz/files/all/documents/ltccp/2012-2022/coastal.pdf
} 


\section{Box 6.1 Council practice to avoid and mitigate climate-related risk}

The previous Waitakere Council purchased and removed floodable buildings as part of a stream restoration scheme, which had multiple benefits. Its success was due to the collaborative nature of the project with communities and availability of funding for property purchase and house removal (Vandenbeld \& MacDonald, 2013).

In the Northland region at Kaeo, central government supported retreat from flooding. This has not proceeded due to a low rating base from which the local community needs to raise their share of the funding which will be matched by central government. [Central government official]

The Canterbury Regional Coastal Environment Plan 2005 acknowledges potential climate change effects, discourages protection of new development, uses a 100-year timeframe for planning and identifies alternative lower-risk locations for existing high-risk development and encourages natural buffers for protection from sea water inundation. Structures damaged by the sea cannot be rebuilt in that location.

Dunedin City, following a climate change impacts assessment (Fitzharris, 2010) updated its Climate Change Adaptation Policy in 2011. In 2014, it released hazard maps and a preferred natural hazards policy plan under the RMA for consultation. It included the effects of sea-level rise and increased flood risk. Dunedin has capital assets and infrastructure in low-lying liquefiable land, reclaimed from the sea, and groundwater rising in south Dunedin on tidal cycles which will get worse as sea-level rises. [City property manager]

\section{Box 6.2 Auckland and Manukau city case studies}

Prior to amalgamation, Auckland and Manukau cities used minimum building site and freeboard measures in their district plan rules to limit risks from existing coastal and inundation hazards based on 1\% AEPs. Soft protection measures, like beach nourishment, were used to retain amenity and complement hard protection measures like seawalls. Such measures face practical and economic limits as sea levels rise. Sand supply will become limited, economic costs of structural protection and pumping of waste and storm water will increase the need for hard protection measures that will increase in cost.

Auckland and Manukau cities had no explicit provisions for sea-level rise or other climate change effects in their statutory planning assumptions. Both councils undertook modelling of inundation risk from sea-level rise. Different timeframe assumptions were used, and implications of sea-level rise above $1 \mathrm{~m}$ by the end of the century were not assessed. Data and cost limited consideration of changes in erosion risk and storm surge. At the regional level, climate change effects on erosion using a $0.5 \mathrm{~m}$ sea-level rise were considered.

Adapted from (Hart, 2011)

The practice examples set out in this section so far have either been guided by the precautionary principle embedded in the NZCPS or taken a risk-based approach to address uncertainty to some 
extent. They do not, however, explicitly address the dynamic climate change characteristics because of the use of static measures. Only a few examples do address dynamic change in an adaptive way.

The land transport sector invests in assets with long lifetimes that will be affected by sea-level rise and the impacts of increased heavy rainfall. The sector undertook a comprehensive assessment of climate change risks for their operations (see Box 6.3), but there was little evidence found that the results were being used for long-term planning.

\section{Box 6.3 Land Transport Climate Change Risk Assessment}

The New Zealand Land Transport Agency in 2008/9 commissioned research on climate change effects and a national risk profile. This identified the highest risk categories on all transport modes (rail, road and sea ports) as heat stress on the rail network, inundation of the low-lying coastal land transport infrastructure from sea-level rise and storm surge and future increased flood risk from climate changes on state highways and the rail network currently prone to flooding as the likely regional effects concluding moderate vulnerability across the sector but with regional and local variability.

Barriers identified to consideration of the risks to the sector included the lack of national strategic drive in legislation and policy with a risk of inefficiencies through uneven responses giving rise to differential social and economic consequences at local levels, a lack of national monitoring of impacts and of the implementation of adaptation policies and their adequacy, gaps in knowledge and capacity to understand changing climate risks including uncertainty in regional climate projections and expected effects, a lack of sector-specific information to assess effectiveness of responses, funding pressures and a lack of institutional capacity.

(Gardiner et al., 2009; Gardiner et al., 2008)

One example that does attempt to address change in climate over time, arising from the transport sector climate change risk assessment, is an update of the Transport Agency Bridge Manual (2005) which factored in climate change considerations for assets with a greater than 100-year life [Transport advisor]. This manual ${ }^{58}$ considers climate change effects in terms of the influence on the intensity and frequency of precipitation and sea level for bridges, and culverts discharging into waterways, sea coast and estuarine sites.

\footnotetext{
58 The NZ Transport Agency's Bridge manual SP/M/022. Effective from May 2013. Available at http://www.nzta.govt.nz/resources/bridge-manual/docs/bridge-manual-3rd-edition-section-2.pdf
} 
The manual states:

c) Design for climate change effects

Where it is practical and economic for a bridge or culvert structure to be retrofitted at a later date to accommodate increased flood flows arising from the effects of climate change, the structure need not initially be designed to accommodate increased flood flows arising from the effects of climate change. Where future retrofitting is not practical or does not reflect value for money, future climate change impacts shall be taken into account in the design. Assessment of the effects of climate change shall be based on the Ministry for the Environment manual Climate change effects and impacts assessment and other material based on more recent research published by reputable sources accepted by the road controlling authority. Where relevant, changes in sea level shall be assessed based on the Ministry for the Environment manual Coastal hazards and climate change. ${ }^{59}$

While the two guidance documents referred to in the Bridge Manual include an element of dynamic change in risk, they provide little guidance about how to implement this at a practical level. The Bridge Manual does, however, anticipate an adaptive approach where that is economic and practical and where it is not, anticipates consideration of uncertainty and dynamic change.

There were two examples where TLAs had factored an element of changing climate risk into land transport infrastructure decisions. In Auckland, some roads are now being built with higher elevations; for example, the new section of causeway for Auckland's Upper Harbour Corridor, State Highway 18 was built 0.3 metres higher than the existing causeway, which was then raised to match it [Auckland Council engineer]. The second example was in Dunedin where the response to frequent sea inundation of a coastal road led to the design of foundations to road widening that could accommodate a higher sea wall in future [city engineer]. However, given the inevitable continuous sea-level rise, these responses are, at best, a transition for consideration of sea-level rise and for buying time while more transformational responses are developed; for example, new concepts of mobility and settlement patterns.

There is added risk where central government guidance is not being followed; for example, where local corrections for flood flows and a range of scenarios are not used consistently for impact assessments, as discussed in Section 6.2.2. The emergency management system picks up the

59 The New Zealand Transport Agency's Bridge manual SP/M/002.2.3 Waterway design, section 2.3.2 Design Floods c) Design of climate change effects. 
residual risk in the immediate response to the extreme climate events. Recovery occurs in the same location and to the previous standards in conformity with the Earthquake Commission policies regarding 'betterment' (Earthquake Commission., 2013). EQC covers repairs to existing buildings and land affected by storm events. Respondents, aware of the consequences of such an approach, commented that:

A change in thinking is needed: retreat instead of rebuild if it's been destroyed. [Emergency manager at a city council]

It is also a lot cheaper to rebuild elsewhere in the long term than desperately clinging to the same location that will be affected again and again. [City council strategy planner]

We need to think about how to influence these decisions earlier in the process. Do you really want to rebuild there? [City council climate change advisor]

Preparedness and risk reduction is largely left to the planning system (RMA) and, if there are no regional rules, such rebuild is affected by existing use rights (see Appendix 2) and to structural protection schemes (SC\&RCA and BA) to address. The degree to which these practices are even addressing the current risk levels was questioned by some respondents. An over-reliance on large flood protection schemes designed to historic standards, old coastal sea walls and under-designed storm water systems which limit their ability to respond to current climate conditions, were described. The practice in Wellington city is:

For storm water system capacity upgrade, work is funded at $\sim 1 \%$ of network each year to raise the standard from 1:5 years to a 1:20-1:50 year standard-well behind what will be required even to keep up with current flood risk. [City council storm water engineer]

And for Auckland city the:

estimated cost of addressing existing storm water deficit effects is $\$ 5.4$ billion [incl. contaminant management of $\$ 2.1$ billion] with a further $\$ 4.5$ billion of additional storm water infrastructure required to support growth. [Auckland Council asset manager] 
Box 6.4 Auckland Council Asset Management Plan July 2012-2032

Appendix 5: Flood mitigation summary

\begin{tabular}{|l|l|}
\hline $\begin{array}{l}\text { Number of habitable floors in 100- } \\
\text { year floodplain }\end{array}$ & 7,850 \\
\hline $\begin{array}{l}\text { Number of habitable floors } \\
\text { affected by 100-year overland flow }\end{array}$ & 7,000 \\
\hline Reticulation under capacity & $\begin{array}{l}655 \mathrm{~km} \\
\text { of }\end{array}$ \\
$\begin{array}{l}6,500 \mathrm{~km} \\
(10 \%)\end{array}$ \\
\hline Properties not connected to a & $\begin{array}{l}55,600 \\
\text { of } \\
491,800 \\
(11.3 \%)\end{array}$ \\
\hline
\end{tabular}

Source: Auckland Council Asset Management Plan July 2012-2032

The plan notes:

- It is assumed that the cost of addressing flooding problems will continue to increase. This is because legacy councils have understandably taken a cost benefit approach to prioritising flood alleviation - that is, the easier, lower cost/higher benefit projects have already been undertaken leaving the more difficult and costly problems to be resolved in the future, if at all practical or affordable.

- As the cost to mitigate the remaining flooding issues will become increasingly difficult and expensive, and sometimes practically not possible, it was assumed that a best practicable option approach will be adopted. The practical implication of this is that not all flooding problems will be resolved by traditional flood mitigation improvement works. This is reflected in the costing by using the lower cost estimate of the range.

- Not all of the legacy floodplain models have considered the impact of climate change and hence the indicated flood plains may be smaller than what may occur in the future. In future, every assessment will consider climate change (changing rainfall and sea-level rise) and floodplains will be reviewed accordingly. It is not expected that changes in number of properties affected will be very significant, however the scope and costs of improvement works can still significantly change and the related solutions will be more expensive. [My emphases]

Approximately $70 \%$ of the Auckland backlog will be included for expenditure over the 50-year life of the asset plan, using the Best Practicable Option approach, making it $\$ 3.4$ billion over 50 years to clear the backlog (Jan Heijs, Auckland Council, personal communication, 2013; see Box 6.4).

An adaptation deficit is articulated in the notes to Box 6.4. Cost-benefit has, to date, driven upgrades, leaving for the future the more costly upgrades or system changes which will also need to have climate change assumptions added to them. However, the uncertainties are made clear and the affordability and practical limits to upgrade noted, with the necessity of other approaches highlighted, such as land use planning (Auckland Council, 2012, pp. S7-9). The Auckland Asset Management Plan has a time horizon for storm water flooding upgrades of 50 years, compared 
with the recent changes to the Local Government Act 2002 for long-term infrastructure plans of 30 years. ${ }^{60}$

\section{Practice of the courts}

The courts can only adjudicate based on cases that happen to come before them and on the evidence presented to them by the parties. The courts make legal judgments that can set case law for the consideration of uncertainty and dynamic climate change. The following court decisions illustrate examples of how the regulatory framework has been interpreted.

When talking about the degree of precaution in Foreworld Developments Limited v Napier City Council $^{61}$ the Environment Court said:

The kind and degree of precaution to be taken depends on the level of knowledge of the risk, its likelihood of occurrence, and its consequences. We do not live in a riskfree world and the RMA does not require the avoidance of all risk.

The courts also commented on the planning horizon contemplated in a coastal hazard setting in 1994 in Bay of Plenty Regional Council v Whakatane District Council. ${ }^{62}$

... as far as the "“foreseeable future" may reasonably be extended, allowing for the uncertainties of scientific knowledge and balancing the interests of the applicant and succeeding landowners...

Uncertainties are addressed by a 'reasonableness' test at the time, which is balanced by private interests, despite the positive responsibility for councils to avoid hazard risk situations. The Foreworld decision however extended the horizon to 100 years based on the life expectancy of the building and commented that, unless specifically limited, land use consents have an 'infinite life'. It went on to demonstrate its difficulty in dealing with other than 'predictions' of the future and ways of reflecting uncertainty that might avoid lock-in. The court considered that there might be an argument for the time horizon to be longer, but considered that the uncertainties of attempting to predict coastal movement strain even a 100-year span.

More recently the courts have interpreted the time horizon and uncertainty using the NZCPS of "at least 100 years". For a new development in a remote coastal area, ${ }^{63}$ the Environment Court

\footnotetext{
60 The Local Government Act 2002 Amendment Act (No 3) section 101B Infrastructure Strategy.

61 Foreworld Developments Limited v Napier City Council [2006] NZEnvC W029/2006 13 April, 2006.

${ }^{6}$ Bay of Plenty Regional Council v Whakatane District Council [1994] NZEnvC A3/94, 24 January 1994.

${ }^{63}$ Mahanga E Tu Inc v The Hawkes Bay Regional Council and the Wairoa District Council, [2014] NZEnvC 83, 10 December 2014.
} 
addressed uncertainty by placing the responsibility for future risk back on the consent holder, even though the development was in a regulated coastal hazard zone that was put there as a precautionary measure. This notion of voluntary assumption of risk seems to be a growing trend in the courts practice, as shown in Hemi v Waikato District Council ${ }^{64}$ where the court commented that:

...the risk of coastal hazard is required to be assessed, but it would be wrong to conclude that a proposal must satisfy the court that all such risk is eliminated. We adopt the reasoning in Waterfront Watch Inc $v$ Wellington Regional Council ${ }^{65}$ where the Court determined that a development that might be subject to coastal hazard should be able to be designed and operated at an acceptable level of risk. We agree that there is an element of 'voluntary assumption of risk' by people who choose to live near the coast in situations such as this, and the Court's concern must be whether such risk is acceptable on all of the facts presented to it, rather than whether such risk is able to be avoided absolutely.

The Environment Court in this decision introduced three practice concepts that are used as risk heuristics in their decision making: whether the risk can be mitigated; acceptable levels of risk; and the voluntary assumption of risk. The implications of such concepts applied in practice, are discussed further in the adequacy assessment in Section 6.3.

In Hawkes Bay, where a Regional Coastal Environment Plan had policies and rules expressed through progressive hazard zones over a historic residential zoning, a subdivision was allowed by the Environment Court in the hazard zone. Conditions were applied, based on a spatial metric of sea-level rise within 7 metres of the dwelling that would trigger removal of the allowed removable dwellings. The court applied a bond, payable upfront to the council, to cover removal in the future. This was designed to avoid future council liability, cost shifting to future ratepayers and the moral hazard that would be created for subsequent owners of the land.

In another instance, the Environment Court took a different approach and refused consents, where in coastal settings there was a moderate to high likelihood of storm surge and tsunami risk within a $50-100$-year period. ${ }^{66}$ More recently in another coastal case, ${ }^{67}$ the court declined consent for a plan change from rural to residential where the area was subject to multiple coastal hazards of

\footnotetext{
${ }^{64}$ Hemi v Waikato District Council, [2010 NZEnvC A688, 24 June 2010.

${ }^{65}$ Waterfront Watch Incorporated v Wellington Regional Council, NZEnvC W43, 9 June 2009.

${ }^{66}$ Buckley v South Wairarapa District Council [2008] NZEnvC W004, 4 February 2008

${ }^{67}$ Southern Environmental Association (Wellington) Inc v Wellington City Council [2010] NZEnvC W190, 15 April 2010.
} 
inundation, erosion, tsunami and sea-level rise. In a coastal case ${ }^{68}$ concerning replacement of a sea wall to protect 84 houses worth $\$ 64$ million and which were at extreme risk and requiring relocation, the court made a medium-term decision to allow the consent for 25 years and suggested the council build a fund for future costs for measures to protect properties, which could include managed retreat (Kenderdine, 2010, p. 59). This approach appears not to have been progressed in subsequent court decisions, but highlights innovation in decision making that could foreshadow adaptive management.

\section{$\underline{\text { Summary }}$}

The practice evidence relating to governance and regulation has highlighted a number of themes. The multiple levels of government have created ambiguity for those implementing the framework through regulatory practice. Lack of functional coordination across those levels and gaps in implementation of mandated measures has left councils to adopt separate, often different and unsupported approaches to addressing climate change risk, resulting in inconsistencies across the country. The ad hoc nature of the decision making at the individual units of local government and through the Environment Court and other courts reinforces this lack of integration. The absence of national-level direction through statutory instruments and application of regional rules to support TLA decision making and the legacy effects of past decisions using static assessment methodologies and measures makes the introduction of more flexible measures and assessment tools difficult for councils to implement. Where the NZCPS had been applied in the courts, greater precaution has resulted. However, the regulatory codification of uncertainty and dynamic climate change challenged the practitioners and decision makers alike. The desire expressed for greater consistency across all levels of government had led to attempts being made to better integrate climate risk decision making, however, these were at their early stages of development

\subsubsection{Organisations and actors-the practice}

Organisational form and function and actor characteristics influence decision making. Organisations and the actors undertake the statutory responsibilities assigned to them, which are reflected in the functions. The functions inform the structural arrangements within organisations. Decision making is influenced by the professional disciplines advising elected councillors through processes that are designed to enable the values of the communities they represent, to be reflected. Consideration of the effects of climate change is just one of many considerations organisations have to address; but climate change potentially influences most local government responsibilities to a greater or lesser extent and many of the organisations that invest in infrastructure. Decision

\footnotetext{
${ }^{68}$ Mason v Bay of Plenty Regional Council, NZEnvC A098, 30 November 2007.
} 
making occurs across the many functions set out in the different statutes which were found to be weakly linked. For example, there are no statutory links between the LGA asset plans and spatial planning under the RMA, or between flood protection considerations under the SC\&RCA and the RMA, or under the CDEMA and the RMA and BA.

The distinctive and divergent technical disciplines required to carry out the statutory functions influence how the climate-related risk is framed and responses developed. In turn this affects the degree of integration between the functions and between the disciplines and thus the decisions taken. The three main disciplines that drive decision making by local government on climate change effects are: planning, which operates under a quasi-legal framework and strives for certainty of outcome; engineering/hazards which, although risk-based, are dominated by quantifiable risk and historical experience; and emergency management, which focuses on immediate response and recovery from extreme events, addressing residual risk that is not routinely 'protected' by engineering and planning practice.

Professional practice is governed through professional associations like the New Zealand Institution of Professional Engineers, the New Zealand Planning Institute and the New Zealand Law Society, each of which sets professional practice standards and training requirements through their accreditation systems. Practice is determined through engineering, planning and legal 'protocols' expressed in standards and practice guidance (e.g., Quality Planning best practice guidance $^{69}$ (Ministry for the Environment, 2008a, 2008b, 2009, 2010; Woods et al., 2010) ${ }^{70}$ and standards such as (AS/NZS ISO 31000, 2009; NZS 9401, 2008). These apply to professional practice in water and flood management, coastal planning and the design and management of storm water systems, to legal practice through planning and resource consenting processes, and to the use of assessment tools used to weigh up options.

The previous section discussed how the governance arrangements and regulations affected the practice. In contrast, this section discusses how organisations operate internally across their functions, within the professional disciplines and amongst elected councillors to influence practice.

\footnotetext{
${ }^{69}$ Available at http://www.qualityplanning.org.nz/

${ }^{70}$ New Zealand Treasury cost benefit guidance

http://www.treasury.govt.nz/publications/guidance/planning/costbenefitanalysis
} 


\section{$\underline{\text { Functions within organisations }}$}

The institutional framework exhibited functional fragmentation. Whether fragmentation was reflected in the way the functions were organised and in turn what effect that had on the practice of the actors is now examined. Council organisational arrangements were largely functionallybased and thus enhanced fragmentation of the institutional framework. For example, at a territorial level, consent processing is often separate from plan development and at a regional level, planning is separate from hazards and river engineering. This has resulted in climate change consideration lacking coherence where issues interact between those functions; for example, planning and engineering in flood risk and hazard management affecting land uses, or interaction amongst all four functions. Functional fragmentation can impact on the ability to consider uncertainty and dynamic climate changes where cross-functional implementation is required to achieve council responsibilities in a consistent manner.

For example, the newly created Auckland Council had its waste water and water supply services functionally managed within an arm's length Council Owned Company organisational structure, ${ }^{71}$ while storm water management and land-use planning were retained within the Auckland Council structure; the Auckland Council holds statutory responsibility for all water services. To assure accountability, a memorandum of understanding set out the Auckland Council's purpose and expectations of Water Care Services (the council-owned company). The significance of this for climate change considerations is that Water Care Services is making multi-million dollar investments in infrastructure in locations that are likely to be affected by sea-level rise and increased rainfall intensity and which will be influenced by storm water and land-use decisions taken by the Auckland Council.

In Dunedin and Wellington City Councils, there were officers charged with responsibility for climate change, or sustainable development at a strategic level, to work across functions. The degree to which integration occurred depended on the level of senior executive and council support within the organisation and the leadership abilities of the particular officers concerned. Leadership by such officers resulted in an opportunity being taken to widen community engagement during 2014 on the future options for the Island Bay seawall discussed in Section 6.2.2, resulting in agreement by the Wellington City Council to develop a long-term resilience strategy that addresses the consequences of sea-level rise, for implementation by 2018-2021 (Z. Rittel, Wellington City Council, personal communication, 2015).

\footnotetext{
${ }^{71}$ Council Owned Company organisational arrangements are commonly used for delivery of the three water services.
} 
Adding to fragmentation of organisational form and function was the practice of councils using different consultants to undertake different technical assessments because of the cost of retaining expert advisors. Several examples of work undertaken for councils show the difficulties in representing climate change risk (Christchurch City Council, Wellington City Council and Kapiti District Council) in ways that can be applied by the respective council; for example, on coastal hazard risk and sea-level rise. Participants commented that:

Different consultants deal with different aspects of the risk assessment. [Consultant engineer]

It's very hard to do the flood probabilities and the socio-economic impacts in an integrated project and very few councils would be able to do that and to implement that. Normally, they would have different consultants for reporting on flood modelling and for reporting on socio-economic costs. So splitting up the complex question of risk into discrete work items leads to inadequate/not integrated information and approach. How do you bring events of low probability back into the game? Combining socio-economic damage data with flood modelling is very hard, especially for council. [Climate change science advisor]

Where current practice does not consider changing climate risk, siloed functions within organisations were strongest. This observation was gauged by the degree to which respondents defined their sphere of practice within their statutory responsibilities and thus to the different professional discipline-driven practices such as risk assessment (engineering), process-driven and legal practice (planners and lawyers), cost-driven practice (economists, financial and corporate management). One area where greater strategic integration was evidenced was across natural hazard, flood engineering and climate change functions (e.g., Greater Wellington Regional Council). However, this was not seen as a guarantee that integration of climate change considerations would get embedded into practice, due to the strong influence of the statutory framework on the way organisations operated functionally.

Leadership emerged as a theme in the sense that it is necessary for functional integration across organisations and for more integrated decision making. For example, at the management level one city planner observed that if officers higher up in the organisation thought strategically, that enabled climate change risks to be raised at council. Some practitioners reported that sceptical views were held by some higher-level managers who had neither the time nor background to understand the detail needed to address climate change as a long-term issue; an absence of leadership for consideration of climate change for council functions. At the decision-making level, 
a city planner commented that when a particular councillor asked questions of a more strategic nature about climate change, it resulted in a more in-depth consideration of the issues because the councillor was regarded as influential by fellow councillors.

Where linkages between the practices occurred, this was largely a result of leadership by practitioners knowledgeable about climate change risk, such as climate change or sustainability officers; for example, at Dunedin City Council, Wellington City Council, Greater Wellington Regional Council, Kapiti Coast District Council, Tasman District Council and Hawkes Bay Regional Council from interviews and workshops; through links forged between councils and researchers (Lawrence \& Manning, 2012); and increasingly through the Environment Court processes when consents for developments occur.

The themes that emerged from the functional arrangements for practice within organisations link closely to the degree of fragmentation of those functions, how leadership was exercised by the actors, the resourcing constraint that fragments expert advice across functions and the extent to which functions sit in siloes or are integrated. These are all organisational practice issues that are weakly incentivised by the institutional framework.

The influence of the disciplinary traditions of the actors within organisations is now examined, followed by the specific influence of the decision makers.

\section{Planning and legal practice}

Planning and legal practices that were described by practitioners or observed in relevant documents are driven by the quasi-legal processes under the RMA. There are 10-year review cycles for plans and resource consents which are governed by rules under the plans at regional and district levels of government. These activities are dominated by pre-decision processes addressing issues through public 'consultation' and the standards required for judicial review, much as described by Ruhl (2010). The practice is in turn driven by evidentiary tests of likelihood or past experience and seeks certainty of outcome. A static framing of risk usually resulted, as discussed in Sections 6.2.1 and 6.2.2, by assuming that future climate will be like the past. Even where the future was considered, as in some coastal settings for sea-level rise, and where adaptive conditions were placed on consents, ${ }^{72}$ the primary methods used were static ones; used to create certainty.

The influence of the legal system on practice is most apparent in the context of existing use rights. As discussed in Section 6.2.2, the absence of regional rules has created inertia amongst regional

72 Mahanga E Tu Inc v The Hawkes Bay Regional Council and the Wairoa District Council [2014] NZEnvC 8310 December 2014. 
councils in exercising rules over existing use rights where land is at risk from natural hazards and climate change effects. This is despite the ability to do so (Berry \& Vella, 2011) since 2005 (section 65(1) of the RMA; see Appendix 2) by using regional rules to require TLAs to give effect to them in existing developed areas (where TLAs cannot revoke existing use rights). Regional council reluctance to exercise this power is only in part a disciplinary practice issue since multi-level governance and political issues also come into play as discussed in Section 6.2.2. Planners reported that councillors did not want to use development controls to limit private property expectations that might adversely affect property values when climate change information was uncertain. However, one regional council flood engineer commented that it was negligent to allow development when they knew it will get worse. In the context of existing developments, a city planner commented that "changing existing development will be costly for local government, but who pays? If we don't take a precautionary approach, who pays?"

A default to 'mitigation' was a theme reported by planning practitioners. Even at Greenfield sites, pressure to develop at the coast and on floodplains is high. Mitigation of risk was often considered possible (using measures such as sea walls, flood levees, raising floor levels and using progressive hazard lines) in preference to avoiding new areas that are at risk. Not all practitioners interviewed saw this as a problem for the future, since there were near-term benefits from development in areas 'protected'. However, most of those undertaking flood risk management, hazards management and strategic planning saw such measures as short-sighted. This view was reflected in one unitary council strategic planner comment that such an approach was "temporary at best and entrenching risk at worse", due to the lock-in effect and increasing assets at risk when higher than design-level extreme events occurred. Practitioners were aware that there was no guarantee that areas outside the levees, hazard lines and zones would be 'safe' from future climate change effects.

Practitioners reported that pressure was placed on council planners to provide certainty through their evidence and advice to decision makers. Fear of litigation from making climate hazard-related information public was observed and had led to some information not being presented to the council for recommended regulatory responses [Council politician, and a planner]. The planner characterised fear of litigation from releasing hazard information as a stronger pressure than the fear of litigation if the hazard risk was not made transparent and damages subsequently resulted. The councillor regarded climate change as a 'distant threat' and outside their term in office so was responding to the near-term fear.

However, there were some signs during 2013 and 2014 of councils taking proactive steps to make hazard risk information public. For example, the legal liability for non-disclosure of known hazard 
risk information played a major role in the Kapiti Coast District Council making such information publicly available for prospective property owners on the Land Information Memoranda, for coastal land exposed to erosion, inundation and sea-level rise. While the council considered it was "doing the right thing by its community" to communicate the risk, it failed by not bringing its community along with it when it used the same information to design planning controls. However, this cautionary tale has not subsequently deterred other councils from publicising hazard maps and plan rules based on them. Rather, it has changed the way they have released such information and proposed actions based on them. For example, Dunedin City Council, when it released (June 2014) draft hazard maps and proposed new hazard zonings based on them, sought feedback before formal notification in late 2014. The community was asked to consider the information for accuracy and alteration, for consideration by the council, prior to release of the maps and proposed rules.

Public engagement is primarily driven by the legal planning processes as prescribed in the statutory framework. They are prescribed in eligibility terms, are time-bound and operate in formally prescribed settings where community values and a range of options cannot be explored to enable community buy-in. Experimentation with engagement processes outside the strictures of the statutory processes have occurred (see Chapter 5) as they relate to the institutional framework and the difficulty of implementing the results of such processes.

Time-inconsistency in the regulatory processes, quest for certainty, static framing of risk and measures used, reluctance to address existing uses at risk and tensions in the use of hazard risk information were consistent themes in the practices driven by planning and legal practitioners within the institutional framework.

\section{Engineering practice}

The engineering discipline has dominated flood risk and coastal zone management over decades. Historically it has used static structural responses based on quantitative risk management assessments (Ericksen, 2005a, 2005b). The avoidance or minimisation of risk using non-structural measures has emerged primarily in coastal settings for protection of dunes and other sensitive ecosystems in New Zealand more recently (Blackett, Hume, \& Dahm, 2010).

Engineering practice is driven primarily by safety concerns. The perception of safety was demonstrated amongst engineering practitioners when considering the design flood level of 1:440year return period for the Hutt river (Wellington Regional Council, 2001) at a workshop conducted early in the research process. One engineer's comment summed up the practice: "the 440 year design standard was chosen, because it was considered 'high enough'...the development behind the stop banks was considered 'flood-free'"; a false sense of security had been set up. 
When designing the Hutt river flood management plan in 2001 (Wellington Regional Council, 2001), responses that could manage the residual risk above flood design levels were identified. Residual risk was perceived by the city planners as an emergency management issue, whereas the regional council saw it as initiating an evaluation of complementary non-structural measures such as land-use planning controls and the provision of secondary flood paths for handling the residual risk. The Hutt river flood management plan identified such options and relied upon the district council to implement them, but this was done weakly. The regional council had to appeal to the Environment Court to have the necessary measures implemented, which were finally agreed outside the court process and appeals withdrawn (G. Campbell, Greater Wellington Regional Council, personal communication, 2012). The different disciplinary approaches within the different functional areas and across governance scales drove the separate processes.

Engineering practice across several councils used the 'best estimate' to convert heavy rainfall into flood frequency because the guidance manuals based on precaution were perceived as "not practical within the decision frameworks under which we operate" [Regional council engineer]. They had difficulty translating scenarios and a range of possible outcomes into their risk analysis and response options.

Updating guidance information and standards was perceived negatively by some engineering practitioners, not only because of the resources required to amend long-term asset plans through community consultation processes, but also because of the difficulty of making decisions based on changing risk. There was a discernible shift in thinking amongst some of the engineering participants during the course of my research after being exposed to new information on climate change risk following the 2007 and 2014 IPCC assessments, and to assessment tools that enable uncertainty to be managed. Presenting the uncertainties visually as a changing risk increased respondents' awareness of the range of possible futures, especially the potential damage consequences at the extremes (Lawrence, Reisinger, et al., 2013) and (G. Campbell, Greater Wellington Regional Council, personal communication, 2012, 2014). In their own words:

The depiction of changed probability and damage using a risk based approach... hadn't thought about it that way before... a good way of describing the impacts. And use to identify range and timing, and lead time, and stages for action. We will use the new climate change information in the technical review of the flood control scheme. [Regional council engineer] 
There has been a significant attitude shift at our council which acknowledges the issue for asset management amongst staff and politicians. There has been a huge step forward over [the] last 12 months - coincidence of issues - what is going on in other local councils in the region has created a higher profile for climate change impacts, resulting in the planners approaching us for information for storm water management. In the past we didn't have contact with them. [Regional strategic planner]

As a result, the uncertainties and changing character of the risk have been incorporated into the design and planning assumptions for the next stages of the Hutt river flood management plan implementation ${ }^{73}$ and as a basis for the economic assessment of pathways using a range of options. However, a risk assessment of flooding in Westport, New Zealand, did not include climate change effects over time in its analysis but it included a caveat to that effect (Keenan \& Oldfield, 2012). Managing uncertainty through engineering practice is clearly 'a work in progress'.

Standard risk management methodologies are adopted by most local government engineers. However, not all of them integrate consideration of uncertainty and dynamic climate change. For example, Wellington Water (a council-owned water infrastructure company) uses the NAMS Guidance (NAMS, 2004) which has a module for climate change. However, on close inspection, it does not acknowledge the changing nature of the climate risk, and bases the input data on historical records and static judgements in time and space. Wellington Water also uses a multicriteria analysis tool for risk assessments of water management options, like many similar organisations. This tool requires caution in its use because results can be biased depending on the characteristics of the participants (Hunt \& Watkiss, 2013) and the assumptions used (De Bruin \& Ansink, 2011). The effects of sea-level rise and likely increases in intensity of rainfall events had not been included in the way the storm water system was being managed.

Engineering practitioners typically used statistical probability statements like annual return interval (ARI) and annual exceedance probability (AEP) to communicate design protection levels. However, these were not well understood within local communities or, in some cases, by the planning practitioners and decision makers who rely upon risk assessments (Quade \& Lawrence, 2011):

\footnotetext{
${ }^{73}$ Presented at the RAND Second Annual Workshop on Decision Making Under Deep Uncertainty, 18-19 November 2014. Judy Lawrence, Marjolijn Haasnoot, Laura McKim, Daya Atapattu and Graeme Campbell 2014. Dynamic Adaptive Pathways New Zealand Application. This work is the subject of a paper for publication under preparation.
} 
Risk management as a framing device doesn't resonate yet, because it sounds too far out. Frequency of storm events...people struggle with more severe and more frequent events. [Consultant engineer]

Practice was often described by engineers as "risk-based", but on closer examination reflected physical risk, expressed in quantitative terms, rather than representing differential vulnerabilities within communities arising from societal, cultural or economic factors. One consequence of this approach was found in a parallel study. Flood-affected households in one area in the Hutt valley were perceived by others in another flood-prone area as having greater influence over priorities for flood protection than they had, due to higher value assets at risk (Quade \& Lawrence, 2011). To some extent this reflected the realities of the time taken to implement the staging of a major flood scheme and the resources available to work on different areas at risk outside the major scheme (A. Allan, Greater Wellington Regional Council, personal communication, 2012). Nevertheless, decisions were made to proceed with the other area first.

Over-confidence by land owners outside, but close to, the coastal hazard lines and by those 'protected' by flood levees has been another consequence of engineering practice to build structural protection. High house valuations in coastal areas with structural protection (e.g., \$1.6 billion in assets in the Kapiti Coast for 1,800 properties) despite the obvious hazard risk have been one consequence. On the other hand, an assessment of the effect of coastal hazard zones in the Hawkes Bay region on property valuations (Hawkes Bay Regional Council, 2008, p. 23) concluded that:

...there does not appear to have been any adverse effects to value that can be identified as caused by the proposed Regional Coastal Environment Plan and the introduction of Coastal Hazard Zones.

...demand and economic factors can quickly overcome the perception of negative effects of property damage and adverse publicity, even when it is of a potentially reoccurring nature. (p. 23)

But a regional councillor commented about non-structural responses to downstream flooding that:

...banning infill and more hard surfaces and implementing swales [secondary flood ways] and banning development in the upper catchment brought strong push back from the city councillors, because of their development aspirations for the upper catchment. But you can't just go on building more and more walls along our streams and rivers. [Regional councillor] 
Difficulties that uncertainty and change pose for those advising within the quasi-legal framework and for its representation in design standards has led to use of tools that have the potential to obscure changing risk and extremes. In some respects this is surprising, since engineering practice is based on both objective and subjective risk assessment, as discussed in Chapter 4. However, these concepts were not clearly delineated in the actual practice adopted by the engineering professionals.

\section{Emergency management practice}

Emergency management professionals within councils and at a national level have a predominant focus on response and recovery. This has resulted in less attention being given to reduction of risk and to readiness (Glavovic, 2014). This allocation of attention is historical and emanates from the Civil Defence and Emergency Management Act, as noted in Chapter 5. I could find no evidence of consideration of the ability of emergency management to cope with increased residual risk as protection design levels are exceeded with changing sea level, coastal storms and increased flood frequency and intensity. Despite calls for more integrated catchment planning and the potential for avoidance planning through the RMA (Glavovic et al., 2010), planning, engineering and emergency management approaches have been slow to converge (Lee, 2010) due to the dominance of a disaster management discourse (Glavovic \& Smith, 2014). Emergency management practitioners have, however, led integration across governance scales. For example, in the Wellington Region Emergency Management Office (WREMO), management actions are integrated across nine councils, lifelines utilities, welfare agencies, emergency services and response teams. But this integration has not extended to system integration across functions such as structural protection and planning, or to managing uncertainty and dynamic climate change impacts. In other words, practice has not shifted through integrated governance alone.

Many research participants, when asked what would trigger consideration of climate change risk, replied "disasters". The spectre of climate change exacerbating other natural hazard risk is focusing councils nation-wide following the Canterbury earthquakes in 2010 and 2011 which raised awareness amongst decision makers and practitioners of hazard risk and the disruption that can occur if the impacts are inadequately anticipated. An example is the Christchurch City Council District Plan Review. ${ }^{74}$ This is, however, an example of practice developments arising as a consequence of non-climate disasters, rather than autonomous practice changes within a discipline that anticipates changing climate risk. The changes to insurance cover and premiums that followed

\footnotetext{
${ }^{74}$ The District Plan review of the Hazards section can be found at: http://www.ccc.govt.nz/thecouncil/policiesreportsstrategies/districtplanning/districtplanreview/ourdistrictplanreview /naturalhazards.aspx
} 
were also strong motivators for consideration of multiple natural hazards, including climate change effects, by all councils in this study across their assets, services and liability in event of inadequate consideration of risk. For example, a council property officer at a city council with significant assets at risk on reclaimed harbour land said that he had been contacted by the council insurers the day he was interviewed to discuss what the council was doing about the risk.

In New Zealand, as elsewhere in the world (Carlman, 2005), new institutional design that follows disasters tends to be focused on the particular type of disaster that had just occurred. This was evidenced after the Indonesian tsunami in 2004 when government put significant new focus on tsunami warning (GNS Science., 2008). After the Canterbury earthquakes, natural hazards were the focus of institutional reform; for example, the amendment to the LGA section 101B, which provides for infrastructure planning over 30 years to manage risks relating to natural hazards. The link with land-use planning measures is only now beginning to emerge with a proposal to elevate consideration of natural hazards to the matters of national importance in Part 2 of the RMA (New Zealand Government, 2013). This is where "the effects of climate change" is located in the statute. Unfortunately, no explicit link has been made between climate change and natural hazards management in this proposal.

Emergency management practice was largely reactive. Only warning systems and some personal preparedness by homeowners were anticipatory. The reactive focus stems from the singular focus of the institutional framework and the disaster management discourse on large one-off events. Emergency management professionals are therefore constrained by the institutional framework within which they operate, much like planners, lawyers and engineers are under their statutory mandates.

\section{Councillor practice}

External influences on councillors have a large impact on how decisions are made within the institutional framework. Therefore, in this sub-section I have identified councillor-specific issues that affect their practice. This also emphasises decision maker-specific issues that interact with uncertainty and dynamic climate change characteristics, multi-scale governance and practice issues already raised and decision-makers' relationship to the organisations and actors with which they interact.

As already reported by practitioners, councillors were influenced by the uncertainties surrounding climate change which fed a perception that climate change was a contested issue, leading to the inertia described in adaptation decision making. One councillor suggested these perceptions were a reason why climate change issues did not get to the decision-making agenda in a way that they 
could be discussed strategically. The councillor suggested that "We need a layered conversation and this needs a committed council with more time to look at the consequences and the analysis about a resilient city" [Unitary council politician].

Uncertainty and contestation around climate change emerged from the workshops and interviews as a stronger motivator for decision makers than councils' responsibility to consider the effects of climate change; some councillors were not fully aware of this responsibility. One aware councillor suggested that the reason could be that most councillors have limited exposure to the detail of plan preparation and consent decision making because most land-use consents under the RMA are considered in detail at officer level under delegated authority. For example, in the year 2010/11, $91 \%$ of decisions on resource consents were made by local authority officers. ${ }^{75}$ This meant that elected decision makers were not being exposed to the consideration of climate change effects under the planning system on a regular basis. There was a mix of understanding amongst elected councillors about the decision significance of climate change for their responsibilities; some did not 'believe' in human-induced climate change and there was resistance observed to having an informed debate about sea-level rise.

There was also a perception that the consequences of inaction are negligible in the short term:

There are no consequences if we don't address climate change as it is difficult to enforce compliance with the RMA. There is liability for non-disclosure of hazard information, but litigation risk of publicising hazard information is stronger on council behaviour. [Unitary council politician]

The uncertainties surrounding the timing and magnitude of climate change effects compounded a perception by some councillors that there was a lack of evidence of climate change. This played out in different ways. There was a desire for information to be certain to reduce risk of getting it wrong and which was delaying climate change adaptation decisions, while further information was gathered to position their council to be the best informed as possible.

Uncertainty was interpreted by some councillors as an apparent inconsistency of information. While there was a general understanding that councils had a responsibility to provide risk-related information and to exercise their roles and responsibilities wisely, the short-term focus under a 3year electoral cycle, made them nervous about considering the information available to them. This corroborated the observations of the practitioners. One politician commented that Official Information requests had been refused because hazard information was in draft form [this is not a

\footnotetext{
${ }^{75}$ Refer to: http://www.mfe.govt.nz/publications/rma/annual-survey/2010-2011/key-facts/index.html
} 
reason for withholding information under the Local Government and Official Information and Meetings Act 1987]. Another suggested new hazard information should not be sent to the council because it would be regarded as official information and just complicate a contested situation about coastal change. One practitioner commented that "councillors are assessing the guidance in terms of what is at stake politically". But other councillors were aware of the council culpability for such practice: "there is a naive belief that if hazard information is not in front of council it has no standing because it has not been received".

A 'belief' that risk could be mitigated ${ }^{76}$ was prevalent across councillors, reflected in this comment by a city councillor: "the RMA has a wide purpose in section 5 , but the practice drops down to mitigation very quickly". Extreme climate events were regarded as one-off events that could be easily dismissed in the short term. The possibility that extremes could become more frequent and increase damages was not the focus of most councillors. There were, however, signs that this view was changing, motivated by the release of the 2014 IPCC assessment and leadership from practitioners as opportunities arose. (e.g., Wellington City, Hutt City, Christchurch City).

Councillors expressed concern that each council across New Zealand was addressing climate change effects in different ways and, as individual councils, were facing legal challenges. This made them reluctant to be the test case at their own council's cost thus acting as a demotivator to considering climate change risk. Councillors considered that all levels of government had a stake in addressing climate change risk and that the costs should be borne accordingly. Some councillors expressed the view that a more integrated approach across New Zealand hazard risk management that included consideration of climate change impacts nationally would achieve more consistent results over time.

Some councillors called for a wider conversation about who pays for precautionary responses to climate change effects:

"Discussion of risks and options and what tools are available and who pays. The district plan is not the only tool, for example, communication of risk using physical effects demonstration is needed" [City councillor].

A concern was expressed by many councillors that no one council had the means to address ongoing protection in exposed and vulnerable communities, nor to start a retreat process. As noted by two:

\footnotetext{
${ }^{76}$ Mitigation in this context refers to reduction of climate change impact severity as defined in the RMA and not mitigation in the sense of reduction of greenhouse gas emissions.
} 
If we don't take a precautionary approach, who pays? Government tends to step in post hoc. [City councillor]

Government always ends up paying and that is you and I the taxpayers, so we pay twice through local rates and again through the spill-over effects to the economy generally. [Regional councillor]

Practitioners pointed out that mechanisms exist under the SC\&RCA for equitable distribution of costs using differential rating based on benefit and exacerbation. Such rating methods are used routinely by regional councils, for example, the Hawkes Bay coastal erosion problem used differential rating to assess the beneficiaries of coastal protection works and managed retreat (Hastings District Council, 2012). Here, different benefits were apportioned to private property interests and the public interest (roads and reserves) in the funding model. However, there was a general perception that adaptation to climate change "would cost a lot upfront"; the corollary, that climate change could cost a lot if not addressed, was perceived as less important.

This perception is consistent with the cognitive barriers described by Kunreuther and Weber (2012) that taking something away in the immediate time has a far greater effect cognitively than giving a benefit in the long term. Two other cognitive biases at play here are: the effect of a distant threat (Milfont, 2010; Spence, Poortinga, \& Pidgeon, 2012; Weber, 2006, 2010) because of uncertainty about its attribution to any particular climate event; combined with what Weber (2006, p. 115) describes as a tendency for people to have a "finite pool of worry" crowding out new and long-term concerns like climate change and focusing attention on the near-term.

\section{$\underline{\text { Summary }}$}

In summary, councillor decision practice exhibited a strong aversion to uncertainty and dynamic climate change. While most accepted their responsibilities, there was a poor understanding of the decision significance of considering uncertainty and dynamic change. This was in part due to the lack of exposure to climate change risk information. Practitioners observed that near-term drivers had a greater motivating effect on councillors' actual practice, along with a belief that the risk could be mitigated primarily by hard structures. Councillor concern focused on the costs of action and who would pay when resources were constrained and fiscal exposure increased. The institutional, governance, political and cognitive drivers on councillors were constraining the ability to make decisions on climate change risk that could move beyond a 'protection' and 'mitigate' approach. This demonstrated a misfit with the elements of the institutional framework that could enable proactive and precautionary decisions to be made in an adaptive way. 


\subsection{The practice adequacy}

The adequacy of the practice presented in Sections 6.2 to address uncertainty and dynamic climate change characteristics in adaptation decision making is now assessed using the 12 criteria developed in Chapter 4.

\subsubsection{Understanding and representing uncertainty and dynamic climate change characteristics}

\section{a) Uncertainty treatment criterion}

Treat climate changes as uncertain in some respects and consider unlikely but severe damaging changes as well as 'best estimates' of change.

The practice that addresses the "effects of climate change" (see Appendix 5) has been grafted onto measures used for decades to manage current natural hazards like coastal erosion and flooding within current climate variability. The design levels used for the dominantly hard structures and static measures are based on risk-management assessments that do not adequately take account of the changing risk or extremes. By relying on 'best estimates' that are rooted in historic experience or where a range of future scenarios are not embedded into the analysis, decisions based on such assessments create a rigidity that perpetuates the status quo leaving little room for flexibility for future climate conditions. There was a widespread lack of understanding of the decision relevance of uncertainty and dynamic climate change; for managing the effects of sea-level rise and storm surges and flood frequency changes over time. This means that the precautionary principle and risk-based concepts that underpin the institutional framework have not been implemented adequately. The lack of understanding and consequent practice can be sourced back to the influence of the disciplinary traditions of the practitioners, the lack of integration between them (see Section 6.2.3).

A problem for decision makers related to professional practice in the court context can be illustrated. One Judge (Jackson, 2007) observed that "the probability of the effect [climate change effect] is a matter of fact to be decided by the Court on the scientific evidence before it". However, probability is never a matter of fact, by definition. This is why the IPCC uses an uncertainty guidance protocol for its statements (Mastrandrea et al., 2010) that assigns quantitative and qualitative certainty statements and indicates the level of confidence in those statements. For example, (Church et al., 2013a) assigned probabilities for upper levels of sea-level rise, but made it clear what they are certain about and what level of confidence they can put in the probability statement, while also noting that sea level could rise higher because there are uncertainties at higher sea levels. Judge Kenderdine (2010, pp. 62,63) found comfort in the ability to define 
probabilities using the IPCC uncertainty guidance suggesting they are baselines from which the RMA can operate. Other Judges have had difficulty with qualitative expert judgement and have used expert caucusing to arrive at risk numbers. ${ }^{77}$ Applying a risk-based approach within the quasilegal processes relies upon quantitative evidence which the courts find easier to apply to their judgments. However, this has left consideration of uncertainty and dynamic climate change largely unaddressed. The opportunity to apply the precautionary principle in more innovative ways is being lost. Nevertheless, the recent case of a subdivision appeal in a coastal zone in Tasman District $^{78}$ demonstrates that, even where the experts don't all agree, the Environment Court was able to apply the precautionary principle, based on the NZCPS, to decline a subdivision. Such decisions are, however, particular to the locality and facts of the case so cannot be said to provide a consistent approach the whole country, but may signal a change in practice.

A lack of environmental feedback, because such changes are not visible above the usual climate variability experienced, and perceptions that climate change is a distant threat, have been suggested as reasons for the weak understanding of climate change risk in New Zealand and elsewhere (Lawrence et al., 2014; Weber, 2006, 2010). The use of probability formats that are not understood exacerbates the lack of environmental feedback. Public perception of safety has become entrenched, especially outside coastal hazard lines or flood levees, and 10-yearly review periods for adjustment were largely ineffective because much development has occurred over that time, thus further entrenching the risk. Kennedy, Stocker, and Burke (2010) in Australia also found that risk management of climate change ignored non-linear effects and led to an over-reliance on structural protection. This has encouraged a sense of 'safety' behind the protection structuresthe levee effect described by Tobin (1995). A sense of safety not only encourages further development, it also increases the expectation of more hard physical protection (Lawrence et al., 2014) which will inevitably reach structural integrity and affordability limits. At best, consideration of risk has become a series of intermittent snapshots in time, thus locking in investment decisions spatially and for long timeframes.

The empirical evidence did, however, show promising signs that coastal engineers and flood managers are beginning to understand the decision significance of anticipating ongoing and changing climate (see Section 6.2.3). There emerged from the analysis an evident openness to learn from the international experience using more flexible tools such as robust decision making and dynamic adaptive policy pathways assessment and planning approaches. However, the practice showed that the decision significance of uncertainty and dynamic climate change is

\footnotetext{
${ }^{77}$ Hemi v Waikato District Council, [2010] NZEnvC A688, 24 June 2010.

${ }^{78}$ Gallagher $v$ the Tasman District Council [2014] NZEnvC WLG 245, 3 December 2014.
} 
inadequately understood and represented and the emerging practice is weakly developed and under-supported.

\section{b) Lifetime of decisions criterion}

Work with a changing risk profile to ensure that responses that are fit for a specific timeframe do not make it more difficult to respond to risks that emerge only after this timeframe.

The practice showed that the practitioners have difficulty reflecting the possibility of changing risk into the way they advise and design measures within the institutional framework. The consequence was that changing risk has not been sufficiently integrated into professional practice methods and standards (see Section 6.2.3). This means that there are likely to be difficulties changing course in the future with high transition and transfer cost. The differing timeframes within the statutes are not well integrated (as discussed in Chapter 5) which adds to the difficulty of addressing changing risk profiles over time.

The differing timeframes of land-use consents, building consents, flood schemes and infrastructure planning mean that there is little connection to the lifetimes of the decisions in the practice. The provision in the institutional framework for reviews of plans and consents was inadequate for reflecting risk profiles that change over time, due to their being a snapshot-in-time using static spatial measures. The different timeframes impact on the affordability of expenditure on assets affected by climate change and consideration of risks that will be felt by decisions taken today, within their lifetime. This flows on to risks and costs to future communities. Timeframes also have important implications for the suite of response options considered and used to address those risks (see criterion f) below).

Consideration of the lifetime of decisions and the ability to anticipate and change course as the use-by date of measures expires is not a part of current practice. There is, however, some sign that more flexible measures are beginning to be used as practitioners are exposed to tools developed elsewhere in the world.

\section{c) Framing of climate change risk criterion}

Frame climate change risk in ways that can be understood by and are relevant to different interests.

A consistent theme was that the practice does not frame climate change risk in ways that can be understood and are relevant to the different interests. Probability statements were an ineffective way of conveying climate change risk, because it is not possible to assign probabilities to deeply 
uncertain risk and because those receiving the risk statement often misunderstand what the formats are actually saying.

There were, however, some examples of practice where councils had tried new ways of communicating climate change risk, with the result that dynamic change could be leveraged within assessment processes. These examples all built on an understanding of behavioural science and continuous adaptive management that anticipates changing course, as discussed in Chapter 2; in particular, the ability to use experience of near-term events and experience in making decisions under uncertainty about the future, to shift thinking towards managing uncertainty and dynamic change. Relating probabilities to commonly experienced chance formats was used by some practitioners to bring climate change effects closer to people's own experiences. The result was an increased level of engagement and consequent understanding of the possible climate changes.

Current practice in framing changing risk and the possibility of surprise is nascent in a few localities, but inadequate in most. Heightened awareness of natural hazard risk, consequent upon the Canterbury earthquakes, may yet leverage changed practice if the signals are embedded in the institutional framework. Current formats for framing climate change risk are inadequate to reflect uncertainty and dynamic climate change.

\section{d) Consistency and accessibility of climate risk information criterion}

Develop and manage information bases that inform climate risk consistently over time and are accessible to public and private interests.

Official data and information are managed by two agencies: Land Information New Zealand, which has a data stewardship function for land titles, geodetic and cadastral surveys, topographic and hydrographic information; and Statistics New Zealand, which collects and holds official statistics and undertakes some environmental monitoring, including of climate change indicators, albeit greenhouse gas and climate indicators only. ${ }^{79}$ Each unit of central and local government holds its own information according to a set of principles ${ }^{80}$ for data and information management. However, there is no central repository of information about climate change risk, nor a monitoring system that can track changing risk and vulnerability across the country. NIWA is the main source of consistent information on New Zealand's climate change science, and several inter-agency

\footnotetext{
${ }^{79}$ Refer to http://www.stats.govt.nz/browse_for_stats/snapshots-of-nz/Measuring-NZ-progress-sustainable-dev$\% 20$ approach/sustainable-development/air-and-atmosphere.aspx as part of New Zealand's progress using a sustainable development approach.

${ }^{80}$ Refer to https://ict.govt.nz/guidance-and-resources/open-government/new-zealand-data-and-informationmanagement-principles/
} 
research programmes on impacts and adaptation are Crown funded ${ }^{81}$ Locally-derived information is poorly linked into these data systems.

The consequence is a weakly developed national understanding of vulnerabilities and potential future costs of adaptation because of the fragmentation of climate risk information and the ad hoc manner of its application through Environment Court evidence. Each unit of local government assesses risk for its territory using different consultants who use a variety of different approaches.

Inconsistency of information and its use was a consistent theme that derived from the fragmentation attendant upon a multi-scale decision system and inattention to the value of a national data repository at central government level that could be accessible to all decision makers. The consistency of data and information management and its accessibility is inadequate for decision making under conditions of uncertainty and dynamic climate change.

\subsubsection{Governance and regulation-the adequacy}

\section{e) Precautionary decision-making criterion}

Prevent harm by anticipating potential damages and have supporting measures that would reduce or avoid such damages, without relying exclusively on information 'precision' and 'certainty' of evidence.

Councils are increasingly using measures that reflect progressive hazard risk from the coast and flood-ways. The practice is presented as precautionary. However, this practice can only be regarded as a temporary measure because sea-level rise is certain, accelerating and continuous over centuries. It is thus certain that many buildings in coastal settings will be affected by sealevel rise within their lifetimes. Measures that delineate spatial zones and progressive risk are inadequate for controlling existing land uses and new developments in such circumstances over long timeframes because they are static, applied as snapshots-in-time and set up expectations of ongoing protection which will become physically and cost limited. Nevertheless, participants observed that the measures do signal future risk, even if they are contested when used. The current focus of practice is on coping strategies through emergency management and on the static approaches that entrench risk; for example, rebuilding in areas exposed to risk, and flood defences or coastal seawalls (Reisinger et al., 2015). The development of accommodation and retreat strategies are less well developed and New Zealand is no exception (Abel et al., 2011; Gibbs \& Hill, 2011; Measham et al., 2011; Reisinger et al., 2015; Tompkins et al., 2010).

\footnotetext{
${ }^{81}$ Refer, for example, to http://ccii.org.nz/
} 
The certainty objective set up by the institutional framework and its practice in quasi-legal processes where uncertainties were being perceived as "lack of evidence" constrained the level of precaution that was adopted. The practice of using single numbers, or the middle or low end of the range, to express climate risk showed weak application of the precautionary approach central to the NZCPS that stresses a risk-based approach over "at least 100 years" (Minister of Conservation, 2010, Policy 24).

The courts also had difficulty using uncertain and changing information as a basis for anticipatory decisions that apply the precautionary principle. There is a tension within the courts between those cases where the principle of voluntary assumption of risk has been applied and those cases where the precautionary principle has been applied. The cases show that new subdivisions can be declined at the coast drawing on the power of the NZCPS. Transitioning from static measures of risk and consequence is currently reliant on the courts taking precautionary decisions based on the NZCPS. This may, over time, give rise to the development and use of more flexible planning measures that enable a regime shift that changes existing land uses. Participants in the research were not hopeful that this would be possible without a national level policy response that incentivises a transition of land uses away from exposed areas over time. The precautionary principle is not being adequately translated into practice.

\section{f) Risk consideration over long timeframes criterion}

Address risk over long timeframes and recognise that decisions taken today will affect the ability to change course in the future.

The practice of risk management has not enabled uncertainty and dynamic change to be addressed over long timeframes. The institutional framework and the practice have contributed to a greater or lesser extent resulting in the lock-in of activities spatially and over time. The courts have become the default decision makers because they have been left to interpret the meaning of risk-based approaches to decision making in coastal and other settings, using new heuristics because legally binding national direction, regional rules and their integration across multiple scales are largely absent. The courts have also had to adjudicate on cases where councils have designed planning rules and measures that do address risk over long timeframes and where they become contested. Because of this decision making 'default setting', the courts' practice is discussed in more detail.

Three new heuristics, arising from the default setting in which the courts find themselves, stand out. The first is the notion of 'acceptability' of risk. This does not appear in the RMA; it appears in the purpose of the Civil Defence and Emergency Management Act (CDEMA section 3 (b); see Appendix 2). The concept of acceptable risk comes from the theory of risk perception (Fischhoff, 
Lichtenstein, Slovic, Derby, \& Keeney, 1981) and has been adopted in the courts' practice following its use in a natural hazards context, derived from the CDEMA. However, acceptability tests beg the question of to whom the risk will be acceptable; current or future generations? Making judgements about future acceptability and tolerability could at best be speculative, suggesting that such a test provides an inadequate way of planning for the future.

The second is the 'voluntary assumption of risk', which is equally fraught, especially as sea levels rise and flooding intensifies. It ignores the primary duty of a council to avoid such risk or accept liability. If applied as a consent condition it is unlikely to override a statutory duty. Applying 'voluntary assumption of risk' can also mislead. Those who assume the risk today will not be those in the future who experience the risk. There is also a high likelihood that the risk will be transferred to others in the future-through taxes, rates and higher insurance premiums. Some decisions discussed in Section 6.2.3 rely upon conditions that could be unenforceable in the future, thus creating a moral hazard for future generations.

The third heuristic is that risk can be mitigated ${ }^{82}$ in most cases, often 'supported' by 'experts' before the courts whose evidence can often convey inadequate consideration of uncertainty and dynamic climate change. Assuming the ability to mitigate underlies many of the Environment Court decisions discussed in Section 6.2. When decision makers focus on mitigation of harms it takes the focus away from reflecting the precautionary principle in plans based on the NZCPS for controlling land-use and subdivision consents in areas likely to be affected by natural hazards and climate change impacts. Many of the court decisions highlighted in Section 6.2 appear to have struck a balance between short-term certainty for current landowners and averting damage in the future; rather than drawing from the NZCPS and its principles and policies to refuse consent or adopt conditional consents that could phase out land uses in a staged manner. Some court-derived mitigation measures and conditions discussed in Section 6.2 do not consider the practicality of enforcement at a future time. Nor do they consider the likelihood that damage could occur during extreme storm events by amplifying the effects of sea-level rise, affect many properties at the same time and render building removal impractical, especially if alternative sites for the buildings have not been identified. Given the dominant mitigation methods used, such decisions appear inconsistent with uncertainty and dynamic climate change characteristics and the NZCPS. Most mitigation in coastal settings, and in some flood settings, will be temporary over the timeframes

\footnotetext{
${ }^{82}$ Mitigation in this context means reduction of harm, not elimination of harm, although those relying on mitigation often perceive mitigation as risk elimination.
} 
of existing buildings, and those being built today, quite apart from the potential path dependency and expectations of ongoing protection that mitigation sets up.

Time inconsistency is rife in the decision-making context and what happens in the future is constrained in the decisions made using static measures. The ability to change course in the future was not reflected in the practice assessed. Such thinking was at its very early stages for flood risk management and not yet being addressed in a sea-level rise context at the coast. However, the attempts by some councils to introduce hazard management on the coast and the awareness-raising effect of the Canterbury earthquakes nationally may leverage such consideration. They do, however, require more leverage from the institutional framework (e.g., through NPSs and NESs). Risk consideration over long timeframes is inadequately practised currently.

\section{g) Experimentation and learning criterion}

Enable experimentation and learning that addresses changing community values over time and enables institutional settings and their application to be adjusted over time.

Experimentation and learning was evidenced in the practice; for example, sharing of knowledge acquired through experimentation that could provide leverage for more flexible practice to emerge. New networks were emerging amongst practitioners and there was active engagement with researchers on decision making under conditions of uncertainty and dynamic change; even if their endeavours have not yet yielded either consistent practice or the implementation of flexible measures. Nevertheless, sharing of knowledge is occurring about what does and does not 'work', and is likely to be a precursor to greater consistency of practice. Such self-organisation (Pelling, 2011, p. 61), use of web-based tools, regional council professional Special Interest Groups and research workshops are examples of informal, but temporary, arrangements sustained by individuals and dependent on available funding. While necessary, they are not sufficient to sustain new adaptation practice over several political and planning cycles. Neither do they address the need expressed for greater consistency of approach nationally. Facilitative factors are currently missing; including leadership, culture and technical disciplinary drivers and the coordination of roles and responsibilities between different governance scales, where consistent gaps were identified in organisational practice and are discussed in criterion k). The experimentation and learning evidenced would have to increase apace and be adequately resourced to enable development of new ways of building uncertainty and dynamic change considerations into decision-making practice. Experimentation and learning is weakly developed but holds promise. 


\section{h) Codification of changing risk and complementary measures criterion}

Ability to codify changing risk into formal instruments that can guide practice across multiple scales in reinforcing ways, and recognise that other measures will be necessary to complement formal rules for them to be effectively sustained over time.

The codification of changing risk in practice was the most challenging aspect of climate change adaptation decision making. While uncertainty and dynamic climate change are included in some official guidance documents for local government practitioners, applying the guidance in decision practice was largely absent. This was because practitioners could not use more flexible practice tools within the quasi-legal processes of the institutional framework; a matter of institutional 'fit', as discussed in Chapter 2 and Section 6.2. Paradoxically, the timeframe of planning cycles is too long for flexible responses to operate, while the short-term political cycle is too short for consideration of risks emerging over longer timeframes. The reluctance of decision makers to control land uses in areas potentially affected by climate changes and pressure to close off response options early has limited the ability to develop new practices.

There are tools that can be used to address uncertainty and dynamic climate change (e.g., robust decision making, dynamic adaptive policy pathways, real-options analysis), but they are largely untested in New Zealand and not yet embedded in professional disciplinary practice. However, their spatial translation under statutory frameworks is a nascent area of scholarship internationally. Close links with networks that can 'test' institutional settings using the tools available will form an important opportunity for addressing codification of uncertainty and dynamic change. Practitioners expressed the view that new practice will only be embedded and sustained if it transfers through their networks and is supported by the elected councillors and central government. Current codification of changing risk was inadequate for addressing uncertainty and dynamic climate change.

\section{i) Transition to new institutions criterion}

Ability to transition to new institutional states that can address uncertainty and dynamic change by making continuous adjustments ahead of societal and physical thresholds that take timeframes and lead time into account.

There was evidence that a shift to new institutional states had occurred in the past, but largely borne of necessity - either after national-scale economic events or natural disasters - usually with strong national political leadership. The Canterbury earthquakes raised awareness and sensitivity to hazard risks and some legislative changes have been made to acknowledge statutory gaps that contributed to harms; for example, long-term infrastructure planning and higher-order 
consideration of natural hazards in planning. However, such awareness and changes are at the margins and do not address some of the more embedded inadequacies in the framework and practice discussed in this thesis.

The anticipation of a transition to new institutional states could appear anathema to existing units of government as the opposition to proposed local government reforms currently underway in New Zealand attests. In a situation of an uncertain future that involves climate change, such a prospect seems unlikely unless the national consequences of climate change across the economy and for society can be amply demonstrated and greater integration of governance and use of national instruments occurs. Transitions to new institutions are currently incremental, marginal and likely to be inadequate for addressing uncertainty and dynamic climate change.

\subsubsection{Organisations and actors—the adequacy}

\section{j) Organisational learning criterion}

Capacity for organisational learning to align instruments of risk management practice across the different disciplines at multiple scales.

Organisational learning across disciplines and scales is impeded by lack of strategic oversight and a lack of coordination between risk management functions. Integration between hazards and asset management with regulatory planning activities are examples. There are some specific statutory impediments such as the amendment to the RMA in 2009 that gave land-use 'rules' in a proposed plan legal effect only after decisions on submissions are taken and publicly notified, and the nonuse of national and regional instruments. This has made it more difficult for councils to be proactive in contested situations where there are multiple hazards and climate change impacts that require an anticipatory approach. There were a few examples of practice within councils where the managers for natural hazards, climate change, flood risk and emergency management had come together across governance scales. Also, there were examples of regional and district councils joining together to initiate a region-wide natural hazards or a coastal plan to address climate change as an exacerbator of hazard risk (see Section 6.2.3). These examples demonstrate that there is capacity for integration across governance scales and for consideration of climate change risk, but only where political leadership exists in addition to leadership by the practitioners. Organisational learning is nascent or weakly developed and currently inadequate to support climate change adaptation decision making. 


\section{k) Leadership capability criterion}

Leadership capability within organisations that can manage complex and changing circumstances, and manage across governance scales and the different functions.

The professional disciplines and quasi-legal processes for decision making constrained adequate consideration of uncertainty and dynamic climate change. Recent proposals for amalgamation of councils in New Zealand, if successful, will remove the jurisdictional distinctions between levels of local government and help build more consistent approaches to managing climate risks by having region-wide land-use planning and region-wide flood risk and coastal management planning all within the same governance scale. There was some evidence of this happening within the new Auckland Council for water assets management and coastal planning resulting in greater consistency of standards across the region. However, it is not yet evident whether the leadership capability exists to enable climate change effects to adequately be anticipated and managed. Where initiatives have been taken outside the regulatory processes by leaders within organisations more effective engagement with community values has reflected strategic choices for communities at risk from sea-level rise and increased frequency and intensity of flooding. While leadership is at an emergent stage, there are signs that innovative processes could help leverage change, but only if supported by national policy instruments and with the buy-in by communities.

\section{l) Community engagement criterion}

Ability to interact and learn from engagement with communities to enable changing and different values to be reflected in decision making.

Community engagement observed was primarily tied to the quasi-legal processes under the RMA and submissions on plans under the LGA. The focus was on problems with the plans, rather than strategy and community objectives. The assessment of community values and their influence on decision practice was thus time- and space-bound, ad hoc and opportunistic, rather than systematic and strategic. This was despite the provision for Long-Term Plans under the LGA which commence with consultation on priorities. The processes observed were reactive rather than a full engagement where mutual learning occurs. Traditionally, the New Zealand public is disengaged from its local councils, evidenced by the very low turn-out at local body elections ( $40 \%$ in 2013 compared with $78 \%$ for a national-level election). ${ }^{83}$ Where they were engaged, the focus was often on how the council was affecting 'property rights' and property values. Perceptions of risk by the community, reflected in market prices, make it difficult for councils to consider the increasing

\footnotetext{
${ }^{83}$ New Zealand Social Indicators. Voter Turnout. Statistics New Zealand, 2014.

Refer http://www.stats.govt.nz/browse_for_stats/snapshots-of-nz/nz-social-

indicators/Home/Trust\%20and\%20participation\%20in\%20government/voter-turnout.aspx
} 
residual risk associated with climate change. This is because communities resist measures used by councils to publicise the hazard risk, and its reflection in statutory plans. There were examples of councils widening the engagement outside the statutory framework and experimenting with collaborative processes of engagement. Such efforts have not yet been institutionalised in law. There were also examples where interactive formats for characterising climate change risk were being used in community discussions about flood risk. These show promise for similar applications at the coast. Practice of engagement was weakly developed with some nascent forms of collaborative engagement developing but not yet embedded in practice. Community engagement has so far proven inadequate for addressing uncertainty and dynamic climate change.

\subsection{Summary of the adequacy of practice}

\subsubsection{Understanding and representing uncertainty and dynamic characteristics of climate change}

Representation of uncertainty and dynamic climate change is currently inadequate across the professional disciplines, the decision makers and the courts. This originates in a lack of understanding of the climate change characteristics of uncertainty and dynamic change and their significance for decision making. Quasi-legal processes that derive from the institutional framework that 'requires' certainty of evidence lead to static measures being used to represent and mitigate climate risk. This results in weakly-developed avoidance decisions, thus compounding the deficit in understanding. The effect of such practice is that decisions taken today are likely to constrain decisions in the future because the lifetime of the activities is not being reflected in decision making. Practitioners face difficulties working with the changing nature of the risk when faced with existing use rights in the absence of national and regional statements and rules. Risk becomes framed in absolute terms and information that could assist with more flexible framing is either not being widely disseminated or not used to inform decisions that will need to change course in the future.

\subsubsection{Governance and regulation}

Performance of the different roles and responsibilities at multiple governance scales influences the ability to take precautionary decisions. Multi-scale, yet devolved, roles and responsibilities across governance scales compound consideration of uncertainty and dynamic climate change. Some critical statutory instruments available to central and regional government are voluntary and not being used to support the devolved system of governance. Time inconsistency across the institutional framework leads to decisions that are not well integrated across the statutes. There are nascent examples of practice that could address dynamic climate change through experimentation 
and learning, using professional networks, and leveraged by action research. The ability to codify changing risk is the main challenge for practice, stemming largely from the quasi-legal context of decision making. Leadership consistently emerged as a critical motivator of improved practice. New institutions are considered unlikely to emerge through incremental adjustments to the institutional framework and practice to address the need for continuous adjustments to be made ahead of societal thresholds and thus take timeframes and lead time into account. Disasters were the consistent trigger mentioned for enabling new institutional frameworks and practice to emerge that could support anticipatory and flexible practice. The regulatory practice appears locked into a space and time warp which is difficult to change at any one governance scale or by any one unit of local government in the devolved system. Full participation across multiple scales is required to unlock the inertia.

\subsubsection{Organisations and actors}

Organisational practice is functionally-based with different disciplinary practices dominating the practice. There is a tendency for advice based on different conceptual bases to result in different assessments of risk, thus one set of advice can counteract another. There are some positive signs of experimentation to align practice within organisations and across disciplines and scales, but these are not widespread. They rely upon the leadership of a few key individuals or organisations and informal networks and therefore are unlikely to be sustained over time. Capability that can manage across scales and the complexity of decision making under conditions of uncertainty and dynamic climate change also appears nascent. Engagement practice that demonstrated mutual learning is also nascent, in part due to the low levels of community participation in local government activities and at the polls. Where engagement is occurring, it is outside the statutory frameworks where quasi-legal processes dominated. While positive outcomes were observed for decision makers and communities alike through such processes, their implementation faced institutional challenges. Collaborative engagement processes are not yet embedded in practice so are largely untested for considering uncertainty and dynamic climate change.

\subsection{Concluding comment}

Within each category of practice there are inadequacies in addressing uncertainty and dynamic climate change currently. The institutional framework is interpreted within its quasi-legal and professional disciplinary contexts which combine to lock practice into a time- and space-bound suite of practice tools. This has resulted in greater exposure of humans and assets to climate change risk which is now difficult to change. While there are signs that, for new developments, longer timeframes are being considered, the uncertainties and dynamic change characteristics are not informing the uptake of tools specifically designed to address uncertainty and change. 
The practice has become dislocated from the intentions of the institutional framework which in many respects has elements of an adequate framework. The framework is also fragmented across a number of largely unlinked statutes that all have an effect on decision making about climate change risk over long timeframes. The adequacy assessment of the practice identified where the barriers to practice lie. This assessment also highlighted other factors at play when decisions are being made and which fall outside the framework and the practice, but which are critical for adequate practice. Any institutional framework sits within a wider political and societal set of constraints that influence the ability to implement statutory principles and objectives. 


\section{Chapter 7 Space for change}

The adequacy assessments presented in Chapters 5 and 6 found that the institutional framework itself has many elements that could, in principle, address uncertainty and dynamic climate change. It enables long-term considerations and emphasises precaution and risk-based decision making. However, adaptive and transformational objectives are largely absent, coordination across multiple levels of government is constrained and timeframes are inconsistent across statutes. Practice shows that climate risk has been entrenched by misrepresentation of climate change characteristics, leading to static framings of the risk problem and consequent response measures. The resulting ambiguity is compounded at the different levels of government by gaps in the use of national and regional instruments and consequent differences in court decisions. Practitioners-driven by their disciplinary traditions - use simplistic heuristics to represent uncertainty and thus obscure the implications of the uncertainty and dynamic characteristics of the climate risk. Their reliance on static, time-bound treatments of risk reinforces unrealistic community expectations of ongoing protection even as the climate continues to change, which makes it difficult to introduce transformational measures. Some efforts to reflect changing risk were observed but are, at best, only transitional measures because of the static treatments of risk in time and space. Some experimentation was found in local government practice and boundary organisations ${ }^{84}$ were used as change-agents.

This chapter examines the space for change by first elaborating the features of the policy environment in New Zealand which constrain the space for potential improvements to both the institutional framework and to the practice that could enable flexible and robust adaptation to climate change. Second, the barriers are presented and used to inform potential enablers and entry points for improvements in both the institutional framework design and the practice. Also nonclimate decision settings are examined for design features they may offer for decision making under conditions of uncertainty and dynamic climate change.

\subsection{Policy constraints on improved framework and practice}

Taking anticipatory actions that turn out to be wrong because the climate impacts are different from what was expected, can create high opportunity costs. But taking inadequately conceptualised problems due to both human and technical factors, use of short historic records and neglect of

\footnotetext{
${ }^{84}$ In this thesis, 'boundary organisation' refers to an organisation that links different domains to enhance the understanding of both (e.g., the New Zealand Climate Change Research Institute and the New Zealand Climate Change Centre acting between science and practice).
} 
interconnections can lead to disasters; for example, Japan's Fukushima nuclear accident and the United States' financial crisis (Stein \& Stein, 2014).

New Zealand practice, too, shows failure to consider the decision significance of uncertainty and dynamic change in many coastal and floodplain situations, which has led to continued development on at-risk land which is locked into current development patterns. The consideration of uncertainty and dynamic climate change has not advanced. There has been an inability of practitioners to represent and codify the risk characteristics using the practice measures available to them. The quasi-legal context within which decisions are taken that strive for certainty of outcome has been a significant contributor. The lack of integration across governance scales and inadequate use of statutory tools that could provide stronger leverage for decision making at the local level has also contributed. These features result in a strong focus on reacting after climate events.

A reactive approach is not particular to climate change consideration. There have been the spectacular policy failures contributing to the Pike River Mine explosion in 2010 (Royal Commission on the Pike River Coal Mine Tragedy, 2012), leaky buildings (Mumford, 2011) and liquefaction damage from the 2010 and 2011 Canterbury earthquakes (Canterbury Earthquakes Royal Commission, 2012). These examples saw health and safety practice and governance, building safety codes, earthquakes standards and consideration of natural hazard risk being strengthened after the fact. The failures had huge economy-wide and social implications and provide 'cautionary tales' for institutional design and practice improvements for climate change adaptation; all these cases had light-handed regulation, weak national oversight and devolution of responsibilities at the core of the failure. These types of problems are what Bazerman (2006) called "predictable surprises" that can be anticipated and acted upon.

In a democratic society like New Zealand, the exercise of so-called 'property rights' collides with the public interest that is reflected in national statutes and policies. In the New Zealand statutory framework, property rights have been explicitly constrained as a matter of legislative design in the public interest to 'do no harm', as discussed in Chapters 2 and 5. The community, as distinct from individuals, has a legitimate expectation of equitable decision making today that does not transfer risk to them, nor increase harm to current or to future generations, or their ability to adapt in the future. The enabling design of the RMA, the light-handed implementation of the rest of the regulatory framework and its fragmented character reflect the norms in the New Zealand legal and regulatory practice over the last two decades (Lawrence, Wolf, et al., 2013). There is thus an open question as to whether local government is able to use existing institutions to anticipate and 
proactively manage the impacts of climate change. Van Buuren et al. (2013) examined the ability of institutional frameworks for spatial planning to address uncertainty, contentiousness, multiplicity and complexity of climate change. They called for adaptive approaches that embody learning, experimentation, dialogue and flexibility. These are the practices that are largely absent in the New Zealand institutional framework and in practice.

In New Zealand, the cognitive feedback from major damaging natural disasters and crises occurs in some localities and not others, with differing frequencies: relatively often in the case of floods, and less so with major earthquakes. The impact of the Canterbury earthquakes was so large (estimated at $\$ 40$ billion in addition to the loss of 185 lives) that it triggered some institutional change; direct central government intervention that overrode local government recovery functions through a special purpose organisation (CERA). However, neither frequent localised floods nor earthquakes with significant national effects have influenced a change in cultural norms that could trigger the transformational change required in some areas as sea levels rise and high intensity storms become more frequent. This leaves the consideration of dynamic climate change within a framework that has not proven to be anticipatory of 'predictable surprises', flexible or adaptive. This outcome makes the current framework and the practice inadequate for addressing changing climate risk across council functions and between governance scales.

Scholars of institutional theory (Ostrom, 1990, 2009, 2010; Young, 2002) discuss nested levels in institutional form that govern behaviours of the players according to their distinct roles and the dependencies between these players. In New Zealand, such an institutional framework has not adequately motivated the use of precautionary measures or risk management that address the range of climate change impacts. In New Zealand, institutional dependencies, combined with a high level of devolution and fragmentation of responsibilities emerged as barriers, rather than being well interconnected as envisaged by Ostrom and Young in a theoretical context.

Changing climate challenges the governance and institutional rules that have been used previously for incremental adaptation addressing current climate variability. The coping capacity of existing institutions is likely to be stretched by the projected climate changes that are outside the range of climate experienced to date, especially at the extremes: an adaptation deficit already challenges those responsible for major assets (New Zealand Office of the Auditor-General, 2014). This means that transformational change from the current state (Kates et al., 2012) will be required where incremental legislative changes no longer meet future needs. However, ideas of transformational adaptation in a climate change context were shown in Chapter 4 to be light on 'how' change can 
be achieved to enable institutions to anticipate and address more extreme climate effects such as rising sea levels, increased coastal storm frequency and changes in flood frequency and intensity.

\subsection{Framework and practice barriers}

The policy constraints discussed to this point help identify the source of the inadequacies within the current institutional framework and practice. Discussion of the barriers that arose from the adequacy assessments provides a starting point for opening up the space for how and where framework and practice improvements might be made. The barriers are inter-related. For example, fragmented practice has its source in fragmented statutes; the disciplinary traditions of the practitioners frame climate risk differently; practitioners are unable to implement climate change adaptations because of the social, cultural and political contexts within which decisions are made. The barriers thus reinforce one another and broadly encompass the concepts of 'fit', 'interplay' and 'scale', as discussed in Chapter 2. Table 7.1 presents a summary of the barriers and shows the connections between framework barriers and practice barriers. This provides a reference point for the narrative that follows. 
Table 7.1 Barriers to uncertainty and dynamic change considerations

\begin{tabular}{|c|c|c|}
\hline Barriers & Institutional framework & Practice \\
\hline $\begin{array}{l}\text { Understanding } \\
\text { and } \\
\text { representing } \\
\text { uncertainty and } \\
\text { dynamic climate } \\
\text { change } \\
\text { characteristics }\end{array}$ & $\begin{array}{l}\text { - } \\
\text { tratutory processes and practice } \\
\text { - } \quad \text { Fragmentation of data and } \\
\text { information stewardship affects } \\
\text { accessibility } \\
\text { - Weak and fragmented monitoring } \\
\text { requirements in statutes }\end{array}$ & 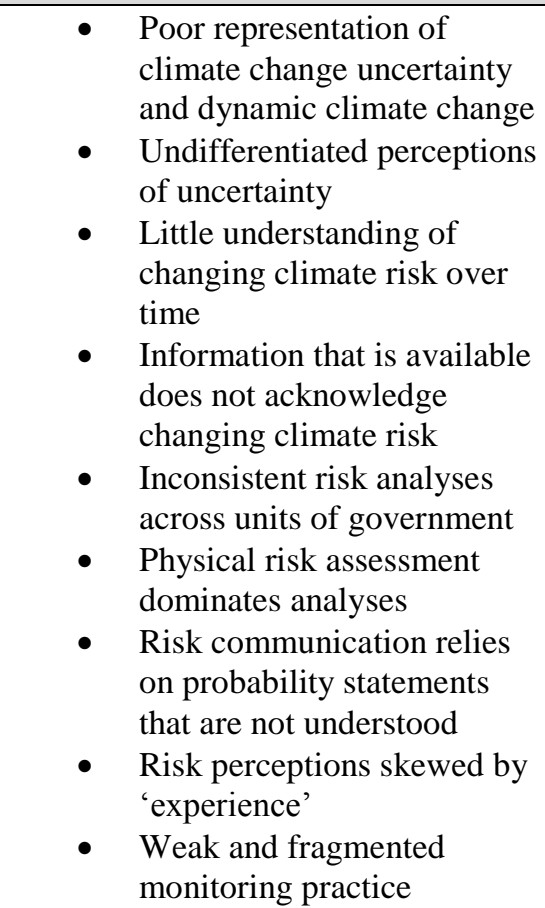 \\
\hline $\begin{array}{l}\text { Governance } \\
\text { and regulation }\end{array}$ & $\begin{array}{ll}\text { - } & \text { Fragmented and misaligned } \\
\text { statutes } \\
\text { - } & \text { Case-by-case decision making } \\
\text { - } & \text { Lack of governance and } \\
\text { regulatory integration across } \\
\text { multiple scales } \\
\text { - Quasi-legal processes in statutes } \\
\text { demand certainty of evidence } \\
\text { Overlapping responsibilities for } \\
\text { hazard management and climate } \\
\text { change effects between regional } \\
\text { and territorial local government }\end{array}$ & 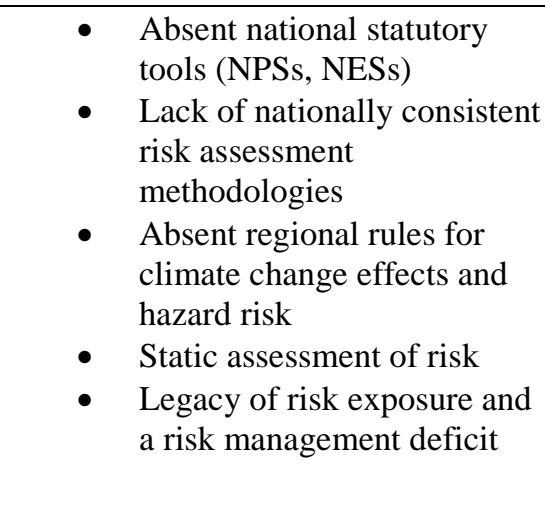 \\
\hline $\begin{array}{l}\text { Organisations } \\
\text { and actors }\end{array}$ & 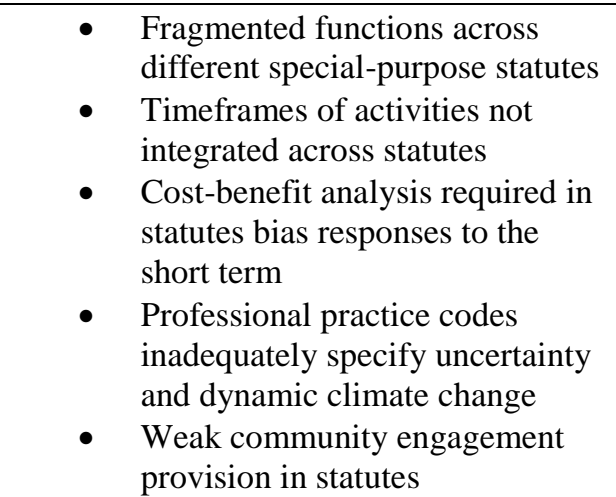 & $\begin{array}{ll}\text { - } & \text { Inconsistent professional } \\
\text { discipline practices } \\
\text { - } & \text { Reaction to one-off events } \\
\text { dominates over risk } \\
\text { reduction by anticipation } \\
\text { - } & \text { Siloed council processes } \\
\text { across functions } \\
\text { - } \quad \text { Inflexible planning measures } \\
\text { used over space and time } \\
\text { Capacity and capability } \\
\text { deficits in using robust and } \\
\text { flexible assessment tools }\end{array}$ \\
\hline
\end{tabular}




\subsubsection{Understanding and representing uncertainty and dynamic climate change characteristics}

The institutional framework determines how the characteristics of climate change risk can be understood and thus the decision significance of them. The framework sets up a quasi-legal setting for decision making, that constrains the way 'evidence' can be used by striving for certainty. The resulting practice represents climate risk as a 'central tendency' or uses 'single numbers' that can be easily translated into static measures for 'protection' and thus creating 'certainty' of outcome. But any measure that is static in space and time will be outflanked by rising sea levels or greater frequency of intense rainfall events.

The framework is fragmented, which leads to fragmentation of data and its accessibility, leading to inconsistent risk analyses and inconsistency of decision making across the small units of local government. By concentrating on physical risk considerations, advisors and decision makers also fail to identify differential vulnerabilities at a community level. Integration of statutes and timelines and using communication formats that convey the nature of the climate change risk in ways that have 'meaning' for people may be a fruitful place to start addressing these barriers. Using monitoring systems and communicating the consequences at a level that communities can 'experience' the risk is another way to improve environmental feedback to those at risk, thus making the threat more tangible.

\subsubsection{Governance and regulation}

The fragmentation and misalignment of the relevant statutes act as a barrier to integrated decision making that could avoid decisions in one area 'trumping' decisions in another. The fragmentation and misalignment thus exacerbates the existing risk. Two other barriers also exacerbate risk: the gap in instrument use at national and regional levels that could help with the integration process; and the overlapping and different responsibilities for hazard risk management and consideration of the effects of climate change at the regional and district levels of government.

Devolution of functions in the absence of cross-scale integration and uptake of tools for addressing uncertainty and dynamic climate change has resulted in an inefficient system that makes ad hoc decisions at the lowest level of government. Devolution has had the effect of compounding climate change risk by creating path dependency which is difficult to change. This outcome challenges the assumption in the literature, based on subsidiarity, that local government is the most appropriate location for climate change adaptation decision making. Others have also challenged this assumption (Conway \& Mustelin, 2014) in the context of developing countries. The practice evidence in Chapter 6 suggests that cross-scale decision making that supports each level and is 
coordinated across the scales has potential for framework and thus practice improvements. Governance fragmentation also has the effect of blurring responsibilities, leading to gaps in the implementation of national and regional instruments; providing such instruments could be a critical place to start improving practice because it would provide the support needed to motivate changed decision making.

\subsubsection{Organisations and actors}

Fragmented statutes have led to siloed council functions operating under their statutory mandates. Combined with different professional practices within each mandate, this has created outcomes at odds with uncertainty and dynamic change: they are either not considered; or advice in one discipline constrains what another can advise, by limiting the possible measures and their flexibility. The tendency to react to one-off events using emergency management institutions rather than reduce risk by anticipating it has further entrenched risk.

Disciplinary traditions under each functional mandate create a barrier to consideration of uncertainty and dynamic climate change and result in the significance of decisions not being reflected in assessments and in the use of static response measures. The capability for using robust and flexible tools that are already available is weakly developed. Overcoming legacy decisions as risks change demands new ways of thinking that are not envisaged within the scope of the current framework. The ability of organisations to make a shift from short-term perspectives when making decisions about future climate risk will be critical to effective adaptation over time. Such a shift will come from finding enablers and entry points that can address the barriers discussed in this section and a number of contextual barriers that will influence robust and flexible adaptation outcomes.

\subsubsection{Contextual barriers}

The institutional framework and practices do not sit or operate in isolation of the context within which decisions are taken. While the focus of this thesis is on the adequacy of the institutional framework and practices, what follows are two further barriers that influence the ability of decision makers to operate under the framework and address uncertainty and dynamic climate change. Discussing such barriers will give a better sense of whether the suggested framework and practice improvements set out in Sections 7.3-7.5 can be practically implemented without addressing the contextual issues.

\section{$\underline{\text { Resourcing barriers }}$}

Resources emerged as a barrier in two different ways - actors and their capability, and funding for anticipatory actions. 
The capability of the actors within local government for addressing uncertainty and dynamic climate change is growing, as evidenced in Chapter 6. However, there are barriers to the uptake of current and new tools. Tools and techniques available and used internationally are not in current use in New Zealand; for example, robust decision making and real options analysis (Dobes, 2008; Lempert \& Collins, 2007). This is not surprising given the small pool of expertise for their application here. Uptake of such tools is a slow process and requires resources and networks to build familiarity with them. Simple ways of applying the tools are developing and can be used currently but will require resourcing of capability development to become mainstreamed into decision-making processes.

The lack of developed financial mechanisms to fund managed retreat along rivers and at the coast was identified as a barrier to implementing more transformational adaptation that will be required eventually as sea levels rise and rainfall frequency and intensity increase. Where managed retreat has been successfully implemented in New Zealand, success has been due to the availability of funding and community engagement in the project (Vandenbeld \& MacDonald, 2013). Funding barriers were reported also for risk identification, its framing and communication, and for tools for assessing adaptation options. More effective risk identification and accessible ways to disseminate and communicate information that is relevant to the real problems faced by councils will be required. This will need funding and coordination among the research communities and their networks nationally and internationally and with the practitioners on the ground.

The importance of better uptake of decision-making tools is further highlighted by the cost of provision of assets rising as capital costs increase to cope with increasing risk (e.g., pipe capacity, land purchase adjacent to streams and secondary flood flow paths). The goal posts are changing. Community expectations of increased service levels will place significant pressure on the funding tools currently available to councils. The reform of the Local Government Amendment Act $2012^{85}$ which has reduced the debt levels allowed by councils and removed provision for integrated management across economic, social, environmental and cultural wellbeings will place further funding pressures on councils. This legislative change also provides another example of lack of integration between statutes affecting infrastructure provision and climate change adaptation.

\section{Political barriers}

Political barriers were ever present in the practice observed, in decision making about climate change adaptation. Prominent was central government equivocation about adaptation to climate change as reflected in public statements (Radio NZ., 6 April 2014) by the President of Local

\footnotetext{
${ }^{85}$ Local Government Act 2002 Amendment Act 2012.
} 
Government New Zealand and the Minister for Climate Change on the release of the IPCC Fifth Assessment WG 2 Report in March 2014. The call by local government for integrated thinking about climate change was responded to by the Minister as being a local issue for local government:

Local Government New Zealand President Lawrence Yule says Parliament needs to set national directives and timelines for climate change adaptation.

"Without any central government directive it is quite difficult for councils to do what effectively might be the right thing for the future, but is seen as being too aggressive for the people of the present."

The Climate Change Minister, Tim Groser, favours setting general guidelines. "We still think it's better to give generalised approaches and let local communities work through that process within their own democratic frameworks."

Chapter 6 illustrates that local solutions are unlikely to be implemented without a greater role from central government supporting local decision making. Two reasons for a greater central government role are; the potentially wide range and national implications of climate change across society and the economy; and for economies of scale of supporting policies and activities, such as national policy statements, information provision and funding support for transformational actions such as the inevitable managed retreat from the coast over time. These policies and activities cannot be instituted effectively by single units of local government through devolved functions.

Political barriers arose from decision-makers' perceptions of community expectations driving their political representation on councils. Councils have a number of competing priorities and near-term priorities often win out to long-term considerations, especially if there is a perceived uncertainty surrounding the long-term outcomes of climate change. Reluctance by decision makers to engage in the strategic conversations with communities about climate change and the range of possible responses, for fear of ridicule, legal challenge or for the impact on their political future was evident. The false sense of security set up by static responses to existing climate risks and the use of orthodox technical formats for describing risk probability has maintained community expectations that councils will continue to protect them from harm (Lawrence et al., 2014). Within the 3-year electoral cycle, climate change risk is a hard issue for councils to tackle alone.

Vision and leadership around long-term futures affected by climate change is generally lacking across councils. While attempts are underway, for example, by the Auckland Council through its mandated spatial and unitary plans, greater strategic spatial planning is unlikely to happen 
autonomously in most councils under their current statutory mandates. One reason is the mismatch between what is politically and socially acceptable and what the science, the law and risk management is telling councils about their liability for damages if business-as-usual continues.

Political barriers have the potential to create ongoing uncertainty for assessment of climate risks for large investments of public money and for calls on the public purse for 'climate events'. Political barriers are the inevitable consequence of a democracy with a 3-year electoral system that can change the policy parameters, both formally through legislation and informally through council and ministerial preferences. To what extent governance and institutional reform could provide a stable platform for anticipating and managing climate risk is not clear. Leaving consideration of "climate change effects" primarily with small units of local government, without the institutional support and tools to 'do the job', is likely to create greater damages in the future and the transfer of risk to the most vulnerable and to future generations.

None of these barriers is unique to the New Zealand situation. Similar barriers have been identified elsewhere (Adger et al., 2007; Adger et al., 2009; Amundsen, Berglund, \& Westskog, 2010; Biesbroek, Termeer, Kabat, \& Klostermann, 2009; Burch, 2010; Juhola, Haanpää, \& Peltonen, 2012; Measham et al., 2011; Moser \& Ekstrom, 2010; Productivity Commission, 2012; Storbjörk, 2010). What this study offers is a new perspective because the New Zealand practice operates under an institutional framework that already has many of the characteristics of an adequate framework for considering uncertainty and dynamic change, unlike other jurisdictions (see Chapter 5). However, New Zealand lacks transparent and inclusive risk governance at multiple scales. This raises the question of missing links in the adequacy of institutional frameworks and practice for climate change adaptation. It also suggests that the full range of 'fit', 'interplay' and 'scale' (Young, 2002); risk and adaptive governance (Renn, 2008; Renn, \& Schweizer, 2009; Klinke, \& Renn, 2012); and anticipatory governance (Boyd, Nykvist, Borgström, \& Stacewicz, 2015), could help complement the existing governance and institutional framework and practice. In a New Zealand institutional setting Glavovic, (2014) suggested that public and stakeholder deliberation can build understanding of different values and preferences where controversy reigns over evidence, and build acceptability and tolerance where views differ, making it clear that responses will need to fit the risk problem.

Several sources were used to identify possible enablers and entry points for framework and practice improvements: incremental legislative changes suggested by some local government research participants; demonstrated success factors identified by three councils' practice; the framework and practice ideas that emerged from the adequacy analysis of the 
framework and practice; and the analysis of non-climate decision settings where decisions under conditions of uncertainty and dynamic change are also made.

\subsection{Suggested incremental legislative improvements and success factors}

Part of the methodology for this study (see Chapter 3) was to discuss with a sample of practitioners initial ideas emerging on opportunities for framework improvements. This resulted in some suggestions for legislative and practice changes (Box 7.1) and identified some success factors (Table 7.2) from councils' attempts to address uncertainty and dynamic climate change in their current practice. The legislative and practice suggestions were seen as necessary improvements which, in the practitioners' view, would support their ability to address uncertainty and dynamic change. But they were not seen as sufficient. The suggestions made address understanding and representing uncertainty and dynamic climate change characteristics, governance and regulatory change that align responsibilities across the multiple scales and new ways rules can deliver on the precautionary and risk management intent of the framework. However, the improvements are largely incremental and only address the decision-making challenge at the margins, doing little to enable greater adaptive management or more transformative change. 


\section{Box 7.1 Incremental improvements to the framework suggested by practitioners}

Understanding and representation of uncertainty and dynamic change characteristics

- Utilise Land Information memoranda (LIMs) and hazard records for properties at risk including photographs.

- Develop consistent and flexible planning rules and 'zoning' approaches that address uncertainty and changing climate risk.

- Develop measures for applying the intergenerational provisions in RMA.

- Develop consistent measures for addressing private ownership issues/existing uses in hazard zones (e.g., planned retreat).

\section{Governance and regulations}

- Utilise opportunities for integration from unitary governance and greater governance scale.

- Amend legislation so all hazard risk rules can have immediate effect, without having to go to the Environment Court.

- Use section 106 RMA more for refusal of subdivisions and amended to define "sufficient provision has been made or will be made in accordance with subsection (2)" that links this provision with the intergenerational provisions of the RMA.

- Align the Soil Conservation and Rivers Control Act with the climate change and hazards provisions of the RMA and BA.

- Review adequacy of the Building Code standard at 2\% AEP for flood risk in light of changing climate risk.

- Improve the BA decision-making arrangement for building consents under sections 71, 72 (for example, reduce the specific duty under section 72 in light of the general duty under section 71).

- Add climate change effects to the contingent cover for hazard risk in the EQC

\section{Organisations and the actors}

- Develop organisational links across functions.

- Integrate functions to facilitate connections between climate change and other responsibilities.

- Enhance networks across technical disciplines through professional bodies.

- Revise practice standards that frame the risk as changing rather than static.

- Adopt tools that can assist decision making under uncertainty and change.

- Develop capability in decision making under conditions of uncertainty and changing climate risk.

The success factors show how practice that attends to risk understanding and its representation, governance, regulatory and organisational integration, actor capability through professional disciplinary practice integration and political integrity supported by the courts, can reap practice success; success, because precautionary practice was implemented, risk over time was considered, provision for flexibility through adaptive design of rules was made and the courts were confident making precautionary decisions. However, as noted in Chapter 6, such practice is ad hoc at the individual units of local government and has been slow to embed in practice nationally (Lawrence, Wolf, et al., 2013). 


\section{Table 7.2 Success factors}

\begin{tabular}{|c|c|}
\hline Success factors & $\begin{array}{l}\text { Practice } \\
\text { (based on Tasman and Kapiti Coast districts; } \\
\text { Hawkes Bay region) }\end{array}$ \\
\hline Council approach & $\begin{array}{l}\text { Hazards assessment; graduated development of } \\
\text { controls }\end{array}$ \\
\hline Strategic approach & $\begin{array}{l}\text { Decade-long processes; comprehensive } \\
\text { development strategies }\end{array}$ \\
\hline Professional focus & $\begin{array}{l}\text { Continuity of staff; expertise and information } \\
\text { available; monitoring }\end{array}$ \\
\hline Integrated functions & $\begin{array}{l}\text { Highly integrated, with corroborative 'evidence' } \\
\text { across functions }\end{array}$ \\
\hline Community engagement & Ongoing community engagement at critical stages \\
\hline Political fortitude & $\begin{array}{l}\text { Consistency maintained over long timeframes; } \\
\text { political commitment driven off high staff } \\
\text { capability and political continuity }\end{array}$ \\
\hline Judicial integrity & $\begin{array}{l}\text { Two councils tested their policies and plan rules in } \\
\text { Environment Court successfully; one upheld in the } \\
\text { High Court; one subdivision appeal by a private } \\
\text { interest was declined }\end{array}$ \\
\hline
\end{tabular}

\subsection{What can be learnt from analogous non-climate decision settings?}

Empirical experience is limited about how institutions that govern human systems address uncertainty and dynamic climate change (IPCC, 2014a). Some analogous non-climate decision settings were therefore examined to see whether their institutional frameworks and practice were better than those used for climate change adaptation. Seven possible analogues were examined (see Table 1 Appendix 5). Three-pandemics, biosecurity incursions and earthquakes—addressed known and sudden threats; four-financial crises, insured risk, retirement income and surgical risk - addressed known, progressive or changing risks. All have some uncertain elements and have some elements in their institutional frameworks and practices that have potential for managing changing climate risk over long timeframes. They have all been tested in practice. The utility of present day analogues for understanding institutional responses that have learning potential for considering uncertainty and dynamic climate change does not appear to have been considered in the literature. ${ }^{86}$

\footnotetext{
${ }^{86}$ This analysis of potential analogues for institutional framework and practice learning for making decisions about uncertainty and dynamic climate change is the subject of a paper I have in preparation for publication.
} 


\subsubsection{Institutional analogues that respond to sudden threats}

In a New Zealand context, the statutory framework for managing pandemic risk was developed ahead of a pandemic. This enabled legislation to be developed and agreed that had executive powers to curtail civil liberties by relaxing a number of statutory requirements on Ministers and local government to ensure speedy response. This was unlike what happened in response to the Canterbury earthquakes in 2010 and 2011; when a special purpose recovery agency was set up (CERA) in a rush, in the chaos of the disaster with similar curtailment of civil liberties but with weak links to the precautionary intent of the RMA, setting up further fragmentation of statutory responsibilities.

Both pandemic and biosecurity risk management combine a number of elements of pathways management, monitoring and response capability that link precaution and response together in their institutions. However, a weak link was identified by the Office of the Auditor-General for biosecurity management in the maintenance of capability for these functions. Earthquakes are also managed in a similar monitoring- and capability-dependent system based on response to one-off events that failed to anticipate "overlapping multiple events" [reinsurer] and which underestimated the capacity required to deal with the ensuing claims, through the EQC (see Chapter 6). Earthquake and climate risk management both rely upon similar institutions for response and recovery after 'events'. There may, therefore, be potential for integration of risk reduction activities that could break the cycle of recovery in the same at-risk locations and thus help reduce risk exposure.

This first category of potential analogues focus on one-off event management, containment of risk or on recovery processes. They are therefore reactive rather than anticipating potential contemporaneous impacts nationally in space and over time. They do, however, exhibit supporting institutional arrangements that enable future risk to be managed through protection (building code for integrity of structures), monitoring (through access to international surveillance of risk) and scientific information systems (through international and domestic research) that can provide either early warning or ready systems for immediate response. These latter systems are essential elements of any risk-management system (Handmer \& Dovers, 2013).

\subsubsection{Institutional analogues that respond to known progressive and changing risks}

The financial supervision oversight developed by New Zealand's central bank demonstrates an institutional response that minimises risk arising from uncertainty and dynamic change but which also anticipates future financial crises. It is based on the experience of the global financial crisis in 2008. A number of flexibility mechanisms derived from the Basel Accord ${ }^{87}$ are used for

\footnotetext{
${ }^{87}$ See http://www.bis.org/bcbs/basel3.htm
} 
reducing sovereign risk, such as the concept of a 'living will' which protects governments from exposure to banks that have taken on excessive risks knowing that the government will bail them out (a moral hazard). A 'living will' is a contingency plan to prevent financial panic in event of a financial crisis, by quarantining certain risk categories to avoid exacerbation of risk. Measures include: requirements on banks to take precautionary prudential management by setting capital aside for underwriting risks ahead of a crisis (self- insurance); borrowing rules to manage liquidity to avoid banks off-loading risk to the government (reducing transfer of risk); resilience reporting (performance management); prudential supervision to manage relationships between risk governance levels (relationship management); forecasting and scenario planning (uncertainty management); and risk communication (risk framing) and public transparency (accountability and knowledge management). These features form an interconnected framework of measures for managing known and unknown risks. Shortfalls of this framework were identified by the respondents as the short decadal focus and banks having a vested interest in understating the risks. Nevertheless, it does speak to some of the weaknesses in the institutional framework and practices for managing climate change risk - its anticipatory design, its attention to risk transfer, availability of contingency funding, relationship management across scales and transparent decision making, for example.

Central banks have another institutional measure for anticipatory risk management—-stress testing (Tattersall, 2010)—which tests the impact of a changing risk environment and thus enables acceptable risk levels to be determined and brought within threshold levels. This is analogous to sensitivity analysis of the vulnerability of systems to changing climate risk. An approach that does this uses scenario discovery (Groves \& Lempert, 2007; Kwakkel, Auping, \& Pruyt, 2013; Lempert, Groves, Popper, \& Bankes, 2006) to address known and unknown risks by testing thresholds or tipping points in human systems' ability to cope with the changes. Likely losses that could make some interventions not viable for dealing with change can be identified, and interventions that can be used in an adaptive manner can also be identified. Stress testing used in this way has been suggested in the New Zealand context (Lawrence, Reisinger, et al., 2013) and demonstrated in the Netherlands context (Haasnoot et al., 2013; Kwadijk et al., 2010) where it has been implemented by the Delta Commission (Pieter Bloemen, Dutch Delta Commission, personal communication, 2014).

The main institutional mechanisms used in insurance to manage risk are the one-year contract and risk rating. Historically, insurance has provided a weak incentive to avoid or reduce exposure to 
hazard risk. The Canterbury earthquakes created pressure from the reinsurance industry to reduce exposure, arising from an increase of global disasters. The effect was to remove insurance coverage for new buildings in some at-risk areas; tailor insurance products that better reflect the risk through increased premiums or increased deductibles; and to shift the basis on which insurance cover is given, from unlimited replacement policies to a system of nominated (based on insured replacement value which is the responsibility of the homeowner) and capped replacement policies. There was some historic evidence of insurance having been used as a lever on local councils to identify climate hazards risks and to use planning measures to reduce risk (for example, after a 'weather bomb' in the Thames Coromandel district). A number of risk mitigation measures were undertaken by the council and home owners collaboratively and insurance cover continued. However, insurance is a blunt instrument which only becomes sharper after major climate or other hazard events have occurred.

The New Zealand superannuation policy has three institutions of interest: the New Zealand Superannuation Fund, a taxpayer-funded fund set up by statute in 2001 to put "Super above Politics"88; a Crown entity to manage and administer the fund (the Guardians of New Zealand Superannuation); and the Commission for Financial Literacy and Retirement Income, set up in 1993 to improve financial wellbeing throughout New Zealanders' lives. These institutions are a package designed to sustain the retirement benefit paid to all New Zealanders over the age of 65, over future generations. The management of the future risk is based on three principles: a stable and effective government policy; a trusted financial services sector; and a financially educated population. Underpinning this high-level framework are assumptions that a lifetime savings approach will result in a better-off population in the later years of life and that preparedness after a working life and shared personal/employer responsibility will deliver sustainable outcomes. The framework addresses several weaknesses in the climate change institutional framework and practice: built-in review and political continuity; independence; anticipation; and prefunding to address intergenerational equity. Accordingly, these design elements could also be used for funding the adjustments that will be necessary ahead of climate change impacts and to share the burden across generations.

Surgical risk management is the only potential analogue that explicitly addresses cognitive behavioural aspects of decision making; aspects that are significant in consideration of climate change impacts that are perceived as a 'distant threat'. Surgical risk has similarities to managing climate change risk in that both decision settings are dealing with a complex system (interventions

${ }^{88}$ Press statement by Hon. Michael Cullen. Refer to http://www.beehive.govt.nz/node/9207 
on human bodies versus interactions between climate changes and human systems), the consequent uncertainties and the dynamic change are at the extremes (life and death versus climate extremes and consequent human security). Both settings have a range of professional disciplines operating. Many medical decisions are made with a lack of good evidence and based on expert judgement, not unlike decision making about climate risks, and both have a 'discipline' of evidence diagnosis of problems.

Uncertainty is managed in surgical settings through anticipatory preoperative diagnosis methods to eliminate likely causes of presenting problems and particularly 'nasty' problems. Medical practitioners have varying degrees of tolerance for uncertainty (Ghosh, 2004) manifest by high levels of diagnostic testing, variation of medical treatments and non-compliance with medical practice guidelines, for example. Factors contributing to these variations include differences in prioritisation of factors, knowledge gaps, time pressures and lack of resources; all factors affecting adequate decision making about climate risks. Practices employed in medical settings to overcome these variations include prompts to undertake certain activities using checklists, computer support of practice activities, action education that introduces new skills and which challenges barriers to variability that are sourced to unsafe or inappropriate behaviours.

Uncertainty management pre-surgery is reinforced in the surgical theatre setting through clear role definition for the 'ABC' procedures which dictate checking Air, Breathing and Circulation. For example, if a patient's heart rate goes up the surgeon deals with any bleeding and the anaesthetist deals with blood pressure. This practice addresses clarity of roles and responsibilities. The actions taken are based on assessment of probability and risk which involves System 1 responses that are procedural, and System 2 responses that are intuitive (Stanovich \& West, 2000), a dual process system of thinking that has also been adopted by behavioural economics (Kahneman, 2011).

Risk response is supported by different equipment being available in clearly identifiable locations (special equipment and different trolleys) for rapid response; akin to tools that address uncertainty and dynamic climate change. Those involved in surgical settings are trained not to disregard things and to ask questions about what is observed. Medical practitioners are constantly identifying, classifying and categorising a situation they are presented with; akin to dynamic adaptive responses and based on the principle that no one brain can take in everything occurring during surgery. Therefore an element of redundancy and contingency for the unexpected is provided for in practice, based on cognitive factors that govern the behaviours of the actors. The role definitions and permission to question across the team provide the necessary backup for dealing with the complexity of the situations encountered. The injection of checklists into this environment to 
address flaws that arise from System 2 thinking has successfully reduced the rate of major complications in operating theatres (36\% drop in the rate of complications, with a decline of deaths by $47 \%$ (Gawande, 2011, p. 154; Haynes et al., 2009)). Gawande also found (p. 156) that the rate of bleeding also declined because there was a significant increase in the level of communication across the team with the introduction of the checklists; akin to making connections across functions and governance scales which is a weakness in the handling of climate risk decisions.

Human behavioural and cognitive barriers emerged as the dominant barriers to safe decision making in an uncertain environment; for example, 'pride' in not asking for help from others; role of hierarchies in reducing willingness to question others; flaws in pattern definition; inability to articulate uncertainty when things don't make sense. 'Fixation error' is "the most potent barrier" often based on inadequate knowledge and previous experience, leading to $x$ when there is a possibility of $y$ and $z$. Thinking de novo by treating each case as unique as a diagnostic procedure and fostering a culture of collaborative learning for shared understanding through team communication, debriefs and training emerged as critical for managing uncertainty and change.

Surgical risk management has institutionalised an understanding of cognitive and behavioural issues that create barriers to managing risk through redundancy, backup safety elements, disciplinary norms, structures and sanctions that can diagnose risk exposure and enable effective responses, backed up by a number of monitoring and performance tools on the organisations and professional disciplines. These elements reinforce a strong professional learning ethic to maintain a safe environment for making decisions in uncertain and changing situations; all matters that are weak in the climate change institutional framework and practices.

\subsubsection{Summary of analogue learning}

The first category of potential analogues — pandemics, biosecurity threats and earthquakes - focus on one-off event management, containment of risk or on recovery processes. However, they all exhibit supporting institutional arrangements that enable future risk to be managed through protection (building code for integrity of structures), monitoring (through access to international surveillance of risk) and scientific information systems (through international and domestic research) that can provide either early warning or ready systems for immediate response.

The second category of potential analogues - financial risk supervision, insurance, superannuation and surgical risk management - have anticipatory design in their institutions to a greater or lesser degree. Financial risk supervision exhibits 'stress testing', a tool to test risk sensitivity which has relevance for managing deep uncertainty about climate change using scenario discovery and has the ability to be used to quarantine (prioritise) risk so it can be contained to reduce widespread 
damage. However, the focus of financial risk supervision is short term; while the institutional design anticipates future damage, its implementation is ex-post facto thus it is not truly precautionary in the sense that actions are taken ahead of time to avert the damage from an event. Insurance that reflects the risk can provide leverage for risk mitigation by responsible agents and individuals but operates on short timeframes.

Superannuation is the only example that has institutions based on the anticipation of long-term changing risk by adjusting policy settings after review, using instruments to manage intergenerational risk and, at the same time, delivering certainty of outcome, political stability and continuity of policy settings. It is also supported by learning, through education. Surgical risk management institutionalises the management of human behavioural flaws in its actors through monitoring, education, professional performance tools and sanctions. This high level of risk management is appropriate in 'life-and-death' situations where public expectations of 'safety' are high. Given the likely consequences of climate change, similar institutional arrangements have salience for decision making under conditions of uncertainty and dynamic climate change.

None of these is a complete analogue for managing uncertainty and dynamic climate change, but each provides several design elements that have salience for decision frameworks and practice that is both robust and flexible-review provisions, clear role responsibility, capacity to address procedural and intuitive behaviours, capacity and tools to manage risk over long timeframes, professional practice norms and sanctions, integrated practice across governance scales and the ability to test decisions against a range of future outcomes. These features have salience for the design of complementary organisational and practice measures that could make the current framework and practice for climate change adaptation more robust and flexible over long timeframes. Figure 7.1 summarises such potential design features. 


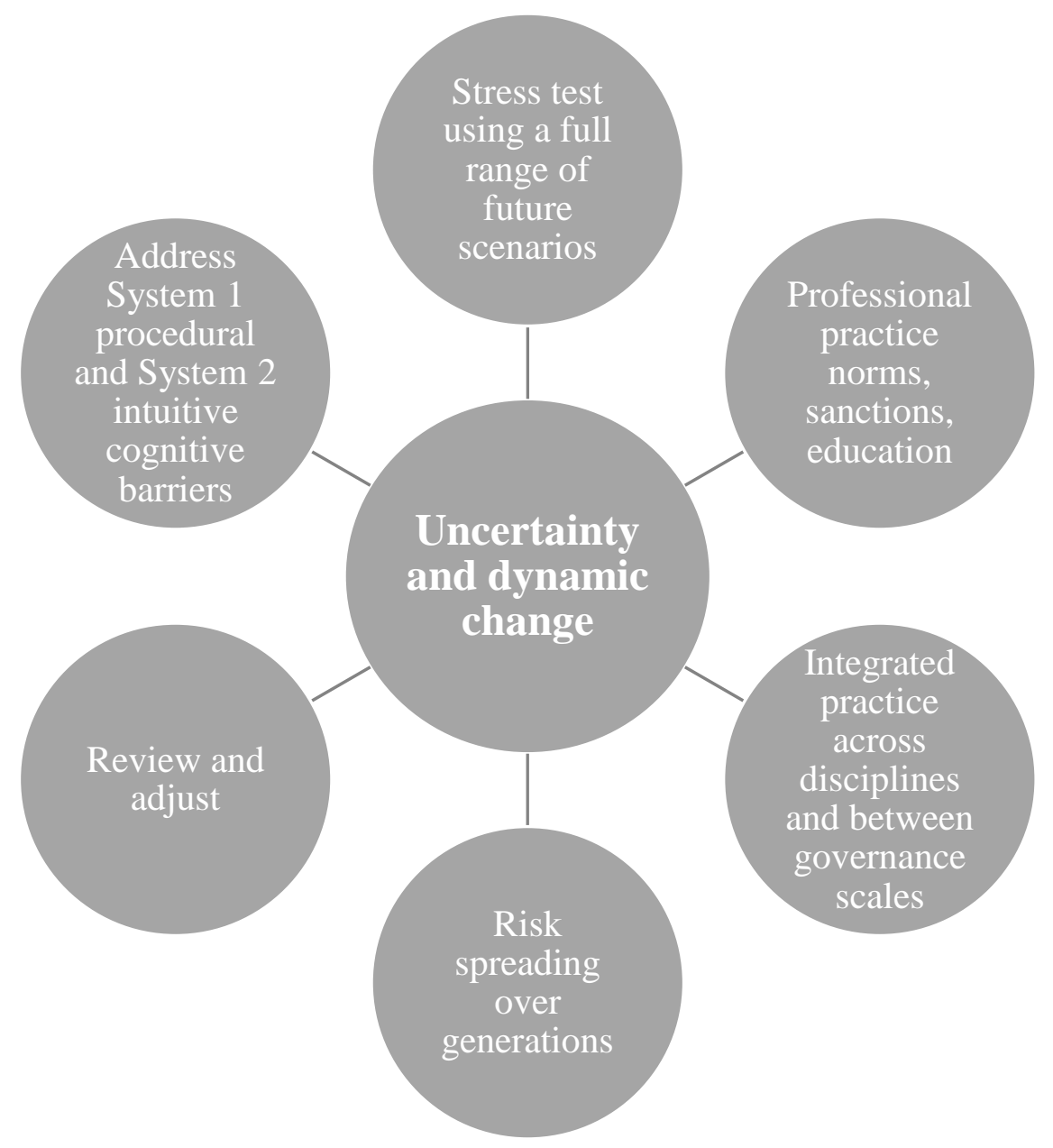

Figure 7.1 Potential framework and practice design features from analogues

These features could be incorporated as enablers alongside those discussed below in section 7.5. There is acknowledgement already in the context of financial supervision that stress testing has a place in managing uncertainty and change; the NZ Super Fund already incorporates elements of risk spreading over generations; New Zealand already has an earthquake damages fund that covers other natural disasters; and new organisations have emerged rapidly from time to time to address pressing problems. It is not such a big stretch to translate the concepts that underlie these institutional frameworks and practice, and apply them to institutional frameworks and practice for addressing climate change adaptation. The more challenging area for change is in human behaviours and professional practice norms; and better integration across disciplines and between governance scales. This is where risk and adaptive governance can inform institutional frameworks and practice. 


\subsection{Institutional enablers and entry points}

By way of introduction an overview is given of some of the institutional literature relating to barriers, enablers and entry points, before discussing potential enablers and entry points.

\subsubsection{The institutional space and interconnections}

The manner in which the governance and institutional arrangements are designed has an important bearing on the ability of the actors to consider climate change risk in their decision making. Several scholars have identified institutional fit, interplay and scale as being critical when making decisions that involve interactions amongst biophysical, economic and social worlds (Folke et al., 2005; Young, 2002). From a decision perspective, governance and institutional design also sit within a wider context of supporting processes that enable the framework and practice to operate effectively.

A recent discussion of barriers to adaptation (Biesbroek, Klostermann, Termeer, \& Kabat, 2013) noted that most studies of adaptation to climate change have focused on barriers as though they are static one-dimensional entities rather than considering them as part of a dynamic governance process. Considering barriers in isolation from one another and from the aim of the adaptation response (Adger, Lorenzoni, \& O'Brien, 2009; Burch, 2010) can result in a dislocation of the framework from the practice. Such observations emphasise the critical importance of considering the dependencies of any institutional system - the statutory framework, the practice drivers like professional norms and standards, the tools and measures used and the political context within which it sits - to 'get the job done'. Governance and institutional innovations for improved consideration of climate change risk in decision making may not be enough by themselves for sustained flexibility. For example, barriers can reinforce one another and create inertia as shown in the New Zealand practice. By understanding how this happens can focus attention on the barriers as enablers for change (Burch, 2010).

Attending to the contextual factors that influence decision outcomes has potential for bridging between the barriers and better practice. For example, the design of sustainable funding institutions that account for change; using scenarios in decision practice; using procedures that address cognitive behaviours. These design features have potential to support adaptive and transformative institutions for climate change adaptation decision making.

The critical sources of path-dependent outcomes which, if addressed, might enable course correction as the climate changes are: low levels of understanding of climate change risks and their misrepresentation; fragmented multi-level governance with unused measures; fragmented 
statutory framework with overlapping responsibilities; siloed organisational design and practice; and different disciplinary practices that can counteract each other.

Innovations in all five areas have relevance for transitioning from the current institutional framework and practice to practice that is more flexible and thus potentially more robust. The use of tools that address intuitive and routine cognitive behaviours may result in improved outcomes; a more robust professional performance system with common systems for review using triggers and to enable lead-time of actions to be addressed as future conditions change; and the use of stress testing to identify priority areas for attention. The use of such innovations is consistent with technological innovation and transitions theory which consider the specific social setting of the intervention in linked socio-technical systems (Kemp, Loorbach, \& Rotmans, 2007; Rotmans et al., 2001).

\subsubsection{Enablers and entry points for improved institutional framework and practice}

Table 7.3 shows enablers, entry points and contextual influences on decision making at multiple governance scales; and the courts. These are grouped according to: a) understanding and representing the uncertainty and dynamic characteristics of climate change; b) governance and regulations; and c) organisations and actors. Understanding the relationships between these three decision-relevant categories of issues may help identify how to transition to more transformative decision-making by the actors to reflect climate change risk more effectively over long timeframes. As Hon. Sir Geoffrey Palmer, the architect of the RMA, said recently about New Zealand climate change policy:

There are many ingredients to the transformative change required-individual behaviours are important, leadership and 'nudges' from government will matter. Most critical is an effective policy framework. (The Dominion Post, 17 February $2015)^{89}$

\footnotetext{
${ }^{89}$ See full speech delivered at Victoria University of Wellington on 16 February 2015 at http://www.victoria.ac.nz/law/about/news/new-zealands-defective-law-on-climatechange/ClimateChangeSpeech16Feb2015Final.pdf
} 
Table 7.3 Institutional enablers and entry points

\begin{tabular}{|c|c|c|c|c|}
\hline Entry points & $\begin{array}{l}\text { Central } \\
\text { government }\end{array}$ & $\begin{array}{l}\text { Regional } \\
\text { government }\end{array}$ & TLAs & Courts \\
\hline $\begin{array}{l}\text { Understanding } \\
\text { and } \\
\text { representing } \\
\text { uncertainty } \\
\text { and dynamic } \\
\text { change } \\
\text { characteristics } \\
\text { of climate } \\
\text { change }\end{array}$ & $\begin{array}{l}\text { Amend national } \\
\text { guidance to make } \\
\text { uncertainties and } \\
\text { dynamic change } \\
\text { more prominent } \\
\text { and add tools that } \\
\text { can manage } \\
\text { uncertainty and } \\
\text { changing risk } \\
\text { Reflect uncertainty } \\
\text { and dynamic } \\
\text { change in standard } \\
\text { scenarios } \\
\text { Undertake regular } \\
\text { updates under the } \\
\text { Environmental } \\
\text { Reporting } \\
\text { legislation climate } \\
\text { domain }\end{array}$ & $\begin{array}{l}\text { Use dynamic } \\
\text { adaptive pathways } \\
\text { approach to address } \\
\text { uncertainty and } \\
\text { dynamic change } \\
\text { Make climate change } \\
\text { information } \\
\text { available early in } \\
\text { planning processes } \\
\text { and regularly update } \\
\text { to reflect changes } \\
\text { Stress test a range of } \\
\text { response options } \\
\text { using scenario } \\
\text { discovery } \\
\text { Review and adjust } \\
\text { using triggers to } \\
\text { chart future } \\
\text { pathways }\end{array}$ & $\begin{array}{l}\text { Implement dynamic } \\
\text { adaptive pathways } \\
\text { for spatial planning } \\
\text { Use regional climate } \\
\text { risk information and } \\
\text { make it publicly } \\
\text { available early in } \\
\text { planning processes } \\
\text { Stress test a range of } \\
\text { response options } \\
\text { using scenario } \\
\text { discovery } \\
\text { Review and adjust } \\
\text { using triggers to } \\
\text { chart future } \\
\text { pathways }\end{array}$ & $\begin{array}{l}\text { Reflect the } \\
\text { NZCPS in } \\
\text { decisions } \\
\text { routinely for } \\
\text { precautionary } \\
\text { decisions }\end{array}$ \\
\hline $\begin{array}{l}\text { Governance } \\
\text { and regulation }\end{array}$ & $\begin{array}{l}\text { Exercise } \\
\text { partnership with } \\
\text { local government in } \\
\text { climate change } \\
\text { adaptation } \\
\text { Support governance } \\
\text { integration between } \\
\text { regional and local } \\
\text { scales } \\
\text { Promulgate NPS } \\
\text { for climate change } \\
\text { Make explicit links } \\
\text { between RMA, } \\
\text { LGA, BA, } \\
\text { SC\&RCA for } \\
\text { consideration of } \\
\text { climate change } \\
\text { risks } \\
\text { Add climate change } \\
\text { to EQC Act, } \\
\text { provisions for } \\
\text { monitoring and } \\
\text { updating Crown } \\
\text { contingent risk } \\
\text { Make climate } \\
\text { change risk } \\
\text { monitoring a part of } \\
\text { the Environmental } \\
\text { Reporting } \\
\text { legislation climate } \\
\text { domain }\end{array}$ & $\begin{array}{l}\text { Partner with TLAs } \\
\text { for managing climate } \\
\text { risk } \\
\text { Promulgate regional } \\
\text { rules for climate } \\
\text { hazard risk that } \\
\text { avoid future climate } \\
\text { risk in decisions for } \\
\text { new developments } \\
\text { and adopt } \\
\text { transitional adaptive } \\
\text { measures for existing } \\
\text { uses } \\
\text { Undertake regional } \\
\text { climate hazard risk } \\
\text { assessments and } \\
\text { integrate with other } \\
\text { hazard risk planning } \\
\text { Highlight decision } \\
\text { timeframes and lead- } \\
\text { times for action }\end{array}$ & $\begin{array}{l}\text { Align local spatial } \\
\text { planning with } \\
\text { regional climate risk } \\
\text { Link with regional } \\
\text { councils to develop } \\
\text { regional hazard } \\
\text { assessments and } \\
\text { spatial plans that } \\
\text { address uncertainties } \\
\text { and dynamic change } \\
\text { Implement regional } \\
\text { rules that avoid } \\
\text { future climate risk in } \\
\text { decisions for new } \\
\text { developments and } \\
\text { adopt transitional } \\
\text { adaptive measures } \\
\text { for existing uses } \\
\text { Highlight decision } \\
\text { timeframes and lead- } \\
\text { times for action }\end{array}$ & $\begin{array}{l}\text { Consider the } \\
\text { practical } \\
\text { implications of } \\
\text { 'voluntary } \\
\text { assumption of } \\
\text { risk' and } \\
\text { 'acceptability of } \\
\text { risk' for future } \\
\text { generations } \\
\text { Practise } \\
\text { avoidance of } \\
\text { future climate } \\
\text { risk in decisions } \\
\text { for new } \\
\text { developments } \\
\text { and adopt } \\
\text { transitional } \\
\text { adaptive } \\
\text { measures for } \\
\text { existing uses that } \\
\text { highlight } \\
\text { decision } \\
\text { timeframes and } \\
\text { lead-times for } \\
\text { action }\end{array}$ \\
\hline
\end{tabular}




\begin{tabular}{|c|c|c|c|c|}
\hline Entry points & $\begin{array}{l}\text { Central } \\
\text { government }\end{array}$ & $\begin{array}{l}\text { Regional } \\
\text { government }\end{array}$ & TLAs & Courts \\
\hline $\begin{array}{l}\text { Organisations } \\
\text { and actors }\end{array}$ & $\begin{array}{l}\text { Institutionalise } \\
\text { adaptive } \\
\text { management in the } \\
\text { institutional } \\
\text { framework }\end{array}$ & $\begin{array}{l}\text { Share practice } \\
\text { models between } \\
\text { governance scales } \\
\text { and functional areas } \\
\text { that address } \\
\text { uncertainty and } \\
\text { dynamic change and } \\
\text { that address } \\
\text { intergenerational } \\
\text { equity of outcome } \\
\text { Engage with } \\
\text { communities early } \\
\text { and continuously } \\
\text { using a range of } \\
\text { interactive and visual } \\
\text { tools } \\
\text { Develop new } \\
\text { practice norms } \\
\text { through education } \\
\text { and action research } \\
\text { Use boundary } \\
\text { organisations to } \\
\text { facilitate practice } \\
\text { change mindful of } \\
\text { cognitive behaviours } \\
\text { of the actors }\end{array}$ & $\begin{array}{l}\text { Share practice } \\
\text { models between } \\
\text { governance scales } \\
\text { and functional areas } \\
\text { that address } \\
\text { uncertainty and } \\
\text { dynamic change and } \\
\text { that address } \\
\text { intergenerational } \\
\text { equity of outcome } \\
\text { Engage with } \\
\text { communities early } \\
\text { and continuously } \\
\text { using a range of } \\
\text { interactive and visual } \\
\text { tools } \\
\text { Use boundary } \\
\text { organisations to } \\
\text { facilitate practice } \\
\text { change, mindful of } \\
\text { cognitive behaviour } \\
\text { of the actors }\end{array}$ & $\begin{array}{l}\text { Use informal } \\
\text { educative } \\
\text { opportunities for } \\
\text { understanding } \\
\text { changing climate } \\
\text { risk and options } \\
\text { for addressing it }\end{array}$ \\
\hline
\end{tabular}

The enablers that could help address the characteristics of climate change as a problem (uncertainty, timeframes and framing of the problem); the constraints of governance and regulations (roles and levels of government, evidenced-based decision practice, use of static measures, time-inconsistency) and constraints in organisations and for the actors (organisational design, disciplinary practices, capability and engagement processes) are now suggested, along with contextual enablers outside the legislative framework that could support robust and flexible responses to uncertainty and dynamic climate change.

\section{$\underline{\text { Understanding and representing uncertainty and dynamic climate change characteristics }}$}

How climate-related risk is communicated currently acts as a barrier to understanding its changing and dynamic characteristics and instils a false sense of security in those with whom councils communicate. Framing climate change impacts in a way that reflects the uncertainties and changing nature of the risks is required, along with tools to translate changing risk into workable practice.

As part of the research process, I tested a number of ways of communicating uncertainty and dynamic change with a sample of research participants. One example cited in Chapter 6 
illustrates how entrenched thinking about a problem can change. Using visual framings similar to Figure 2.3 focused attention on the decision significance of the tail of the distribution. By so doing, the inadequacy of current flood risk management planning was highlighted, leading to serious consideration of a range of different options and pathways to them. Using Figure 2.2, which conveyed flood frequency changes over time using a simple algorithm to generate a range of scenarios, enabled decision makers to see the effect of climate change on flood discharge. The related effect of using such a simple approach enabled strategic consideration of the effect of climate change before decisions were taken on the final options for the Hutt river flood management scheme where structural solutions are constrained spatially and by affordability over time. This opened up the space for using the dynamic adaptive policy pathways approach in the decision-making setting, after using the Sustainable Delta Game to 'socialise' understanding of uncertainty in decision making. ${ }^{90}$

By providing information in a form that demonstrates what could happen with a levee or seawall breach condition (inundation with banks down to show residual effects), and by superimposing that information on critical facilities and populations at risk, decision makers could see the potential effects better than if they were presented with flood maps showing a static hazard risk. Furthermore, interactive maps were used by some councils to depict flow rates and depth under different scenarios of rainfall intensity and duration. This provided councils with the opportunity to reality check their information with those who had specific local knowledge and incorporate this into the modelling. This also provided important validation and legitimisation of the knowledge used. By so doing, trust was built with those affected.

How reframing of the risk is communicated - in graphical representations, discussions, interactive games $^{91}$ - is critical to understanding the risk. However, official guidance has not yet embedded reframing of risk and its communication into official guidance, nor have the different disciplinary traditions adopted such approaches across councils. Embedding new learning in practice will take time and require systematic updating of climate change impacts information over time. The Environmental Reporting Bill currently before the House is one possible entry point for this to be done, through the domain reports proposed, for every three years.

However, framing by itself does not address how such information can inform land-use planning and regulatory practice in space and time. Rather, it provides supporting information on which

\footnotetext{
90 This is further research underway currently by the author of this thesis.

${ }^{91}$ Towards the end of my research I used the Sustainable Delta Game (developed at Deltares in the Netherlands) with the councils in the Wellington region and documented the effect it had on decision choices. This is the subject of a paper in preparation for publication.
} 
response options can be formulated and tested for their veracity with communities prior to decision making — itself an important part of the process of addressing long-term risk. However, for successful integration across statutory functions such as flood risk management, asset management and planning, closer linkages will need to be developed since the choice of options traverses the three statutes governing these three functions. Minor legislation changes could be drafted that align the statutes more directly; for example, by adding the words "reduction of exposure of people and buildings to climate change effects" in the RMA, the LGA, the BA and the SC\&RCA purposes and planning provisions; defining flood risk management in the SC\&RCA to include non-structural measures and for reducing exposure and enabling managed retreat for existing areas at risk using staged adaptive management. An NPS on climate change adaptation could cover information provision, risk reduction in existing areas at risk, coordination across governance units; council accountability and expenditure across statutes (RMA and LGA for assets); timeframes and lead-time to be considered in priority setting; the use of dynamic adaptive tools for managing risk (Lawrence \& Allan, 2009). The suggestions made in Box 7.1 could also be implemented. Such changes would, with minimum effort, serve to integrate responsibilities better for addressing changing climate risk.

\section{Governance and regulations}

The roles of the three levels of government under the statutory framework are limited by the lack of integration of functions under the different statutes and the failure to use existing national and regional statutory instruments. Decision making about climate change effects is a government responsibility and my thesis is that coordination is required across all levels of government to anticipate the risks to the whole economy and society adequately. This responsibility has been recognised in law, but central government exhibits a limited role currently, signalling a low priority to climate change adaptation through ambiguous messages. This makes it difficult for the local actors to make robust decisions in the face of pressures from property development interests.

Enablers that could address the barriers are: use of flexible measures that can adjust over time and avoid locking in further path dependency of existing and new land uses; regional hazard assessment supported by consistent information across district boundaries; use of regional rules to guide existing and new land use decisions at a local level; differentiate decision timeframes and led-times for action; reframe the risk through evidence that gives the courts confidence to avoid risk rather than temporarily mitigating the risk. The courts have had some success in upholding the intent of the RMA although there are widely differing approaches taken. Recent clarification by the Supreme Court about the role of the NZCPS (discussed in Chapter 5) will help guide the application of the precautionary principle for sea-level rise; the use of NPS and NES for climate 
change adaptation would help support practice for other climate change effects. The national instruments play a strong enabling role by giving clear leadership about the principles and policies that can be applied to climate change risk. Clarification of the roles between regional and district councils with respect to consideration of climate change effects and hazard risks is also needed. I would argue that such issues are best addressed at a regional level where there are greater economies of scale and professional capacity to give effect to those responsibilities. Stronger regional rules would give clearer direction to TLAs that currently struggle to implement anticipatory risk management at a spatial level, and where private interests are at their strongest.

The links between the statutes are weak or non-existent, making interconnections between them difficult where matters are related; for example, the RMA, LGA, SC\&RCA and the BA for consideration of approvals for subdivision, buildings and their servicing by water infrastructures, where sea-level rise or flood risk is known. This calls for greater alignment of the purposes of the primary statutes and the wording of hazard risk exacerbated by climate change to overcome the entrenched professional practices that seek always to mitigate a risk in a short-term timeframe and use static measures to achieve that.

The introduction of risk management and cost-benefit standards that include uncertainty and dynamic change considerations would support any statutory change. For example, the use of a consistent range of scenarios of the future, and by giving due weight to changing risk in assessment tools such as cost-benefit analysis (some nations like the Netherlands have specified low costbenefit ratios to help drive this (De Bruin \& Ansink, 2011)). There is a growing literature on adaptive management tools and measures in climate change adaptation decision making. Box 7.2 shows some of the developments in practice. New tools are available for assessing the risk, for identifying options and prioritising options that can manage the impacts from change in the climate and the contextual conditions within which decisions are made (Hunt \& Watkiss, 2013). However, to be able to assess costs and risks, a level of certainty is required that does not exist for 'when, where and how' climate changes will occur. Thus, proxies are needed for decision makers to be able to adapt in response to dynamic changes in the physical environment and in the social and economic spheres. 


\section{Box 7.2 Adaptive management decision tools and measures in practice}

\section{Adaptive management decision tools}

- Dynamic adaptive policy pathways decision approach (Walker, Haasnoot, \& Kwakkel, 2013) for choice of adaptation options, enabling adjustments in time and space, using policy triggers for changing course, such as climate event size and frequency, flexibility or adaptability of design; for example, wider footprint than immediately necessary for flood defences enabling increase in height later to maintain standards of protection as risk changes

- $\quad$ Robust decision making (Lempert, Scheffran, \& Sprinz, 2009)

- Real options analysis chooses options that may seem sub-optimal today, but which increase flexibility at later times, leading to better decision making when more is known about the project (Hunt \& Watkiss, 2013)

- $\quad$ Portfolio analysis (Aerts, Botzen, van der Veen, Krywkow, \& Werners, 2008)

- Assumptions-based analysis identifies the most important assumptions in a plan, to test these assumptions and to accommodate unexpected outcomes

\section{Measures}

- Incremental adaptations using hard and soft approaches and different timeframes which incorporate transitions leading to eventual transformational change

- Time-limited developments, after which there is no maintenance, or their removal, using time-bound and conditional permits

- Back-zoning to counteract expectations of more intense development, and planning for relocation; alternative plans for new areas to develop and move to; voluntary purchase and lease-back arrangements where use is physically limited by sea-level rise

- Use of land information memoranda to alert prospective property purchasers and/or notations on titles

- Differential rating that embodies risk for funding adaptation

- Requirements to take account of the location risk and lifetime of development

- Reversible options, where some measures can be reversed if climate change effects don't eventuate as anticipated

- $\quad$ Staged retreat

- Long-term protection

- Raising of building floor levels, wharves and roads

- Space made for natural systems to adapt; for example, buffer areas and soft options like wetlands, dune restoration and public reserves; avoidance of substantial new investment in areas at risk

- Staged infrastructure design upgrades or redesign before service performance is compromised; built-in redundancy

The main approaches that have been developed to address dynamic changes in such circumstances include real options analysis (Dobes, 2008; Ranger et al., 2010), robust decision making (Lempert \& Collins, 2007), dynamic adaptive policy pathways (Haasnoot et al., 2011; Kwadijk et al., 2010) and strategic planning approaches (Roggema, 2009). Some of these approaches have been applied over the past decade internationally, while some are still being developed and others are in the early stages of application. They all could be tested across a range of scales, and in different institutional jurisdictions, to further highlight their respective strengths for decision making under conditions of uncertainty and dynamic climate change. However, little research has been done on how these methods interface with existing institutions governing land uses and in coastal settings 
and the measures that might be used to implement adaptation policies. Such research can flow from this thesis.

Funding mechanisms will also be needed to anticipate more transformational changes as planning thresholds are reached (Abel et al., 2011). In the New Zealand context, the Canterbury Earthquakes Royal Commission (2012) set out the importance of decision makers understanding the consequences of the risk information and developing anticipatory risk reduction strategies for implementation. This will require supporting processes and activities for long-term institutional change; for example, making available 'risk-free' land for new developments; funding transitions where appropriate; funding collaborative institutions and coordinated research and outreach; and development and use of assessment tools and planning measures that can be flexible over time.

The question remains whether the barriers identified are indeed limits (Adger et al., 2009) to leveraging flexibility in planning policies and rules that can be adaptively managed over time, or whether they can be adjusted to work in a flexible and adaptive manner. There is evidence building that adaptive management tools can be integrated with institutional arrangements (Haasnoot et al., 2013). However, in the Netherlands there is a high level of central control and monitoring that sustains the approaches now embodied in the Delta Commission methodologies for managing water resources. Whether such tools can be effectively used in a highly devolved governance system like in New Zealand will require further experimentation. The genesis of a 'new practice' is underway through the 'testing' of the dynamic adaptive policy pathways approach in New Zealand. Such approaches are by definition transitional as they are incrementally changing how risk is viewed and thus hold promise for more transformational change in framework and practice, in anticipation of sea-level rise and more frequent flooding effects.

\section{Organisations and the actors}

Strengthening interconnections between council functions is likely to be a strong enabler for robust decision making on climate change risk. Examples such as Tasman District Council, a unitary authority with both regional and TLA functions, provide an exemplar of integration across resource management and land-use planning. Having both regional and TLA statutory functions in the one organisation has allowed professional practice to develop in a more integrated manner. Governance review across New Zealand provides an opportunity for such integration to be forged, either in large- or smaller-scale amalgamations of local government.

Experimentation has important learning outcomes which can be diffused through existing professional practice groups, including for how the law deals with uncertainty. Networks and 
boundary organisations are important tools to diffuse new practice and to integrate it into existing processes. Others have observed how networks have value for interactions at the science-practice interface (Vogel, Moser, Kasperson, \& Dabelko, 2007). There is never a clearly defined route for interactions and most are highly informal; for example, professional networks, conferences, interactions with research organisations, workshops, personal interactions between scientists and practitioners. Spider webs of interactions can be developed to reflect the dynamics of what actually happens, to increase transparency.

Knowledge brokers that work across these networks by framing the science understanding in ways that resonate with the actors and processes in decision-making settings are developing in New Zealand. As one engineer practitioner said: "boundary organisations can 'signal' changes in knowledge that can shape the perceptions of the science". One-way notions of communications are increasingly being replaced by democratic communication models which involve a range of people who bring different perspectives to the table - experts, risk-bearers and local communities. Two ad hoc examples in New Zealand - the Land and Water Forum and the Lake Taupo Protection Trust-were collaborative experiments in the water allocation and water quality domains acting respectively as a precursor to a proposed method under the RMA for collaborative governance in conditions of complexity and uncertainty for water management (Ministry for the Environment, 2013), and an experiment using economic instruments for trading within nutrient limits which is allowed within the RMA (section 24(h)). The ability to implement the outcomes of such processes needs attention to uphold challenge and enable course correction over time as operating conditions change. Such initiatives have proven successful in location-based decision making that is well linked into research and driven by community leaders, NGOs and research institutions along with local government. Some similar initiatives can be found in Norway for flood management (Næss, Bang, Eriksen, \& Vevatne, 2005) and in Australia on the coast (Measham et al., 2011). Such examples provide promise for new models of engagement with different publics.

However, they are isolated and resource intensive experiments where governments focus priority attention and community players had agreed to participate. This will not be the case in all areas affected by climate change due to the potential scale of contemporaneous impacts, spatially across the country and the strong interests of existing generation of land users. Such examples are also reliant on continuous leadership within a generally agreed framework with tools that are currently missing in New Zealand for climate change adaptation.

In settings where practitioners and decision makers are confronted with long histories of coastal erosion/inundation with no long-lasting action to manage increasing risk from climate change 
and/or where dissent is rife (e.g., Kapiti Coast District Council, Hawkes Bay Regional Council and Tasman District Council) a new resolve has emerged that can provide space for 'testing' emerging thinking about flexible institutional frameworks and practices.

Greater professional networking for sharing knowledge and experience has potential to strengthen integration of the different professional practices across organisational functions. Because they rely on informal links development of new practices will require new organisational design for their effect to be sustained. Measures to help build capacity in organisations include the Envirolink programme ${ }^{92}$ to support the smaller under-resourced regional councils; a good case exists for this to be extended to TLAs where capacity is even more limited. The use of boundary organisations discussed above could be mandated. Their value lies in focusing on real problems for decision makers which gives them a greater likelihood of leveraging capability within the current frameworks of practice, at least as a transitional mechanism.

There is also a case for strengthening learning between disaster risk management and adaptation to climate change by addressing the capacity to anticipate, adapt flexibly and reduce risk. Merging climate change with the emergency management regime is, however, fraught with difficulty. Different professional cultures and theoretical discourses drive each domain. Emergency management focuses on the immediate response and recovery where anticipatory learning and adjusting to changing risk appears absent. It is embedded in engineering resilience (bouncing back to prior conditions) that continues the status quo and results in static framing and responses. This is antithetical to the design of flexible practices that can anticipate a range of possible futures and change course with minimum disruption.

The spaces for change presented in Figure 7.2 offer possible ways that the framework and the practice can be improved for addressing uncertainty and dynamic climate change and thus contribute to the implementation of more flexible and robust practice for climate change adaptation.

\footnotetext{
${ }^{92}$ A government funded programme targeted at regional councils for adapting management tools to local needs, and translating environmental science knowledge into practical advice.
} 


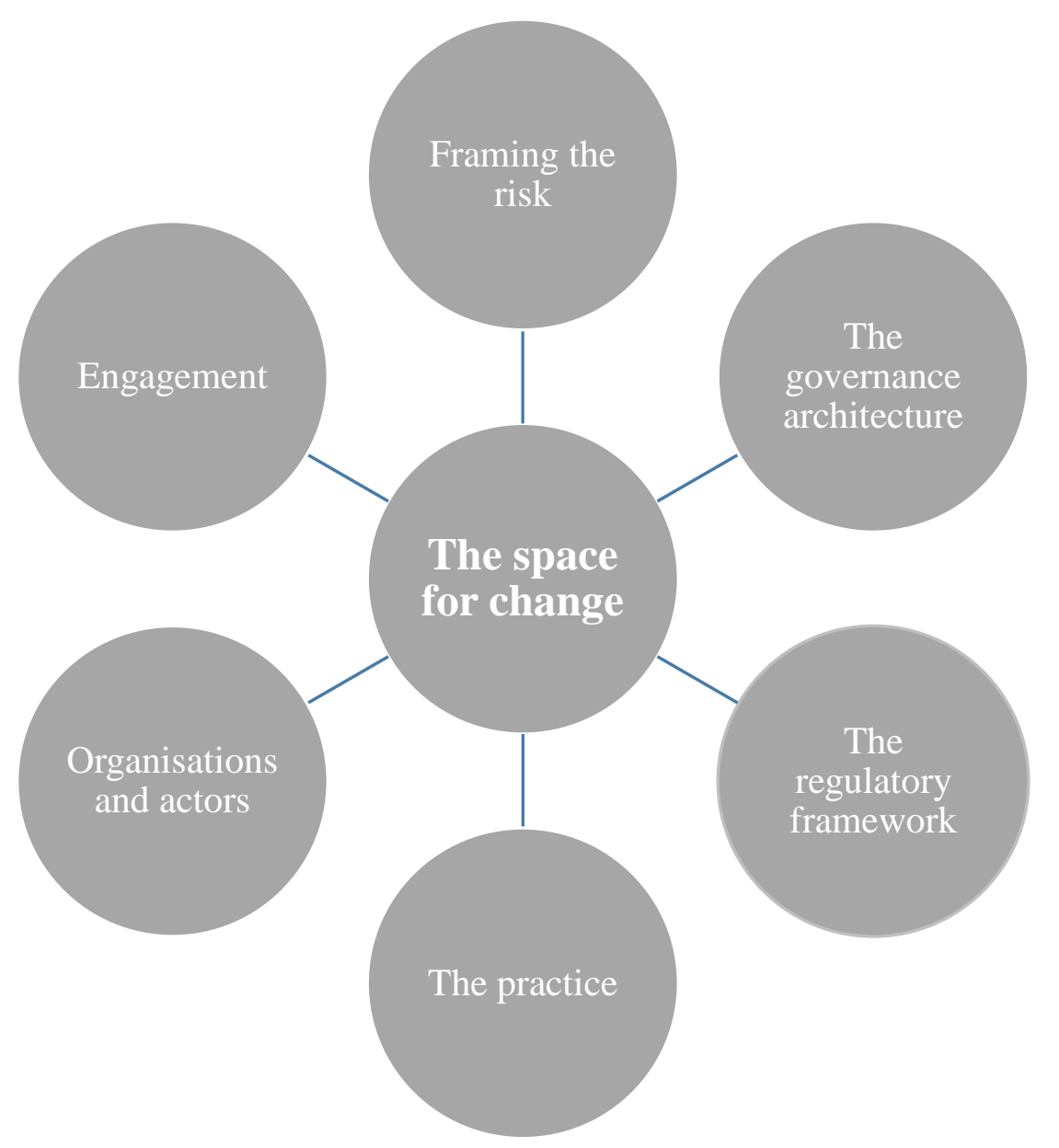

Figure 7.2 The space for change 


\section{Chapter 8 Conclusions and looking forward}

\subsection{Conclusions}

The central concern of this thesis is an examination of how adequate the institutional framework and practice is in a New Zealand setting for enabling climate change adaptation decision making that addresses uncertainty and dynamic climate change characteristics. The concern was motivated by a gap in the literature identified by Dovers and Hezri (2010) who identified the critical role that institutions play in climate change adaptation policy and its implementation; noting that few studies had examined the practicalities of institutions' role at national and sub-national levels. The ability of institutions to enable uncertainty and dynamic climate change characteristics to be reflected in decision making practice is at the heart of this inquiry.

I therefore started by discussing the climate change characteristics of uncertainty and dynamic change and why they pose a decision problem in the context of societal changes over time. I then set out the nature of the institutional framework within which decisions are made relating to climate change adaptation; and why the combination of the climate change characteristics and the institutional arrangements and processes makes a challenging decision environment for the organisations and actors. This was followed by a summary of the relevant literature that informed the analysis and analytical framework.

By examining four risk-based concepts, a three-part analytical framing to the decision-making challenge was developed as it relates to sea-level rise and increased flood frequency and intensity. The institutional framework and the actual decision-making practice was examined for their ability to reflect uncertainty and dynamic climate change. This examination provided the basis for gauging the adequacy of the institutional framework and practice for its ability to take account of uncertainty and dynamic climate change in climate change adaptation decision making. I chose to focus on New Zealand's multi-level governance arrangement, national, regional and local decision makers and their advisors, because New Zealand has mandated consideration of "the effects of climate change" in its institutional framework, and experiences natural hazards regularly that will be exacerbated by climate change in some respects. The examination of the framework and the practice under it enabled barriers, enablers and entry points to be identified for suggesting framework and practice improvements that may better address uncertainty and dynamic climate change.

As a starting point for the examination of my research question, four risk-based concepts were examined - precautionary principle, risk management, adaptive management and transformational change - for their utility to address uncertainty and dynamic climate change, complemented by 
consideration of transitions and resilience theory. I concluded that the precautionary principle can address uncertainty, but not dynamic change. The precautionary principle gives little guidance on its use (for example, the degree of precaution). Risk management can address uncertainty and has potential for dynamic change to be considered if applied iteratively using many scenarios of the future. Adaptive management is a concept that lends itself to managing change, but only if it is used in anticipation of threats of harm, rather than purely as static incremental adjustments. Transformational change inherently addresses uncertainty and dynamic change as regime shifts, and thus potentially bridges to adaptive management in a more dynamic manner. All four concepts demonstrate some capacity to guide consideration of uncertainty and dynamic climate change impacts, depending on the characteristics of the decision, in particular, its lifetime.

This led to examining whether the four concepts were reflected in the New Zealand decision framework for consideration of the effects of climate change. I concluded that precaution and risk management were reflected, while adaptive management and transformational change were, at best, reflected only experimentally. The current institutional framework could nevertheless be used for adaptive management, and transitions were foreshadowed in part. However, the framework is highly fragmented across the statutes. The organisations responsible for its implementation operate as separate decision-making units and thus lack co-ordination in decision making where a wider area of concern is more appropriate, for example where the impacts cross jurisdictional boundaries. Organisations operate within functional and disciplinary silos, but there are signs that the professional advisor groups are beginning to co-ordinate their functions across scales and within their organisations. There is a nascent level of experimentation with decision-making tools that enable uncertainty and change to be addressed, aided by boundary organisations.

To enable the adequacy of the framework and practices to be assessed, I developed a three-part analytical framework and 12 criteria, derived from the suite of literature discussed in Chapter 2 and from the concepts of precaution, risk management, adaptive management and transformational change that have significance for decision making under uncertainty and dynamic change: a) understanding and representing uncertainty and dynamic climate change characteristics; b) governance and regulations at multiple levels; and c) organisations and actors within them. This analytical framework enabled the adequacy of the institutional framework and practice to be assessed.

The institutional framework has many elements that could, in principle, address uncertainty and dynamic climate change. It enables long-term considerations and emphasises precaution and riskbased decision making. However, adaptive and transformational objectives are largely absent, coordination across responsibilities at multiple governance scales is constrained and timeframes are 
inconsistent across statutes. Practice shows that climate risk is being entrenched by misrepresentation of climate change characteristics due to difficulties codifying uncertainty and dynamic climate change within the quasi-legal decision settings. This has led to static framings of the risk problem and of the consequent responses. The resulting ambiguity is compounded at the different levels of government by gaps in the use of national and regional instruments and consequent differences in the court decisions. Practitioners use simplistic heuristics that obscure uncertainty and dynamic climate change characteristics in advice. They rely heavily upon static, time-bound treatments of risk, which reinforces unrealistic community expectations of ongoing protections even as the climate continues to change, which makes it difficult to introduce transformational measures. Some efforts to reflect uncertainty and changing risk were observed but are, at best, transitional measures because of the static treatments of risk in time and space. Some experimentation was found in local government practice, and boundary organisations were used as change-agents.

The analysis of the current practice in New Zealand to address climate risk across different governance scales within organisations and by actors, across diverse council functions, decision makers and the courts, enabled an assessment to be made of the barriers to uptake and implementation of more robust and flexible approaches for managing uncertainty and dynamic climate changes. Current practice reflects precaution and risk, based on historic conditions, but adaptive practices were not truly adaptive due to reliance on static measures. Transformational practice was absent. The current practice has set up path dependency, locking in current development patterns and exposure to risk over long timeframes. The result has been decisionmaking inertia that makes adaptive measures harder to implement. There are gaps in the use of existing institutional measures at national and regional levels, in governance arrangements, in engagement with affected communities, and in co-ordination between levels of government. These gaps mean that the necessary support mechanisms for the devolved responsibility to local government for consideration of climate change effects are weakly developed. Developments in practice are ad hoc through the courts, often using simplistic and unsustainable heuristics as a 'default setting' in the absence of national and regional policy and instruments or not reflecting the precautionary principle embedded in the NZCPS. While there is some promise in practices based on new knowledge and tools for understanding uncertainty and dynamic change, the current framework and its practice are largely inadequate for addressing uncertainty and dynamic climate change in decision making affected by sea-level rise and increased flood risk.

Drawing on the adequacy analyses, institutional enablers and entry points for them that may address the barriers identified, are suggested. Analogous non-climate decision settings that in 
some respects have institutional frameworks and practices that address uncertainty and dynamic change were examined for potential design elements for enhancing the framework and practice. From the analogue analysis several features emerged that showed promise for enhancing the enablers identified; features that addressed procedural and intuitive human responses, changing circumstances and future risk, reinforced by measures that have built-in redundancy, monitoring of change, strong professional regulatory regimes and support from institutional measures that can test sensitivity and stress, backed up by robust scientific information, enabled the analogous decision contexts to address uncertainty or dynamic change. Such features could address intergenerational equity, cognitive biases and had features that could enable flexibility to be built into decisions, while retaining some level of certainty of outcome as evidenced in several uniquely-New Zealand institutions designed in response to complex policy problems. The enablers and the analogue features were then used to suggest framework and practice improvements that may better address uncertainty and dynamic change and reduce path dependency as the climate changes, to gain flexibility and robustness in responses. The suggested improvements would, however, require supporting policies to leverage them and to sustain decision making through time. Those which hold promise stem from risk and adaptive governance scholarship, such as public and stakeholder deliberation conducted transparently to build understanding of different values and preferences where controversy reigns over evidence, and to build acceptability and tolerance where views differ, while at the same time fitting responses to the particular type of risk problem.

This research has undertaken a detailed empirical analysis of current decision frameworks and practice under them in a developed Western democracy. The institutional framework that set up a multi-scale institutional arrangement for integrated resource management, and devolved responsibility for consideration of the effects of climate change to two levels of local government with support and direction from central government, was world-leading in 1991. However, it has failed to enable a shift to be made from static to dynamic governance or from reactive to anticipatory practice that is flexible and robust enough for what is likely to be experienced from climate change over the coming decades and centuries. The roots of this failure are in the misrepresentation and therefore poor understanding of climate change risk characteristics; the fragmented governance arrangements and a statutory framework that is not well integrated across governance scales; the legacy of past decisions based on historical experience; the quasi-legal approach to decision making that seeks certainty and evidence largely of a static nature; embedded professional practices that work best where there is little uncertainty and in stationary conditions; 
a focus on responding to 'events' and short-term political imperatives, combined with a reluctance by decision makers to engage effectively with the public and stakeholders.

Nested governance, as envisaged in the literature discussed in Chapter 7, and devolution to the local level, play out as a set of barriers between governance scales, rather than as an integrated institutional framework and practice under it. For multi-scale governance to adequately support climate change adaptation decision making requires all governance scales to be active participants, using the elements in the framework that can enable uncertainty and dynamic climate change to be addressed and the instruments currently available, to implement the intention of the framework. But this, alone, will not be adequate because precautionary and adaptive measures applied by practitioners using periodic reviews of plans and monitoring of structures are incremental only and do not break the cycle of 'protection and expectation of further protection'; and mitigation has physical and affordability limits and entrenches risk. Other measures addressing understanding and representing uncertainty and dynamic change, the design of governance and regulations, organisational form and function and actor behaviour, both inside and outside the institutional framework and practices, will be required, in addition to inclusive and deliberative governance. This study has identified inadequacies across institutional 'fit', 'interplay' and 'scale' to which the enablers and entry points could be applied.

This thesis makes an original contribution to understanding how uncertainty and dynamic climate change characteristics matter for adaptation decision making, by examining both a country-level institutional framework and practice under it. The adequacy analysis, based on three groups of criteria-a) understanding and representing uncertainty and dynamic climate change characteristics ('fit'); b) governance and regulations at multiple levels ('interplay' and 'scale'); and c) organisations and actors within them ('interplay' and 'scale') — offers a new way of identifying institutional barriers, enablers and entry points for change in the context of decision making under uncertainty and dynamic climate change.

\subsection{Transferability of this research}

My research has applicability across New Zealand because it examined the institutional framework and its practice that applies to all actors in decision making about climate change adaptation in the New Zealand context. By situating the research within the wider theoretical framings of climate change science, impacts and adaptation, decision making under conditions of uncertainty, and cognitive behavioural science, the findings have salience for other jurisdictions and can be reinterpreted to take specific local contexts into account. A number of the findings are already reflected in the literature and thus confirm or build on previous research. The new findings that 
link uncertainty and dynamic change in climate with governance, regulatory, organisational and actor characteristics provide another lens through which to view the research problem in other jurisdictions and thus have comparative value. My research adds to the empirical body of knowledge that is developing on institutional design for addressing uncertainty and dynamic climate change. The ability to link with researchers in Australia, the United States and the Netherlands during the course of this research has enabled me to develop new projects. Through these projects I am further testing my findings using tools developed elsewhere, thus enabling me to contribute to their further development. An example is the use of the dynamic adaptive policy pathways approach (Haasnoot et al., 2013; Kwadijk et al., 2010) which has the potential to guide practitioners more broadly than in New Zealand by adding institutional considerations for implementing robust and flexible decisions where uncertainty and change are a fundamental part of the context when making climate change adaptation decisions.

\subsection{Research looking forward}

Detailed qualitative empirical studies of institutional frameworks and their practice have value for their ability to unpack what is actually going on in decision settings. They help understand the role of governance arrangements, how responsibilities are exercised within them, how the actors within organisations behave and the influence of the contextual characteristics of the decision-making setting. Action research can enable experimentation with new practice methods that address uncertainty and dynamic change, which can provide new insights to enablers that can leverage uptake of frameworks and tools by decision makers in other areas within New Zealand and internationally. Empirical studies that delve into the institutional issues affecting decision making on the effects of climate change are starting to receive attention by researchers elsewhere; for example, in California (Ekstrom \& Moser, 2014; Hill Clarvis \& Engle, 2015), in Canada (Burch, 2010), in Finland, Norway and Sweden (Juhola, Haanpää, et al., 2012; Naess et al., 2005; Storbjork, 2007) and in Australia (Matthews, 2013; Measham et al., 2011). However, none of these jurisdictions has express statutory provision for consideration of the effects of climate change as New Zealand has already mandated, through a devolved system of resource management, nor the range of hazard risk that is frequently experienced across New Zealand.

New Zealand thus provides an interesting location for research that links climate change adaptation to the management of risks of extreme events and disasters; two fields where the IPCC (2012) highlighted integration was necessary. Understanding the reasons for parallel discourses and attempting to link them more specifically is ripe for further research. The role of institutional arrangements alone in lifting the veil on anticipating dynamic climate change will be insufficient to change institutional frameworks and practice. Thus, further multi-disciplinary research is 
needed that combines communities, practitioners, decision makers and scientists from different domains, including physical and biological science, sociology, psychology, decision science, organisational change, governance and politics. Addressing climate change effects will be a change management task. It will require transformational thinking across jurisdictions and across the different governance scales, with the communities affected and with attention to how people receive knowledge and frame problems about climate change.

Empirical studies are also needed on how to use statutory frameworks and spatial planning to anticipate changing climate, and what assessment and decision tools can enable decisions that are flexible and robust and that can be practically implemented within the comfort zones of decision makers and those affected by the decisions. Uncertainty and dynamic change is the 'new normal'. This means that the cognitive sciences will play an increasingly important role in understanding how the known cognitive effects of uncertainty on human behaviour can be shifted to enable climate change effects to be addressed without unacceptable disruption, at costs that are manageable and without inequity being entrenched within vulnerable groups.

Further research on the design of flexible institutions, informed by analogous non-climate decision settings, offers promise for addressing climate change adaptation. Developing ways of integrating disciplinary practice and making assumptions of practice more transparent in the decision process will also contribute.

Further research on the role that risk and adaptive governance could play in institutional practice for contested decision settings will be necessary to enable legitimate and acceptable decision making about the climate changes envisaged. Understanding the political dimensions of managing change and its relevance to uncertainty and dynamic climate change would help enhance understanding of the use of power and the role of interest groups in decision making, and thus contribute to more robust and flexible climate change adaptation decisions that can change course over time. 



\section{Appendix 1 Abbreviations and definitions}

AEP

ARI

BA

CDEMA

CERA

EQCA

IPCC

LDA

LGA

TLA

NPS

NZCPS

NES

RMA

RPS

SC\&RCA

EEZA
Annual Exceedance Probability

Annual Return Interval

Building Act

Civil Defence and Emergency Management Act

Canterbury Emergency Recovery Authority

Earthquake Commission Act

Intergovernmental Panel on Climate Change

Land Drainage Act

Local Government Act

Territorial local authority

National Policy Statement

New Zealand Coastal Policy Statement

National Environmental Standard

National Water and Soil Conservation Authority

Resource Management Act

Regional Policy Statement

Soil Conservation \& Rivers' Control Act

Exclusive Economic Zone and Continental Shelf (Environmental Effects) Act 
Adaptation

Adaptation deficit

Adaptive capacity

Adaptive management

Boundary organisation

Flexible

Institutions

Organisations

Path dependency

Residual risk

Resilience

Risk

Risk management

Robust

Transformational change

Transitions

Vulnerability
The process of adjustment to climate change and its effects to moderate harm and exploit opportunities; incremental adaptation aims to maintain system functioning at a particular scale; transformational adaptation aims to change system characteristics in response to climate change and its effects

Gap between the current system state and what is required to address existing climate conditions and its variability

Ability to adjust to potential damage, to take advantage of opportunities or to respond to consequences

Iterative response to uncertainty and change as system feedback is received

Agent that bridges between science and policy

Ability to change as operating conditions change

Rules and norms held by social actors that shape interactions and decision making

Agencies that act within the institutional frameworks

Conditions at a point in time that constrain adaptation at future points in time by entrenching current conditions

Risk that remains after protection and avoidance measures - or the unavoidable risk

The ability of a system to anticipate, absorb, accommodate, or recover from the effects of a shock in a timely and efficient manner

The potential for consequences where there is something at stake and where the outcome is uncertain

Processes and actions that reduce the likelihood and consequences of risks

Able to operate over a range of conditions

A change in the fundamental attributes of a system

A means of moving from an activity or state to another and thus manage risk

The predisposition to be adversely affected 


\section{Appendix $2 \quad$ Statutory framework}

\begin{tabular}{|c|c|}
\hline $\begin{array}{l}\text { Regulatory } \\
\text { instruments }\end{array}$ & Sections relevant to consideration of climate change adaptation \\
\hline $\begin{array}{l}\text { Local Government Act } \\
2002\end{array}$ & $\begin{array}{l}\text { Sub-part } 3 \text { - Coordination of responsibilities of local authorities } \\
\text { Section } 10 \text { Purpose of local government } \\
\text { (1) The purpose of local government is- } \\
\text { (a) to enable democratic local decision-making and action by, and on behalf } \\
\text { of, communities; and } \\
\text { (b) to meet the current and future needs of communities for good-quality } \\
\text { local infrastructure, local public services, and performance of regulatory } \\
\text { functions in a way that is most cost-effective for households and businesses. } \\
\text { (2) In this Act, good-quality, in relation to local infrastructure, local public } \\
\text { services, and performance of regulatory functions, means infrastructure, } \\
\text { services, and performance that are- } \\
\text { (a) efficient; and } \\
\text { (b) effective; and } \\
\text { (c) appropriate to present and anticipated future circumstances. } \\
\text { Section } 11 \text { A Core services to be considered in performing role } \\
\text { (d) the avoidance or mitigation of natural hazards } \\
\text { Section } 14 \text { Principles relating to local authorities } \\
\text { (1) In performing its role, a local authority must act in accordance with the } \\
\text { following principles: } \\
\text { (h) in taking a sustainable development approach, a local authority should take } \\
\text { into account- } \\
\text { (i) the social, economic, and cultural interests of people and communities; } \\
\text { and } \\
\text { (ii) the need to maintain and enhance the quality of the environment; and } \\
\text { (iii) the reasonably foreseeable needs of future generations. } \\
\text { Section } 15 \text { Triennial agreements } \\
\text { Section } 16 \text { Significant new activities proposed by regional councils } \\
\text { Section } 17 \text { Transfer of responsibilities } \\
\text { Section } 101 \text { B Infrastructure strategy } \\
\text { (3) The infrastructure strategy must outline how the local authority intends to manage } \\
\text { its infrastructure assets, taking into account of the need to- } \\
\text { (e) provide for the resilience of infrastructure assets by identifying and managing } \\
\text { risks relating to natural hazards and by making appropriate financial provision for } \\
\text { those risks }\end{array}$ \\
\hline
\end{tabular}




\section{Resource \\ Management Act 1991}

\section{Section 3 Meaning of effect}

In this Act, unless the context otherwise requires, the term effect includes-

a) any positive or adverse effect; and

b) any temporary or permanent effect; and

c) any past, present or future effect; and

d) any cumulative effect which arises over time or in combination with other effects - regardless of the scale, intensity, duration, or frequency of the effect, and also includes-

e) any potential effect of high probability; and

f) any potential effect of low probability which has a high potential impact.

\section{Section 5 Purpose}

1) In this Act sustainable management means managing the use, development, and protection of natural and physical resources in a way, or at a rate, which enables people and communities to provide for their social, economic, and cultural well-being and for their health and safety while-

(a) sustaining the potential of natural and physical resources (excluding minerals) to meet the reasonably foreseeable needs of future generations; and

(b) safeguarding the life-supporting capacity of air, water, soil, and ecosystems; and

(c) avoiding, remedying, or mitigating any adverse effects of activities on the environment.

\section{Section 7 Other matters}

In achieving the purpose of this Act, all persons exercising functions and powers under it, in relation to managing the use, development, and protection of natural and physical resources, shall have particular regard to-

(i) the effects of climate change

NB: Resource Management (Energy and Climate Change) Amendment Act 2004 Purpose

Section 3 (b) to require local authorities-

(i) to plan for the effects of climate change

(ii) not to consider the effects on climate change of discharges to air of greenhouse gases.

\section{Section 30 Functions of regional councils}

1) Every regional council shall have the following functions for the purpose of giving effect to this Act in its region:

(a) the establishment, implementation, and review of objectives, policies, and methods to achieve integrated management of the natural and physical resources of the region:

(b) the preparation of objectives and policies in relation to any actual or potential effects of the use, development, or protection of land which are of regional significance:

(c) the control of the use of land for the purpose of-

(i) soil conservation:

(ii) the maintenance and enhancement of the quality of water in water bodies and coastal water:

(iii) the maintenance of the quantity of water in water bodies and coastal water:

(iiia) the maintenance and enhancement of ecosystems in water bodies and coastal water:

(iv) the avoidance or mitigation of natural hazards 


\section{Section 31 Functions of territorial authorities under this Act}

(1) Every regional council/territorial local authority shall have the following functions for the purpose of giving effect to the RMA in its region/district; (a) the establishment, implementation, and review of objectives, policies, and methods to achieve integrated management of the effects of the use, development, or protection of land and associated natural and physical resources of the district:

(b) the control of any actual or potential effects of the use, development, or protection of land, including for the purpose of -

(i) the avoidance or mitigation of natural hazards;

Section 32 Requirements for preparing and publishing evaluation reports

(2) An assessment under (1) (b) (ii) must-

(c) assess the risk of acting or not acting if there is uncertain or insufficient information about the subject matter of the provisions

(6) In this section-

provisions means, -

(a) for a proposed plan or change, the policies, rules, or other methods that implement, or give effect to, the objectives of the proposed plan or change

\section{Section 33 Transfer of powers}

(1) A local authority may transfer any 1 or more of its functions, powers, or duties under this Act, except this power of transfer, to another public authority in accordance with this section.

\section{Section 34 Delegation of functions, etc, by local authorities}

\section{Section 45 Purpose of national policy statement}

(2) In determining whether it is desirable to prepare a national policy statement, the Minister may have regard to-

(g) anything which, because of its uniqueness, or the irreversibility or potential magnitude or risk of its actual or potential effects, is of significance to the environment of New Zealand

Section 65 Preparation and change of other regional plans

(1) A regional council may prepare a regional plan for the whole or part of its region for any functions in section $30(1)(c)$

\section{Section 104 Consideration of applications}

(1) When considering an application for a resource consent and any submissions received, the consent authority must, subject to Part 2, have regard to-

(a) any actual and potential effects on the environment of allowing the activity; and

(b) any relevant provisions of -

(i) a national environmental standard:

(ii) other regulations:

(iii) a national policy statement:

(iv) a New Zealand coastal policy statement:

(v) a regional policy statement or proposed regional policy statement:

(vi) a plan or proposed plan; and

(c) any other matter the consent authority considers relevant and reasonably necessary to determine the application. 
New Zealand Coastal

Policy Statement 2010

\section{Policy 3 Precautionary approach}

1. Adopt a precautionary approach towards proposed activities whose effects on the coastal environment are uncertain, unknown, or little understood, but potentially significantly adverse.

2. In particular, adopt a precautionary approach to use and management of coastal resources potentially vulnerable to effects from climate change, so that:

a) avoidable social and economic loss and harm to communities does not occur;

b) natural adjustments for coastal processes, natural defences, ecosystems, habitat and species are allowed to occur; and

c) the natural character, public access, amenity and other values of the coastal environment meet the needs of future generations.

\section{Policy 10 Reclamation and de-reclamation}

2. Where a reclamation is considered to be a suitable use of the coastal marine area, in considering its form and design have particular regard to:

a. the potential effects on the site of climate change, including sea level rise, over no less than 100 years;

\section{Policy 24: Identification of coastal hazards}

Identify areas in the coastal environment that are potentially affected by coastal hazards (including tsunami), giving priority to the identification of areas at high risk of being affected. Hazard risks, over at least 100 years, are to be assessed having regard

to: a) physical drivers and processes that cause coastal change including sea rise;

b) short-term and long-term natural dynamic fluctuations of erosion and accretion;

c) geomorphological character;

d) the potential for inundation of the coastal environment, taking into account potential sources, inundation pathways and overland extent;

e) cumulative effects of sea level rise, storm surge and wave height under storm conditions;

f) influences that humans have had or are having on the coast;

g) the extent and permanence of built development; and

h) the effects of climate change on:

i) matters (a) to (g) above;

ii) storm frequency, intensity and surges; and

iii) coastal sediment dynamics;

taking into account national guidance and the best available information on the likely effects of climate change on the region or district.

Policy 25: Subdivision, use, and development in areas of coastal hazard risk In areas potentially affected by coastal hazards over at least the next 100 years: avoid increasing the risk of social, environmental and economic harm from coastal hazards;

a) avoid redevelopment, or change in land use, that would increase the risk of adverse effects from coastal hazards;

b) encourage redevelopment, or change in land use, where that would reduce the risk of adverse effects from coastal hazards, including managed retreat by relocation or removal of existing structures or their abandonment in extreme circumstances, and designing for relocatability or recoverability from hazard events;

c) encourage the location of infrastructure away from areas of hazard risk where practicable;

d) discourage hard protection structures and promote the use of alternatives to them, including natural defences; and

e) consider the potential effects of tsunami and how to avoid or mitigate them. 


\section{Appendix $3 \quad$ Research Participants}

\begin{tabular}{|c|c|c|}
\hline Governance scale & Organisation & Interviewees \\
\hline \multirow[t]{9}{*}{ Central government } & Department of Conservation (DOC) & Coastal policy advisor \\
\hline & $\begin{array}{l}\text { New Zealand Transport Agency } \\
\text { (NZTA) }\end{array}$ & Senior advisors (2) \\
\hline & Office of the Auditor-General (OAG) & Senior advisor \\
\hline & Ministry for the Environment & $\begin{array}{l}\text { Adaptation and science } \\
\text { advisor }\end{array}$ \\
\hline & Earthquake Commission* & Research manager \\
\hline & GNS Science * & Seismologist \\
\hline & Reserve Bank of New Zealand* & Senior advisor \\
\hline & The New Zealand Treasury* & Senior advisor \\
\hline & $\begin{array}{l}\text { Commission for Financial Literacy and } \\
\text { Retirement Income NZ* }\end{array}$ & CEO \\
\hline \multirow[t]{2}{*}{ Regional government } & $\begin{array}{l}\text { Greater Wellington Regional Council } \\
\text { (GWRC) }\end{array}$ & $\begin{array}{l}\text { Strategic advisor } \\
\text { Flood risk manager } \\
\text { Politician }\end{array}$ \\
\hline & Otago Regional Council (ORC & $\begin{array}{l}\text { CEO } \\
\text { Environmental engineer } \\
\text { Natural hazards manager }\end{array}$ \\
\hline \multirow[t]{3}{*}{ Unitary councils } & Tasman District Council & $\begin{array}{l}\text { Strategy manager } \\
\text { Flood engineer }\end{array}$ \\
\hline & Nelson City Council & Councillor \\
\hline & Auckland Council & $\begin{array}{l}\text { Politician } \\
\text { Chief planner } \\
\text { Senior planner } \\
\text { Coastal design planner } \\
\text { Infrastructure operations } \\
\text { engineer } \\
\text { Science manager } \\
\text { Land and environment } \\
\text { strategic planner } \\
\text { Water infrastructure } \\
\text { engineer and manager (2) }\end{array}$ \\
\hline
\end{tabular}




\begin{tabular}{|c|c|c|}
\hline District Councils & Wellington City Council (WCC) & $\begin{array}{l}\text { Climate change advisor } \\
\text { Transport planner } \\
\text { Storm water planner } \\
\text { Urban design planner }\end{array}$ \\
\hline & Kapiti Coast District Council & $\begin{array}{l}\text { Planning manager } \\
\text { District planner } \\
\text { Storm water manager and } \\
\text { engineer (2) } \\
\text { Coastal hazards engineer }\end{array}$ \\
\hline & Hutt City Council (HCC) & $\begin{array}{l}\text { General manager } \\
\text { infrastructure } \\
\text { Asset manager and advisor } \\
\text { (3) }\end{array}$ \\
\hline & Dunedin City Council (DCC) & $\begin{array}{l}\text { Politician (3) } \\
\text { CEO } \\
\text { General manager strategy } \\
\text { General manager } \\
\text { environment } \\
\text { Corporate policy manager } \\
\text { Property manager } \\
\text { Transport planner } \\
\text { Risk manager } \\
\text { Consents manager } \\
\text { Senior advisor water and } \\
\text { waste water } \\
\text { Asset manager }\end{array}$ \\
\hline $\begin{array}{l}\text { Local government } \\
\text { advocate }\end{array}$ & Local Government Association (LGNZ) & $\begin{array}{l}\text { Environment advisor } \\
\text { Risk management advisor } \\
\text { President }\end{array}$ \\
\hline Legal professionals & & $\begin{array}{l}\text { Barristers (3 incl. } 2 \text { Queen's } \\
\text { Counsels) } \\
\text { Judiciary } \\
\text { Resource management } \\
\text { lawyers (2) }\end{array}$ \\
\hline Consultants & & $\begin{array}{l}\text { Water and river engineer } \\
\text { Risk manager }\end{array}$ \\
\hline $\begin{array}{l}\text { Non-climate decision } \\
\text { settings }\end{array}$ & $\begin{array}{l}\text { Note: Companies and names withheld. } \\
\text { *Earthquakes, financial risk } \\
\text { management and superannuation } \\
\text { interviewees are listed under central } \\
\text { government. }\end{array}$ & $\begin{array}{l}\text { Earthquake (2) } \\
\text { Reinsurance (2) } \\
\text { Insurance companies (4) } \\
\text { Anaesthesiology (2) } \\
\text { Financial risk advisor (2) } \\
\text { Superannuation advisor (2) }\end{array}$ \\
\hline
\end{tabular}




\section{Appendix $4 \quad$ Information Sheet}

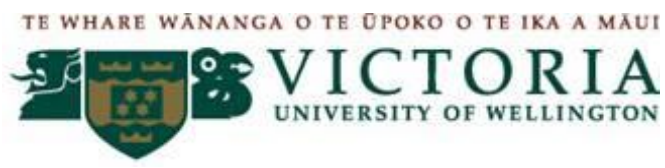

PhD Research project

\section{Flexible time adapted decision making-local government response to the effects of climate change}

\section{$\underline{\text { Information sheet for participants in interviews on current practice* }}$}

Researcher: Judy Lawrence, PhD candidate, School of Government, Victoria University of Wellington.

I am a PhD candidate undertaking research in Public Policy based in the School of Government at Victoria University of Wellington. The aim of my research is to develop an understanding of what is necessary to design a decision-making response to enable NZ local government to address the constraints posed by uncertainty and long timeframes associated with climate change impacts on the coast and on floodplains.

Climate change impacts will be felt globally and across communities in New Zealand. Impacts such as sea level rise are projected to continue into the future for centuries at unknown rates and surprises cannot be ruled out. Increased flood frequency will also be a feature of climate change impacts in New Zealand. Characteristics such as uncertainty, dynamic change, time inconsistency in responses and potential maladaptation of those responses raise significant issues for local government when addressing climate change impacts. Local government has a mandate to address these issues but little is known about local government capacity to do so.

This research will be done by addressing 3 principal questions

- What is current practice?

- What can be learned from analogous decision contexts?

- What factors in the local government decision context constrain and enable decision makers?

Views about current practice, constraints and enablers, and the analogous decision contexts will be elicited using interviews with a selection of central and local government advisors and managers, politicians and significant practitioners from the legal profession.

Workshops will be conducted during 2012 to test the emerging themes and a preliminary design for a flexible time- adapted decision response, with a selection of the local government practitioners including those interviewed previously. Requests for participation in the workshops are expected to be made later in 2011. "

I would like to invite you to take part in this research by agreeing to be interviewed about current practice and the constraints and factors that enable decisions to be made in a situation of uncertainty, dynamic change and long time frames that are characteristic of decisions about climate change impacts, such as sea level rise and increased flood frequency and intensity.

* A similar information sheet was sent to workshop and analogue respondents 
I am inviting a range of practitioners from different disciplines and roles in regional and district councils, relevant government agencies and a number of legal professionals. These will comprise regional, district and strategic planners, hazards and emergency managers, asset managers, engineers and flood managers, CEO's and politicians, and legal professionals. The interviews are intended to be semi-structured and I have appended an outline of the sort of areas I wish to cover in the interview. However this should not be seen as constraining the conversation and the interview will be as open-ended as possible. The interviews could take 1-2 hours and will be recorded, if you agree. A consent form is attached for your consideration and signing if you agree to be a participant in this research. Prior to the interview I will send you some background material.

The information collected will be used to inform my $\mathrm{PhD}$ which will be written up and submitted to examiners.

No views expressed in interviews will be attributed to an individual, but I would like to attribute some responses in the general form of 'expert type from a specific organisation' (e.g. "planners from a regional council emphasised xyz, whereas engineers from a City Council put greater weight on zyx"). I intend to list your name and professional role as having participated in the research, but can withhold this information from publicly released information if you request me to do so. You can express your choice in this regard through the Consent Form attached.

The record of the interview which enables identification of and attribution of statements to individuals will be destroyed 5 years after the research has been concluded, at the latest by 30 September 2018 when all research publications will be completed. Records of interviews will be kept in secure/locked files accessible only seen by myself and my academic supervisors $\mathrm{Dr}$ Amanda Wolf, School of Government, Victoria University of Wellington, and Dr Andy Reisinger, AgResearch, formerly at Victoria University of Wellington. The recordings and notes will be destroyed in 2018. The primary data will only be used for the research described above for my $\mathrm{PhD}$ thesis and any follow-up investigation consistent with requirements of the $\mathrm{PhD}$ examiners or academic peer review of publications and presentations based on this research.

Your participation in this research is entirely voluntary. Following strict procedures for research involving human participants at Victoria University of Wellington, this study has been assessed and approved by the University's Human Ethics Committee.

The $\mathrm{PhD}$ thesis will be available on the internet following examination (anticipated in 2013). I will notify you by email of any final publications arising from this research as soon as those are publicly available.

If you have any questions or would like some additional information about this research, please do not hesitate to contact me judy.lawrence@vuw.ac.nz 021499011 or 04 5685118, or my primary supervisor Amanda Wolf amanda.wolf@vuw.ac.nz 044635712 at the School of Government, P.O. Box 600, Wellington or Dr Andy Reisinger at andy.reisinger@nzagrc.org.nz +64 21613125

Yours sincerely

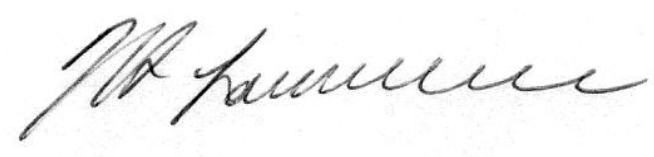

Judy Lawrence 


\section{Current practice interviews}

The following general areas of inquiry will be discussed at the interviews:

- The current approach to flood and coastal risk management, its adequacy for current climate risks, how remaining residual risks are managed and what determines decisions about the balance between the investment costs and benefits of current risk management plans.

- Whether the current approach to flood and coastal risk management can be up-scaled as new information becomes available about increases in flood and coastal risk as a consequence of climate change, over what time frames and what the limits are to up-scaling the current flood and coastal risk management approaches and whether such up-scaling can maintain the balance between investment in flood and coastal risk reduction and the benefits of risk reduction in the current plans.

- Thresholds that could require a fundamental change in the current approach to flood risk management and at what point in time a fundamental change in approach would need to be decided to be effective, what trigger points might look like.

- The effect of flood risk and coastal management decisions in the near term on the ability of communities to manage a possible increase in future risk given the uncertainty in risk projections and the near term costs of increasing protection.

- Frameworks, tools and regulatory options that are currently used by councils to manage uncertainty in flood and coastal risk estimates for the present and future and whether they can deal with the range of potential future changes under climate change and balance near-term and long-term benefits, costs and risks in a context of uncertainty.

- The opportunities and barriers that councils have to implement long term flood and coastal risk management that considers climate change, factors that give flexibility to decisions and the role of uncertainty and capacity of staff.

- The role that risk management and cost benefit analysis play in decision making when uncertainty is involved and how long timeframes and dynamic and abrupt changes are dealt with and what determines how they are considered.

Analogue interviews (non-climate decision settings)

The following general themes will guide the semi-structured interviews with practitioners from analogous contexts:

- The frameworks, tools and regulatory or voluntary options that guide your decision making

- The uncertainties, dynamic changes and timeframes that are faced when making decisions in this domain

- How the frameworks, tools and regulatory or voluntary options in your domain address uncertainty, dynamic change and long time frames.

- The barriers and opportunities to addressing uncertainty, dynamic change and long time frames

- The factors that influence overcoming barriers or taking up opportunities 



\section{Appendix $5 \quad$ Potential analogues and design features}

Table 1 Non-climate decision settings: similarities and differences

\begin{tabular}{|c|c|c|c|c|}
\hline $\begin{array}{l}\text { Climate change } \\
\text { characteristics/ } \\
\text { Analogous } \\
\text { institutions }\end{array}$ & Magnitude & Scale & Rate & $\begin{array}{l}\text { Time } \\
\text { (changing risk) }\end{array}$ \\
\hline Pandemics & Large & $\begin{array}{l}\text { Widespread } \\
\text { disruption }\end{array}$ & $\begin{array}{l}\text { Fast due to high } \\
\text { movement } \\
\text { numbers and } \\
\text { contacts }\end{array}$ & $\begin{array}{l}\text { Unpredictable } \\
\text { and random } \\
\text { over time }\end{array}$ \\
\hline $\begin{array}{l}\text { Biosecurity } \\
\text { incursions }\end{array}$ & $\begin{array}{l}\text { Varies from } \\
\text { whole herds or } \\
\text { specific species }\end{array}$ & $\begin{array}{l}\text { Specific locations } \\
\text { or economy-wide }\end{array}$ & $\begin{array}{l}\text { Slow start then } \\
\text { can be fast } \\
\text { depending on } \\
\text { vector }\end{array}$ & $\begin{array}{l}\text { Unpredictable } \\
\text { and random } \\
\text { over time }\end{array}$ \\
\hline Earthquakes & Large & Site-specific & Sudden/frequent & $\begin{array}{l}\text { Unpredictable } \\
\text { and random } \\
\text { over time }\end{array}$ \\
\hline $\begin{array}{l}\text { Financial } \\
\text { supervision }\end{array}$ & $\begin{array}{l}\text { Response to } \\
\text { crises }\end{array}$ & $\begin{array}{l}\text { Widespread } \\
\text { disruption }\end{array}$ & Sudden and fast & $\begin{array}{l}\text { 'Predictable } \\
\text { surprises' }\end{array}$ \\
\hline Insurance & Response to loss & $\begin{array}{l}\text { Most of the } \\
\text { population/location } \\
\text { specific }\end{array}$ & $\begin{array}{l}\text { Sudden event } \\
\text { related }\end{array}$ & $\begin{array}{l}\text { Short-term } \\
\text { through annual } \\
\text { contract but has } \\
\text { leverage post } \\
\text { event }\end{array}$ \\
\hline Superannuation & $\begin{array}{l}\text { Managing future } \\
\text { population-wide } \\
\text { risk }\end{array}$ & $\begin{array}{l}\text { Covers whole } \\
\text { population }\end{array}$ & Slow change & $\begin{array}{l}\text { Addresses } \\
\text { future changing } \\
\text { risk from } \\
\text { demographic } \\
\text { changes and } \\
\text { addresses } \\
\text { intergenerationa } \\
1 \text { risk }\end{array}$ \\
\hline $\begin{array}{l}\text { Surgical risk } \\
\text { management }\end{array}$ & $\begin{array}{l}\text { Managing } \\
\text { potential and } \\
\text { current risk at } \\
\text { an individual } \\
\text { level }\end{array}$ & $\begin{array}{l}\text { Location/person } \\
\text { specific }\end{array}$ & $\begin{array}{l}\text { Varies between } \\
\text { fast and slow }\end{array}$ & $\begin{array}{l}\text { Anticipates } \\
\text { future risk } \\
\text { within a short } \\
\text { timeframe }\end{array}$ \\
\hline
\end{tabular}


Table 2 Institutional design features relevant for addressing uncertainty and dynamic climate change

\begin{tabular}{|c|c|c|c|c|}
\hline $\begin{array}{l}\text { Analogue/ } \\
\text { lessons }\end{array}$ & Framework & Practice & Process & Relevance/risks \\
\hline Pandemics & $\begin{array}{l}\text { Anticipatory } \\
\text { legislation } \\
\text { Single agency focus } \\
\text { Links to emergency } \\
\text { management }\end{array}$ & $\begin{array}{l}\text { 'Event' focused and } \\
\text { dependent on } \\
\text { response capability } \\
\text { Pathways } \\
\text { management } \\
\text { system }\end{array}$ & $\begin{array}{l}\text { Precautionary } \\
\text { monitoring and } \\
\text { surveillance }\end{array}$ & $\begin{array}{l}\text { Anticipatory } \\
\text { legislation } \\
\text { Dependent on } \\
\text { capability } \\
\text { Integrated support } \\
\text { systems }\end{array}$ \\
\hline $\begin{array}{l}\text { Biosecurity risk } \\
\text { management }\end{array}$ & $\begin{array}{l}\text { Anticipatory } \\
\text { legislation } \\
\text { Post-border pest } \\
\text { management } \\
\text { devolved to local } \\
\text { government } \\
\text { Links to emergency } \\
\text { management }\end{array}$ & $\begin{array}{l}\text { Dependent on } \\
\text { response capability } \\
\text { Pathways } \\
\text { management } \\
\text { system }\end{array}$ & $\begin{array}{l}\text { Precautionary pre- } \\
\text { threat and post- } \\
\text { border } \\
\text { monitoring, } \\
\text { intelligence and } \\
\text { surveillance }\end{array}$ & $\begin{array}{l}\text { Devolution to } \\
\text { local government } \\
\text { Relies on } \\
\text { different levels of } \\
\text { government } \\
\text { Integrated support } \\
\text { systems }\end{array}$ \\
\hline Earthquakes & $\begin{array}{l}\text { Based on single } \\
\text { events } \\
\text { Multiple agents } \\
\text { with different } \\
\text { responsibilities }\end{array}$ & $\begin{array}{l}\text { Practice codes not } \\
\text { fit for purpose and } \\
\text { reluctance to update } \\
\text { Risk transfer occurs }\end{array}$ & $\begin{array}{l}\text { Precautionary } \\
\text { monitoring, } \\
\text { intelligence and } \\
\text { surveillance of } \\
\text { risk } \\
\text { Capability } \\
\text { dependent }\end{array}$ & $\begin{array}{l}\text { Weak links } \\
\text { between statutes } \\
\text { and levels of } \\
\text { government } \\
\text { Integrated } \\
\text { research strategy } \\
\text { Single event focus } \\
\text { Risk transfer } \\
\text { exacerbates risk } \\
\text { No mechanism to } \\
\text { update risk levels }\end{array}$ \\
\hline $\begin{array}{l}\text { Financial } \\
\text { supervision }\end{array}$ & $\begin{array}{l}\text { One statute makes } \\
\text { roles and purpose } \\
\text { clear } \\
\text { Central bank } \\
\text { prudential risk } \\
\text { management }\end{array}$ & $\begin{array}{l}\text { Deposit Guarantee } \\
\text { Scheme } \\
\text { Open Bank } \\
\text { Resolution } \\
\text { Scheme } \\
\text { Basel Accord and } \\
\text { 'living will' }\end{array}$ & $\begin{array}{l}\text { Clear risk } \\
\text { responsibility } \\
\text { Resilience } \\
\text { reporting } \\
\text { Relationships } \\
\text { between } \\
\text { governance scales } \\
\text { Communication } \\
\text { and transparency }\end{array}$ & $\begin{array}{l}\text { Stress testing for } \\
\text { sensitivity to risk } \\
\text { and prioritising } \\
\text { actions } \\
\text { Risk insurance } \\
\text { Risk } \\
\text { responsibility } \\
\text { Resilience } \\
\text { reporting } \\
\text { Relationships } \\
\text { between } \\
\text { governance scales } \\
\text { Risk } \\
\text { communication, } \\
\text { Transparency } \\
\text { Short-term focus }\end{array}$ \\
\hline
\end{tabular}




\begin{tabular}{|c|c|c|c|c|}
\hline $\begin{array}{l}\text { Analogue/ } \\
\text { lessons }\end{array}$ & Framework & Practice & Process & Relevance/risks \\
\hline Insurance & $\begin{array}{l}\text { Blunt instrument } \\
\text { unless risk-based on } \\
\text { location }\end{array}$ & $\begin{array}{l}\text { Annual contract } \\
\text { enables some } \\
\text { flexibility } \\
\text { Reinsurance } \\
\text { provides leverage } \\
\text { over time } \\
\text { Replacement value- } \\
\text { based insurance }\end{array}$ & $\begin{array}{l}\text { National fiscal } \\
\text { risk managed } \\
\text { through EQC and } \\
\text { some risk } \\
\text { spreading across } \\
\text { generations } \\
\text { through the levy } \\
\text { fund }\end{array}$ & $\begin{array}{l}\text { Combining } \\
\text { insurance with } \\
\text { risk mitigation by } \\
\text { local government } \\
\text { Annual contract } \\
\text { too short term for } \\
\text { risk trends to be } \\
\text { reflected } \\
\text { Insurance and } \\
\text { EQC reduces } \\
\text { incentive for risk } \\
\text { reduction unless } \\
\text { linked to locality } \\
\text { risk }\end{array}$ \\
\hline Superannuation & $\begin{array}{l}\text { A Fund } \\
\text { Independent } \\
\text { Guardians of the } \\
\text { Fund } \\
\text { Education an } \\
\text { savings literacy }\end{array}$ & $\begin{array}{l}\text { Pre-funded } \\
\text { Tax burden } \\
\text { smoothed across } \\
\text { generations }\end{array}$ & 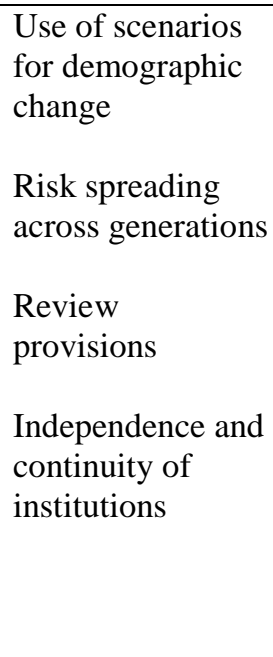 & $\begin{array}{l}\text { Changing risk } \\
\text { included and } \\
\text { uncertainty and } \\
\text { dynamic change } \\
\text { considered } \\
\text { Independence, } \\
\text { continuity, } \\
\text { review, ability to } \\
\text { spread risk, } \\
\text { anticipatory and } \\
\text { education } \\
\text { Pre-funding } \\
\text { spreads burden } \\
\text { across generations }\end{array}$ \\
\hline $\begin{array}{l}\text { Surgical risk } \\
\text { management }\end{array}$ & $\begin{array}{l}\text { Procedural and } \\
\text { intuitive risk } \\
\text { management } \\
\text { Built-in redundancy } \\
\text { Supporting } \\
\text { institutional } \\
\text { regulatory tools } \\
\text { 'belt and braces' } \\
\text { performance of } \\
\text { professionals; } \\
\text { formal checking } \\
\text { processes aid } \\
\text { communications } \\
\text { Professional } \\
\text { education targets } \\
\text { human behaviour } \\
\text { flaws }\end{array}$ & $\begin{array}{l}\text { Precautionary } \\
\text { Addresses } \\
\text { procedural and } \\
\text { intuitive risks } \\
\text { Redundancy gives } \\
\text { flexibility }\end{array}$ & $\begin{array}{l}\text { A safety culture } \\
\begin{array}{l}\text { Organisation } \\
\text { performance }\end{array} \\
\begin{array}{l}\text { Professional } \\
\text { performance }\end{array} \\
\text { Addresses client } \\
\text { safety interests }\end{array}$ & $\begin{array}{l}\text { Addresses } \\
\text { procedural and } \\
\text { human intuitive } \\
\text { factors in } \\
\text { managing risks } \\
\text { A 'belt and } \\
\text { braces' } \\
\text { framework with } \\
\text { disciplinary } \\
\text { norms, structures } \\
\text { and sanctions, } \\
\text { education } \\
\text { Reduces risks } \\
\text { because System } 1 \\
\text { and } 2 \text { thinking is } \\
\text { addressed }\end{array}$ \\
\hline
\end{tabular}





\section{References}

Abel, N., Gorddard, R., Harman, B., Leitch, A., Langridge, J., Ryan, A., \& Heyenga, S. (2011). Sea level rise, coastal development and planned retreat: Analytical framework, governance principles and an Australian case study. Environmental Science \& Policy, 14(3), 279-288.

Adger, W. N. (2000). Social and ecological resilience: Are they related? Progress in Human Geography, 24, 347-364.

Adger, W. N. (2006). Vulnerability. Global Environmental Change, 16(3), 268-281.

Adger, W. N., Agrawala, S., \& Mirza, M. M. Q. et al. (2007). Assessment of adaptation practices, options, constraints and capacity. In M. Parry, O. Canziani, J. Palutikof, P. van der Linden, \& C. Hanson (Eds.), Climate Change 2007: Impacts, Adaptation and Vulnerability. Contribution of Working Group II to the Fourth Assessment Report of the Intergovernmental Panel on Climate Change (pp. 717-743). Cambridge, UK: Cambridge University Press.

Adger, W. N., Arnell, N. W., \& Tompkins, E. L. (2005). Successful adaptation to climate change across scales. Global Environmental Change, 15(2), 77-86. doi: 10.1016/j.gloenvcha.2004.12.005

Adger, W. N., \& Barnett, J. (2009). Commentary: Four reasons for concern about adaptation to climate change. Environment and Planning A, 41, 2800-2805.

Adger, W. N., Dessai, S., Goulden, M., Hulme, M., Lorenzoni, I., Nelson, D., . . W Wreford, A. (2009). Are there social limits to adaptation to climate change? Climatic Change, 93(3), 335-354.

Adger, W. N., Lorenzoni, I., \& O'Brien, K. L. (2009). Adapting to Climate Change: Thresholds, values, governance. Cambridge, UK: Cambridge University Press.

Aerts, J., Botzen, W., van der Veen, A., Krywkow, J., \& Werners, S. (2008). Dealing with uncertainty in flood management through diversification. Ecology and Society, 13(1).

Alexander, D. E. (2013). Resilience and disaster risk reduction: An etymological journey. Natural Hazards and Earth System Sciences, 13, 2707-2716. 
Allan, S., \& Fowler, R. (2014). Draft Independent Review of the Kāpiti Coast Proposed District Plan. Wellington: Allan Planning and Research Ltd.

Amundsen, H., Berglund, F., \& Westskog, H. (2010). Overcoming barriers to climate change adaptation: A question of multilevel governance? Environment and Planning $C$ : Government and Policy, 28(2), 276-289.

Argyris, C., \& Schön, D. (1978). Organizational learning: A theory of action perspective. Reading, Mass: Addison Wesley.

Arts, B. (2006). Forests, Institutions, Discourses. A discursive-institutional analysis of global forest politics. Inaugural address. Wageningen University, Wageningen.

AS/NZS ISO 31000. (2009). Risk management-Principles and guidelines . Sydney and Wellington: Standards Australia and Standards New Zealand.

Auckland Council. (2012). Stormwater Asset Management Plan 2012-2032 261). Auckland: Author.

Auld, H., \& Maciver, D. C. (2006). Changing weather patterns, uncertainty and infrastructure risk: Emerging adaptation requirements (Vol. Occasional Paper 9). Toronto: Adaptation and Impacts Research Division, Environment Canada.

Barnett, J., Graham, S., Mortreux, C., Fincher, R., Waters, E., \& Hurlimann, A. (2014). A local coastal adaptation pathway. Nature Climate Change, advance online publication. doi: $10.1038 /$ nclimate2383

Barnett, J., \& O'Neill, S. (2010). Maladaptation. Global Environmental Change, 20(2), 211213.

Bazerman, M. (2006). Climate change as a predictable surprise. Climatic Change, 77(1), 179193. doi: 10.1007/s10584-006-9058-x

Bell, R. G., \& Hannah, J. (2012). Sea Level Variability and Trends: Wellington region. NIWA Client Report No: HAM2012-043. Wellington: Greater Wellington Regional Council.

Berkhout, F. (2012). Adaptation to climate change by organizations. Wiley Interdisciplinary Reviews: Climate Change, 3(1), 91-106. doi: 10.1002/wcc.154 
Berkhout, F., Hertin, J., \& Gann, D. (2006). Learning to adapt: Organisational adaptation to climate change impacts. Climatic Change, 78(1), 135-156. doi: 10.1007/s10584-0069089-3

Berry, S., \& Vella, J. (2011). Planning Controls and Property Rights: Striking the balance. In T. Daya-Winterbottom, Resource Management Law Reform Association of New Zealand Inc (Ed.), Resource Management Theory and Practice. (pp. 136-194). Auckland: Thomson Reuters

Biesbroek, G. R., Klostermann, J., Termeer, C., \& Kabat, P. (2013). On the nature of barriers to climate change adaptation. Regional Environmental Change, 13(5), 1119-1129. doi: 10.1007/s10113-013-0421-y

Biesbroek, G. R., Termeer, C., Kabat, P., \& Klostermann, J. (2009). Institutional Governance Barriers for the Development and Implementation of Climate Adaptation Strategies. Amsterdam, The Netherlands: Earth System Governance: People, Places, and the Planet.

Birkmann, J., Buckle, P., Jaeger, J., Pelling, M., Setiadi, N., Garschagen, M., . . Kropp, J. (2010). Extreme events and disasters: A window of opportunity for change? An analysis of organisational, institutional and political changes, formal and informal responses after mega-disasters. Natural Hazards, 55, 637-655.

Bjerklie, D. M., Mullaney, J. R., Stone, J. R., Skinner, B. J., \& Ramlow, M. A. (2012). Preliminary Investigation of the Effects of Sea-Level Rise on Groundwater Levels in New Haven, Connecticut. US Geological Survey.

Blackett, P., Hume, T., \& Dahm, J. (2010). Exploring the social context of coastal erosion management in New Zealand: What factors drive environmental outcome. Australasian Journal of Disaster and Trauma Studies, 1 .

Board of Inquiry New Zealand Coastal Policy Statement. (2008). Proposed New Zealand Coastal Policy Statement Working Papers (Vol. 2). Wellington: Author.

Boehmer-Christainsen, S. (1994). The precautionary principle in Germany: Enabling government. In T. O'Riordan \& J. Cameron (Eds.), Interpreting the Precautionary Principle (pp. 31-60). London: Earthscan Publications. 
Bosselmann, K., \& Grinlinton, D. (Eds.). (2002). Environmental Law for a Sustainable Society (Vol. 1). Auckland: NZ Centre for Environmental Law. Boyd, E., Nykvist, B., Borgström, S., Stacewicz, I. A. 2015. Anticipatory governance for social-ecological resilience. Ambio, 44,149-161.

Braun, V., \& Clarke, V. (2006). Using thematic analysis in psychology. Qualitative Research in Psychology, 3(2), 77-101.

Brockhaus, M., \& Kambire, H. (2009). Decentralisation: A window of opportunity for successful adaptation to climate change. In W. N. Adger, I. Lorenzoni, \& K. O' Brien (Eds.), Adapting to Climate Change: Thresholds, values, governance (pp. 399-416). Cambridge, UK: Cambridge University Press.

Bulkeley, H., \& Betsill, M. (2006). Rethinking sustainable cities: Multilevel governance and the 'urban' politics of climate change. Environmental Politics, 14(1), 42-63.

Burby, R. J. (2006). Hurricane Katrina and the paradoxes of government disaster policy: Bringing about wise governmental decisions for hazardous areas. The Annals of the American Academy of Political and Social Science, 604(1), 171-191.

Burby, R. J., Nelson, A. C., Parker, D., \& Handmer, J. (2001). Urban containment policy and exposure to natural hazards: Is there a connection? Journal of Environmental Planning and Management, 44(4), 475-490.

Burch, S. (2010). Transforming barriers into enablers of action on climate change: Insights from three municipal case studies in British Columbia, Canada. Global Environmental Change, 20(2), 287-297. doi: 10.1016/j.gloenvcha.2009.11.009

Burton, I. (2009). Climate change and the adaptation deficit. In L. E. Schipper \& I. Burton (Eds.), The Earthscan Reader on Adaptation to Climate Change (1st ed., pp. 89-95). London: Earthscan.

Burton, I., Huq, S., Lim, B., Pilifosova, O., \& Schipper, E. L. (2002). From impacts assessment to adaptation priorities: The shaping of adaptation policy. Climate Policy, $2,145-159$.

Burton, I., Kates, R. W., \& White, G. (1994). The Environment as Hazard (2nd ed.). New York: Guilford Press. 
Cameron, J., \& Abouchar, J. (1991). The precautionary principle: A fundamental principle for the protection of the global environment. Boston College International and Comparative Law Review, 14, 1-27.

Canterbury Earthquakes Royal Commission. (2012). Final Report. Volume 7. Roles and Responsibilities. Christchurch: Author.

Carley, J., Komar, P., Kench, P., \& Davies, R. (2014). Coastal Erosion Hazard Assessment for the Kapiti Coast: Review of the science and assessments undertaken for the proposed Kāpiti Coast District Plan 2012. Draft V1.1. Paraparaumu: Kapiti Coast District Council.

Carlman, I. (2005). The rule of sustainability and planning adaptivity. Ambio, 34(2), 163-168.

Charmaz. (2006). Constructing Grounded Theory: A Practical Guide to Qualitative Analysis. London: SAGE Publications.

Church, J., Clark, P., Cazenave, A., Gregory, J., Jevrejeva, S., Levermann, A., . . . Unnikrishnan, A. S. (2013a). Sea level rise by 2100. Science, 342(20 December 2013), 1445-1446.

Church, J., Clark, P. U., Cazenave, A., Gregory, J., Jevrejeva, S., Levermann, A., . . . Unnikrishnan, A. S. (2013b). Chapter 13: Sea Level Change. In T. Stocker, D. Qin, \& P. Midgley (Eds.), Working Group I Contribution to the IPCC Fifth Assessment Report (AR5), Climate Change 2013: The Physical Science Basis (pp. 1137-1216). Cambridge, UK.

Conway, D., \& Mustelin, J. (2014). Strategies for improving adaptation practice in developing countries. Nature Climate Change, 4(5), 339-342. doi: 10.1038/nclimate2199

Creswell, J. W. (2009). Research Design: Qualitative, quantitative and mixed methods approaches. L.A.: SAGE Publications.

Crotty, M. (Ed.). (1998). The Foundations of Social Research: Meaning and Perspective in Research Process. St Leonards, NSW: Allen and Unwin.

De Bruin, K., \& Ansink, E. (2011). Investment in flood protection measures under climate change uncertainties. Climate Change Economics, 2(4), 321-339. 
Department of the Prime Minister and Cabinet New Zealand. (2007). National Hazardscape Report. Wellington: Officials' Committee for Domestic and External Security Coordination.

Dessai, S., \& Hulme, M. (2004). Does climate adaptation policy need probabilities? Climate Policy, 4(2), 107-128. doi: 10.1080/14693062.2004.9685515

Dessai, S., \& Hulme, M. (2007). Assessing the robustness of adaptation decisions to climate change uncertainties: A case study on water resources management in the east of England. Global Environmental Change, 17(1), 59-72. doi: 10.1016/j.gloenvcha.2006.11.005

Dobes, L. (2008). Getting real about adapting to climate change: Using 'real options' to address uncertainties. Agenda, 15(3), 55-68.

Domingues, C. M., Church, J., White, N. J., Gleckler, P. J., Wijffels, S. E., Barker, P. M., \& Dunn, J. R. (2008). Improved estimates of upper-ocean warming and multi-decadal sea-level rise. Nature, 453, 1090-1094.

Dovers, S., \& Handmer, J. (1995). Ignorance, the precautionary principle, and sustainability. Ambio, 24, 92-97.

Dovers, S., \& Handmer, J. (1999). Ignorance and the precautionary principle: Toward an analytical framework. In R. Harding \& E. Fisher (Eds.), Perspectives on the Precautionary Principle. pp 167-189. Sydney: Federation Press.

Dovers, S., \& Hezri, A. (2010). Institutions and policy processes: The means to the ends of adaptation. Wiley Interdisciplinary Reviews: Climate Change, 1(2), 212-231.

Duit, A., \& Galaz, V. (2008). Governance and complexity: Emerging issues for governance theory. Governance: An International Journal of Policy, Administration and Institutions, 21(3), 311-335.

Earthquake Commission. (2013). Statement of Intent 2013-2016. Wellington: Author.

Eisenack, K., \& Stecker, R. (2012). A framework for analyzing climate change adaptations as actions. Mitigation and Adaptation Strategies for Global Change, 17(3), 243-260. doi: 10.1007/s11027-011-9323-9 
Ekstrom, J. A., \& Moser, S. C. (2014). Identifying and overcoming barriers in urban climate adaptation: Case study findings from the San Francisco Bay Area, California, USA. Urban Climate 9, 54-74. doi:10.1016/j.uclim.2014.06.002

Ericksen, N. J. (2005a). The hang-up in flood hazard planning (Part II). Planning Quarterly, December 2005, 28-32.

Ericksen, N. J. (2005b). Hang-ups in flood hazard planning (Part I). Planning Quarterly, September 2005, 24-28.

Evans, L., Grimes, A., Wilkinson, B., \& Teece, D. (1996). Economic reform in New Zealand 1984-95: The pursuit of efficiency. Journal of Economic Literature, 34(4), 1856-1902.

Evans, L., Milfont, T. L., \& Lawrence, J. (2012). Perceptions of Sea Level Rise in the Wellington City and Kapiti Coast Districts. Wellington: Victoria Universty of Wellington School of Psycology and the New Zealand Climate Change Research Institute.

Fankhauser, S., Smith, J. B., \& Tol, R. S. J. (1999). Weathering climate change: Some simple rules to guide adaptation decisions. Ecological Economics, 30(1), 67-78. doi: 10.1016/s0921-8009(98)00117-7

Fischhoff, B., Lichtenstein, S., Slovic, P., Derby, S. L., \& Keeney, R. L. (1981). Acceptable Risk. Cambridge, UK: Cambridge University Press.

Fisher, E. (2001). Is the precautionary principle justifiable? Journal of Environmental Law, 13(3), 315-334. doi: 10.1093/jel/13.3.315

Fisher, E., \& Harding, R. (2006). The precautionary principle and administrative constitutionalism: The development of frameworks for applying the precautionary principle. In E. Fisher, J. Jones, \& R. von Schomberg (Eds.), Implementing the Precautionary Principle (pp. 113-136). Cheltenham, UK \& Northampton, USA: Edward Elgar Publishing.

Fisher, E., Jones, J., \& von Schomberg, R. (2006). Implementing the precautionary principle: Perspectives and prospects. In E. Fisher, J. Jones, \& R. von Schomberg (Eds.), Implementing the Precautionary Principle. (pp.1-16) Cheltenham, UK \& Northampton, USA: Edward Elgar Publishing.] 
Fitzharris, B. (2010). Impacts of Climate Change on Dunedin City. Dunedin: Dunedin City Council.

Flick, U. (2002). An Introduction to Qualitative Research (2nd ed.). London: SAGE Publications.

Folke, C., Carpenter, S., Elmqvist, T., Gunderson, L., Holling, C. S., \& Walker, B. (2002). Resilience and sustainable development: Building adaptive capacity in a world of transformations. Ambio, 31(5), 437-440.

Folke, C., Carpenter, S., Walker, B., Scheffer, M., Chapin, T., \& Rockström, J. (2010). Resilience thinking: Integrating resilience, adaptability and transformability. Ecology and Society, 15(4).

Folke, C., Hahn, T., Olsson, P., \& Norberg, J. (2005a). Adaptive governance of socialecological systems. Annual Review of Environment and Resources, 30, 441-473.

Foxon, T. J., Reed, M. S., \& Stringer, L. C. (2009). Governing long-term social-ecological change: What can the adaptive management and transition management approaches learn from each other? Environmental Policy and Governance, 19(1), 3-20.

Freeman, C., \& Cheyne, C. (2008). Coasts for sale: Gentrification in New Zealand. Planning Theory and Practice, 9(1), 33-56.

Freudenburg, W. R. (1992). Heuristics, biases, and the not-so-general publics: Expertise and error in the assessment of risks. In S. Krimsky \& D. Golding (Eds.), Social Theories of Risk (p. 229-249). Westport, CT: Praegar.

Funtowicz, S. O., \& Ravetz, J. R. (1990). Uncertainty and Quality of Science for Policy. Dordrecht, NL: Kluwer Academic Publishers.

Funtowicz, S. O., \& Ravetz, J. R. (1992). Three types of risk assessment and the emergence of post-normal science. In S. Krimsky \& D. Golding (Eds.), Social Theories of Risk (pp. 251-274). Westport, CT: Praeger.

Gardiner, L., Firestone, D., Osborne, A., Kouvelis, B., Clark, A., \& Tait, A. (2009). Climate Change Effects on the Land Transport Network Volume Two: Approach to risk management (p. 142). NZ Transport Agency Research Report 378. Available at: http://www.nzta.govt.nz/resources/research/reports/378/docs/378-v2.pdf 
Gardiner, L., Firestone, D., Waibl, G., Mistal, N., Van Reenan, K., Hynes, D., . . Clark, A. (2008). Climate Change Effects on the Land Transport Network Volume One: Literature review and gap analysis (p. 226). NZ Transport Agency Research Report 378. Available at: http://www.nzta.govt.nz/resources/research/reports/378/docs/378v1.pdf

Gawande, A. (2011). The Checklist Manifesto-How to Get Things Right. London: Profile Books.

Geels, F. W. (2004). From sectoral systems of innovation to socio-technical systems: Insights about dynamics and change from sociology and institutional theory. Research Policy, 33(6-7), 897-920. doi: 10.1016/j.respol.2004.01.015

Geels, F. W., \& Schot, J. (2007). Typology of sociotechnical transition pathways. Research Policy, 36(3), 399-417. doi: 10.1016/j.respol.2007.01.003

Ghosh, A. K. (2004). On the challenges of using evidence-based information: The role of clinical uncertainty. Laboratory and Clinical Medicine, 144(2), 60-64.

Gibbs, M., \& Hill, T., (Blake Dawson). (2011). Coastal Climate Change Risk: Legal and policy responses in Australia. Canberra: Commonwealth of Australia (Department of Climate Change and Energy Efficiency)

Glaser, B., \& Strauss, A. (1967). The Discovery of Grounded Theory. Chicago: Aldine.

Glavovic, B. C. (2014). The 2004 Manawatu floods, New Zealand: Integrating risk reduction and climate change adaptation. In B. C. Glavovic, G. Smith (Eds.), Adapting to Climate Change: Lessons from natural hazards planning. Dordrecht: Springer.

Glavovic, B. C., Saunders, W., \& Becker, J. (2010). Realising the potential of land-use planning to reduce hazard risks in New Zealand. The Australasian Journal of Disaster and Trauma Studies, 1. Available at: http://www.massey.ac.nz/ trauma/issues/20101/glavovic.htm

Glavovic, B. C., \& Smith, G. E. (2014). Adapting to Climate Change: Lessons from natural hazards planning. Dordrecht: Springer.

GNS Science. (2008). Proceedings of a Workshop on Emergency Management and Social Science Disaster Research in New Zealand 6th December 2007. Paper presented at the 
Workshop on Emergency Management and Social Science Diasaster Research in New Zealand, Wellington.

Goring, D. G., Stephens, S. A., Bell, R. G., \& Pearson, C. P. (2011). Estimation of extreme sea levels in a tide-dominated environment using short data records. Journal of Waterway, Port, Coastal and Ocean Engineering, May/June, 150-159. doi: 10.1061/(ASCE)WW.1943-5460.0000071

Groves, D. G., \& Lempert, R. J. (2007). A new analytic method for finding policy-relevant scenarios. Global Environmental Change, 17, 73-85.

Gunderson, L. (1999). Resilience, flexibility and adaptive management-antidotes for spurious certitude? Conservation Ecology, 3(1), 7.

Gunderson, L., \& Holling, C. (2002). Panarchy: Understanding transformations in systems of humans and nature. Washington D.C.: Island Press.

Gupta, J., Termeer, C., Klostermann, J., Meijerink, S., van den Brink, M., Jong, P., . . . Bergsma, E. (2010). The Adaptive Capacity Wheel: A method to assess the inherent characteristics of institutions to enable the adaptive capacity of society. Environmental Science \& Policy, 13(6), 459-471.

Haasnoot, M., Kwakkel, J., Walker, W., \& ter Maat, J. (2013). Dynamic adaptive policy pathways: A method for crafting robust decisions for a deeply uncertain world. Global Environmental Change, 23(2), 485-498.

Haasnoot, M., Middelkoop, H., Van Beek, E., \& Van Deursen, W. P. A. (2011). A method to develop sustainable water management strategies for an uncertain future. Sustainable Development, 199(6), 369-381.

Hall, J., Brown, S., Nicholls, R., Pidgeon, N., \& Watson, R. (2012). Proportionate adaptation. Nature Climate Change, 2(12), 833-834.

Hall, J., Lempert, R., Keller, K., Hackbarth, A., Mijere, C., \& McInerney, D. (2012). Robust climate policies under uncertainty: A comparison of robust decision making and infogap methods. Risk Analysis, 32(10), 1657-1672. doi: 10.1111/j.15396924.2012.01802.x

Hallegatte, S. (2009). Strategies to adapt to an uncertain climate change. Global Environmental Change, 19, 240-247. 
Hallegatte, S., Green, C., Nicholls, R., \& Corfee-Morlot, J. (2013). Future flood losses in major coastal cities. Nature Climate Change, 3(9), 802-806. doi: 10.1038/nclimate1979

Hallegatte, S., Shah, A., Lempert, R., Brown, C., \& Gill, S. (2012). Investment decision making under deep uncertainty. Policy Research Working Paper. New York: The World Bank.

Handmer, J. (2008). Risk creation, bearing and sharing on Australian floodplains. International Journal of Water Resources Development, 24(4), 527-540. doi: 10.1080/07900620801921439

Handmer, J., \& Dovers, S. (2013). Handbook of Disaster Policies and Institutions: Improving emergency management and climate adaptation (2nd ed.). Abingdon: Routledge.

Hansard. (1989). Resource Management Bill. Wellington: New Zealand Parliament.

Hanson, S., Nicholls, R., Ranger, N., Hallegatte, S., Corfee-Morlot, J., Herweijer, C., \& Chateau J. (2011). A global ranking of port cities with high exposure to climate extremes. Climatic Change, 104(1), 89-111.

Hargrove, R. (2003). Masterful Coaching. New York: John Wiley \& Sons.

Hart, G. (2011). Vulnerability and Adaptation to Sea-Level Rise in Auckland, New Zealand. Wellington: New Zealand Climate Change Research Institute, School of Geography, Environment and Earth Sciences, Victoria University of Wellington.

Hastings District Council. (2012). Sustainable Long Term Solutions to Coastal Hazards at Haumoana: Statement of proposal: Hastings: Author. Available at: http://www.hastingsdc.govt.nz/files/all/documents/ltccp/2012-2022/coastal.pdf

Hawkes Bay Regional Council. (2008). Coastal Hazard Zones: Valuation report HBRC EMI 0808 Plan Number 4021 Environmental Management Group Policy Report. Napier: Author. Available at: http://www.hbrc.govt.nz/HBRCDocuments/HBRC\%20Document\%20Library/20080404\%20WHL\%20Report\%20\% 28Full\%29.pdf

Hawkes Bay Regional Council. (2012). Hawkes Bay Regional Coastal Environment Plan Version 3. Napier: Author. Available at: http://www.hbrc.govt.nz/HBRC- 
Documents/HBRC\%20Document\%20Library/Current\%20RCEP\%20(All\%20Vol1). pdf

Haynes, A. B., Weiser, T. G., Berry, W. R., Lipsitz, S. R., Breizat, A.-H. S., Dellinger, E. P., ... Gawande, A. A. (2009). A surgical safety checklist to reduce morbidity and mortality in a global population. The New England Journal of Medicine, 360(5), 491499. doi: 10.1056/NEJMsa0810119

Hill Clarvis, M., \& Engle, N. L. (2015). Adaptive capacity of water governance arrangements: A comparative study of barriers and opportunities in Swiss and US states. Regional Environmental Change, 15(3), 517-527. doi: 10.1007/s10113-013-0547-y

Hinkel, J., Jaeger, J., Nicholls, R., Lowe, J., Renn, O., \& Shi., P. (2015). Sea-level rise scenarios and coastal risk management. Nature Climate Change, 5(March), 188-190.

Holling, C. S. (1973). Resilience and stability of ecological systems. Annual Review of Ecology and Systematics, 4. pp 1-23.

Holling, C. S. (1978). Adaptive Environmental Assessment and Management. Chichester: Wiley.

Holling, C. S. (1996). Engineering resilience versus ecological resilience In P. Schulze (Ed.), Engineering with Ecological Constraints (pp. 31-44). Washington D.C.: National Academy Press.

Holling, C. S., Gunderson, L. H., \& Ludwig, D. (2002). In quest of a theory of adaptive change. In L. H. Gunderson \& C. S. Holling (Eds.), Panarchy: Understanding transformations in human and natural systems (pp. 3-22). Washington, D.C.: Island Press.

Hovi, J., Sprinz, D., \& Underdal, A. (2009). Implementing long-term climate policy: Time inconsistency, domestic politics, international anarchy. Global Environmental Politics, 9(3), 20-39. doi: 10.1162/glep.2009.9.3.20

Howden, S. M., Crimp, S. J., \& Nelson, R. (2010). Australian Agriculture in a Climate of Change. Paper presented at the Managing Climate Change: Papers from GREENHOUSE 2009, Melbourne, Victoria.

Hunt, A., \& Watkiss, P. (2013). Method overview: Decision support methods for adaptation. Briefing Note 1. Summary of methods and case study examples from the 
MEDIATION Project. European Commission. Available from http://www.mediationproject.eu/platform/pbs/pdf/Briefing-Note-1-LR.pdf

Huntjens, P., Lebel, L., Pahl-Wostl, C., Camkin, J., Schulze, R., \& Kranz, N. (2012). Institutional design propositions for the governance of adaptation to climate change in the water sector. Global Environmental Change, 22(1), 67-81. doi: 10.1016/j.gloenvcha.2011.09.015

IFRC. (2010). World disasters report: Focus on urban risk. Geneva: International Federation of Red Cross and Red Crescent Societies.

Inderberg, T. H., \& Eikeland, P. O. (2009). Limits to adaptation: Analysing institutional constraints. In W. N. Adger, N. I. Lorenzoni, \& K. O'Brien (Eds.), Adapting to Climate Change: Thresholds, values, governance (pp. 443-447). Cambridge, UK: Cambridge University Press.

Insurance Council of New Zealand. (2012). Cost of Disaster Events. Claims History. Accessed April 2012, from http://www.icnz.org.nz/current/weather/index.php

IPCC. (2007). Impacts, adaptation and vulnerability. Contribution of Working Group II to the Fourth Assessment Report of the Intergovernmental Panel on Climate Change. In M. L. Parry, O. F. Canziani, J. P. Palutikof, P. J. van der. Linden, \& C. E. Hanson (Eds.), Climate Change 2007. Cambridge, UK: Cambridge University Press.

IPCC. (2012). Managing the risks of extreme events and disasters to advance climate change adaptation. Summary for policymakers. In [C. B. Field, V. Barros, T. F. Stocker, D. Qin, D. J. Dokken, K. L. Ebi, M. D. Mastrandrea, K. J. Mach, G.-K. Plattner, S. K. Allen, M. Tignor, and P. M. Midgley (eds.)]. A Special Report of Working Groups, I and II of the Intergovernmental Panel on Climate Change. Geneva, Switzerland.

IPCC. (2013). Climate Change 2013: The physical science basis. Contribution of Working Group I to the Fifth Asssessment Report of the Intergovernmental Panel on Climate Change. Summary for policy makers. In T. F. [Stocker, D. Qin, G.-K. Plattner, M. Tignor, S. K. Allen, J. Boschung, A. Nauels, Y. Xia, V. Bex and P.M. Midgley (eds.)]. Cambridge, UK, and New York, USA: Cambridge University Press.

IPCC. (2014b). Annex XX: Glossary. [Agard, J., E. L. F. Schipper, J. Birkmann, M. Campos, C. Dubeux, Y. Nojiri, L. Olsson, B. Osman-Elasha, M. Pelling, M. J. Prather, M. G. Rivera-Ferre, O. C. Ruppel, A. Sallenger, K. R. Smith, A. L. St. Clair, K. J. Mach, M. 
D. Mastrandrea, and T. E. Bilir (eds)]. In: Climate Change 2014: Impacts, Adaptation, and Vulnerability. Part B: Regional Aspects. Contribution of Working Group II to the Fifth Assessment Report of the Intergovernmental Panel on Climate Change [Barros, V. R., C. B. Field, D. J. Dokken, M. D. Mastrandrea, K. J. Mach, T. E. Bilir, M. Chatterjee, K. L. Ebi, Y. O. Estrada, R. C. Genova, B. Girma, E. S. Kissel, A. N. Levy, S. MacCracken, P. R. Mastrandrea, and L. L. White (eds.)] (pp. 1757-1776). Cambridge, UK, and New York, USA: Cambridge University Press.

IPCC. (2014a). Summary for Policy Makers. In: Climate Change 2014: Impacts, Adaptation and Vulnerability. Part A: Global and Sectoral Aspects. Contribution of Working Group II to the Fifth Assessment Report of the Intergovernmental Panel on Climate Change. In [Field, C.B., V. R. Barros, M. D. Mastrandrea, \& K. J. Mach (Eds.)]. Cambridge, UK, and New York, USA: Cambridge University Press.

Isendahl, N., Dewulf, A., \& Pahl-Wostl, C. (2010). Using framing parameters to improve handling of uncertainties in water management practice. Environmental Policy and Governance, 20(2), 107-122.

Jackson, J. (2007). Risk assessment and probabilities: White swans and black swans. Paper presented at the Environment Institute of Australia, New Zealand.

Jonas, H. (1984). The Imperative of Responsibility: In search for an ethics of the technology age. Chicago: University of Chicago Press.

Jones, R. (2001). An environmental risk assessment/management framework for climate change impact assessments. Natural Hazards, 23, 197-230.

Jones, R.N., A. Patwardhan, S.J. Cohen, S. Dessai, A. Lammel, R.J. Lempert, M.M.Q. Mirza, and H. von Storch, 2014: Foundations for decision making. In: Climate Change 2014: Impacts, Adaptation, and Vulnerability. Part A: Global and Sectoral Aspects. Contribution of Working Group II to the Fifth Assessment Report of the Intergovernmental Panel on Climate Change [Field, C.B., V.R. Barros, D.J. Dokken, K.J. Mach, M.D. Mastrandrea, T.E. Bilir, M. Chatterjee, K.L. Ebi, Y.O. Estrada, R.C. Genova, B. Girma, E.S. Kissel, A.N. Levy, S. MacCracken, P.R. Mastrandrea, and L.L. White (eds.)]. Cambridge University Press, Cambridge, United Kingdom and New York, NY, USA, pp. 195-228. 
Joughin, I., Smith, B., \& Medley, B. (2014). Marine ice sheet collapse potentially under way for the Thwaites Glacier Basin, West Antarctica. Science, 344(6185), 735-738.

Juhola, S., Haanpää, S., \& Peltonen, L. (2012). Regional challenges of climate change adaptation in Finland: Examining the ability to adapt in the absence of national level steering. Local Environment, 17(6/7), 629-639. doi: 10.1080/13549839.2012.665860

Juhola, S., Peltonen, L., \& Niemi, P. (2012). The ability of Nordic countries to adapt to climate change: Assessing adaptive capacity at the regional level. Local Environment, 17(6/7), 717-734. doi: 10.1080/13549839.2012.665861

Kahneman, D. (2011). Thinking Fast and Slow. Camberwell: Penguin Australia.

Kahneman, D., Slovic, P., \& Tversky, A. (1982). Judgement Under Uncertainty: Heuristics and biases. Cambridge, UK: Cambridge University Press.

Kates, R. W. (1971). Natural hazard in human ecological perspective: Hypotheses and models. Economic Geography, 47(3), 438-451.

Kates, R. W., Travis, W. R., \& Wilbanks, T. J. (2012). Transformational adaptation when incremental adaptations to climate change are insufficient. PNAS, 109(19), 7156-7161.

Katsman, C. A., Sterl, A., Beersma, J. J., van den Brink, H. W., Church, J. A., Hazeleger, W., ... Weisse, R. (2011). Exploring high-end scenarios for local sea level rise to develop flood protection strategies for a low-lying delta: The Netherlands as an example. Climatic Change, 109, 617-645.

Keenan, N. J., \& Oldfield, S. G. (2012). The Urban Impacts Toolbox: An initial assessment of climate change flood adaptation options for Westport. Weather and Climate, 32(2), 40-61.

Kemp, R., Loorbach, D., \& Rotmans, J. (2007). Transition management as a model for managing processes of co-evolution towards sustainable development. International Journal of Sustainable Development \& World Ecology, 14(1/2), 78-91.

Kenderdine, S. (2010). Examining climate change: An Environment Court perspective. In T. Daya-Winterbottom, Resource Management Law Reform Association of New Zealand Inc (Ed.), Resource Management Theory and Practice (pp. 35-92). Auckland: Thomson Reuters. 
Kennedy, D., Stocker, L., \& Burke, G. (2010). Australian local government action on climate change adaptation: Some critical reflections to assist decision-making. Local Environment, 15(9/10), 805-816. doi: 10.1080/13549839.2010.514602

Kerr, S., Claridge, M., \& Milicich, D. (1998). Devolution and the New Zealand Resource Management Act. Treasury Working Paper 98/7. Wellington: New Zealand Treasury.

Keskitalo, E. C. H. (2010). Adapting to climate change in Sweden: National policy development and adaptation measures in Vastra Gotaland. In E. C. H. Keskitalo (Ed.), Developing Adaptation Policy and Practice in Europe: Multi-level governance of climate change (pp. 189-232). Berlin: Springer.

Keskitalo, E. C. H., \& Kulyasova, A. A. (2009). The role of governance in community adaptation to climate change. Polar Research, 28(1), 60-70.

Klein, R., Midgley, G., Preston, B., Alam, M., Berkhout, F., Dow, K., \& Shaw, M. (2014). Adaptation opportunities, constraints and limits. In C. B. Field, V. R. Barros, D. J. Dokken, K. J. Mach, M. D. Mastrandrea, T. E. Bilir, M. Chatterjee, K. L. Ebi, Y. O. Estrada, R. C. Genova, B. Girma, E. S. Kissel, A. N. Levy, S. MacCracken, P. R. Mastrandrea, \& L. L. White (Eds.), Climate Change 2014: Impacts, adaptation, and vulnerability. Part A: Global and sectoral aspects. Contribution of Working Group II to the Fifth Assessment Report of the Intergovernmental Panel on Climate Change (pp. 899-943). Cambridge, UK and New York, USA: Cambridge University Press.

Klein, U. (2005). Assessment of New Zealand's environmental planning model. New Zealand Journal of Environmental Law, 9, 287-309.

Klijn, E. H., \& Koppenjan, J. F. M. (2006). Governing policy networks: A network perspective on decision making in network society. In G. Morcol (Ed.), Handbook of DecisionMaking (pp. 169-187). New York: CRC Press.

Klinke, A., \& Renn, O. (2012): Adaptive and integrative governance on risk and uncertainty, Journal of Risk Research, 15(3), 273-292

Knight, F. (1921). Risk, Uncertainty and Profit. London: Houghton Mifflin.

Kousky, C. (2009). Adapting to extreme events: Managing fat tails. Issues Brief. Washington D.C.: Resources for the Future. 
Kousky, C., Pratt, J., \& Zeckhauser, R. (2010). Virgin versus experienced risks. In E. MichelKerjan \& P. Slovic (Eds.), The Irrational Economist. (pp. 99-106). New York: Public Affairs.

Krimsky, S., \& Golding, D. (2006). Social Theories of Risk. Westport, Connecticut: Praegar.

Kunreuther, H., \& Weber, E. U. (2012). Facilitating and Aiding Human Decisions to Adapt to or Mitigate the Impacts of Climate Change. Working paper 2012-19. University of Pennsylvania, Center for Research on Environmental Decisions, Columbia University: Wharton School Risk Management and Decision Process Center, Philadelphia.

Kwadijk, J., Haasnoot, M., Mulder, J., Hoogvliet, M., Jeuken, A., Van der Krogt, R., . . de Wit, M. (2010). Using adaptation tipping points to prepare for climate change and sea level rise: A case study in the Netherlands. Wiley Interdisciplinary Reviews: Climate Change, 1(5), 729-740.

Kwakkel, J. H., Auping, W. L., \& Pruyt, E. (2013). Dynamic scenario discovery under deep uncertainty: The future of copper. Technological Forecasting and Social Change, 80(4), 789-800. doi: 10.1016/j.techfore.2012.09.012

Land and Water Forum. (2012). Second Report of the Land and Water Forum: Setting limits for water quality and quantity, and freshwater policy-and-plan-making through collaboration. Wellington: Author.

Lawrence, J., \& Allan, S. (2009). A Strategic Framework and Practical Options for Integrating Flood Risk Management to Reduce Flood Risk and the Effects of Climate Change. Report prepared for the Ministry for the Environment, Wellington.

Lawrence, J., \& Manning, M. R. (2012). Developing Adaptive Risk Management for our Changing Climate: NZCCRI 2012 report. Wellington: New Zealand Climate Change Research Institute, Victoria University of Wellington.

Lawrence, J., Quade, D., \& Becker, J. (2014). Integrating the effects of flood experience on risk perception with responses to changing climate risk. Natural Hazards, Published online 18 June 2014. doi: 10.1007/s11069-014-1288-z

Lawrence, J., Reisinger, A., Mullan, B., \& Jackson, B. (2013). Exploring climate change uncertainties to support adaptive management of changing flood-risk. Environmental Science \& Policy, 33(0), 133-142. doi: 10.1016/j.envsci.2013.05.008 
Lawrence, J., Wolf, A., \& Reisinger, A. (2013). Institutional Transformation in a Devolved Governance System: Possibilities and limits. Paper presented at the Transformation in a Changing Climate Conference 19-21 June 2013, Oslo, Norway.

Lebel, L., Anderies, J. M., Campbell, B., Folke, C., Hatfield-Dodds, S., Hughes, T., \& Wilson, J. (2006). Governance and the capacity to manage resilience in regional socialecological systems. Ecology and Society, 11(1).

Lee, B.-Y. (2010). Working together, building capacity: A case study of civil defence and emergency management in New Zealand. Journal of Disaster Research, 5(5), 565575.

Leiserowitz, A. (2006). Climate change risk perception and policy preferences: The role of affect, imagery, and values. Climatic Change, 77, 45-72.

Lempert, R., \& Collins, M. (2007). Managing the risk of uncertain threshold responses: Comparison of robust, optimum, and precautionary approaches. Risk Analysis, 27(4), 1009-1026. doi: 10.1111/j.1539-6924.2007.00940.x

Lempert, R., Groves, D., Popper, S., \& Bankes, S. (2006). A general, analytic method for generating robust strategies and narrative scenarios. Management Science, 52(4), 514528. doi: $10.1287 / \mathrm{mnsc} .1050 .0472$

Lempert, R., Popper, S., \& Bankes, S. (2003). Shaping the Next One Hundred Years: New methods for quantitative, long-term policy analysis. Santa Monica, C.A.: RAND.

Lempert, R., Scheffran, J., \& Sprinz, D. (2009). Methods for long-term environmental policy challenges. Global Environmental Politics, 9(3), 106-133.

Lempert, R., \& Schlesinger, M. (2000). Robust strategies for abating climate change. Climatic Change, 45, 387-401.

Lloyds. (2008). Coastal communities and climate change: Maintaining future insurability. Available at: http://www.lloyds.com/ /media/lloyds/reports/360/360\%20climate\%20reports/360_c oastalcommunitiesandclimatechange.pdf

Local Government Commission. (2014). Local Government Reorganisation. Wellington: Greater Wellington Regional Council. Available at: 
http://www.lgc.govt.nz/lgcwebsite.nsf/wpg_URL/Reorganisation-Local-CouncilsReorganisation-Applications-Greater-Wellington-Regional-Council

Local Government New Zealand. (2011). The Local Government Case for a National Policy Statement for Flood Risk. Wellington: Author.

Logan, H. (2013). Inside the Black Box: The influence of government executive forces on environmental policy effectiveness in New Zealand. PhD, Lincoln University, New Zealand.

Loorbach, D., \& Rotmans, J. (2010). The practice of transition management: Examples and lessons from four distinct cases. Futures, 42(3), 237-246.

Manning, M., Lawrence, J., King, D. N., \& Chapman, R. (2015). Dealing with changing risk: A New Zealand perspectve on climate change adaptation. Regional Environmental Change, 15, 581-594. doi: 10.1007/s10113-014-0673-1

March, J. G., \& Olsen, J. P. (1998). The institutional dynamics of international political orders. International Organisations, 52, 943-969.

Marjone, G. (2002). What price safety? The precautionary principle and its policy implications. Journal of Common Market Studies, 40, 89-100.

Mastrandrea, M. D., Field, C. B., Stocker, T. F., Edenhofer, O., Ebi, K. L., Frame D.J., . . . Zwiers, F. W. (2010). Guidance Note for Lead Authors of the IPCC Fifth Assessment Report on Consistent Treatment of Uncertainties: Intergovernmental Panel on Climate Change. Available at <http://www.ipcc.ch>

Matthews, T. (2013). Institutional perspectives on operationalising climate adaptation through planning. Planning Theory \& Practice, 14(2), 198-210. doi: $10.1080 / 14649357.2013 .781208$

McCaskill, L. W. (1973). Hold this Land. Wellington: A.H \& A.W. Reed.

McDonald, J. (2007). A risky climate for decison-making: The liability of development authorities for climate change impacts. Environment and Planning Law, 24, 405-416.

McDonald, J. (2010). Mapping the legal landscape of climate change adaptation. In T. Bonyhady, A. Macintosh, \& J. McDonald (Eds.), Adapting to Climate Change in Australia: Law and policy. (pp. 1-37). Annandale: The Federation Press. 
McDonald, J. (2011). The role of law in adapting to climate change. Wiley Interdisciplinary Reviews: Climate Change, 2(2), 283-295. doi: 10.1002/wcc.96

McGranahan, G., Balk, D., \& Anderson, B. (2007). The rising tide: Assessing the risks of climate change and human settlements in low elevation coastal zones. Environment and Urbanization, 19(1), 17-37. doi: 10.1177/0956247807076960

Measham, T., Preston, B., Smith, T., Brooke, C., Gorddard, R., Withycombe, G., \& Morrison, C. (2011a). Adapting to climate change through local municipal planning: Barriers and challenges. Mitigation and Adaptation Strategies for Global Change 16(8), 889-909. $10.1007 / \mathrm{s} 11027-011-9301-2$

Memon, P. A., \& Gleeson, B. J. (1995). Towards a new planning paradigm? Reflections on New Zealand's Resource Management Act. Environment and Planning B: Planning and Design, 22(1), 109-124.

Milfont, T. L. (2010). Global warming, climate change and human psychology. In V. CorralVerdugo, C. H. Garcia-Cadana \& M. Frias-Arment (Eds.), Psychological Approaches to Sustainability: Current trends in theory, research and practice (pp19-42). New York: Nova Science.

Minister for the Environment. (2012). Report of the Minister for the Environment's Resource Management Act 1991 Principles Technical Advisory Group.Wellington: Author.

Minister of Conservation. (2010). New Zealand Coastal Policy Statement. In Department of Conservation (Ed.). Wellington: Department of Conservation.

Ministry for the Environment. (1988). Directions for change: A discussion paper. Resource Management Law Reform. Wellington: Author.

Ministry for the Environment. (2008a). Climate Change Effects and Impacts Assessment: A guidance manual for local government in New Zealand (2nd ed., Wellington: Author.

Ministry for the Environment. (2008b). Coastal Hazards and Climate Change: A guidance manual for local government in New Zealand (2nd ed.) Wellington: Author.

Ministry for the Environment. (2008c). Meeting the Challenges of Future Flooding in New Zealand. Wellington: Author. 
Ministry for the Environment. (2009 ). Preparing for Coastal Change: A guide for local government in New Zealand (p. 36). Wellington: Author.

Ministry for the Environment. (2010). Preparing for Future Flooding: A guide for local government. Wellington: Author.

Ministry for the Environment. (2013). Freshwater Reform 2013 and Beyond. Wellington: Author.

Ministry for Primary Industries. (2014). Government Assistance for Climatic Events and Natural Disasters Impacting On-farm. Wellington: Author.

Minsitry for the Environment. (2014). A Guide to Section 32 of the Resource Management Act: Incorporating changes as a result of the Resource Management Amendment Act 2013. Wellington: Author.

Moser, S. C. (2009). Whether our levers are long enough and the fulcrum strong? In W. N Adger, N. I. Lorenzoni, \& K. O'Brien (Eds.), Adapting to Climate Change: Thresholds, values, governance (pp. 313-334). Cambridge, UK: Cambridge University Press.

Moser, S. C., \& Ekstrom, J. A. (2010). A framework to diagnose barriers to climate change adaptation. PNAS, 107(51), 22026-22031.

Mumford, P. (2011). Enhancing Performance-based Regulation: Lessons from New Zealand's building control system. Wellington: Institute of Policy Studies, School of Government, Victoria University of Wellington.

Munich Re Group. (2007). Natural Catastrophes 2006: Analyses, assessments, positions. Munich: Author.

Munich Re Group. (2013). Floods Dominate Natural Catastrophe Statistics in First Half of 2013. Retrieved 27 March 2014, from http://preventionweb.net/go/33913

Næss, L. O., Bang, G., Eriksen, S., \& Vevatne, J. (2005). Institutional adaptation to climate change: Flood responses at the municipal level in Norway. Global Environmental Change Part A, 15(2), 125-138.

NAMS. (2004). New Zealand Asset Management Support. Optimised Decision Making Guidelines: A sustainable approach to managing infrastructure (p. 80). Wellington: The NAMS Group. 
Nelson, D., Adger, W. N., \& Brown, K. (2007). Adaptation to environmental change: Contributions of a resilience framework. Annual Review of Environment and Resources, 32, 395-419.

Neumayer, E. (2007). A missed opportunity: The Stern Review on climate change fails to tackle the issue of non-substitutable loss of natural capital. Global Environmental Change, 17(3-4), 297-301. doi: 10.1016/j.gloenvcha.2007.04.001

New Zealand Government. (2008). National Civil Defence Emergency Management Strategy 2007. Wellington: Ministry of Civil Defence and Emergency Management, Department of Internal Affairs.

New Zealand Government. (2013). Improving our Resource Management System: A discussion document. Wellington: Ministry for the Environment.

New Zealand Government National Infrastructure Unit. (2013). Infrastructure 2013: National state of infrastructure report. Wellington: New Zealand Treasury.

New Zealand Office of the Auditor-General. (2014). Water and Roads: Funding and Management Challenges. Wellington: Author.

Nicholls, R. J., \& Cazenave, A. (2010). Sea-level rise and its impact on coastal zones. Science, $328(5095), 1517-1520$.

Nicholson-Cole, S., \& O'Riordan, T. (2009). Adaptive governance for a changing coastline: Science, policy and publics in search of a sustainable future. In W. N Adger, N. I. Lorenzoni, \& K. O'Brien (Eds.), Adapting to Climate Change: Thresholds, values, governance (pp. 368-383). Cambridge, UK: Cambridge University Press.

Niemeyer, A., Petts, J., \& Hobson, K. (2005). Rapid climate change and society: Assessing responses and thresholds. Risk Analysis, 25(6), 1443-1456.

NZS 9401. (2008). Managing Flood Risk: A process standard. Wellington: Standards NZ.

O'Brien, K. (2012). Global environmental change 11: From adaptation to deliberate transformation. Progress in Human Geography, 36, 667-676.

Olsson, J., Folke, C., \& Hahn, T. (2004). Social-ecological transformation for ecosystems management: The development of adaptive co-management of a wetland landscape in southern Sweden. Ecology and Society, 9(4), 26. 
Olsson, P., \& Folke, C. (2001). Local ecological knowledgeand institutional dynamics for ecosystems management: A study of Lake Racken watershed, Sweden. Ecosystems, 4(2), 85-104.

Ostrom, E. (1990). Governing the Commons: The evolution of Institutions for Collective Action. Cambridge, UK: Cambridge University Press.

Ostrom, E. (2009). A general framework for analyzing sustainability of social-ecological systems. Science, 325(5939), 419-422. doi: 10.1126/science.1172133

Ostrom, E. (2010). Polycentric systems for coping with collective action and global environmental change. Global Environmental Change, 20(4), 550-557.

Pahl-Wostl, C. (2006). The importance of social learning in restoring the multifunctionality of rivers and floodplains. Ecology and Society, 11(1).

Pahl-Wostl, C. (2009). A conceptual framework for analysing adaptive capacity and multilevel learning processes in resource governance regimes. Global Environmental Change, 19(3), 354-365. doi: 10.1016/j.gloenvcha.2009.06.001

Pahl-Wostl, C., Holtz, G., Kastens, B., \& Knieper, C. (2010). Analyzing complex water governance regimes: The Management and Transition Framework. Environmental Science \& Policy, 13(7), 571-581. doi: 10.1016/j.envsci.2010.08.006

Pahl-Wostl, C., Sendzimir, J., Jeffrey, P., Aerts, J., Berkamp, G., \& Cross, K. (2007). Managing change toward adaptive water management through social learning. Ecology and Society, 12(2).

Palmer, G. (2013). Going green. Reform: A memoir (pp. 420-433). Wellington: Victoria University Press.

Palmer, G., Driver, S., Gardiner, W., \& Jackson, B. (2012). Future Wellington: An issues paper on local government reform in the Wellington region. Wellington: Wellington Region Local Government Review Panel.

Palutikof, J., Parry, M., Stafford Smith, M., Ash, A., Boulter, S., \& Waschka, M. (2013). The past, present and future of adaptation: Setting the context and naming the challenges. In J. Palutikof, S. Boulter, A. Ash, M. Stafford Smith, M. Parry, M. Waschka, \& D. Guitart (Eds.), Climate Adaptation Futures (pp. 3-29). Brisbane, QLD: John Wiley \& Sons. 
Park, S. E., Marshall, N. A., Jakku, E., Dowd, A. M., Howden, S. M., Mendham, E., \& Fleming, A. (2012). Informing adaptation responses to climate change through theories of transformation. Global Environmental Change, 22(1), 115-126.

Parry, M., Arnell, N., Berry, P., Dodman, D., Fankhauser, S., Hope, C., . . Wheeler, T. (2009). Assessing the Costs of Adaptation to Climate Change: A review of the UNFCCC and other recent estimates. London: International Institute for Environment and Development, Imperial College London and the Grantham Istitute for Climate Change.

Pasquini, L., Cowling, R. M., \& Ziervogel, G. (2013). Facing the heat: Barriers to mainstreaming climate change adaptation in local government in the Western Cape Province, South Africa. Habitat International, 40(0), 225-232. doi: 10.1016/j.habitatint.2013.05.003

Pelling, M. (2011). Adaptation to Climate Change: From resilience to transformation. London and New York: Routledge.

Perkins, H., \& Thorns, D. C. (2001). A decade on: Reflections on the Resource Management Act 1991 and the practice of urban planning in New Zealand. Environment and Planning B: Planning and Design, 28, 639-654.

Pfeffer, W. T., Harper, J. T., \& O'Neel, S. O. (2008). Kinematic constraints on glacier contributions to 21 st-century sea-level rise. Science, 321(5894), 1340-1343.

Pidgeon, N., \& Butler, C. (2009). Risk analysis and climate change. Environmental Politics, 18(5), 670-688. doi: 10.1080/09644010903156976

Pidgeon, N., \& Fischhoff, B. (2011). The role of social and decision sciences in communicating uncertain climate risks. Nature Climate Change, 1(1), 35-41.

Pielke, R. (1999). Nine fallacies of floods. Climatic Change, 42, 413-438.

Pitt Review. (2008). Learning Lessons from the 2007 Floods. Report to the UK Government, ES25. Available at: http://webarchive.nationalarchives.gov.uk/20100807034701/http:/archive.cabinetoffi ce.gov.uk/pittreview/_/media/assets/www.cabinetoffice.gov.uk/flooding_review/pitt_ review_full\%20pdf.pdf 
Preston, B. (2013). Local path dependence of U.S. socioeconomic exposure to climate extremes and the vulnerability commitment. Global Environmental Change, 23(4), 719-732. doi: 10.1016/j.gloenvcha.2013.02.009

Preston, B., Westaway, R., \& Yuen, E. (2011). Climate adaptation planning in practice: An evaluation of adaptation plans from three developed nations. Mitigation and Adaptation Strategies for Global Change, 16 4(4), 407-438.

Productivity Commission. (2012). Barriers to Effective Climate Change Adaptation. Final Inquiry Report. Canberra ACT: Author.

Quade, D., \& Lawrence, J. (2011). Vulnerability and Adaptation to Increased Flood Risk with Climate Change-Hutt Valley household survey NZCCRI-2011-06. Wellington: The New Zealand Climate Change Research Institute, Victoria University of Wellington.

Quade, E. S. (1989). Analysis for Public Decisions (3rd ed.). new York: Elsevier Science Publishing.

Radio NZ. (Writer) \& W. Chapman (Director). (6 April 2014). Intergovernmental Panel on Climate Change, Sunday. Wellington.

Randerson, A., Crosson, P., Salmon, G., Tremaine, K., \& Wheeler, B. (1990). Discussion Paper on the Resource Management Bill. Wellington: Ministry for the Environment.

Ranger, N., Millner, A., Dietz, S., Fankhauser, S., Lopez, A., \& Ruta, G. (2010). Adaptation in the UK: A decision-making process. A policy brief. London: Grantham Institute on Climate Change and the Environment and Centre for Climate Change Economics and Policy.

Ranger, N., Reeder, T., \& Lowe, J. (2013 ). Addressing 'deep' uncertainty over long-term climate in major infrastructure projects: Four innovations of the Thames Estuary 2100 Project. European Journal of Decision Process, 1(3-4), 233-262.

Rayner, S. (1992). Cultural theory and risk analysis. In S. K. D. Golding (Ed.), Social Theories of Risk (pp. 83-115). Westport, Connecticut: Praegar.

Reisinger, A., Kitching, R. L., Chiew, F., Hughes, L., Newton, P. C. D., Schuster, S., Tait, A, Whetton, P. (2014). Australasia. In: Climate Change 2014: Impacts, adaptation and vulnerability. Part B: Regional aspects. Contribution of Working Group II to the Fifth Assessment Report of the Intergovernmental Panel on Climate Change [Barros, V.R., 
C. B. Field, D. J. Dokken, M. D. Mastrandrea, K. J. Mach, T. E. Bilir, M. Chatterjee, K. L. Ebi, Y. O. Estrada, R. C. Genova, B. Girma, E. S. Kissel, A. N. Levy, S. MacCracken, P. R. Mastrandrea, and L. L. White (Eds.)]. (pp. 1371-1438). Cambridge, UK and New York, USA: Cambridge University Press.

Reisinger, A., Lawrence, J., Hart, G., \& Chapman, R. (2015). From coping to resilience: The role of managed retreat in highly developed coastal regions. In B. Glavovic, R. Kaye, M. Kelly, \& A. Travers (Eds.) (pp.285-310). Climate Change and the Coast: Building resilient communities. London: CRC Press.

Renn, O. (2008). Risk Governance. Coping with Uncertainty in a Complex World. London: Earthscan.

Renn, O., Klinke, A., \& van Asselt, M. (2011). Coping with Complexity, Uncertainty and Ambiguity in Risk Governance: A Synthesis. Ambio, 40(2), 231-246.

Renn, O., \& P. Schweizer. (2009). Inclusive Risk Governance: Concepts and Application to Environmental Policy Making. Environmental Policy and Governance 19, 174-185.

Rignot, E., Mouginot, M., Seroussi, H., \& Scheuch, B. (2014). Widespread, rapid grounding line retreat of Pine Island, Thwaites, Smith and Kohler glaciers, West Antarctica from 1992 to 2011. Geophysical Research Letters, online doi:10.1002/2014GL060140

Rignot, E., Velicogna, I., van den Broeke, M. R.., Monaghan, A., \& Lenaerts, J. (2011). Acceleration of the contribution of the Greenland and Antarctic ice sheets to sea level rise. Geophysical Research Letters, 38 (5) (L05503), 1-5. doi:10.1029/2011GL046583

Rip, A., \& Kemp, R. (1998). Technological change. In S. Rayner \& E. L. Malone (Eds.), Human Choice and Climate Change (Vol. 2, pp. 327-399). Columbus, OH: Battelle Press.

Rive, V. (2011). New Zealand climate change regulation. In A. Cameron (Ed.), Climate Change Law and Policy in New Zealand (pp. 165-214). Wellington: LexusNexus NZ Limited.

Rive, V., \& Weeks, T. (2011). Adaptation to climate change in New Zealand. In A. Cameron (Ed.), Climate Change Policy and Law in New Zealand (pp. 345-391). Wellington: LexusNexus NZ Limited. 
Roggema, R. (2009). Adaptation to Climate Change: A spatial challenge. Dordreccht: Springer.

Rosenzweig, C., \& Solecki, W. E. (2010). Climate Change Adaptation in New York City: Building a risk management response. New York City Panel on Climate Change 2010 Report (Vol. 1196, pp. 1-354). New York: Annals of the New York Academy of Sciences.

Rotmans, J. (2005). Societal Innovation: Between dream and reality stands complexity. Inaugural lecture, Erasmus University, Rotterdam.

Rotmans, J., Kemp, R., \& Van Asselt, M. (2001). More evolution than revolution: Transition management in public policy. Foresight-The Journal of Future Studies, Strategic Thinking and Policy, 3(1), 15-31.

Royal Commission on the Pike River Coal Mine Tragedy. (2012). Report of the Royal Commission on the Pike River Coal Mine Tragedy (Vol. 1\&2, pp. 44 \& 404). Wellington: Author.

Ruhl, J. (2010, Spring). Climate change adaptation and the structural transformation of environmental law. Environmental Law, 40(2), 363-435.

Ruhl, J. (2012). Panarchy and the law. Ecology and Society, 17(3). doi: 10.5751/ES-05109170331

Scheffer, M. (2009). Critical Transitions in Nature and Society. Princeton \& Oxford: Princeton University Press.

Schroter, D., Polsky, C., \& Patt, A. G. (2004). Assessing vulnerabilities to the effects of global change: An eight step approach. Mitigation and Adaptation Strategies for Global Change, 10(4), 573-595.

Shove, E., \& Walker, G. (2007). CAUTION! Transitions ahead: Politics, practice, and sustainable transition management. Environment and Planning A, 39(4), 770-783.

Silverman, D. (Ed.). (2011). Interpreting Qualitative Data (4th ed.). London: SAGE Publications.

Slovic, P. (1987). Perception of risk. Science, 236(4799), 280-285. 
Smit, B., Burton, I., Klein, R., \& Street, R. (1999). The science of adaptation: A framework for assessment. Mitigation and Adaptation Strategies for Global Change, 4(3-4), 199213.

Smit, B., \& Wandel, J. (2006). Adaptation, adaptive capacity and vulnerability. Global Environmental Change, 16(3), 282-292.

Smith, A., \& Stirling, A. (2010). The politics of socio-ecological resilience and sustainable socio-technical transitions. Ecology and Society, 15(11). Available at: http://www.ecologyandsociety.org/vol15/iss11/art11/

Somerville, R. (2013). Policy adjudication, adaptive risk management and the Environment Court. Resource Management Theory and Practice, 2013, 13-41.

Spence, A., Poortinga, W., \& Pidgeon, N. F. (2012). The psychological distance of climate change. Risk Analysis, 32(6), 957-972. doi: 10.1111/j.1539-6924.2011.01695.x

Sprinz, D. (2009). Long-term environmental policy: Definition, knowledge, future research. Global Environmental Politics, 9(3), 1-8.

Stafford Smith, M. (2013). Scenarios for picturing a future adapted to $+4^{\circ}$ C. In J. Palutikof, S. L. Boulter, A. J. Ash, M. Stafford Smith, M. Parry, M. Waschka, \& D. Guitart (Eds.), Climate Adaptation Futures.(pp. 119-125) Brisbane, QLD: John Wiley \& Sons.

Stafford Smith, M., Horrocks, L., Harvey, A., \& Hamilton, C. (2011). Rethinking adaptation for a $4^{\circ} \mathrm{C}$ world. Philosophical Transactions Royal Society A, 369(1934), 196-121.

Stankey, G. H., Clark, R. N., \& Bormann, B. (2005). Adaptive Management of Resources: Theory, concepts, and management institutions. General Technical Report. Portland, Oregon: USDA, Forest Service, Pacific Northwest Research Station.

Stanovich, K. E., \& West, R. F. (2000). Individual difference in reasoning: Implications for the rationality debate? Behavioural and Brain Sciences, 23, 645-726.

Statistics New Zealand. (2010). Are New Zealanders living closer to the coast? Internal migration. $\quad$ Retrieved 28 February 2010, from http://www.stats.govt.nz/browse_for_stats/population/migration/internalmigration.aspx 
Stein, J., \& Stein, S. (2014). Gray swans: Comparison of natural and financial hazard assessment and mitigation. Natural Hazards, 72, 1279-1297. doi: 10.1007/s11069012-0388-X

Stirling, A. (1999). On Science and Precaution in the Management of Technological Risk. Seville: IPTS.

Stirling, A., Renn, O., \& van Zwanenberg, P. (2006). A framework for the precautionary governance of food saftey: Integrating science and participation in the social appraisal of risk. In E. Fisher, J. Jones, \& R. von Schomberg (Eds.), Implementing the Precautionary Principle (pp. 284-315). Cheltenham, UK \& Northampton, USA: Edward Elgar.

Stone, C. (2001). Is there a precautionary principle? Environmental Law Reporter, 31, 1079010799.

Storbjork, S. (2007). Governing climate adaptation in the local arena: Challenges of risk management and planning in Sweden. Local Environment, 12(5), 457-469.

Storbjörk, S. (2010). 'It takes more to get a ship to change course': Barriers for organizational learning and local climate adaptation in Sweden. Journal of Environmental Policy \& Planning, 12(3), 235-254. doi: 10.1080/1523908X.2010.505414

Sunstein, C. R. (2003). Beyond the precautionary principle. The Chicago Working Paper Series. Retrieved from http://www.law.uchicago.edu/Lawecon/index.html

Taleb, N. (2010). The Black Swan. New York: Random House.

Tattersall, P. (2010). Stress-testing for authorised deposit-taking institutions. APRA Insight, 2, 12.

Termeer, C., Biesbroek, G. R., \& van den Brink, M. (2012). Institutions for adaptation to climate change: Comparing national adaptation strategies in Europe. European Political Science, 11, 41-53.

Terpstra, T., \& Gutteling, J. M. (2008). Households' perceived responsibilities in flood risk management in The Netherlands. International Journal of Water Resources Development, 24(4), 555-565. doi: 10.1080/07900620801923385 
Tickner, J., \& Kriebel, D. (2006). The role of science and precaution in environmental and public health. In E. Fisher, J. Jones, \& R. von Schomberg (Eds.), Implementing the Precautionary Principle: Perspectives and prospects (pp. 42-62). Cheltenham, UK: Edward Elgar Publishing.

Tobin, G. A. (1995). The levee love affair: A stormy relationship. Journal of the American Water Resources Association, 31(3), 359-367.

Tompkins, E. L., Adger, W. N., Boyd, E., Nicholson-Cole, S., Weatherhead, K., \& Arnell, N. (2010). Observed adaptation to climate change: UK evidence of transition to a welladapting society. Global Environmental Change, 20(4), 627-635.

Tonkin and Taylor. (2013a). Effects of Sealevel Rise for Christchurch City. Report prepared for Christchurch City Council. Christchurch: Christchurch City Council.

Tonkin and Taylor. (2013b). Sealevel Rise Options Analysis. Report prepared for Wellington City Council. Wellington: Wellington City Council.

Trenberth, K. E. (2011). Changes in precipitation with climate change. Climate Research, 47(25), 123-138.

Turbott, C. (2006). Managed Retreat from Coastal Hazards: Options for implementation Environment Waikato Technical Report. Hamilton, New Zealand: Environment Waikato.

United Nations. (1992). Report of the United Nations Conference on Environment and Development: Rio Declaration on Environment and Development. Rio de Janiero: Author.

United Nations. (1992). United Nations Framework Convention of Climate Change. New York: Author.

United Nations World Commission on Environment and Development. (1987). Our Common Future. Report of the World Commission on Environment and Development, WCED, 1987. Published as Annex to General Assembly document A/42/427. Development and International Co-operation: Environment. 2 August 1987.

Van Buuren, A., Driessen, P. P. J., Van Rijswick, M., Reitveld, P., Salet, W., Spit, T., \& Teisman, G. (2013). Towards adaptive spatial planning for climate change: Balancing 
between robustness and flexibility. Journal for European Environmental and Planning Law, 10(1), 29-53.

Van den Berg, M., \& Coenen, F. (2012). Integrating climate change adaptation into Dutch local policies and the role of contextual factors. Local Environment, 17(4), 441-460. doi: 10.1080/13549839.2012.678313

Van der Brugge, R., Rotmans, J., \& Loorbach, D. (2005). The transition in Dutch water management. Regional Environmental Change, 5, 164-176.

Van der Brugge, R., \& Van Raak, R. (2007). Facing the adaptive management challenge: Insights from transition management. Ecology and Society, 12(2), 15.

Van der Sluijs, J. P. (2007). Post Normal Science: Working deliberatively within imperfections. Video lecture. Stadium GeneraleWageningen, The Netherlands.

Van Pelt, S. C., Haasnoot, M., Arts, B., Ludwig, F., Swart, R., \& Biesbroek, R. (2015). Communicating climate (change) uncertainties: Simulation games as boundary objects. Environmental Science \& Policy, 45, 41-52.

Vandenbeld, A., \& MacDonald, J. (2013). Fostering community acceptance of managed retreat in New Zealand. In J. Palutikof, A. Ash, M. Stafford Smith, M. Parry, M. Waschka and D.Guitart (Eds.), Climate Adaptation Futures (pp. 161-166). Chichester: Wiley-Blackwell.

Vermeer, M., \& Rahmstorf, S. (2009). Global sea level linked to global temperature. Proceedings of the National Academy of Sciences, 106, 21, 527-521, 532.

Vick, S. G. (2002). Degrees of Belief: Subjective probability and engineering judgment. Reston, VA: ASCE Press.

Vogel, C., Moser, S. C., Kasperson, R. E., \& Dabelko, G. D. (2007). Linking vulnerability, adaptation, and resilience science to practice: Pathways, players, and partnerships. Global Environmental Change, 17(3-4), 349-364.

Walker, B., Carpenter, S., Anderies, J., Abel, N., Cummings, G., Janssen, M., . . Pritchard, R. (2002). Resilience management in socio-ecological systems: A working hypothesis for a participatory approach. Conservation Biology, 6(1), 14. 
Walker, B., Holling, C. S., Carpenter, S., \& Kinzig, A. (2004). Resilience, adaptability and transformability in socio-ecologocal systems. Ecology and Society, 9(2), 5.

Walker, W., Haasnoot, M., \& Kwakkel, J. (2013). Adapt or perish: A review of planning approaches for adaptation under deep uncertainty. Sustainability 5, 955-979.

Walker, W., Harremoes, P., Rotmans, J., Van der Sluijs, J., Van Asselt, M., Janssen, P., \& Krayer von Krauss, M. (2003). Defining uncertainty: A conceptual basis for uncertainty management in model-based decison support. Integrated Assessment, 4, 517.

Walker, W., Lempert, R., \& Kwakkel, J. (2012). Deep Uncertainty. Available at: http://www.hau.gr/resources/toolip/doc/2012/05/10/deep-uncertainty_warren-ewalker.pdf

Weber, E. U. (2006). Experience-based and description-based perceptions of long-term risk: Why global warming does not scare us (yet). Climatic Change, 77(1-2), 103-120. doi: $10.1007 / \mathrm{s} 10584-006-9060-3$

Weber, E. U. (2010). What shapes perceptions of climate change? Wiley Interdisciplinary Reviews: Climate Change, 1(3), 332-342. doi: 10.1002/wcc.41

Wellington Regional Council. (2001). Hutt River Floodplain Management Plan: For the Hutt river and its environment. Wellington: Author.

White, G. F. (1945). Human Adjustment to Floods. The University of Chicago, Chicago. (Research Paper no. 29)

Wilbanks, T. J., \& Kates, R. W. (1999). Global change in local places: How scale matters. Climatic Change, 43, 601-628.

Wilde, F. (2014, 5 May). Wellington councils seeking efficiencies in natural hazard planning and management. Press release. Retrieved from http://www.gw.govt.nz/wellingtoncouncils-seeking-efficiencies-in-natural-hazard-planning-and-management/

Williman, E. B. (2010). The need for adaptability in river control design to cope with climate change and other flood hazard uncertainties. IPENZ Transactions, 2010/1(1), 17.

Wilson, E. (2006). Adapting to climate change at the local level: The spatial planning response. Local Environment, 11(6), 609-625. doi: 10.1080/13549830600853635 
Wilson, E., \& Piper, J. (2010). Spatial Planning and Climate Change. Abingdon, Oxon: Routledge.

Winsvold, M., Stokke, K. B., Klausen, J. E., \& Saglie, I. (2009). Organisational learning and governance in adaptation in urban development. In W. N. Adger, N. I. Lorenzoni, \& K. O' Brien (Eds.), Adapting to Climate Change: Threshold, values and governance (pp. 476-409). Cambridge, UK: Cambridge University Press.

Wirthlin Worldwide. (2000). The Precautionary Principle. McLean, VA: Author.

Wise, R. M., Fazey, I., Stafford Smith, M., Park, S. E., Eakin, H. C., Archer Van Garderen, E. R. M., \& Campbell, B. (2014). Reconceptualising adaptation to climate change as part of pathways of change and response. Global Environmental Change, 28, September 2014, pp 325-366.

Woods, R., Mullan, A. B., Smart. G, Rouse, H., Hollis, M., McKercher, A., . . Collins, D. (2010). Tools for estimating the effects of climate change on flood flow: A guidance manual for local government in New Zealand. Wellington: Ministry for the Environment.

World Bank. (2010a). Economic Evaluation of Climate Change Adaptation Projects Approaches for the Agricultural Sector and Beyond. Washington, D.C.: Author.

World Bank. (2010b). World Development Report 2010: Development and climate change. Washington, D.C.: Author.

Wynne, B. (1992). Uncertainty and environmental learning: Reconceiving science and policy in the preventive paradigm. Global Environmental Change, 2(2), 111-127. doi: 10.1016/0959-3780(92)90017-2

Young, O. (2002). The Institutional Dimensions of Environmental Change: Fit, interplay, and scale. Cambridge Massachusetts and London: MIT Press. 
